RUY SOMEI NAKAYAMA

\title{
OPORTUNIDADES DE ATUAÇÃO NA CADEIA DE FORNECIMENTO DE SISTEMAS DE AUTOMAÇÃO PARA INDÚSTRIA 4.0 NO BRASIL
}



RUY SOMEI NAKAYAMA

\title{
OPORTUNIDADES DE ATUAÇÃO NA CADEIA DE FORNECIMENTO DE SISTEMAS DE AUTOMAÇÃO PARA INDÚSTRIA 4.0 NO BRASIL
}

\author{
Versão Revisada
}

Tese de Doutorado apresentada à Escola Politécnica da Universidade de São Paulo para obtenção do título de Doutor em Ciências

Área de Concentração: Engenharia de Produção

Orientador: Prof. Dr. Mauro de Mesquita Spínola

São Paulo 
Autorizo a reprodução e divulgação total ou parcial deste trabalho, por qualquer meio convencional ou eletrônico, para fins de estudo ou pesquisa, desde que citada a fonte.

Este exemplar foi revisado e corrigido em relação à versão original, sob responsabilidade única do autor e com a anuência de seu orientador.

São Paulo, de de

Assinatura do autor:

Assinatura do orientador:

\section{Catalogação-na-publicação}

NAKAYAMA, Ruy Somei OPORTUNIDADES DE ATUAÇÃO NA CADEIA DE FORNECIMENTO DE SISTEMAS DE AUTOMAÇÃO PARA INDÚSTRIA 4.0 NO BRASIL / R. S.

NAKAYAMA -- versão corr. -- São Paulo, 2017. $240 \mathrm{p}$.

Tese (Doutorado) - Escola Politécnica da Universidade de São Paulo. Departamento de Engenharia de Produção.

1.Engenharia de Produção 2.Automação Industrial 3.Sistemas de Produção I.Universidade de São Paulo. Escola Politécnica. Departamento de Engenharia de Produção II.t. 
NAKAYAMA, R.S. Oportunidades de atuação na cadeia de fornecimento de sistemas de automação para Indústria 4.0 no Brasil. 2017, 240p. Tese (Doutorado) - Escola Politécnica da Universidade de São Paulo. Engenharia de Produção. São Paulo, 2017.

Aprovado em:

Banca Examinadora

Prof. Dr.

Instituição

Julgamento

Prof. Dr.

Instituição

Julgamento

Prof. Dr.

Instituição

Julgamento

Prof. Dr.

Instituição

Julgamento

Prof. Dr.

Instituição

Julgamento 


\section{AGRADECIMENTOS}

Se hoje estou aqui, é com a ajuda de todos que de alguma maneira me deram apoio e incentivo para que eu pudesse chegar onde estou. A jornada é longa e são inúmeras e incontáveis as pessoas que me ajudaram desde o início de minha existência e influenciaram até me tornar o que sou. Diante de tantas pessoas, um simples agradecimento seria pouco por tudo que recebi nesta existência, e injusto nominar apenas algumas.

Contudo, desculpando-me com aquelas que não poderei nominar, e serei injusto, agradeço ao Criador supremo, aos antepassados e aos pais que me deram esta oportunidade de viver "O Milagre do Universo".

Agradeço também à família: Hilda, Juliana, André e Larissa que tornaram a minha vida mais confortável e jamais me deixaram só nesta jornada.

Em especial nesta empreitada, agradeço imensamente a paciência e dedicação do professor orientador Dr. Mauro de Mesquita Spínola e demais professores que com seus valiosos ensinamentos permitiram o meu aprendizado e a elaboração deste trabalho.

Também dedico especial agradecimento a Ana Lúcia Facin, Eduardo Zied, Nemer Zaguir, Adriana Jacoto Unger e demais amigos de jornada pela ajuda, conhecimento compartilhado e amizade durante este período.

Agradeço também, a todas as empresas e seus gestores que participaram deste trabalho, compartilhando experiências e visões, sem as quais jamais poderia ter realizado este trabalho.

Por último, mas não menos importante, agradeço à Instituição Universidade Tecnológica Federal do Paraná pela oportunidade concedida, e também aos professores e amigos de trabalho que me substituíram e apoiaram durante todo meu período de afastamento. 


\section{RESUMO}

NAKAYAMA, R.S. Oportunidades de atuação na cadeia de fornecimento de sistemas de automação para Indústria 4.0 no Brasil - 2017, 240 p. Tese (Doutorado) - Escola Politécnica da Universidade de São Paulo. Engenharia de Produção. São Paulo, 2017.

Os avanços tecnológicos no setor de Tecnologia de Informações (TI) têm revolucionando a relação entre pessoas e o mundo dos negócios através da conectividade. Esta conectividade agora avança para comunicação entre coisas, dotadas de capacidade de processamento, através daquilo que é chamado de Internet das Coisas (IoT). A loT avança também na área de manufatura, incluindo máquinas, dispositivos, sensores e o próprio produto em processamento, possibilitando uma comunicação autônoma entre máquinas (M2M), produtos e sistemas. Conectada através da internet, esta comunicação não se limita apenas à fábrica, mas integra toda a cadeia produtiva através de redes colaborativas. É neste contexto que se desenha a mudança radical de paradigma para o conceito de Indústria 4.0 (14.0). Diante desta mudança, os atores que participam da Cadeia de Fornecimento de Sistemas para Automação da Manufatura (CFSAM) também precisam rever suas estratégias e estar atentos às novas oportunidades e ameaças que surgem neste novo cenário. $\mathrm{O}$ objetivo deste estudo é compreender, do ponto de vista de gestão, a reação das indústrias de manufatura no Brasil aos paradigmas da 14.0, e os potenciais impactos e oportunidades que a 14.0 traz para estes atores. Este trabalho mostra, através de Estudo de Múltiplos Casos em onze empresas brasileiras, a reação a esta mudança na automação da manufatura e analisa os potenciais impactos e oportunidades para estes atores. A escolha das unidades de estudo foi feita por conveniência e focada principalmente no grupo de provedores de tecnologia e infraestrutura para a implantação da plataforma 14.0. O resultado deste estudo revelou que há uma baixa compreensão do que realmente é a 14.0 entre as empresas de manufatura no Brasil e que ainda estão pouco engajadas na implantação prática dos conceitos da 14.0, adotando uma estratégia de seguidores de tecnologia. A contribuição deste trabalho inclui o esclarecimento do que realmente é a 14.0 fazendo distinção entre conceitos básicos da 14.0 e suas possibilidades tecnológicas. Inclui ainda a identificação das 
principais reações ao paradigma 14.0 e a análise de oportunidades para os atores da CFSAM com base nas mesmas. O estudo conclui que apesar da 14.0 não dispor comercialmente da padronização das duas tecnologias básicas (arquitetura orientada a serviços e semântica), que não permitem o aproveitamento pleno de suas potencialidades ao longo de todas as camadas da ISA-95, os conceitos já estão sendo praticados parcial e gradativamente e estão mais avançados nas atividades de negócios.

Palavras-Chave: Automação da Manufatura. Integração da Manufatura. Indústria 4.0. Cadeia de fornecimento de Sistemas para Automação da Manufatura. 


\begin{abstract}
NAKAYAMA, R.S. Opportunities in the supply chain of automation systems for Industry 4.0 in Brazil - 2017, 240 p. Tese (Doutorado) - Escola Politécnica da Universidade de São Paulo. Engenharia de Produção. São Paulo, 2017.
\end{abstract}

Advances in Information Technology (IT) have revolutionized the relationship between people and the business world through connectivity. This connectivity now advances to communication between things, endowed with processing capacity, through the Internet of Things (IOT). IoT also advances in the manufacturing industry, including machines, devices, sensors and the product in process, enabling autonomous communication between machines (M2M), products and systems. This communication of things through internet is not limited to the factory, but integrates the entire production chain through collaborative networks. It is in this context that the radical paradigm shift is devised for the concept of Industry 4.0 (14.0). Facing this change, actors in the Manufacturing Automation Systems Supply Chain (CFSAM) also need to review their strategies and be aware of the new opportunities and threats that arise in this new scenario. The objective of this study is to understand, from the management point of view, the reaction of the manufacturing industries in Brazil to the paradigms of 14.0 , and the potential impacts and opportunities that 14.0 brings to these actors. This work shows, through a Multiple Case Study, in eleven Brazilian companies, the reaction to this change in manufacturing automation and analyzes the potential impacts and opportunities for these actors. The study units were chosen purposefully and focused mainly on the group of technology and infrastructure providers for the implementation of the 14.0 platform. The result of this study revealed that there is a poor understanding of what is really the 14.0 among manufacturing companies in Brazil and that they are still little engaged in the practical implementation of the concepts of 14.0, adopting a strategy of technology followers. The contribution of this work includes the clarification of what really 14.0 is, distinguishing between basic concepts of 14.0 and its technological possibilities. It also includes the identification of the main reactions to the 14.0 paradigm and the analysis of opportunities for CFSAM actors based on them. The study concludes that although 14.0 does not commercially dispose of the standardization of the two basic technologies (service oriented architecture and 
semantics), which do not allow the full use of its potentialities across all ISA-95 layers, concepts already are being practiced partially and gradually, and are more advanced in the upper business layers.

Keywords: Manufacturing Automation. Manufacturing Integration. Industry 4.0. Manufacturing Automation Systems Supply Chain. 


\section{LISTA DE ILUSTRAÇÕES}

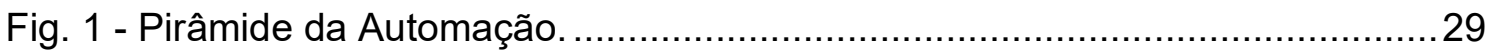

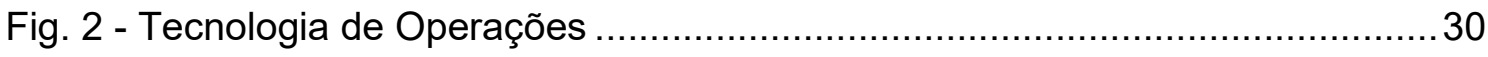

Fig. 3 - Componentes de TI e TO nos níveis hierárquicos ISA-95 …….....................31

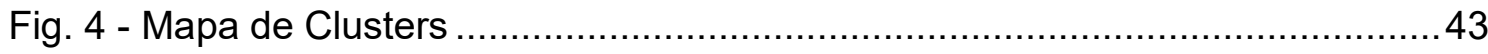

Fig. 5 - Rede de Citações e Centralidade ……………......................................4

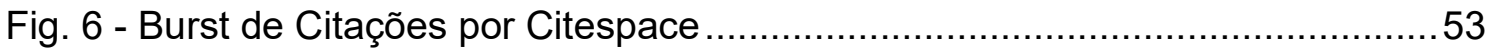

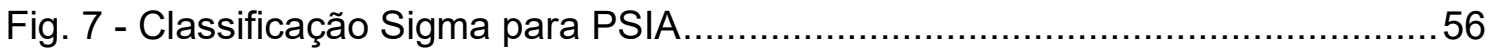

Fig. 8 - Classificação Sigma para Collaborative Network e Internet of Services .......57

Fig. 9 - Evolução das Pesquisas em PSIA …………………………………......59

Fig. 10 - Evolução das Pesquisas Collaborative Network ........................................60

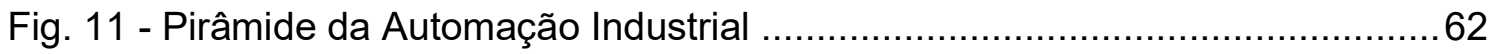

Fig. 12 - Rede Hierárquica de automação industrial ..............................................63

Fig. 13 - As três gerações de Redes de Campo (Field Networks)...............................65

Fig. 14 - Evolução da tecnologia de redes e sistemas de manufatura .......................66

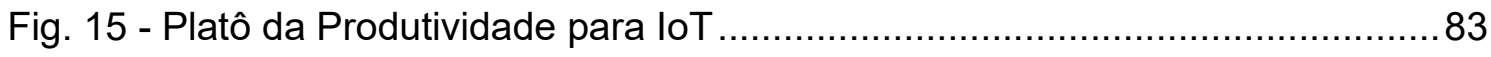

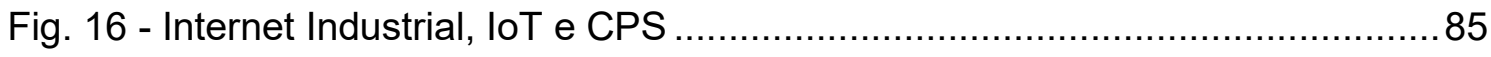

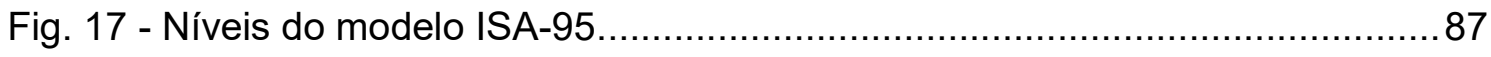

Fig. 18 - Comparação entre o escopo e foco dos padrões ISA-88 e ISA-95 .............. 88

Fig. 19 - Arquitetura Física nos níveis 1, 2 e 3 do modelo ISA-95 ...........................90

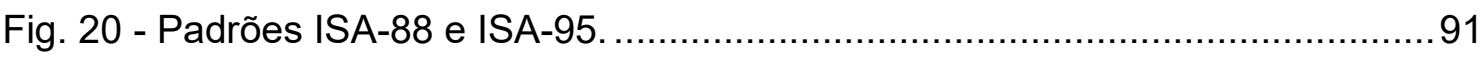

Fig. 21 - Ciclo de realimentação de informações no sistema de produção. ...............93

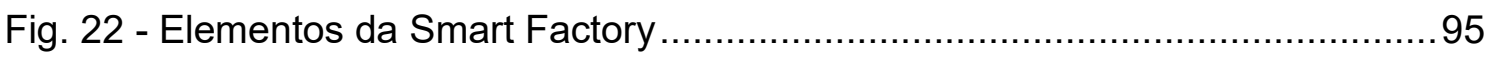

Fig. 23 - Fábrica do Futuro. Sistemas com planejamento orientado a serviço. ..........96

Fig. 24 - Crescimento do número de processadores embarcados .........................100 
Fig. 25 - 14.0 baseada em loS, IoT, CPS e Smart Factory .................................. 100

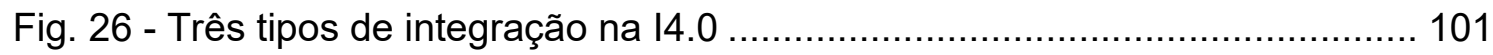

Fig. 27 - "Tudo" como serviço na Computação em Nuvem …………………….... 103

Fig. 28 - DCS / SCADA baseada em Nuvem ........................................................ 104

Fig. 29 - Revoluções Industriais ........................................................................ 107

Fig. 30 - As Revoluções Industriais segundo Rifkin (2012)................................... 107

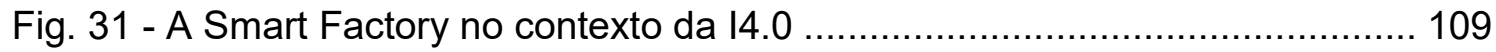

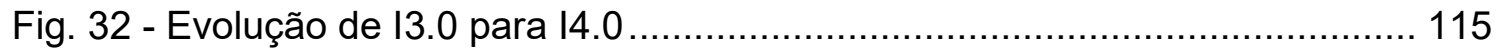

Fig. 33 - Evolução de CIM para 14.0 e possibilidades tecnológicas ....................... 116

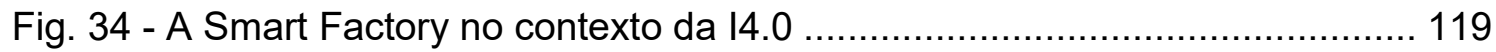

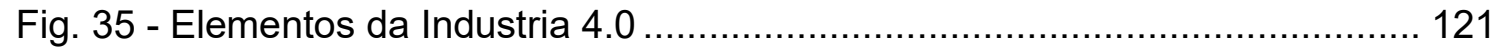

Fig. 36 - Elementos básicos da Plataforma I4.0 ……......................................... 121

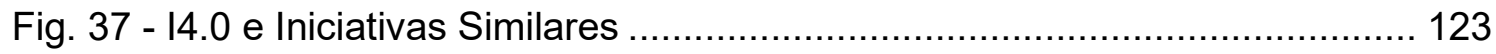

Fig. 38 - Modelo de Referência Padrões Soltos ………….................................. 125

Fig. 39 - Habilitadores para a Produtividade Colaborativa ...................................... 128

Fig. 40 - Principais Resultados da Survey pela TNS Emnid na Alemanha............. 141

Fig. 41 - Cenário típico atual da CFSAM. ………............................................... 143

Fig. 42 - Pirâmide da Automação Clássica x Conectada .......................................... 144

Fig. 43 - Identificação das Variáveis ……............................................................ 146

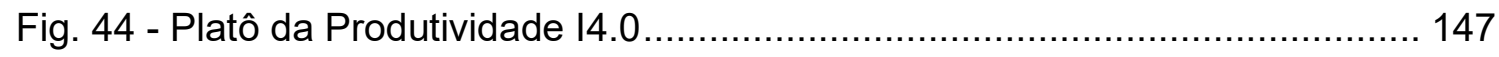

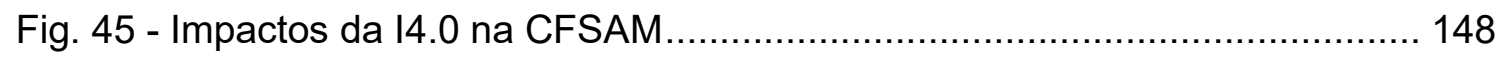

Fig. 46 - Metodologia de Pesquisa - Fluxograma.............................................. 149

Fig. 47 - Os quatro componentes do engajamento sob perspectiva de marketing . 152

Fig. 48 - Quatro componentes para medir engajamento das empresas em I4.0 ... 153

Fig. 49 - H1 Maior eficiencia x Engajamento em 14.0 …..................................... 166

Fig. 50 - H2 Agilidade x Engajamento em 14.0 ................................................. 167 
Fig. 51 - H3 Flexibilidade x Engajamento em I4.0 …........................................168

Fig. 52 - H4 PMEs x Engajamento em I4.0 …….............................................. 168

Fig. 53 - Qualificação Profissional x Engajamento em I4.0 .................................... 169

Fig. 54 - Redução de Offshoring x Engajamento em I4.0 ..................................... 170

Fig. 55 - H7 Risco Cibernético x Engajamento em I4.0 ....................................... 171

Fig. 56 - H8 Servitização x Engajamento em 14.0 ……........................................171

Fig. 57 - Desafios para a Implantação da Plataforma I4.0 ………....................... 174

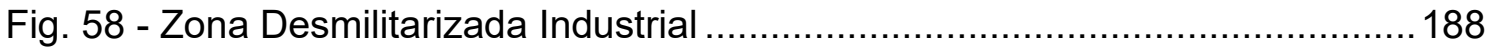

Fig. 59 - Níveis de Maturidade na Manufatura Brasileira ..................................... 194 


\section{LISTA DE QUADROS}

Quadro 1 - Coleta de Dados a partir dos termos chave para PSIA. 36

Quadro 2 - Coleta de Dados para o Termo "Collaborative Network" e "Internet of Services" 38

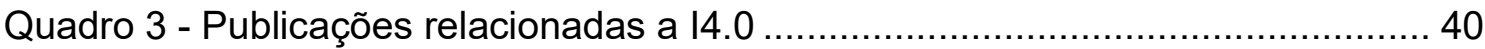

Quadro 4 - Classificação de Clusters em PSIA ………........................................ 44

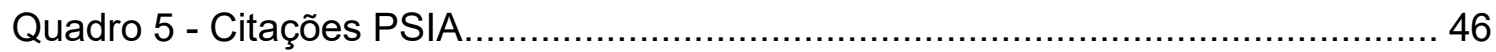

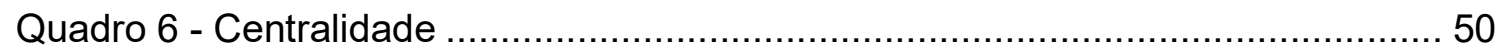

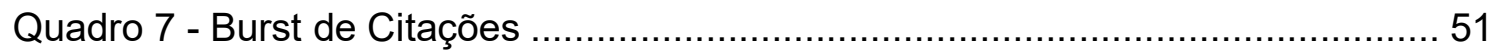

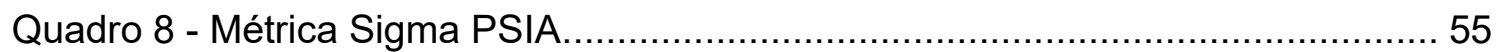

Quadro 9 - Iniciativas para implementação da SOA em Automação Industrial......... 74

Quadro 10 - Tecnologias para loT e questões a serem abordadas ......................... 82

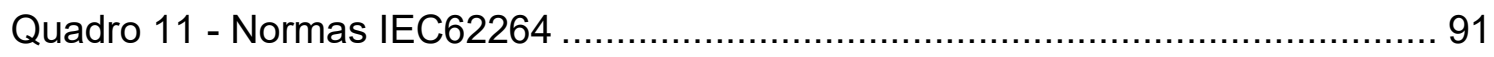

Quadro 12 - Comparativo entre Smart Factory e Linha de Produção Tradicional .... 99

Quadro 13 - Benefícios e Possibilidades Tecnológicas da 14.0 ............................ 117

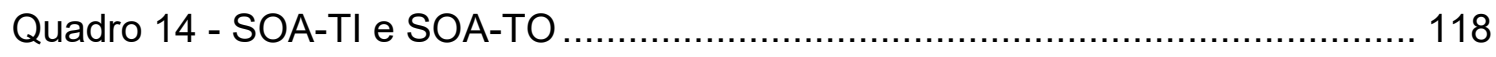

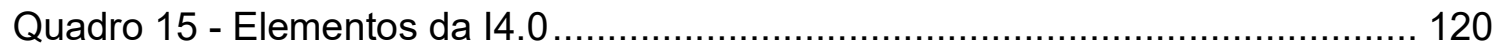

Quadro 16 - Iniciativas Similares na Europa .................................................... 124

Quadro 17 - Grupos de Atores da 14.0 ........................................................ 127

Quadro 18 - 17 Teses da Working Group Industrie 4.0 ................................... 140

Quadro 19 - Métrica para Nível de Engajamento em I4.0................................... 153

Quadro 20 - Recomendações para um bom questionário ..................................... 155

Quadro 21 - Hipóteses para a Questão de Pesquisa .......................................... 156

Quadro 22 - Proposições sobre Desafios para a Implantação da loT e 14.0........... 158

Quadro 23 - Escolha das Unidades de Estudo por conveniência ............................ 163 


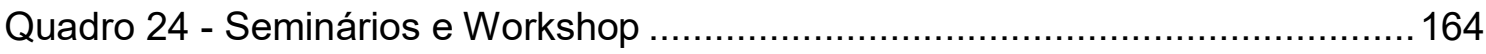

Quadro 25 - Marcos da Evolução Industrial .......................................................... 192

Quadro 26 - Estágios da Evolução Industrial x Controle da Produção...................... 198

Quadro 27 - As Tecnologias Habilitadoras da 14.0 segundo as empresas..............203 


\section{LISTA DE ABREVIATURA E SIGLAS}

\begin{tabular}{ll} 
ANSI & American National Standard Institute \\
APS & Advanced Planning System \\
AS-i & Actuator - Sensor Interface \\
B2MML & Business to Manufacturing Markup Language \\
BPM & Business Process Management \\
BS & British Standard \\
CAPEX & Capital Expenditure \\
CEO & Chief Executive Officer \\
CFSAM & Cadeia de Fornecimento de Sistemas para Automação da \\
CIM & Manufatura \\
CIP & Computer Integrated Manufacturing \\
CLP & Common Industrial Protocol \\
CNC & Controlador Lógico Programável \\
CPPS & Computerized Numeric Control \\
CPS & Cyber Physical Production System \\
CRM & Cyber Physical Systems \\
DCS & Customer Relationship Management \\
DIN & Distributed Control System \\
DPWS & Deutsches Institut für Normung \\
EDI & Device Profile for Web Services \\
EMI & Electronic Data Interchange \\
EPS & Enterprise Manufacturing Intelligence \\
ERP & Evolvable Production System \\
Ethernet IP & Enterprise Resource Planning \\
FMS & Ethernet Industrial Protocol \\
HCP & Hana Cloud Platform \\
HW & Hardware \\
I/O & Imput / Output \\
I1.0 & Indústria 1.0 - Indústria decorrente da Primeira Revolução \\
I2.0 & Industrial \\
& Indústria 2.0 - Indústria decorrente da Segunda Revolução \\
\hline
\end{tabular}


Indústria 3.0 - Indústria decorrente da Terceira Revolução Industrial

14.0

Industrie 4.0 - Indústria 4.0

ICT Information and Communication Technology

IEC International Electrotechnical Commission

IHM Interface Homem Máquina Industrial Internet of Things - Internet Industrial das Coisas

IoS

Internet of Services

IoT

Internet of Things - Internet das Coisas

IP

Internet Protocol

ISA

International Society of Automation

ISO

International Organization for Standardization

IT

Information Technology

IWSN

Industrial Wireless Sensor Network

KPI

Key Performance Indicator

M2M

Machine to Machine

MAS

Multi Agent System

MES

Manufacturing Execution System

MESA

Manufacturing Enterprise Solutions Association

MIMOSA

Operations and Maintenance Information Open System Alliance

MOM

Manufacturing Operations Management

MRP

Material Resource Planning

ODVA

Open Device Vendor Association

OEE

Overall Equipment Efficiency

OLE

Object Linking and Embedding

OPC

OLE for Process Control

OPC-UA

OPC Unified Architecture

OPEX

Operational Expenditure

OSI

Open Systems Interconnection

PC

Personal Computer

PLC

Product Life Cycle

PLC

Programmable Logic Controller

PLM

Product Lifecycle Management

PMEs

Pequena e Média Empresa 


$\begin{array}{ll}\text { PSIA } & \text { Paradigm Shift in Industrial Automation } \\ \text { QR Code } & \text { Qucik Response Code } \\ \text { RFID } & \text { Radio Frequency Identification } \\ \text { SaaS } & \text { Software as a Service } \\ \text { SCADA } & \text { Supervisory Control and Data Acquisition } \\ \text { SCM } & \text { Supply Chain Management } \\ \text { SEI } & \text { Software Engineering Institute } \\ \text { SOA } & \text { Service Oriented Architecture } \\ \text { SOA-AT } & \text { Service Oriented Architecture for Automation } \\ \text { SQL } & \text { Structured Query Language } \\ \text { SSC } & \text { Software Supply Chain } \\ \text { SW } & \text { Software } \\ \text { TI } & \text { Tecnologia da Informação } \\ \text { TIA } & \text { Totally Integrated Automation } \\ \text { TIC } & \text { Tecnologia da Informação e Comunicação } \\ \text { TO } & \text { Tecnologia da Operação } \\ \text { UGC } & \text { User Generated Content } \\ \text { WoS } & \text { Web of Science } \\ \text { WSN } & \text { Wireless Sensor Network } \\ \text { XML } & \text { Extensible Markup Language } \\ \text { XSD } & \text { XML Schema Definition }\end{array}$




\section{SUMÁRIO}

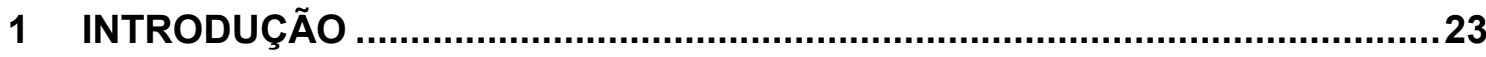

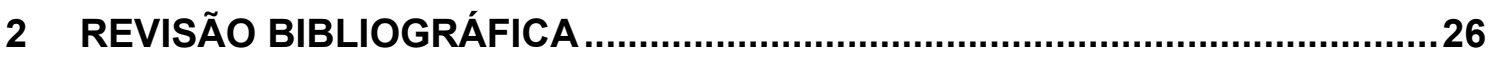

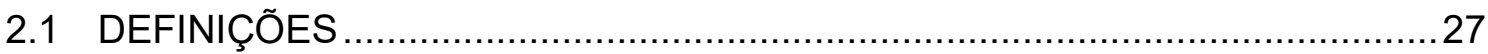

2.1.1 Tecnologia da Automação (Automation Technology) ……............................... 27

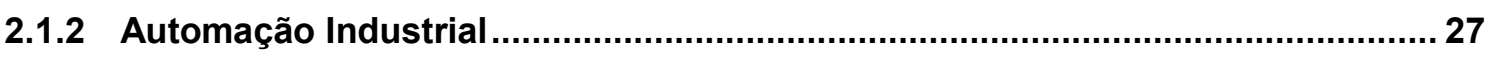

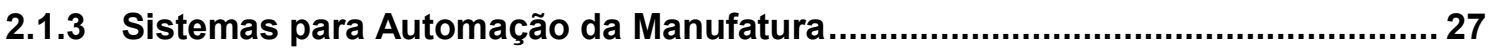

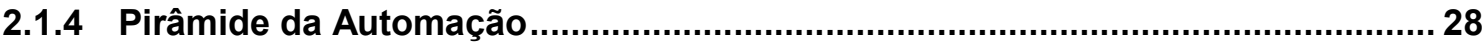

2.1.5 Tecnologia da Informação vs Tecnologia da Informação e Comunicação.......... 29

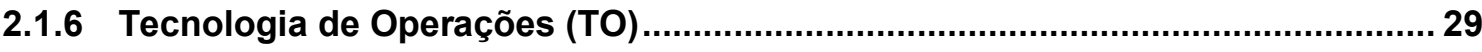

2.1.7 Cadeia de Fornecimento (Supply Chain) …….................................................. 31

2.1.8 Cadeia de Fornecimento de Software ........................................................ 32

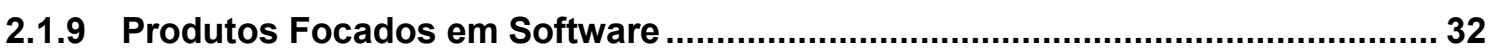

2.1.10 Cadeia de Fornecimento de Sistema para Automação da Manufatura................ 33

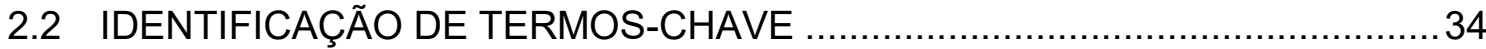

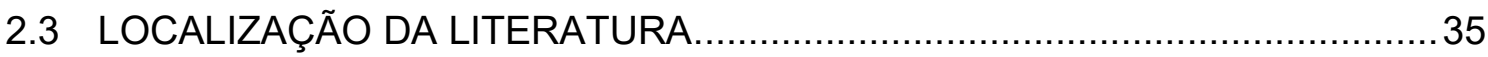

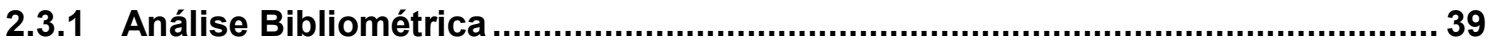

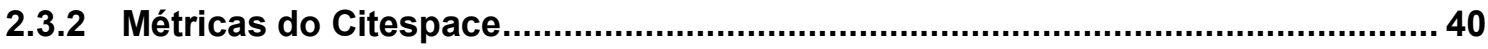

2.3.3 Estruturação do Conhecimento …………........................................................ 42

2.3.4 Análise da Estruturação do Conhecimento PSIA e Collaborative Network ....... 58

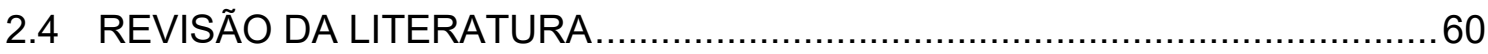

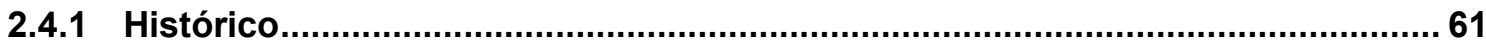

2.4.2 Tecnologia de Redes em Automação da Manufatura ......................................... 63

2.4.3 Redes de Sensores Industriais sem fio (IWSN) ..............................................67

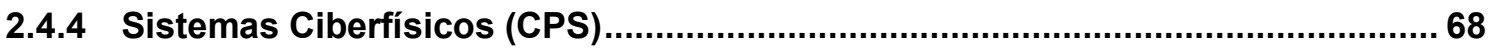

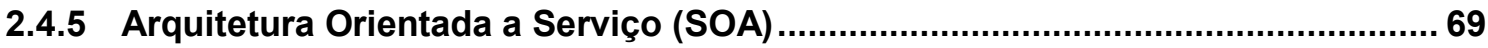

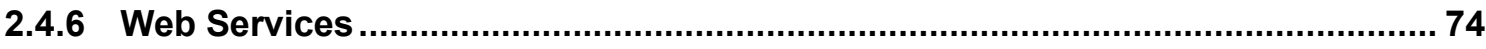

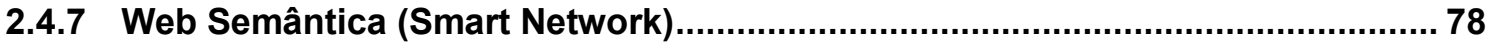

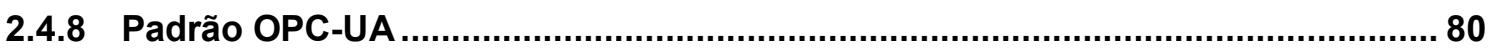

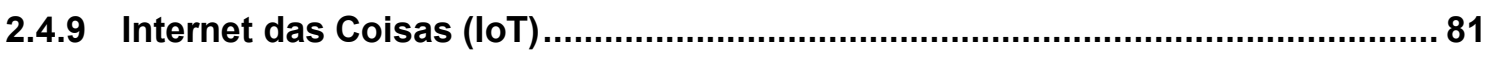

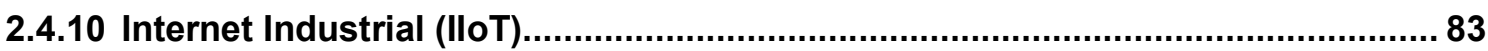

2.4.11 Sistemas de Produção Ciberfísicos (CPPS) ..................................................... 85 


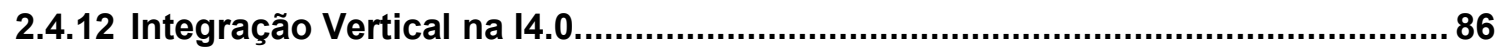

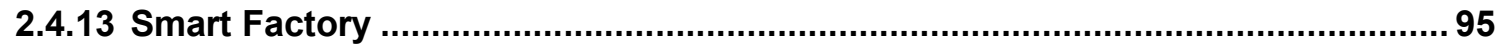

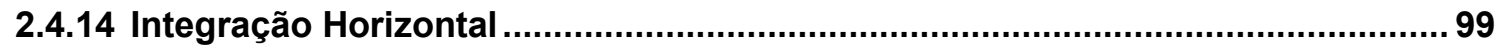

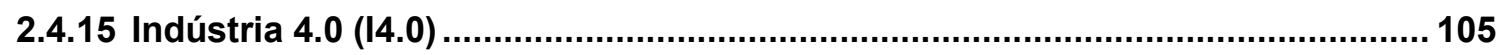

2.4.16 Industria 4.0: Revolução ou Evolução? ......................................................... 111

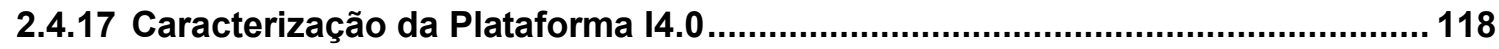

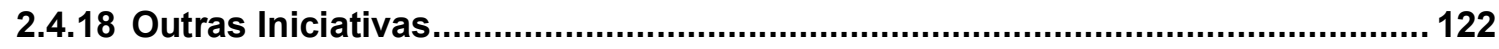

2.5 IMPACTOS DA 14.0 PARA OS ATORES DA CFSAM ............................... 126

2.5.1 Benefícios Pretendidos pela I4.0

2.5.2 Outros Impactos para os atores da CFSAM ............................................ 131

2.6 TRABALHOS SIMILARES ....................................................... 139

2.7 COMPARAÇÃO DOS RESULTADOS COM OUTRAS PESQUISAS............. 142

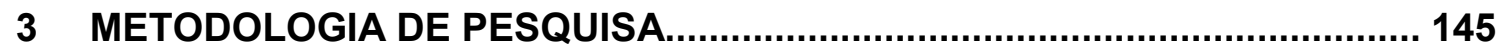

3.1 VARIÁVEIS DA QUESTÃO DE PESQUISA ...................................... 145

3.2 IMPACTOS DA PLATAFORMA 14.0 SOBRE A MANUFATURA .................. 147

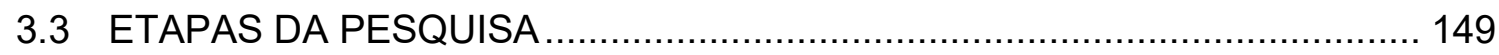

4 DESENVOLVIMENTO DA PESQUISA .................................................. 151

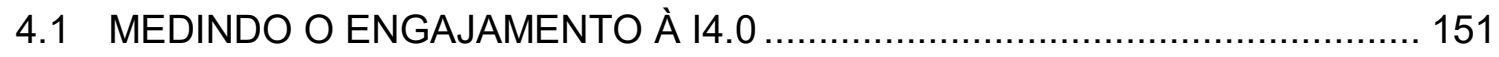

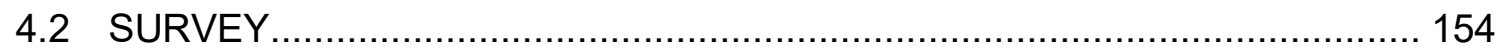

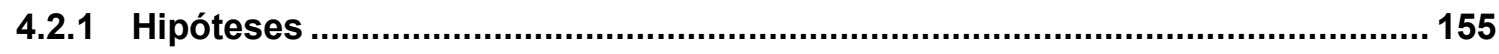

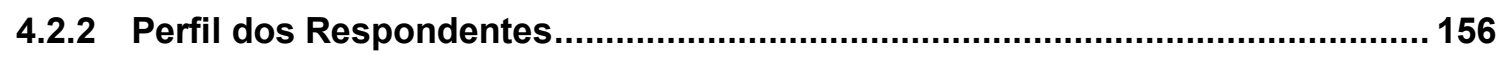

4.3 ESTUDO DE MÚLTIPLOS CASOS ................................................. 157

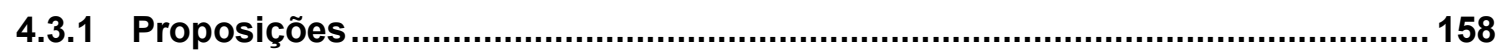

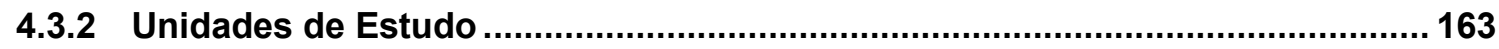

4.4 SEMINÁRIOS E WORKSHOP ........................................................... 163

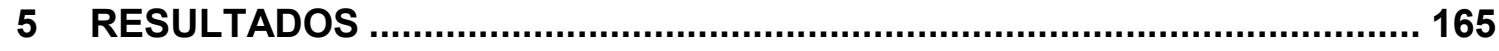

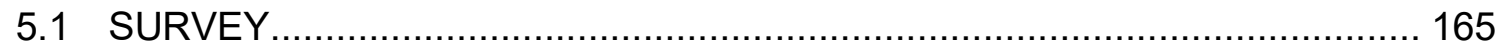

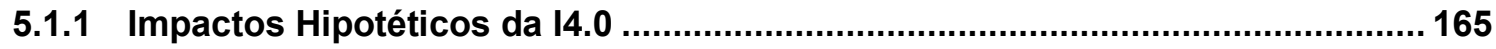

5.1.2 Hipótese 1 - Maior Eficiência Gerencial e Produtiva ........................................ 166

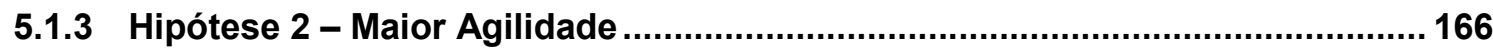


5.1.4 Hipótese 3 - Maior Flexibilidade na Produção ................................................. 167

5.1.5 Hipótese 4 - Maior oportunidade para PMEs ................................................. 168

5.1.6 Hipótese 5 - Novas demandas na Qualificação Profissional ........................... 169

5.1.7 Hipótese 6 - Redução de Offshoring da Produção......................................... 169

5.1.8 Hipótese 7 - Maior Risco Cibernético para Ambiente Industrial ....................... 170

5.1.9 Hipótese 8 - Aumento de oferta de Produtos como Serviços .......................... 171

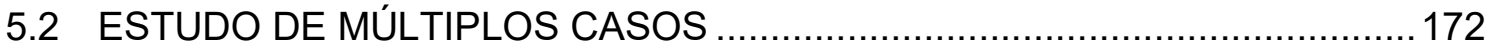

5.2.1 Desafios para a Implantação da Plataforma I4.0 ............................................ 173

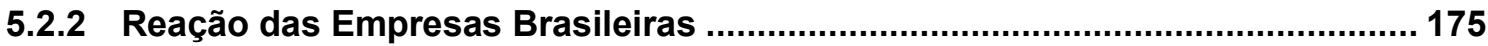

5.2.3 Posicionamento das Empresas de Manufatura em relação a I4.0..................... 192

5.3 ESTADO DA I4.0 NO BRASIL E OPORTUNIDADES NA CFSAM ................200

5.3.1 Habilitadores para $\mathbf{1 4 . 0}$ segundo perspectivas de empresas........................... 201

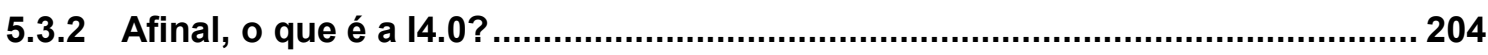

5.3.3 Análise de Oportunidades .......................................................................... 205

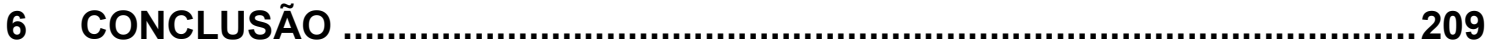

REFERÊNCIAS ..................................................................................... 213

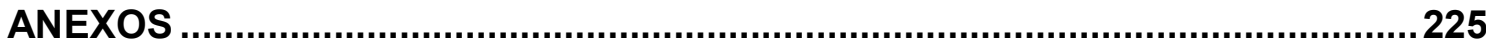





\section{INTRODUÇÃO}

O mundo conectado é fruto dos avanços tecnológicos em Tecnologia de Informação e Comunicação (TIC) que têm permitido uma conectividade cada vez maior entre pessoas. Esta conectividade está avançando agora para conectividade entre "coisas", ao que se está denominando de Internet das Coisas (IoT), que aponta, junto com outras tecnologias como a Internet de Serviços (IoS), para mudanças radicais nos Processos de Manufatura. A conectividade entre coisas permite que as informações sejam geradas e processadas de forma autônoma, através de comunicações diretas entre máquinas (M2M) e "coisas" na indústria (IloT).

Surge assim o conceito de fábrica inteligente (Smart Factory), em que o uso massivo de sistemas com capacidade de processamento embarcada, denominados de Sistemas Ciberfísicos (Cyber Physical System - CPS), conectados a uma rede inteligente (Smart Network) permite adotar uma arquitetura de controle distribuído, orientada a serviço (SOA), que simplifica o complexo processo de integração vertical entre os dispositivos físicos do chão de fábrica e os sistemas de gestão corporativa (ZUEHLKE, 2010).

Tentativas anteriores de integração da manufatura com sistemas CIM (Computer Integrated Manufacturing) encontraram grandes dificuldades (ZUEHLKE, 2010) devido à complexidade apresentada por sistemas de controle centralizados e instalações, formando ilhas tecnológicas, com redes proprietárias e protocolos de comunicação heterogêneas que não se comunicavam entre si (CUCINOTTA et al. 2009; SAUTER, 2007). Para superar estes obstáculos várias organizações têm dedicado esforços no sentido de se criar padrões únicos de comunicação e permitir a integração entre eles e com sistemas de gestão (BRANDL \& OWEN, 2003; SCHOLTEN, 2007; VERHAPPEN, 2010).

A automação integrada dos processos de negócio com a manufatura é essencial para que se consiga a eficiência gerencial e de produção. Além disso, demandas de mercado por customizações em massa requerem sistemas de manufatura cada vez mais flexíveis e ágeis, demandando instalações com capacidades autônomas como de reconfiguração, escalabilidade e autoadaptação às necessidades de produção. 
Contudo, no mundo conectado não basta apenas a integração vertical dentro da empresa. A produção de valores pode ser mais ampla através de redes colaborativas (BRETTEL et al., 2014), em que os sistemas integram informações de toda a rede de maneira autônoma e preditiva, em tempo real. É neste cenário que surge o conceito de Indústria 4.0 (14.0) na Alemanha. A iniciativa Plattform I4.0 que está sendo desenvolvida num esforço conjunto entre a academia e o governo alemães é considerada pelos mesmos, como a Quarta Revolução Industrial, daí o termo Industrie 4.0 (KAGERMANN et al., 2013). Conceitos similares recebem o nome de Industrial Internet (BRUNER, 2013) nos Estados Unidos e de Intelligent Manufacturing na China (RUNKLER, 2013). De forma similar outros países buscam aderência a este modelo através de iniciativas governamentais e/ou de empresas que se preparam para estas mudanças (PATHFINDER, 2014).

No Brasil, a 14.0 também tem sido objeto de atenção e promoção pelas empresas fornecedoras de tecnologia e infraestrutura. Embora até a presente data não se tenha conhecimento de nenhuma iniciativa governamental significativa, a 14.0 tem despertado a curiosidade e o interesse de vários gestores de empresas de manufatura. Igualmente no meio acadêmico, nota-se recentemente uma explosão de publicações relacionadas ao tema 14.0. Uma pesquisa na Web of Science revela que só em 2016 publicaram-se 277 artigos contra um acumulado de apenas 89 artigos até 2015 (TONTA \& DOGANM, 2016). Estes fatos evidenciam a importância que o tema tem alcançado recentemente tanto no meio empresarial como no meio acadêmico. Contudo, ainda há uma grande nebulosidade em torno do que é realmente a 14.0, e qual é a mudança disruptiva que representa a quarta revolução industrial. Hermann et al., (2015) citam que mesmo os promotores chaves da iniciativa apenas descrevem a visão e não apresentam uma definição clara do que é a 14.0. Drath \& Horsh (2014) também citam que várias tentativas de definir a 14.0 e um marketing demasiadamente ambicioso reforçam ainda mais a confusão. Isto faz com que a maioria dos gestores de empresas de manufatura ainda tenham uma baixa compreensão do que é de fato a 14.0 .

No Brasil isso também ocorre, conforme verificou a pesquisa conduzida pela Siemens e IDG (CAMPI - BITMAG, 2016) e também uma relevante sondagem conduzida pela Confederação Nacional das Indústrias (CNI, 2016). A sondagem da CNI (2016) após pesquisar 2.225 empresas brasileiras conclui que embora a adoção 
das tecnologias digitais seja essencial para a competitividade no Brasil, o baixo conhecimento entre os gestores das empresas de manufatura é um entrave à utilização, o que representa uma lacuna no conhecimento deste importante processo evolutivo da indústria, estratégico para o país.

Neste contexto, os objetivos deste estudo são:

- A identificação, através de uma cuidadosa revisão bibliográfica, do que efetivamente caracteriza esta mudança, tão disruptiva, na passagem da I3.0 para 14.0 ,

- Compreender, do ponto de vista de gestão, a reação e o posicionamento atual das indústrias de manufatura no Brasil aos novos paradigmas, e

- Identificar os potenciais impactos e oportunidades que a 14.0 traz para os atores da Cadeia de Fornecimento de Sistemas para Automação da Manufatura (CFSAM).

Enfim, a questão central que se pretende responder com este trabalho é:

Quais impactos a 14.0 está causando na CFSAM no Brasil e que oportunidade de atuação estão surgindo para os atores desta cadeia?

A contribuição teórica que se pretende com esta pesquisa é caracterizar esta mudança de paradigma aprofundando o conhecimento sobre como as empresas de manufatura no Brasil estão aderindo ao paradigma da 14.0 e identificar novas oportunidades de atuação para os atores participantes da CFSAM que inclui também as empresas de manufatura como usuárias dos sistemas. 


\section{REVISÃO BIBLIOGRÁFICA}

Como já exposto anteriormente, há uma grande dificuldade de entendimento do que caracteriza essencialmente a mudança disruptiva de paradigma da I3.0 para a 14.0, o que representa um grande entrave para a adoção das tecnologias digitais para a 14.0 (CNI, 2016). Portanto, um dos objetivos principais desta revisão da literatura é caracterizar claramente esta mudança contribuindo com o preenchimento da lacuna no conhecimento sobre o paradigma da I4.0.

Creswell (2012) cita que a revisão bibliográfica tem o objetivo de documentar como a pesquisa agrega conhecimento à literatura existente. Um estudo não agrega novo conhecimento se ele for duplicado e, portanto, é necessário uma pesquisa o mais abrangente possível para certificar que o estudo representa uma lacuna do conhecimento. É importante ainda que se documente através da revisão bibliográfica que o estudo é de necessidade relevante. Para tanto, Creswell (2012, p.81) recomenda um processo de cinco etapas:

- Identificar os termos-chave a usar na pesquisa de literatura.

- Localizar a literatura sobre um tópico consultando vários tipos de materiais e bancos de dados, incluindo aqueles disponíveis em uma biblioteca acadêmica e na Internet.

- Avaliar criticamente e selecionar a literatura para sua revisão.

- Organizar a literatura selecionada abstraindo ou tomando notas na literatura e desenvolvendo um diagrama visual dela.

- Escrever uma revisão que relata resumos da literatura para inclusão no relatório de pesquisa.

Para que se possa atender ao objetivo deste trabalho citado no capítulo anterior, é necessário que se entenda antes o que exatamente representa esta mudança de paradigma em automação industrial. Para isto, a revisão de literatura foi focada no tema Paradigm Shift in Industrial Automation (PSIA), tomado como ponto de partida para a identificação dos termos chave. Na sequência, a localização da literatura foi feita através do mecanismo de busca da Web of Science (WoS) e do uso de técnicas bibliométricas através do SW Citespace (CHEN, 2014). As técnicas bibliométricas permitiram identificar os trabalhos de maior relevância não apenas pelo número de citações, mas através de outras métricas que apontaram potenciais inovações tecnológicas e áreas de maior atividade de pesquisa. 


\subsection{DEFINIÇÕES}

Antes de se iniciar o processo de identificação dos termos, serão revisadas algumas definições de termos que serão tratados neste trabalho.

\subsubsection{Tecnologia da Automação (Automation Technology)}

A automação refere-se à tecnologia para substituição total ou parcial de uma função previamente realizada pelo operador humano, por um sistema artificial. Isto implica que a automação não é tudo ou nada, mas pode variar nos diversos níveis, desde o mais baixo nível de desempenho, totalmente manual, até o mais alto nível, de automação completa. A automação pode variar em tipo e complexidade, desde a simples organização das fontes de informação, para integrá-los de uma forma resumida, até sugerir opções de decisão que melhor correspondem às informações recebidas, ou mesmo para levar a cabo as medidas necessárias (PARASURAMAN et al., 2000).

\subsubsection{Automação Industrial}

Adotando-se a definição de Automação, como sendo a realização de tarefas sem a intervenção humana com equipamentos e dispositivos que funcionam sozinhos e possuem a capacidade de realizar correções na ocorrência de desvios das condições definidas de operação, podendo estas correções serem feitas através de dispositivos concebidos para tal, dentro de suas características construtivas, sem a utilização de computadores (PESSOA \& SPINOLA, 2014), pode-se particularizar este conceito aplicado ao domínio industrial para definir a Automação Industrial. Da mesma forma, particularizando para aplicações manufatureiras dentro da indústria, tem-se a Automação da Manufatura.

\subsubsection{Sistemas para Automação da Manufatura}

Sistema de Automação é definido como aquele atuante no controle de grandezas físicas de uma maneira geral, para controlar um processo qualquer, que 
significa qualquer operação a ser controlado pelo sistema de automação (PESSOA \& SPINOLA, 2014). Particularizando para o domínio da manufatura, tem-se a definição de Sistemas para Automação da Manufatura.

A automação da manufatura é, portanto, a automação aplicada às atividades de manufatura, com o objetivo de reduzir a necessidade de trabalho humano na produção de bens. Desta forma, pode-se entender que a automação da manufatura engloba a automação dos processos de manufatura e os sistemas de TI relativos ao controle da manufatura tais como os sistemas de execução da manufatura (Manufacturing Execution System - MES), APS (Advanced Planning System), Sistemas Historiadores e planejamento de recursos da empresa (Enterprise Resource Planning - ERP).

\subsubsection{Pirâmide da Automação}

É uma representação hierárquica dos vários níveis pelas quais a informação circula dentro de um sistema de automação da manufatura. Como exemplo, pode-se citar a pirâmide apresentada por Gruner \& Epple (2013) que propõem uma pirâmide de quatro níveis (Fig. 1): a partir do nível do dispositivo de campo, a pirâmide contém o nível de controle de processo, o sistema MES e, em sua parte superior, o planejamento de recursos empresariais $(E R P)$. No nível do dispositivo de campo existem dispositivos com hardware restrito. O nível de controle de processo é normalmente representado por controladores lógicos programáveis (CLPs), enquanto os níveis de MES e ERP são regidos por sistemas baseados em Computadores Pessoais (PC). Esta representação hierárquica é utilizada também no modelo ISA-95 que trabalha o desenvolvimento de padrões abertos para a integração da manufatura através destes níveis denominados de 0 a 4 (BRANDL \& OWEN, 2003; SCHOLTEN, 2007; VERHAPPEN, 2010). 
Fig. 1 - Pirâmide da Automação.

\section{ERP}

MES

Controle de

Processo

Dispositivo de Campo

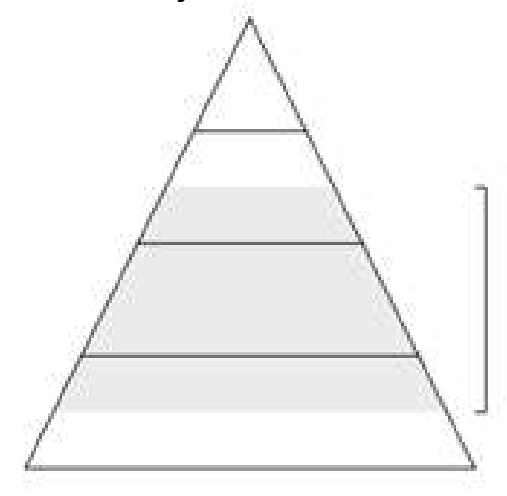

(Fonte: GRUNER \& EPPLE, 2013)

\subsubsection{Tecnologia da Informação vs Tecnologia da Informação e Comunicação.}

Embora autores como Steven (2000) façam distinção entre Tecnologia da Informação (restrito a aspectos técnicos) e Sistemas de Informação (abrangendo questões relativas a fluxo de trabalho, pessoas e informações envolvidas), autores como Henderson \& Venkatraman (1993), entendem que o termo Tecnologia da Informação é um termo mais abrangente que envolve não apenas aspectos tecnológicos como processamento de dados, sistemas de informação, engenharia de software, informática ou o conjunto de hardware e software, mas também aspectos humanos, administrativos e organizacionais. Laurindo et al. (2001), consoante com autores como Luftman et al. (1993) e Weill (1992), adotam o conceito ainda mais amplo de $\mathrm{TI}$ que inclui também a TIC, com o uso de hardware, software, telecomunicações, automação e recursos multimídia, utilizados pelas organizações para fornecer dados, informações e conhecimento. Neste trabalho, utiliza-se esta última forma de definição de TI - sem fazer distinção à TIC - em que tudo será TI.

\subsubsection{Tecnologia de Operações (TO)}

O termo Tecnologia de Operações, cunhada pela Gartner (2016) engloba o conjunto de tecnologia de automação da manufatura e SW (KNOWLES-HALL \& VAN DER VEER, 2014). O termo Tecnologia de Operações é definido pela Gartner (2016) e Bloem et al. (2014) como sendo um conjunto de HW e SW que detecta ou causa 
uma mudança através de monitoramento direto e/ou controle de dispositivos físicos, processos e eventos na empresa. Esta definição é ilustrada graficamente por Piggin (2014) conforme Fig. 2 Segundo Piggin (2014), o termo Tecnologia de Operações foi cunhado pela Gartner (2014) para distinguir o processamento de informações dos sistemas de TI de Sistemas de Controle que interage com equipamentos físicos através de sensores e atuadores. Piggin (2014) cita ainda que Atos (2012) aperfeiçoou esta definição para destacar as estratégias de otimização de negócios para a convergência de TI com TO, baseado no modelo hierárquico ISA-95 (Fig. 3).

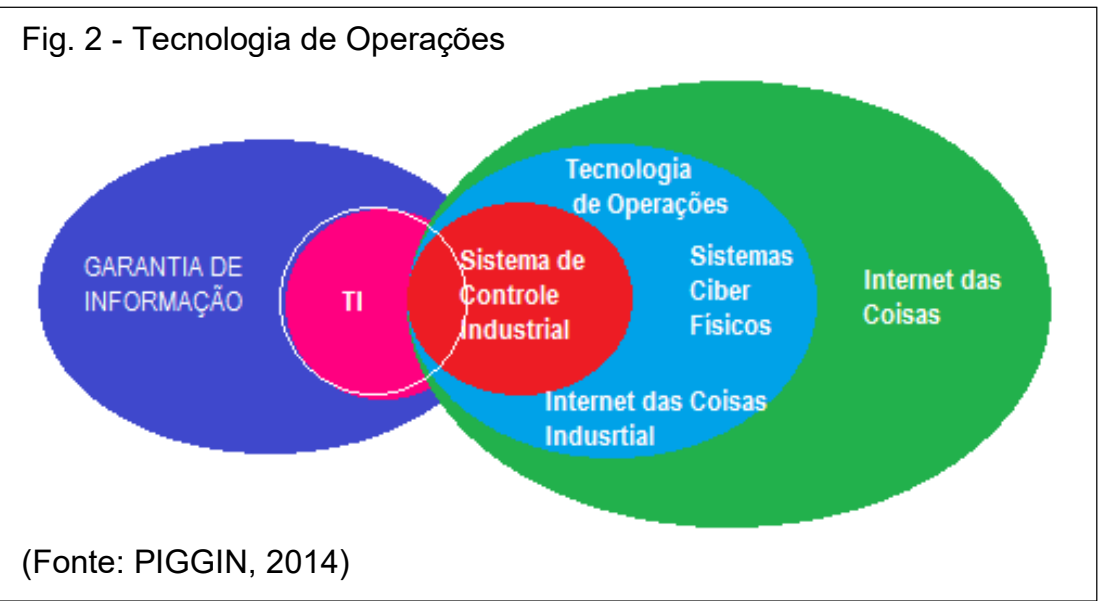

A Atos (2012) define TO como o conjunto de dispositivos e processos que atuam em tempo real em sistemas operacionais físicos, como redes de distribuição de eletricidade, instalações ou fábricas de produção de veículos. Exemplos de elementos OT incluem MES (Sistemas de Execução de Manufatura), SCADA (Controle Supervisor e Aquisição de Dados), medidores, válvulas, sensores, motores, etc. Por outro lado, diferencia a TI como sendo toda a pilha de tecnologia, incluindo a infraestrutura de hardware e os aplicativos de software usados para transformar dados. Um sistema de TI pode, portanto, ser definido como um mecanismo que aceita fluxos de dados como entrada e entrega um novo fluxo de dados, mas não interfere com o mundo físico. Exemplos de sistemas de TI relevantes incluem sistemas ERP (Enterprise Resource Planning) ou CRM (Customer Relationship Management). 
Fig. 3 - Componentes de TI e TO nos níveis hierárquicos ISA-95

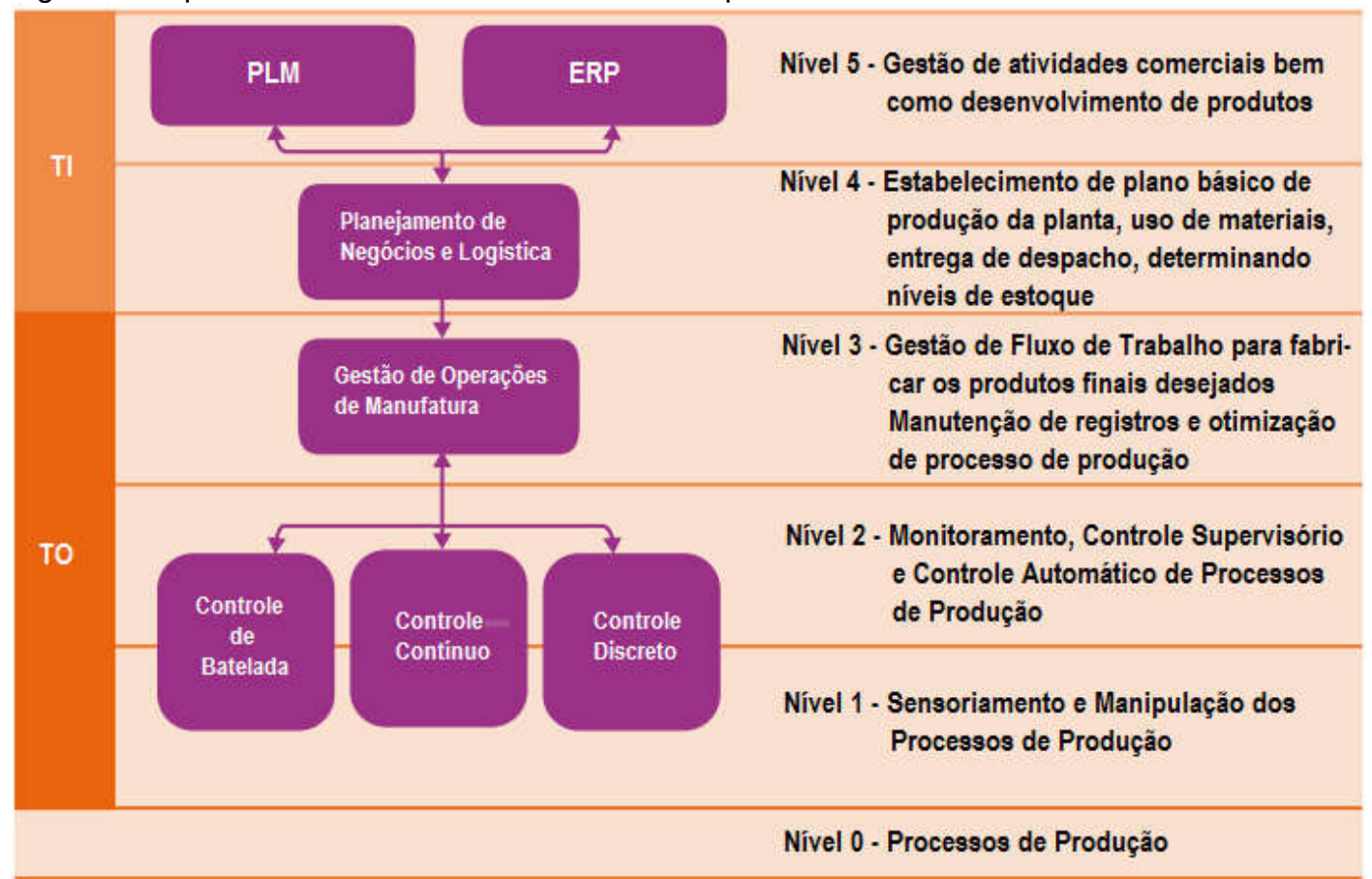

(Fonte: ATOS, 2012)

Exemplos dos vários componentes de Tl e TO ao longo dos níveis hierárquicos ISA-95 da pirâmide da automação podem ser vistos na Fig. 3.

\subsubsection{Cadeia de Fornecimento (Supply Chain)}

A cadeia de fornecimento é uma rede que começa com matéria-prima, transforma-os em bens intermediários, e depois para o produto final entregue aos clientes. Cada participante consome produtos lógicos e/ou físicos de um ou mais fornecedores a montante, agrega valor, geralmente incorporando-os em produtos mais complexos, e fornece os resultados ao consumidor a jusante (LEE \& BILLINGTON, 1994)

La Londe e Masters (1994) definem a cadeia de fornecimento (supply chain) como um conjunto de empresas que participam do fluxo de materiais. Normalmente, várias empresas independentes estão envolvidas na fabricação de um produto até chegar ao usuário final. Produtores de matérias-primas e componentes, montadores de produtos, atacadistas, comerciantes varejistas e empresas de transporte são todos membros de uma cadeia de fornecimento (LA LONDE \& MASTERS, 1994). Lambert 
et al. (1998) definem uma cadeia de suprimentos como o alinhamento das empresas que trazem produtos ou serviços para o mercado. Note-se que estes conceitos de cadeia de suprimentos incluem o consumidor final como parte da cadeia de fornecimento. Especificamente, a cadeia de fornecimento engloba os passos necessários para obter um bem ou serviço do fornecedor ao cliente. Ellison (2010a) define a cadeia de fornecimento como o conjunto de fornecedores que contribuem para o conteúdo de um produto ou sistema (hardware e software), ou que têm a oportunidade de modificar o seu conteúdo.

\subsubsection{Cadeia de Fornecimento de Software}

Hartmann \& Trew (2008) citando a definição de cadeia de fornecimento de Lee \& Billington (1994) estendem o conceito para SW. Isto significa que uma empresa compra um conjunto de componentes de SW de (vários) fornecedores e integra-os em um produto, eventualmente em combinação com o seu próprio SW. Para cada um dos seus clientes, isto é, os próximos participantes na cadeia, uma versão especializada pode ser criada. Cada um dos participantes adiciona novas funcionalidades e opções de configuração, baseado no seu papel e responsabilidade na cadeia de fornecimento.

A Cadeia de Fornecimento de Software é definida pelo Software Engineering Institute (SEI), como a rede de participantes que contribuem para o conteúdo de um produto de software ou que têm a oportunidade de modificar o seu conteúdo (ALBERTS et al., 2011).

Bettin (2004), define cadeia de fornecimento de software, de forma consistente com a natureza de desenvolvimento de software, como uma atividade de projeto. $\mathrm{Ou}$ seja, uma cadeia de fornecimento de software está estreitamente alinhada com os processos que em outros setores seriam rotulados de cadeia de projeto, em vez de cadeia de fornecimento e, portanto, uma prestação de serviço.

\subsubsection{Produtos Focados em Software}

Produtos focados em SW são os que consistem em composição de HW e SW, normalmente constituindo o componente de SW a parte de maior valor no produto, ou 
a grande inovação do produto, ou o principal diferencial do produto (TAN \& YUAN, 2005).

Os sistemas para automação da manufatura na 14.0 também podem ser considerados sistemas focados em Software, compostos de componentes de HW (equipamentos baseados em CPS e infraestrutura de rede) e componente de SW (aplicativos de TO e TI). Nestes componentes de SW é que reside normalmente, a grande inovação que proporciona maior valor agregado.

\subsubsection{Cadeia de Fornecimento de Sistema para Automação da Manufatura}

A cadeia de fornecimento de sistema para automação da manufatura (CFSAM) na 14.0 pode ser equiparada à cadeia de fornecimento de produtos focados em software, visto que HW é composto por máquinas, dispositivos, sensores e sistemas de controle de caráter físico baseados em CPS e SW é composto por aplicativos como programas de CLP, sistemas ERP, MES, APS, CRM, etc. de caráter virtual. A Cadeia de fornecimento de produtos focados em SW enfatiza o fluxo de SW e o processo de integração entre HW e SW (CAO et al., 2006) e têm sido estudadas por vários pesquisadores como Chou et al. (2006), Tan \& Yuan (2005), Xia et al. (2005), Ma \& Yuan (2005), Cao et al. (2006).

$\mathrm{Na}$ CFSAM os componentes de HW são fornecidos pelos fabricantes de máquinas, equipamentos, instrumentos, infraestrutura física e os componentes de SW pelos fornecedores de sistemas de TI e pelos integradores que costuram esta interface entre a TI e TO. Como componentes de SW pode-se citar os programas e parametrizações das máquinas e equipamentos bem como os sistemas de supervisão, controle e planejamento da manufatura (Sistemas Supervisórios, SCADA, MES, APS, MRP, ERP, etc.). De acordo com Lambert et al. (1998), a cadeia de fornecimento inclui ainda o usuário final como ator desta cadeia que normalmente recebe o produto acabado de uma única empresa responsável pelo produto. No entanto, o fornecimento para o usuário final da CFSAM tem atualmente, a particularidade de não haver uma única empresa responsável que entrega o sistema de manufatura completo como um produto. Normalmente os sistemas de TO e TI são entregues por várias empresas distintas, desenvolvidas em tecnologias diversas que não se conversam entre si. O conceito da 14.0 busca superar esta dificuldade que é 
vista como uma lacuna tecnológica. A 14.0 caminha, não no sentido de permitir o fornecimento de um sistema complexo deste porte por apenas uma única empresa, mas no sentido de torná-lo um sistema aberto e padronizado, que mesmo sendo fornecido em partes por várias empresas, as mesmas se integrem perfeitamente de forma autônoma e adaptável.

\subsection{IDENTIFICAÇÃO DE TERMOS-CHAVE}

Okubo (1997) ensina que a bibliometria é um instrumento pelo qual o estado da ciência e da tecnologia pode ser observado através da produção global de literatura científica, em um determinado nível de especialização. É um meio para situar um país em relação ao mundo, uma instituição em relação a um país, e até mesmo cientistas individuais em relação às suas próprias comunidades. Estes indicadores científicos são igualmente adequados - desde que sejam tomadas as precauções específicas para a análise "macro" (por exemplo, a participação de um determinado país na produção global de literatura científica durante um período específico) e estudos "micro" (por exemplo, o papel de uma determinada instituição na produção de trabalhos em um campo altamente circunscrito da ciência). Okubo (1997) explica que a escolha da base de dados para compilar indicadores bibliométricos depende diretamente dos objetivos desejados e das questões que se quer responder. Portanto, a pesquisa deve começar pela escolha da base de dados mais adequada para a finalidade. Okubo (1997) cita ainda que para um estudo bibliométrico a nível macro é necessário que a base de dados seja abrangente, mas não necessariamente que cubra todos os dados. De acordo com o autor, o risco de não ser representativo ou abrangente pode sempre ser minimizado combinando ou fatorando informações de várias fontes na análise. Creswell (2012) lembra ainda da importância de se escolher os termos chave como uma das primeiras etapas da revisão bibliográfica.

Em resposta a estas recomendações os termos chave foram identificadas de forma iterativa, partindo-se do termo inicial Paradigm Shift in Industrial Automation (PSIA) como já foi exposto no início deste capítulo.

Através do mecanismo de busca do Google Acadêmico foram identificadas as primeiras contribuições para este tema. Pela leitura destes artigos, identificaram-se novos termos relacionados com os quais se identificaram outros artigos que levaram 
a novos termos chave, e assim sucessivamente até atingir uma certa saturação. Este processo iterativo permitiu a identificação de vários termos chave que poderiam identificar contribuições interessantes ao tema inicial. Seguindo a recomendação de Okubo (1997) de buscar várias fontes, profissionais que atuam no ramo de automação industrial também foram consultados para identificar termos relacionados às mudanças e tendências em sistemas para automação da manufatura.

\subsection{LOCALIZAÇÃO DA LITERATURA}

Embora Google Acadêmico traga uma lista de artigos, não é possível identificar quais os trabalhos mais relevantes e confiáveis. Entender a evolução da pesquisa em torno de PSIA através da leitura convencional de todos estes artigos também seria bastante trabalhoso, se não impossível. Por este motivo foi utilizado uma ferramenta bibliométrica chamada Citespace (CHEN, 2014) para analisar a estrutura do conhecimento relacionada ao termo PSIA. O Citespace requer uma base de dados, incluindo os artigos relacionados ao tema, com seus respectivos dados bibliográficos para ser compilada e gerar o mapa de citações e demais métricas. Este processo foi realizado através do mecanismo de busca avançada sobre a Coleção Principal da base de dados do Web of Science (WoS) por este permitir a listagem e exportação destes dados em arquivos compiláveis pelo Citespace.

O mecanismo de busca avançada requer ainda a janela temporal para a pesquisa. De acordo com Chen (2014), a base de dados deve ser o mais abrangente possível, porém não demasiadamente grande a ponto de prejudicar a performance do Software (CHEN, 2014 p.13). Após alguns testes com diferentes períodos, chegou-se à conclusão de que a janela temporal de 2005 a 2016 (cerca de dez anos) seria suficientemente abrangente comparando-se à pesquisa de Tonta \& Doganm (2016) sem sobrecarregar a base de dados. Com este intervalo temporal 830 artigos foram obtidos, conforme a totalização dos artigos do Quadro 1 e 1577 artigos conforme a totalização dos artigos do Quadro 2. Os termos chave para a pesquisa estão listados na primeira coluna. Na segunda coluna está a quantidade de artigos encontrados e a última coluna indica os três trabalhos mais citados segundo a classificação feita pelo próprio mecanismo de busca da WoS até a data de 06/11/2016 e 07/09/2017 respectivamente para os termos PSIA e Collaborative Network. Nesta etapa, 
juntamente com a localização da literatura, uma análise crítica (CRESWELL, 2012 p.81) é feita para selecionar apenas os trabalhos pertinentes à pesquisa.

Quadro 1 - Coleta de Dados a partir dos termos chave para PSIA.

\begin{tabular}{|c|c|c|}
\hline $\begin{array}{l}\text { Termos chave para } \\
\text { pesquisa }\end{array}$ & $\begin{array}{l}\text { Quantidade } \\
\text { de Artigos }{ }^{1}\end{array}$ & $\begin{array}{c}\text { Artigos em destaque - Número de Citações }{ }^{2} \\
\text { (Web of Science) }\end{array}$ \\
\hline $\begin{array}{l}\mathrm{TS}=(\text { paradigm shift in } \\
\text { industrial automation })\end{array}$ & 19 & $\begin{array}{l}\text { (CUCINOTTA et al., 2009) A Real-Time Service- } \\
\text { Oriented Architecture for Industrial Automation - } 67 \\
\text { (MAROPOULOS et al., 2014) - A new paradigm in } \\
\text { large-scale assembly-research priorities in } \\
\text { measurement assisted assembly. - } 7 \\
\text { (PEDERSEN et al., 2016) Robot skills for } \\
\text { manufacturing: From concept to industrial deployment - } \\
2\end{array}$ \\
\hline $\begin{array}{l}\mathrm{TS}=((\text { "service oriented } \\
\text { architecture" or SOA) and } \\
\text { industrial automation) }\end{array}$ & 85 & $\begin{array}{l}\text { (JAMMES \& SMIT) Service-oriented paradigms in } \\
\text { industrial automation }-218 \\
\text { (CUCINOTTA et al., 2009) A Real-Time Service- } \\
\text { Oriented Architecture for Industrial Automation - } 67 \\
\text { (CÂNDIDO et al., 2011) Service-Oriented Infrastructure } \\
\text { to Support the Deployment of Evolvable Production } \\
\text { Systems - } 47\end{array}$ \\
\hline $\begin{array}{l}\text { TS=("evolvable production } \\
\text { system" and industrial } \\
\text { automation) }\end{array}$ & 5 & $\begin{array}{l}\text { (CÂNDIDO et al., 2011) Service-Oriented Infrastructure } \\
\text { to Support the Deployment of Evolvable Production } \\
\text { Systems - } 47 \\
\text { (NEVES et al., 2013) Prospection of methods to support } \\
\text { design and configuration of self-organizing mechatronic } \\
\text { systems - } 1 \\
\text { (CÂNDIDO et al., 2010) Service-Oriented Architecture } \\
\text { at device level to support Evolvable Production } \\
\text { Systems-1 }\end{array}$ \\
\hline $\begin{array}{l}\text { TS }=(\text { networked } \\
\text { manufacturing and } \\
\text { industrial automation })\end{array}$ & 130 & $\begin{array}{l}\text { (GUNGOR \& HANCKE, 2009) Industrial Wireless } \\
\text { Sensor Networks: Challenges, Design Principles, and } \\
\text { Technical Approaches - } 379 \\
\text { (VYATKIN, 2011) IEC } 61499 \text { as Enabler of Distributed } \\
\text { and Intelligent Automation: State-of-the-Art Review }-97 \\
\text { (KORBER et al., 2007) Modular wireless real-time } \\
\text { sensor/actuator network for factory automation } \\
\text { applications - 51 }\end{array}$ \\
\hline $\begin{array}{l}\text { TS }=((\text { device profile for web } \\
\text { service or DPWS }) \text { and } \\
\text { industrial automation })\end{array}$ & 14 & $\begin{array}{l}\text { (CANDIDO et al., 2009) SOA in reconfigurable supply } \\
\text { chains: A research roadmap - } 27 \\
\text { (KYUSAKOV et al., 2011) Efficient XML Interchange in } \\
\text { Factory Automation Systems-9 } \\
\text { (POHL et al., 2008) Service-orientation and Flexible } \\
\text { Service Binding in Distributed Automation and Control } \\
\text { Systems - } 6 \\
\text { (SUCIC et al., 2012) Integrating DPWS and OPC-UA } \\
\text { device-level SOA features into IEC } 61850 \text { applications- } \\
3\end{array}$ \\
\hline $\begin{array}{l}\text { TS }=((\text { multi agent system or } \\
\text { MAS }) \text { and industrial } \\
\text { automation })\end{array}$ & 73 & $\begin{array}{l}\text { (PĚCHOUČEK et al., 2008) Industrial deployment of } \\
\text { multi-agent technologies: review and selected case } \\
\text { studies - } 63\end{array}$ \\
\hline
\end{tabular}

\footnotetext{
${ }^{1}$ A quantidade de artigos refere-se à data da última atualização feita em 06/11/2016.

2 O número de citações da Web of Science refere-se ao número total de citações que o artigo recebeu até 06/11/2016.
} 
Termos chave para pesquisa

TS=("cloud manufacturing" and industrial automation)

TS $=(($ Cyber Phisical System or CPS) and industrial automation)

TS=((“Internet of Things" or loT) and "Industrial Automation")

TS=("System of systems" and Industrial Automation)

TS $=(($ IEC62264 or ISA-95) and Industrial Automation)

TS=("industrie 4.0" or "industry 4.0" or "industrial internet" or "smart factory")

$\mathrm{TS}=$ (third industrial revolution)
Quantidade de Artigos

19

31

4

6

386

55
Artigos em destaque - Número de Citações ${ }^{2}$

(Web of Science)

(VRBA et al., 2011) Rockwell Automation's Holonic and Multiagent Control Systems Compendium-35

(LEITÃO et al., 2013) Past, Present, and Future of Industrial Agent Applications - 32

(WU et al., 2013) Cloud manufacturing: Strategic vision and state-of-the-art - 56

(STOKIC, 2014) Engineering Methods and Tools for Collaborative Development of Industrial Cyber-Physical Based Products and Services -1

(DI ORIO et al., 2015) A Cloud-Based Infrastructure to Support Manufacturing Resources Composition - 0

(RIEDL et al., 2014) Cyber-physical systems alter automation architectures - 5

(LEITÃO et al., 2016) Industrial automation based on cyber-physical systems technologies: Prototype implementations and challenges - 2

(LEITÃO et al., 2016) Smart Agents in Industrial CyberPhysical Systems - 0

(JARA et al., 2014) Extending the Internet of Things to the Future Internet through IPv6 support - 8

(IMTIAZ \& JASPERNEITE, 2013) Scalability of OPCUA Down to the Chip Level Enables "Internet of Things"7

(SAPONARA et al., 2009) Smart Transducer Interface in Embedded Systems for Networked Sensors Based on the Emerging IEEE 1451 Standard: H2 Detection Case Study - 6

(COLOMBO et al., 2013) A System of Systems view on Collaborative Industrial Automation - 4

(MORA et al., 2012) Service-Oriented Architecture approach for Industrial "System of Systems": State-ofthe-Art for Energy Management - 4

(VIERHAUSER et al., 2014) A Case Study on Testing, Commissioning, and Operation of Very-Large-Scale Software Systems - 3

(NAGORNY et al., 2012) A service- and multi-agentoriented manufacturing automation architecture: An IEC 62264 level 2 compliant implementation - 14

(MORA et al., 2012) Service-Oriented Architecture approach for Industrial "System of Systems": State-ofthe-Art for Energy Management - 4

(DELSING et al., 2012) Migration of industrial process control systems into service oriented architecture - 3

(DRATH \& HORCH, 2014) Industrie 4.0: Hit or Hype? $-24$

(LEE et al., 2014) Service innovation and smart analytics for Industry 4.0 and big data environment -24 (MONOSTORI, 2014) Cyber-physical production systems: Roots, expectations and R\&D challenges - 24 (HUANG et al., 2013) Additive manufacturing and its societal impact: a literature review - 60

(TIEN, 2013) Big Data: Unleashing information - 18

(TIEN, 2012) The next industrial revolution: Integrated services and goods - 10

(Fonte: o Autor - Coleta de dados atualizada em 06/11/2016) 
Quadro 2 - Coleta de Dados para o Termo "Collaborative Network" e "Internet of Services"

\begin{tabular}{|c|c|c|}
\hline $\begin{array}{l}\text { Termos chave para } \\
\text { pesquisa }\end{array}$ & $\begin{array}{l}\text { Quantidade } \\
\text { de Artigos }{ }^{3}\end{array}$ & $\begin{array}{c}\text { Artigos em destaque - Número de Citações }{ }^{4} \\
\text { (Web of Science) }\end{array}$ \\
\hline $\begin{array}{l}\text { TS=("collaborative } \\
\text { network") }\end{array}$ & 396 & $\begin{array}{l}\text { (HARRIS et al., 2009) Research electronic data } \\
\text { capture (REDCap)-A metadata-driven methodology } \\
\text { and workflow process for providing translational } \\
\text { research informatics support - } 3902 \\
\text { (NIETO et al., 2007) } \\
\text { The importance of diverse collaborative networks for } \\
\text { the novelty of product innovation - } 327 \\
\text { (TSAI \& KULEN-HUNG, 2009) Collaborative networks } \\
\text { and product innovation performance: Toward a } \\
\text { contingency perspective - } 136\end{array}$ \\
\hline $\begin{array}{l}\text { TS=("collaborative } \\
\text { manufacturing") }\end{array}$ & 218 & $\begin{array}{l}\text { (VALILAI et al., 2013) A collaborative and integrated } \\
\text { platform to support distributed manufacturing system } \\
\text { using a service-oriented approach based on cloud } \\
\text { computing paradigm - } 64 \\
\text { (WANG et al., 2009) Assembly process planning and } \\
\text { its future in collaborative manufacturing: a review - } 55 \\
\text { (WANG et al., 2012) DIMP: an interoperable solution } \\
\text { for software integration and product data exchange }\end{array}$ \\
\hline $\begin{array}{l}\text { TS=("manufacturing } \\
\text { service") }\end{array}$ & 282 & $\begin{array}{l}\text { (TAO et al., 2014) CCloT-CMfg: Cloud Computing and } \\
\text { Internet of Things-Based Cloud Manufacturing Service } \\
\text { System - } 112 \\
\text { (TAO et al., 2014) loT-Based Intelligent Perception } \\
\text { and Access of Manufacturing Resource Toward Cloud } \\
\text { Manufacturing - } 98 \\
\text { (ZHANG et al., 2014) Cloud manufacturing: a new } \\
\text { manufacturing paradigm - } 91\end{array}$ \\
\hline $\begin{array}{l}\text { TS=(“Internet of services" } \\
\text { or "loS") and } \\
\text { ("manufacturing" or } \\
\text { "Industry } 4.0 \text { ") }\end{array}$ & 16 & $\begin{array}{l}\text { (SAEED et al., 2005) Examining the impact of } \\
\text { interorganizational systems on process efficiency and } \\
\text { sourcing leverage in buyer-supplier dyads }-147 \\
\text { (TAO et al., } 2014 \text { ) CCloT-CMfg: Cloud Computing and } \\
\text { Internet of Things-Based Cloud Manufacturing Service } \\
\text { System - } 112 \\
\text { (CARDOSO et al., 2009) Service Engineering for the } \\
\text { Internet of Services - } 23\end{array}$ \\
\hline TS=(“Internet of Services”) & 147 & $\begin{array}{l}\text { (TAO et al., 2014) CCloT-CMfg: Cloud Computing and } \\
\text { Internet of Things-Based Cloud Manufacturing Service } \\
\text { System - } 112 \\
\text { (SANCHEZ et al., 2014) SmartSantander: IoT } \\
\text { experimentation over a smart city testbed - } 74 \\
\text { (BENLIAN et al., 2009) Drivers of SaaS-Adoption - An } \\
\text { Empirical Study of Different Application Types - } 57\end{array}$ \\
\hline $\begin{array}{l}\text { TS=("service science" and } \\
\text { "collaborative") }\end{array}$ & 27 & $\begin{array}{l}\text { (LUSCH et al., 2008) Toward a conceptual foundation } \\
\text { for service science: Contributions from service- } \\
\text { dominant logic }-170 \\
\text { (SPOHRER et al., 2008) Service Science - } 31 \\
\text { (CHONG et. Al., 2014) } \\
\text { Demand chain management: Relationships between } \\
\text { external antecedents, web-based integration and } \\
\text { service innovation performance - } 12\end{array}$ \\
\hline
\end{tabular}

\footnotetext{
${ }^{3}$ A quantidade de artigos refere-se à data da última atualização feita em 06/11/2016.

${ }^{4} \mathrm{O}$ número de citações da Web of Science refere-se ao número total de citações que o artigo recebeu até $06 / 11 / 2016$.
} 


\begin{tabular}{|c|c|c|}
\hline $\begin{array}{l}\text { Termos chave para } \\
\text { pesquisa }\end{array}$ & $\begin{array}{l}\text { Quantidade } \\
\text { de Artigos }{ }^{3}\end{array}$ & $\begin{array}{l}\text { Artigos em destaque - Número de Citações }{ }^{4} \\
\text { (Web of Science) }\end{array}$ \\
\hline $\begin{array}{l}\text { TS=("collaborative } \\
\text { network" and } \\
\text { "manufacturing") }\end{array}$ & 21 & $\begin{array}{l}\text { (NIETO et al., 2007) The importance of diverse } \\
\text { collaborative networks for the novelty of product } \\
\text { innovation }-327 \\
\text { (KUEN-HUNG et al., 2009) External technology } \\
\text { sourcing and innovation performance in LMT sectors: } \\
\text { An analysis based on the Taiwanese Technological } \\
\text { Innovation Survey - } 40 \\
\text { (POSCH, 2010) } \\
\text { Industrial Recycling Networks as Starting Points for } \\
\text { Broader Sustainability-Oriented Cooperation?- } 29\end{array}$ \\
\hline $\begin{array}{l}\text { TS=("service science" or } \\
\text { "science of service") }\end{array}$ & 470 & $\begin{array}{l}\text { (OSTROM et al., 2010) Moving Forward and Making a } \\
\text { Difference: Research Priorities for the Science of } \\
\text { Service }-480 \\
\text { (SPOHRER et al., 2007) Steps toward a science of } \\
\text { service systems }-360 \\
\text { (MAGLIO et al. 2008) Fundamentals of service science } \\
-323\end{array}$ \\
\hline
\end{tabular}

(Fonte: o Autor - coleta de dados atualizada em 07/09/2017)

Estas pesquisas feitas pelo WoS permitem relacionar e identificar os artigos mais citados, porém não permitem uma análise mais aprofundada da estruturação do conhecimento em torno do tema PSIA e Collaborative Network, nem a identificação de trabalhos potencialmente inovadores através de outros critérios. Para um entendimento melhor desta estruturação, portanto, foi utilizada uma técnica de análise bibliométrica através do SW Citespace (CHEN, 2014). Como pode-se ver adiante, muitos trabalhos relevantes não apontados nesta lista foram identificados na análise bibliométrica como contribuições cruciais para a evolução da pesquisa.

\subsubsection{Análise Bibliométrica}

A análise bibliométrica auxilia entender melhor a estruturação e a dinâmica do conhecimento dentro de um domínio e permite organizar a literatura desenvolvendo um diagrama visual através de mapas de citações e clusters. De acordo com Chen (2014), o Citespace pode ainda auxiliar a responder questões de pesquisa tais como:

- Quais são as maiores áreas de pesquisa, baseado no conjunto de dados (lista de artigos coletados na Web of Science)?

- Como estas áreas estão conectadas e através de quais contribuições acadêmicas (artigos)?

- Onde estão as áreas mais ativas?

- Do que tratam estas áreas de pesquisa? Quais os trabalhos mais relevantes de cada área?

- Quais são as transições críticas na história do desenvolvimento de uma área? Onde estão os pontos de mudança? 
Para tanto, o Citespace requer uma base de dados de artigos cobrindo um certo domínio (CHEN, 2014). Esta base de dados foi construída através da relação de artigos coletados pelo mecanismo de busca do WoS conforme Quadro 1 e exportados para arquivos texto que foram unificados e processados pelo Citespace.

Uma análise bibliométrica similar foi realizada por Tonta \& Doganm (2016) em 20/12/2015, apenas em torno do tema 14.0 , utilizando a seguinte sintaxe de pesquisa sobre a mesma base de dados do WoS (cobrindo uma janela temporal de 1945 a 2015):

ti=("industry 4.0 ") or ts=("industry 4.0 ") or ti=("industrie 4.0 ") or ts=("industrie 4.0 ") or $t i=$ ("4th industrial revolution") or $t s=($ "4th industrial revolution") or $\mathrm{ti}=$ ("fourth industrial revolution") or ts=("fourth industrial revolution")

Esta busca resultou em 89 registros distribuídos nas cinco colunas até o ano 2015, conforme Quadro 3. Esta mesma pesquisa foi feita em 21/12/2016, um ano após, e verificou-se que 277 novos artigos surgiram apenas em 2016, revelando um aumento drástico de pesquisas sobre este tema, reforçando a sua relevância também no meio acadêmico.

\begin{tabular}{|c|c|c|c|c|c|c|}
\hline \multirow{2}{*}{ Quadro 3 - Publicações relacionadas a 14.0} \\
\cline { 2 - 7 } & $<2000$ & 2012 & 2013 & 2014 & 2015 & $\mathbf{2 0 1 6}$ \\
\hline Artigos no Ano & 4 & 2 & 8 & 33 & 42 & $\mathbf{2 7 7}$ \\
\hline Acumulado & 4 & 6 & 14 & 47 & 89 & $\mathbf{3 6 6}$ \\
\hline (Fonte: Tonta \& Doganm, 2016, com a coluna 2016 complementada pelo autor)
\end{tabular}

Comparando com a pesquisa de Tonta \& Doganm (2016) ilustrada no Quadro 3, pode-se perceber que a escolha da janela temporal de 2005 a 2016 foi relativamente adequada visto que apenas 4 artigos ficaram fora deste período. Por outro lado, a inclusão de 2016 trouxe uma abrangência muito maior em comparação com a base de dados analisada por Tonta \& Doganm (2016).

\subsubsection{Métricas do Citespace}

Antes de se analisar os resultados do Citespace, é necessário entender algumas das métricas utilizadas nesta ferramenta, conforme explicado no Manual do Citespace (CHEN, 2014).

Clustering: Refere-se a agrupamentos de trabalhos de pesquisas em torno de um determinado assunto, permitindo identificar "tribos" de pesquisa e trabalhos de 
referência e conexão. As métricas de modularidade e silhueta média apresentadas ao final do processo de clusterização permite avaliar as propriedades globais da estrutura da rede. Uma modularidade alta indica que a rede está razoavelmente dividida em grupos isolados e a silhueta média alta sugere que em média há uma homogeneidade alta nestes clusters (CHEN, 2014).

Centralidade: A centralidade de intermediação (betweeness centrality) é definida para cada nó da rede de citações e é normalizada para intervalo de [0, 1]. Ela mede a extensão em que um nó é parte de caminhos que ligam um par arbitrário de nós na rede (BRANDES, 2001; CHEN, 2006; FREEMAN, 1977 apud CHEN, 2014). Um nó com alta centralidade de intermediação é normalmente aquele que conecta dois ou mais grandes grupos de nós com o próprio nó intermediando a conexão e identificam publicações científicas potencialmente revolucionárias (CHEN, 2010).

Burst: $O$ burst (explosão) determina se uma dada função de frequência tem flutuações estatisticamente significativas durante um curto intervalo de tempo dentro do período de tempo total. É valioso para os analistas de citação para detectar se e quando a contagem de citação de uma referência especial subiu. $O$ burst de citação é um indicador de uma área mais ativa de pesquisa. É uma detecção de um evento de explosão, que pode durar vários anos, bem como um único ano. Um burst de citação fornece evidências de que uma publicação específica está associada com um aumento de citações. Em outras palavras, a publicação tem atraído extraordinário grau de atenção de sua comunidade científica. Se um cluster contém numerosos nós com fortes bursts de citação, o cluster como um todo representa uma área ativa de pesquisa, ou uma tendência emergente (CHEN, 2014). A detecção de burst no Citespace utiliza o algoritmo de detecção de burst de Kleinberg (2002) que identifica aumentos repentinos na frequência de uso das palavras. Estas palavras podem conectar-se a nomes de autores, nomes de diário, nomes de países, referências, palavras-chave ISI, ou termos utilizados no título e / ou resumo de um artigo. Ao invés de usar frequências simples das ocorrências de palavras, o algoritmo utiliza um autômato probabilístico cujos estados correspondem às frequências de palavras individuais. Transições de estado correspondem a pontos no tempo em torno do qual a frequência da palavra muda significativamente. $O$ algoritmo produz uma lista ordenada das rajadas de palavras no fluxo do documento, em conjunto com os intervalos de tempo em que ocorreram. Isso pode servir como um meio de identificar 
que tópicos, termos ou conceitos importantes para os eventos que estão sendo estudados, que aumentaram no uso, foram mais ativos por um período de tempo, e, em seguida, desapareceram. (Sci² - INDIANA UNIVERSITY, 2010)

Sigma: O indicador sigma mede a força combinada de propriedades estruturais e temporais de um nó, a saber, a sua centralidade e o burst de citações (CHEN et al., 2014). É introduzido como uma medida de novidade científica. Ele identifica publicações científicas que possam representar novas ideias. De acordo com dois critérios de descoberta transformadora. Como demostrado em estudos de caso (CHEN et al., 2009), Prêmio Nobel e outras pesquisas premiadas tendem a ter maiores valores desta medida.

\subsubsection{Estruturação do Conhecimento}

A estruturação do conhecimento no Citespace é feita através de diagramas gráficos tais como a rede de citações e clusters. Além destes diagramas gráficos que permitem ver a relação entre os trabalhos, ainda é possível detectar Bursts de citações identificando trabalhos relevantes que representam trabalhos de transição ou potencialmente inovações (CHEN, 2014).

\subsubsection{Clusters}

Gerando-se o mapa de Clusters pode-se visualizar os grupos de pesquisa em torno de alguns temas conforme mapa ilustrado na Fig. 4. A modularidade $Q=0,8733$ significa que a base de dados permitiu separar razoavelmente bem em grupos isolados de pesquisa e a silhueta média de 0,7663 indica que estes grupos são relativamente homogêneos (CHEN, 2014). 


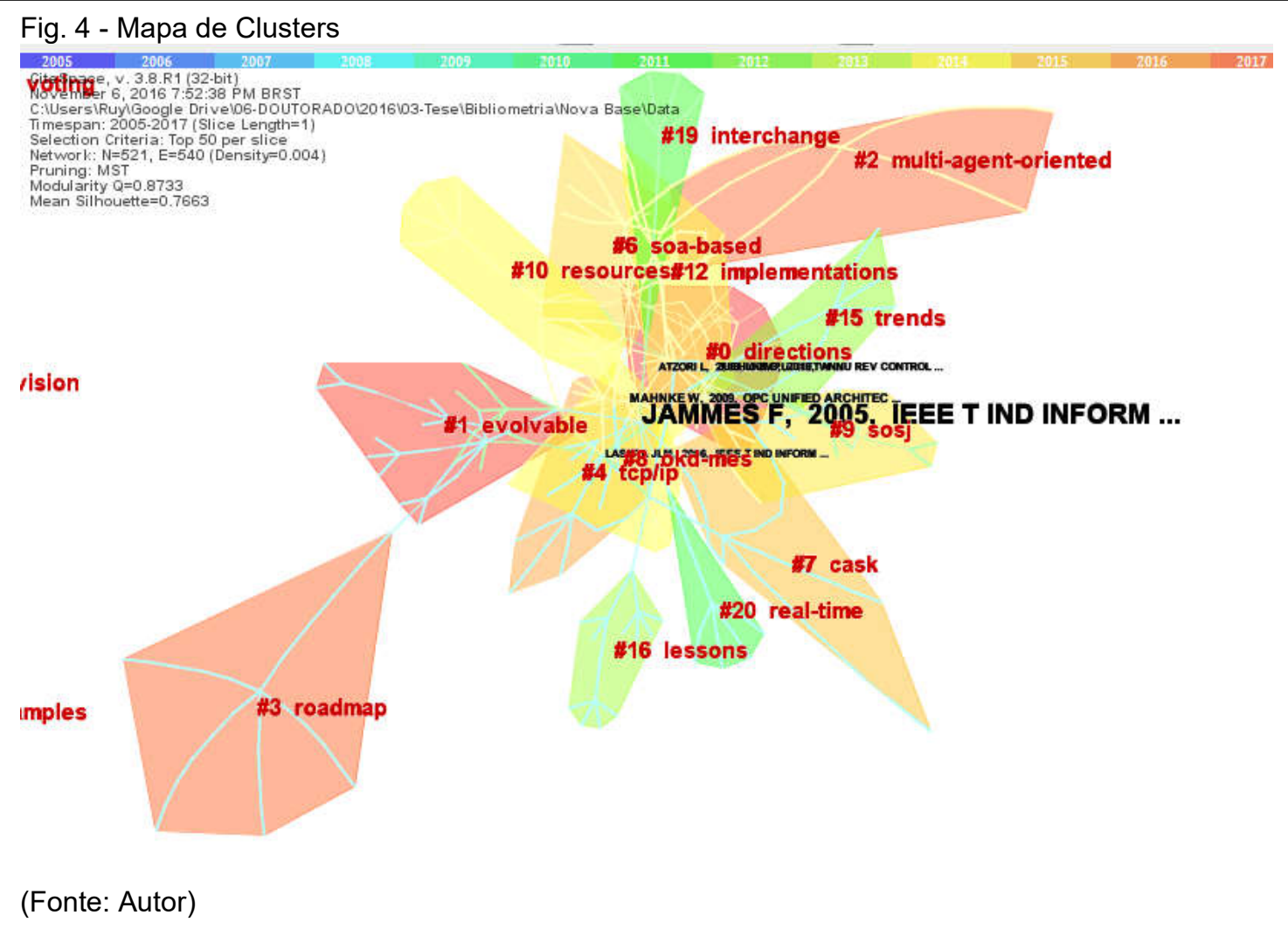

Os clusters apresentados no mapa da Fig. 4 estão também classificados no Quadro 4 em ordem de tamanho. 


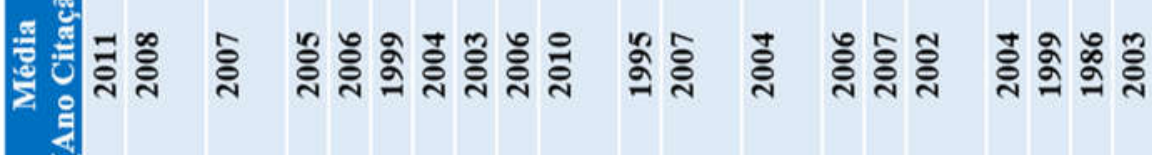

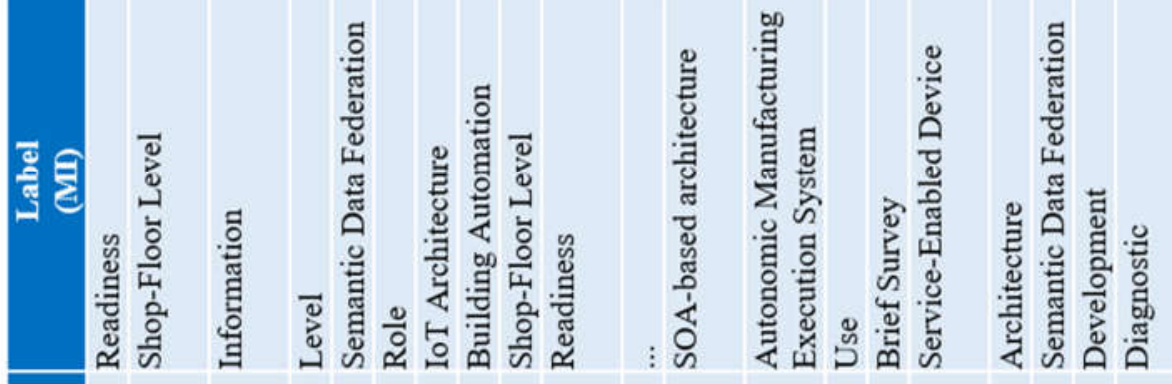

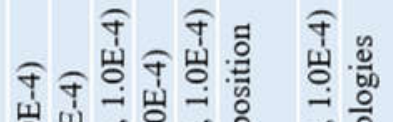

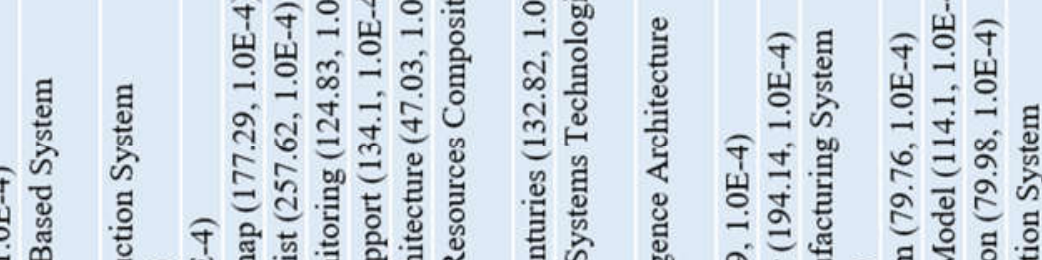

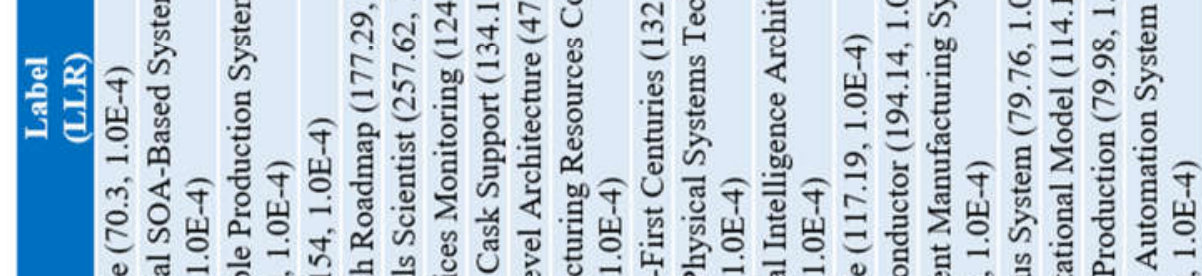

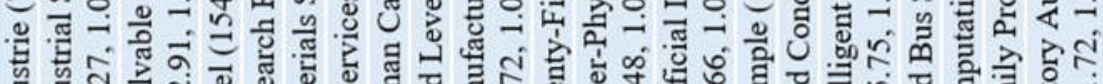

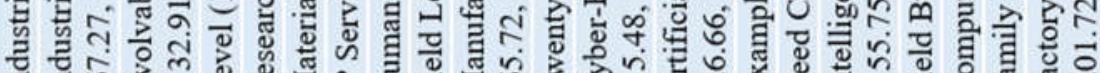

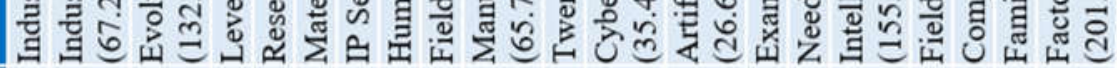

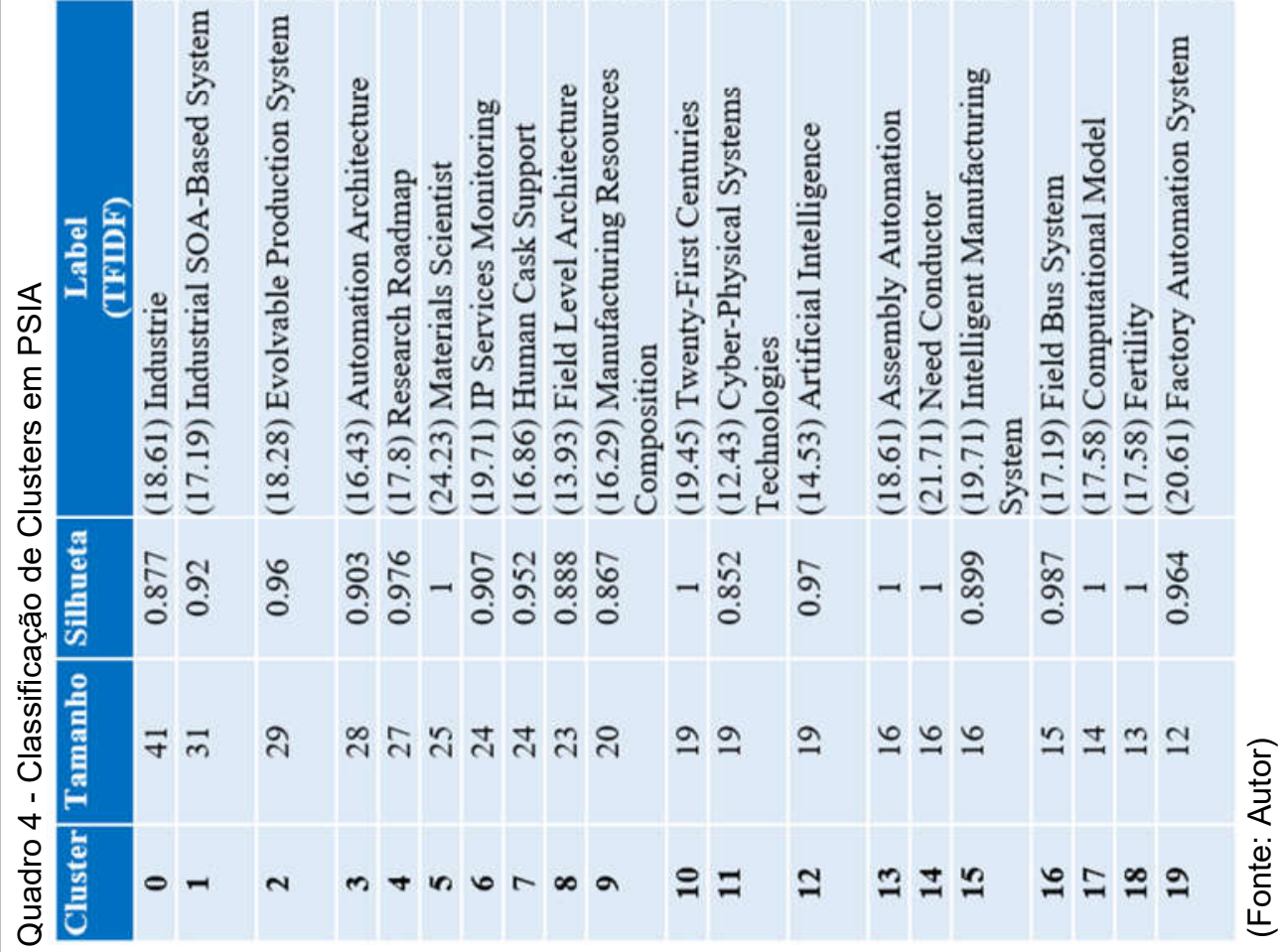


Nota-se que o maior cluster é o Cluster 0 - Industrie com 41 artigos, em que trabalhos de Zuehlke (2010) - que trata sobre a Smart Factory, de Atzori et al. (2010) - que trata sobre a loT e de Kagermann et al. (2013) - que trata sobre as recomendações para 14.0 são os mais citados no grupo, conforme pode-se ver pelo Quadro 5. O fato de ser o maior cluster indica ainda que é a área de maior atividade atualmente no que diz respeito às mudanças de paradigmas na automação industrial. Seguem-se a esta, pesquisas na área de Sistemas Industriais baseados em arquitetura SOA e Sistemas de Produção Evolutivos, conforme pode se verificar pelo Quadro 4.

\subsubsection{Citações}

O Citespace (CHEN, 2014) processa também um quadro de trabalhos mais citados que representam a base de conhecimento nos quais se referenciaram as Mudanças de Paradigma em Automação Industrial (Quadro 5). Nele, o trabalho de Jammes \& Smit (2005) é, com larga margem, o mais citado, seguido por trabalhos de Mahnke et al. (2009), Zuehlke (2010), Atzori et al. (2010), Lastra et al. (2005), Kagermann et al. (2013) e outros. Embora, o trabalho de Jammes \& Smit (2005) seja o mais citado, ele não pertence ao Cluster 0 que é a área de maior atividade atualmente, conforme indica a classificação de clusters no Quadro 4. Isto indica que embora o tema não pertença à área de maior atividade atualmente, a sua proposta de controle distribuído em arquitetura SOA, aplicado em automação industrial serviu de base (vide Fig. 5) para a mudança de paradigma em automação industrial e sua evolução para a concepção de IoT e 14.0. O trabalho de Jammes \& Smit (2005) Service-Oriented Paradigms in Industrial Automation - propõe a introdução do conceito de arquitetura orientada a serviços na automação industrial. Este artigo descreve as oportunidades e desafios no desenvolvimento da próxima geração de dispositivos, aplicações embarcadas, e serviços, resultante da sua crescente inteligência. Traça direções futuras para redes de dispositivos inteligentes com base em protocolos de alto nível orientada a serviços, em especial no que diz respeito ao setor da automação industrial - e descreve a abordagem adotada pelo serviço de infraestrutura para projetos de aplicativos embarcados em rede de tempo real, bem como as vantagens comerciais esperadas por esta abordagem. Pela grande quantidade de citações e 
centralidade, ele representa uma referência inicial nos estudos sobre a mudança de paradigma em automação industrial.

Quadro 5 - Citações PSIA

Citações

60

Jammes \& Smit, 2005 - Service-Oriented Parad

Referências

Cluster

26 Mahnke et al., 2009, OPC Unified Architecture

24

Zuehlke, 2010, SmartFactory - Towards a factory-of-things

22 Atzori et al., 2010, The Internet of Things: A survey

21 Lastra \& Delamer, 2006, Semantic Web Services in Factory Automation:

Fundamental Insights and Research Roadmap

20

Kagermann et al., 2013, Recommendations for implementing the strategic initiative INDUSTRIE 4.0

20 Candido et al., 2011, Service-Oriented Infrastructure to Support the Deployment of Evolvable Production Systems

Van Brussel et al., 1998, Reference architecture for holonic manufacturing

18 systems: PROSA

17 Bellifemine et al., 2007, Developing Multi-Agent Systems with JADE

16 Erl, 2005 - Service Oriented Architecture Concepts, Technology and Design

(Fonte: Autor)

A rede de citações pode ser vista na Fig. 5 onde trabalhos de referência que serviram de ponte entre os clusters estão destacados com alta centralidade. Centralidade representa o quanto um determinado trabalho serviu de ponte para conectar outros nós dentro da rede de citações (CHEN, 2014). Nela pode-se ver com destaque o epicentro das pesquisas de PSIA em Jammes \& Smit (2005). 


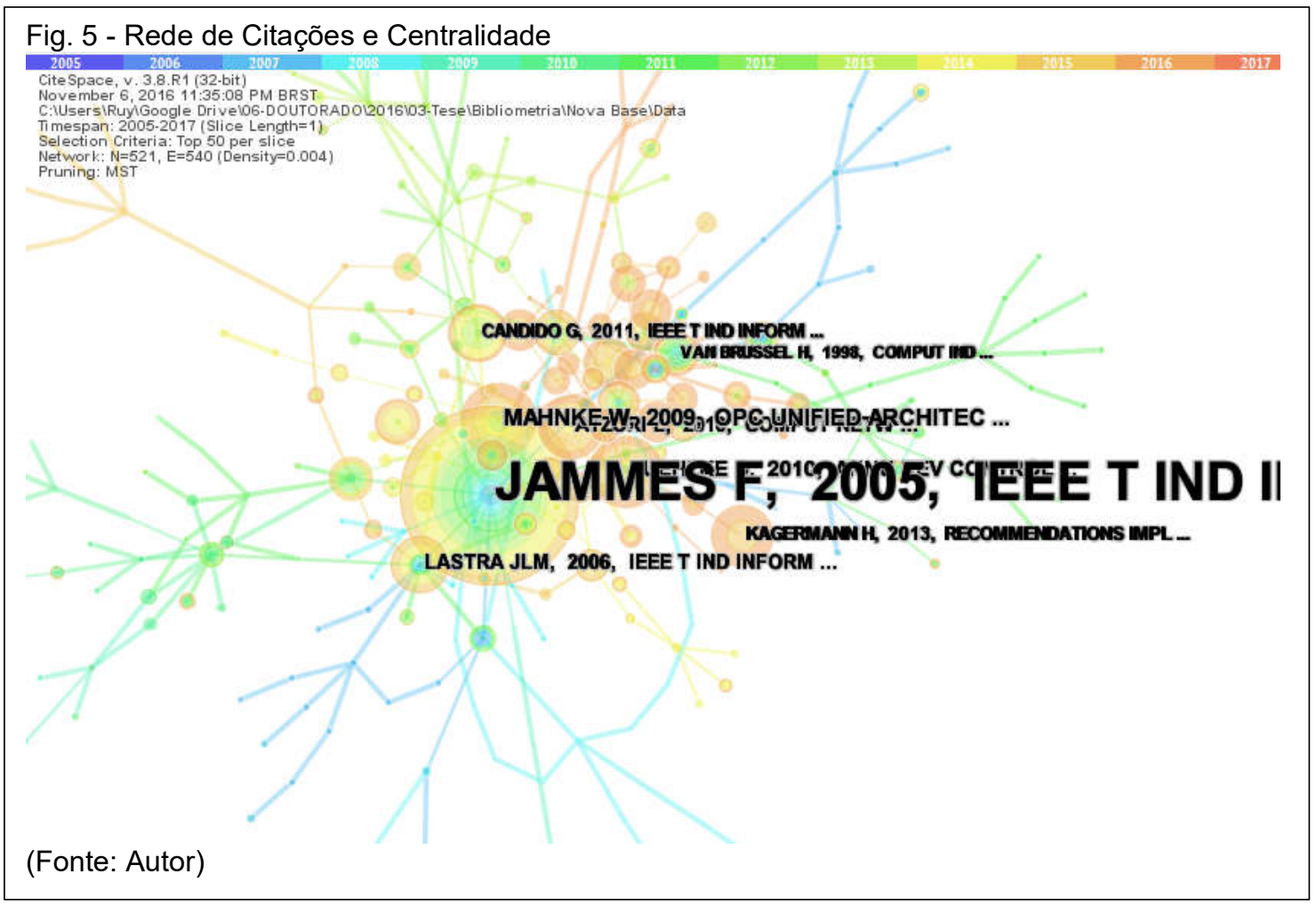

Outras contribuições com alto índice de citações e destaque no mapa de citações são apresentadas na sequência. É interessante notar que trabalhos com alto índice de citação na pesquisa WoS (Quadro 1), não têm necessariamente um alto índice de citação nesta classificação feita pelo Citespace (Quadro 5). A razão desta diferença é que a pesquisa WoS contabiliza todas as citações feitas por todos os artigos da base de dados da WoS, enquanto que no Citespace são contabilizadas apenas as citações feitas pelos artigos contemplados nas pesquisas do Quadro 1. Desta forma, o Citespace permite destacar as citações mais relevantes pertinentes ao contexto da pesquisa PSIA.

Mahnke (2009) - OPC Unified Architecture - trata da arquitetura unificada de OPC 5 que, segundo o autor, tende a ser o novo padrão para comunicação de dados em automação industrial, podendo vir a substituir protocolos como os baseados em

\footnotetext{
${ }^{5}$ OPC-UA (Object Linking and Embedding for Process Control - Unified Architecture) é um protocolo de comunicação Machine-to-Machine (M2M) para interoperabilidade desenvolvida pela OPC Foundation
} 
Microsoft DCOM, pela sua independência de plataforma e pelo uso de tecnologias estado da arte em Web Services. Discute a utilidade da OPC-UA em várias aplicações industriais como em dispositivos, sistemas de controle distribuído (DCS), MES e ERP. Hoje a OPC-UA é vista como a solução para a integração de sistemas legados, permitindo que equipamentos em redes heterogêneas possam ser conectados ao padrão Ethernet.

Zuehlke (2010), no seu artigo "Smart Factory: Towards a factory-of-things" trata dos conceitos da Smart Factory vislumbrando novas possibilidades de simplificar as complexidades de integração de sistemas de automação do passado através da disseminação da computação ubíqua e possibilidade de uma arquitetura de controle distribuída. A Smart Factory é considerada por Hermann et al. (2015) como um dos elementos básicos da 14.0.

Atzori et al. (2010), em seu trabalho "The Internet of Things: A survey", trata das tecnologias habilitadoras deste novo paradigma, chamado de Internet das coisas (IoT), baseado em sistemas CPS. Na loT não apenas pessoas, mas "coisas" de toda natureza seriam conectadas através da internet permitindo a comunicação autônoma entre elas.

Lastra \& Delamer (2006), em seu artigo "Semantic Web Services in Factory Automation: Fundamental Insights and Research Roadmap", propõe o uso da tecnologia semântica para a implantação de Web Services na automação de fábrica e permitir possibilidade de comunicação autônoma entre máquinas vislumbrando uma fábrica adequada às demandas de customização em massa.

Kagermann et al. (2013), em seu trabalho "Recommendations for implementing the strategic initiative INDUSTRIE 4.0", propõem o desenvolvimento de uma plataforma 14.0, através do esforço conjunto da academia e governo alemão com o objetivo de repatriar as atividades de manufatura à Alemanha e venda desta tecnologia a outros países. A 14.0 seria baseada por sua vez, em quatro elementos básicos: CPS, IoT, loS e Smart Factory (HERMANN et al., 2015).

Cândido et al. (2011), em seu artigo "Service-Oriented Infrastructure to Support the Deployment of Evolvable Production Systems", trata da aplicação de infraestrutura baseada em arquitetura SOA para a Implementação de Sistemas de Produção Evolutivos. Argumenta que o surgimento crescente de dispositivos inteligentes 
ubíquos traz preocupações como configuração, controle, gerenciamento, monitoramento.

\subsubsection{Centralidade}

Valores de centralidade de intermediação (betweeness centrality) alta identificam publicações científicas potencialmente revolucionárias (CHEN, 2010). Os trabalhos com centralidade mais alta para as pesquisas PSIA estão relacionados no Quadro 6 e também destacados na Fig. 5.

Por esta métrica, confirma-se novamente a importância da proposta de Jammes \& Smit (2005) como um marco para a mudança de paradigma em automação industrial.

Levando em conta a atualidade, destaca-se ainda o trabalho de Cândido et al. (2011), "Service-Oriented Infrastructure to Support the Deployment of Evolvable Production Systems", que tem dentre os coautores o próprio François Jammes que é o autor do artigo de maior centralidade e maior citação. O artigo de Cândido et al. (2011) também apresenta um burst de citações em 2013, o que evidencia também a sua relevância como um tema atual e ativo. O conteúdo deste tema explora a associação de Sistema de Produção Evolutivo (EPS) e paradigmas de arquitetura SOA na busca de uma solução de arquitetura comum para apoiar as diferentes fases do ciclo de vida dos dispositivos inteligentes. Segundo os autores, a disseminação crescente dos dispositivos inteligentes está elevando as preocupações com aspectos do ciclo de vida destes sistemas, tais como a configuração do dispositivo, controle, gestão, supervisão e diagnóstico. O autor argumenta que desde a implantação e configuração inicial até o monitoramento da evolução ao longo de seu ciclo de vida, cada dispositivo precisa ser facilmente acessível. 


\begin{tabular}{|c|c|c|}
\hline Centralidade & Referências & Cluster \\
\hline 0.39 & $\begin{array}{l}\text { Jammes \& Smit, } 2005 \text { - Service-Oriented Paradigms in Industrial } \\
\text { Automation }\end{array}$ & 6 \\
\hline 0.25 & $\begin{array}{l}\text { Erl, } 2005 \text { - Service Oriented Architecture Concepts, Technology and } \\
\text { Design }\end{array}$ & 6 \\
\hline 0.21 & $\begin{array}{l}\text { Moritz et al., } 2009 \text { - Device Profile for Web Services in Wireless } \\
\text { Sensor Networks: Adaptations and Enhancements }\end{array}$ & 2 \\
\hline 0.19 & $\begin{array}{l}\text { Candido et al., } 2011 \text { Service-Oriented Infrastructure to Support the } \\
\text { Deployment of Evolvable Production Systems }\end{array}$ & 1 \\
\hline 0.18 & $\begin{array}{l}\text { Cichocki et al., } 1998 \text { - Workflow and Process Automation: Concepts } \\
\text { and Technology (Livro) }\end{array}$ & 1 \\
\hline 0.16 & $\begin{array}{l}\text { Kalogeras et al., } 2006 \text { - Vertical Integration of Enterprise Industrial } \\
\text { Systems Utilizing Web Services }\end{array}$ & 6 \\
\hline 0.13 & Mahnke et al., 2009, OPC Unified Architecture & 8 \\
\hline 0.13 & $\begin{array}{l}\text { Lastra \& Delamer, 2006, Semantic Web Services in Factory } \\
\text { Automation: Fundamental Insights and Research Roadmap }\end{array}$ & 6 \\
\hline
\end{tabular}

\subsubsection{Burst de Citações}

A detecção de burst de citações revela áreas mais ativas de pesquisa (CHEN 2014, p.28). Uma explosão de citação fornece evidências de que uma publicação específica está associada a um aumento de citações. Em outras palavras, a publicação tem atraído um extraordinário grau de atenção da comunidade científica. Além disso, se um cluster contém numerosos nós com fortes rajadas de citação, consequentemente, o conjunto como um todo capta uma área ativa de pesquisa, ou uma tendência emergente.

A classificação de trabalhos de acordo com a métrica Burst de Citações está ilustrada no Quadro 7 em que todos os trabalhos, com exceção do Cândido et al. (2011), pertencem ao Cluster 0 que trata da 14.0 reforçando a percepção de que esta é a área de maior atividade no momento.

Kagermann et al. (2013), que introduz os conceitos da 14.0 e apresenta recomendações para sua implementação, é a contribuição mais proeminente de acordo com a métrica Burst. Isto reforça a ideia de que pesquisas sobre 14.0 são a área mais ativa no momento e, portanto, de alta relevância.

Cândido et al. (2011), com seu artigo"Service-Oriented Infrastructure to Support the Deployment of Evolvable Production Systems", é o único na lista que não pertence ao Cluster 0. No entanto, o conteúdo deste artigo está altamente relacionado à 14.0, 
explorando a associação de Sistemas de Produção Evolutivos (EPS) com paradigma SOA, em busca de uma solução de arquitetura comum para suportar as diferentes fases do ciclo de vida dos dispositivos inteligentes.

\begin{tabular}{|c|c|c|}
\hline Bursts & Referências & Cluster \\
\hline 7.77 & $\begin{array}{l}\text { Kagermann et al., } 2013 \text {, Recommendations for implementing the strategic } \\
\text { initiative INDUSTRIE } 4.0\end{array}$ & 0 \\
\hline 5.41 & Drath \& Horsh, 2014, Industrie 4.0: Hit or Hype? & $\mathbf{0}$ \\
\hline 5.03 & Atzori et al., 2010, The Internet of Things: A survey & $\mathbf{0}$ \\
\hline 5.02 & $\begin{array}{l}\text { Lee \& Kao, 2014, Service innovation and smart analytics for Industry } 4.0 \text { and } \\
\text { big data environment }\end{array}$ & 0 \\
\hline 4.77 & $\begin{array}{l}\text { Candido et al., 2011, Service-Oriented Infrastructure to Support the } \\
\text { Deployment of Evolvable Production Systems }\end{array}$ & 1 \\
\hline 4.10 & $\begin{array}{l}\text { Evans \& Annunziata, 2012, Industrial Internet: Pushing the Boundaries of } \\
\text { Minds and Machines }\end{array}$ & 0 \\
\hline 4.01 & Lee, 2008, Cyber Physical Systems: Design Challenges & 0 \\
\hline 4.01 & $\begin{array}{l}\text { Brettel et al., 2014, How Virtualization, Decentralization and Network Building } \\
\text { Change the Manufacturing Landscape: An Industry 4.0 Perspective }\end{array}$ & $\mathbf{0}$ \\
\hline 3.85 & $\begin{array}{l}\text { Colombo et al., 2014, Industrial Cloud-Based Cyber-Physical Systems } \\
\text { The IMC-AESOP Approach (Livro) }\end{array}$ & 0 \\
\hline 3.70 & Zuehlke, 2010, SmartFactory - Towards a factory-of-things & $\mathbf{0}$ \\
\hline
\end{tabular}

A Fig. 6 traz ainda a relação dos 20 Bursts de Citações mais relevantes, na qual surgem ainda trabalhos como de Puttonen \& Lobov (2013) com o artigo "Semantics-Based Composition of Factory Automation Processes Encapsulated by Web Services", que apresenta uma abordagem do uso de serviços web semântica para integração e gestão de processos produtivos. O burst de citações para este trabalho iniciou-se em 2014 e continua até a presente data. Sugere uma área de atividade de pesquisa intensa, em torno de protocolo de comunicação fundamentado em web semântica que é a base para a comunicação $M 2 M$ de nível mais elevado. $A$ comunicação M2M permite promover os Web Services em que as funções das máquinas e equipamentos poderão ser encapsuladas e vistas como serviços pela rede. Este artigo é um indicativo de que o uso de Web Services semântica na gestão de processos de produção, através de dispositivos com interfaces de serviço web (encapsulamento SOA-AT) e descrições de serviços web semântica, tem sido um assunto de pesquisa bastante ativo e atual, e pode estar sugerindo uma tendência tecnológica emergente.

Lee (2008), em "Cyber Physical Systems: Design Challenges", examina os desafios na concepção de CPS e coloca em dúvida se as tecnologias atuais de 
computador e rede fornecem infraestrutura adequada para estes sistemas e conclui que é necessário reconstruir as abstrações de computação e rede para poder usufruir do pleno potencial de CPS. Estas abstrações precisam ainda envolver a dinâmica física e a computação de forma unificada. A conclusão é que a orquestração eficaz de software e processo físico requer modelos semânticos que traduzam propriedades de interesse de ambos (LEE, 2008). Isto apoia a ideia de que o padrão de internet atual não é apropriado para integrar CPS em loT com toda a sua potencialidade e que seria necessária a web semântica.

Atzori et al. (2010) discutem as tecnologias de habilitação para o loT e citam a necessidade de uma "Internet de Próxima Geração" para compartilhar a inteligência distribuída de objetos inteligentes (CPS). Isto reforça a ideia de Lee (2008) de que o atual paradigma da internet não é apropriado para a implementação do loT. Atzori et al. (2010) enfatizam a importância da visão orientação à semântica da loT, uma vez que um grande número de "coisas" heterogêneas está envolvido no processo. $\mathrm{Na}$ verdade, os autores veem a loT como uma convergência de três visões diferentes: "visão orientada à Internet", "visão orientada a coisas" e "visão orientada a semântica". De acordo com os mesmos autores, a arquitetura de middleware proposta para o loT frequentemente segue a abordagem SOA. Portanto, isto indica que SOA e Web Semântica são a base para o paradigma loT. 
Fig. 6 - Burst de Citações por Citespace

Top 20 References with Strongest Citation Bursts

References

KAGERMANN H, 2013, RECOMMENDATIONS IMPL, V, P DRATH R, 2014, IEEE IND ELECTRON M, V8, P56, DOI ATZORI L, 2010, COMPUT NETW, V54, P2787, DOI

LEE J, 2014, PROC CIRP, V16, P3, DOI

CANDIDO G, 2011, IEEE T IND INFORM, V7, P759, DOI EVANS PETER C, 2012, IND INTERNET PUSHING, V, P

LEE EA, 2008, ISORC 2008: 11TH IEEE SYMPOSIUM ON OBJECT/COMPONENT/SERVICEORIENTED REAL-TIME DISTRIBUTED COMPUTING - PROCEEDINGS, V, P363, DOI

BRETTEL M, 2014, INT J MECH IND SCI E, V8, P37

COLOMBO AW, 2014, IND CLOUD BASED CYBE, $V, P$

ZUEHLKE D, 2010, ANNU REV CONTROL, V34, P129, DOI

PUTTONEN J, 2013, IEEE T IND INFORM, V9, P2349, DOI

[ANONYMOUS], 2009, DEV PROF WEB SERV VE, V, P

HERMANN M, 2015, DESIGN PRINCIPLES IN, V, P

MONOSTORI L, 2014, PROC CIRP, V17, P9, DOI

DAVIS J, 2012, COMPUT CHEM ENG, V47, P145, DOI

LEE JAY, 2015, MANUFACTURING LETTERS, V3, P, DOI

CHEN M, 2014, MOBILE NETW APPL, V19, P171, DOI

BELL M, 2008, SERVICE ORIENTED MOD, V, P

JAMSHIDI M, 2008, SYSTEMS SYSTEMS ENG, V, P

KALOGERAS AP, 2006, IEEE T IND INFORM, V2, P120, DOI

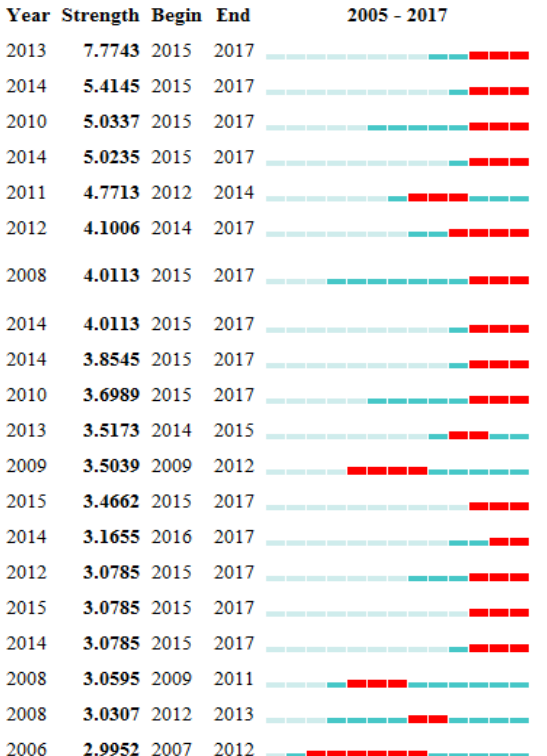

(Fonte: Autor)

Zuehlke (2010) em "Smart Factory - Towards a factory-of-things" relembra as primeiras tentativas de integração da fabricação com a Manufatura Integrada por Computador (CIM) nos anos 80 . No entanto, devido à sua extrema complexidade no planejamento, construção, operação e manutenção, o conceito da Toyota Lean Manufacturing, baseado em princípios mais simples, mostrou-se mais eficiente e foi adotado como paradigma de produção na década de 90. De acordo com Zuehlke (2010), a produção enxuta significava redes, não hierarquias; equipes de trabalho dinâmicas e autocoordenadas, em vez de trabalhos monótonos na linha de montagem; e, o mais importante, a responsabilidade pessoal do trabalhador individual. Contudo, Lean Manufacturing era mais focado na organização e menos em tecnologia. Com a IoT, baseada em CPS independente, distribuída, menos hierárquica, encapsulado como serviços em SOA, a base para a Smart Factory fica alinhada com princípios enxutos, mas agora, com enfoque tecnológico. Monostori et al. (2014) também destacam a importância da CPS como componente fundamental dos Sistemas de Produção Ciberfísicos (CPPS), que é basicamente a parte HW da Smart Factory, já que Dittes (2015) vê a Smart Factory como composta por CPPS e Smart ERP (SERP). 
Evans \& Annunziata (2012), pesquisadores da General Electric (GE), em "Industrial Internet: Pushing the Boundaries of Minds and Machines", propõem o uso da loT para aplicações industriais (IloT) numa perspectiva mais ampla, indo além da indústria de manufatura. Embora baseado na mesma ideia, não é exatamente a mesma coisa que a plataforma 14.0, proposta por Kagermann et al. (2013). O conceito de 14.0 difere um pouco do IloT, uma vez que 14.0 está focado especificamente na automação da Manufatura e compreende não apenas a integração vertical da manufatura (Smart Factory), mas também a integração horizontal ao longo da rede colaborativa de produção (COLOMBO et al., 2014), baseado em quatro elementoschave: CPS, IoT, Smart Factory e loS (HERMANN et al. 2015). Drath \& Horch (2014) em "Industrie 4.0: Hit ou Hype?" apontam a introdução de tecnologias de internet na indústria como a ideia central da 14.0. Isto significa que o evento desencadeador 14.0 foi de fato o advento da comunicação digital - Internet (BRETTEL et al., 2014), que evoluiu principalmente integrando o ambiente de negócios e agora está integrando o ambiente da indústria. Drath \& Horch (2014) citam os três primeiros eventos que desencadearam as revoluções industriais prévias como: Mecanização para a primeira revolução industrial (I1.0), Eletrificação para a segunda revolução industrial (12.0) e Processamento Digital (Digitalização) para a terceira revolução industrial (13.0). Agora, a Comunicação Digital (tecnologias para Internet) estaria desencadeando a quarta revolução industrial (14.0). Como os paradigmas da tecnologia da Internet tais como o SOA e Web Services foram desenvolvidos a princípio para ambiente de TI, e estão sendo agora estendidos ao ambiente do TO, é razoável esperar que a maturidade na integração da manufatura da 14.0 avance mais rapidamente no nível de negócios do que no nível de chão de fábrica.

O Burst de Citações ainda destaca discussões adicionais sobre as possibilidades tecnológicas sobre a plataforma 14.0, conduzidas por Brettel et al. (2014) - sobre Virtualização, Lee \& Kao (2014) - no Smart Analytics, Davis et al. (2012) e Lee et al. (2015) - sobre a fabricação inteligente, Chen et al. (2014) - em Big Data e Cloud Computing.

\subsubsection{Sigma}


Outra métrica que aponta novidade científica é o fator Sigma, conforme classificado no Quadro 8 e comentado no item 2.3.1. Este ranking aponta os trabalhos que mais se destacam nesta métrica tomando-se os dados de 2005 a 2016 no SW Citespace (CHEN, 2014).

\begin{tabular}{|c|l|c|}
\hline $\begin{array}{c}\text { Quadro } 8 \\
\text { Sigma }\end{array}$ & \multicolumn{1}{|c|}{ Rétrica Sigma PSIA } & Cluster \\
\hline 2.31 & $\begin{array}{l}\text { Candido et al., 2011, Service-Oriented Infrastructure to Support the } \\
\text { Deployment of Evolvable Production Systems }\end{array}$ & 1 \\
\hline 1.95 & $\begin{array}{l}\text { Moritz et al., 2009 - Device Profile for Web Services in Wireless Sensor } \\
\text { Networks: Adaptations and Enhancements }\end{array}$ & 2 \\
\hline 1.82 & Erl, 2005 - Service Oriented Architecture Concepts, Technology and Design & 6 \\
\hline 1.57 & $\begin{array}{l}\text { Kalogeras et al., 2006 - Vertical Integration of Enterprise Industrial Systems } \\
\text { Utilizing Web Services }\end{array}$ & 6 \\
\hline 1.23 & $\begin{array}{l}\text { Bell, 2008, SOA Modeling Patterns for Service Oriented Discovery and } \\
\text { Analysis (Livro) }\end{array}$ & 2 \\
\hline 1.21 & $\begin{array}{l}\text { Bloomberg \& Schmelzer, 2006, Service Orient or Be Doomed: How Service } \\
\text { Orientation Will Change Your Business (Livro) }\end{array}$ & 2 \\
\hline 1.17 & $\begin{array}{l}\text { Zuehlke, 2010, SmartFactory - Towards a factory-of-things } \\
\text { Atzori et al., 2010, The Internet of Things: A survey }\end{array}$ & 0 \\
\hline 1.14 & $\begin{array}{l}\text { Lee et al., 2013, Recent advances and trends in predictive manufacturing } \\
\text { systems in big data environment } \\
\text { Brettel, 2014, How Virtualization, Decentralization and Network Building } \\
1.06\end{array}$ & 0 \\
\hline Change the Manufacturing Landscape: An Industry 4.0 Perspective & $\mathbf{0}$ \\
\hline (Fonte: Autor) & \\
\hline
\end{tabular}

Dentre os trabalhos mais recentes, a métrica Sigma aponta os trabalhos de Brettel et al. (2014), Lee et al. (2013), Atzori et al. (2010) e Zuehlke (2010), todos do Cluster $\mathbf{0}$ como os mais potencialmente relevantes em termos de novidade científica. Todos estes trabalhos apontam para estudos sobre a tendência emergente em torno de Smart Factory conectada por IOT e sistemas de manufatura colaborativas e preditivas, que estão alinhados com os estudos sobre o conceito de 14.0.

\subsubsection{A Evolução da Pesquisa em PSIA e Collaborative Network}

Chen (2004) aplicou a técnica de fatiamento de tempo no seu estudo bibliométrico para entender a evolução progressiva em um domínio do conhecimento. Em seu artigo, Chen (2004) usou fatias de tempo de igual duração para construir a rede de citações para correlacionar a parte da rede com o período, mostrando a evolução da pesquisa ao longo do tempo. Nesta pesquisa, utilizou-se técnica semelhante de fatiamento do tempo, porém em períodos que começam sempre em 
2005 e terminam em anos diferentes para determinar a progressão do ranking Sigma (novidade científica) ano a ano.

O objetivo de fazer isto foi de determinar quais contribuições foram considerados pelo Citespace como "indicação da novidade científica" ano a ano. Este estudo está ilustrado na Fig. 7 e Fig. 8. O eixo vertical indica a posição no ranking Sigma e o eixo horizontal o ano correspondente ao ranking. Pode-se observar na Fig. 7, que de 2007 a 2012, as publicações de Jammes \& Smit (2005) e Kalogeras (2006) representaram os trabalhos mais relevantes em termos de novidade científica. Estes artigos tratam respectivamente da arquitetura SOA aplicada à automação industrial distribuída e da utilização de serviços web para a integração vertical de sistemas industriais. De 2012 a 2015, a contribuição de Candido et al. (2010) e Candido et al. (2011) reforçaram as ideias de aplicação da SOA ao nível de dispositivo e da aplicação de Web Services baseados em Web Semântica para suportar os Sistemas de Produção Evolutiva (EPS). O artigo de Candido et al. (2011) relata a experiência de implementação de um protótipo prova-de-conceito de uma infraestrutura. O protótipo combina os modelos SOA e EPS, em um ambiente industrial real. Os resultados mostram que é possível criar-se uma infraestrutura aberta, personalizável, modular e adaptativo o suficiente para permitir sua evolução juntamente com as especificidades e requisitos do sistema ao longo do seu ciclo de vida.

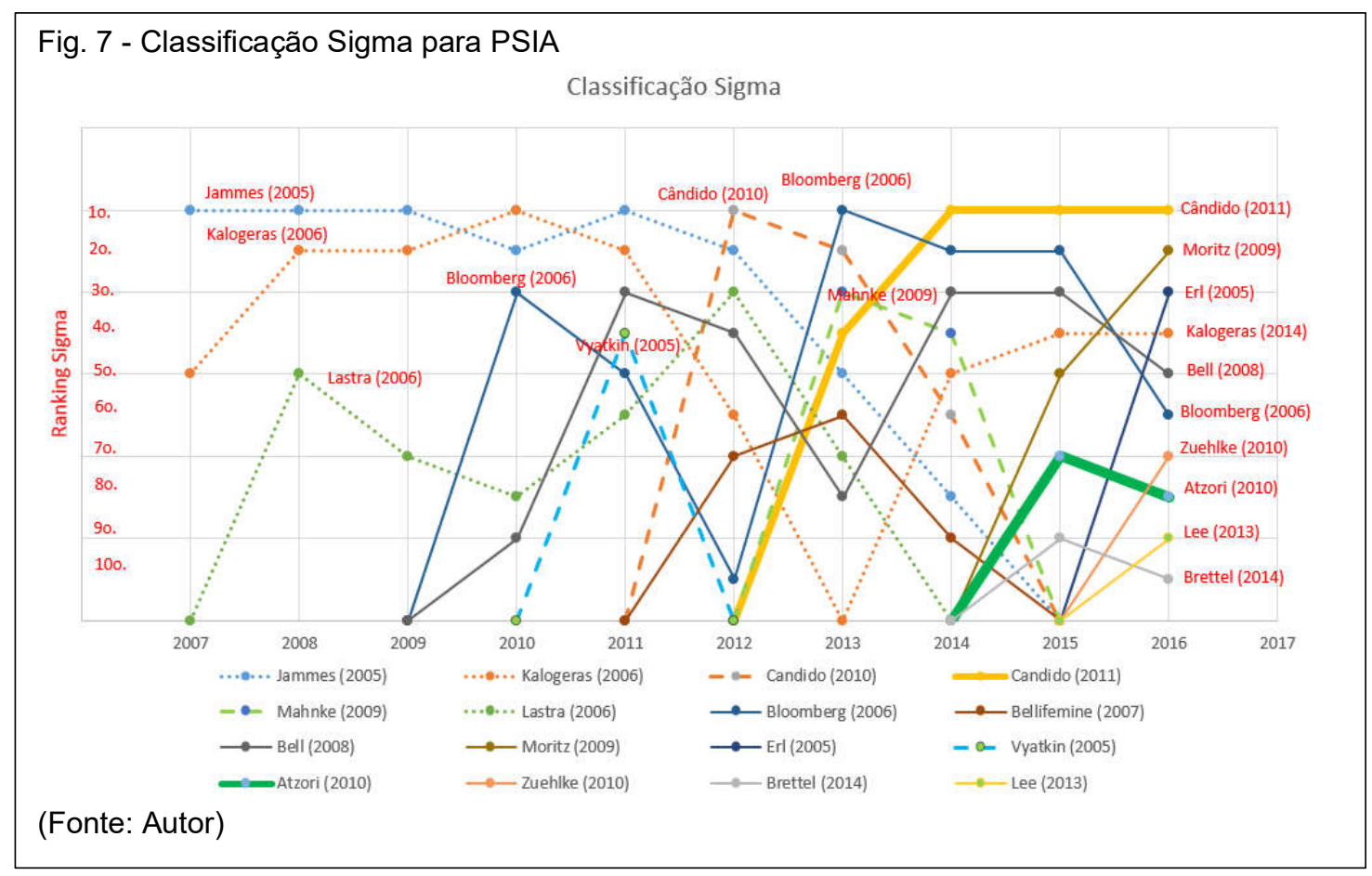


Em 2015, Atzori et al. (2010) e Brettel et al. (2014), começaram a aparecer em destaque com temas relativos a loT e 14.0. No ano seguinte, em 2016, começam a emergir ainda os trabalhos de Zuehlke (2010) e Lee at al. (2013) em torno de temas como a Smart Factory e sistemas de manufatura preditivos com o uso de Big Data que também se relacionam com o conceito de 14.0.

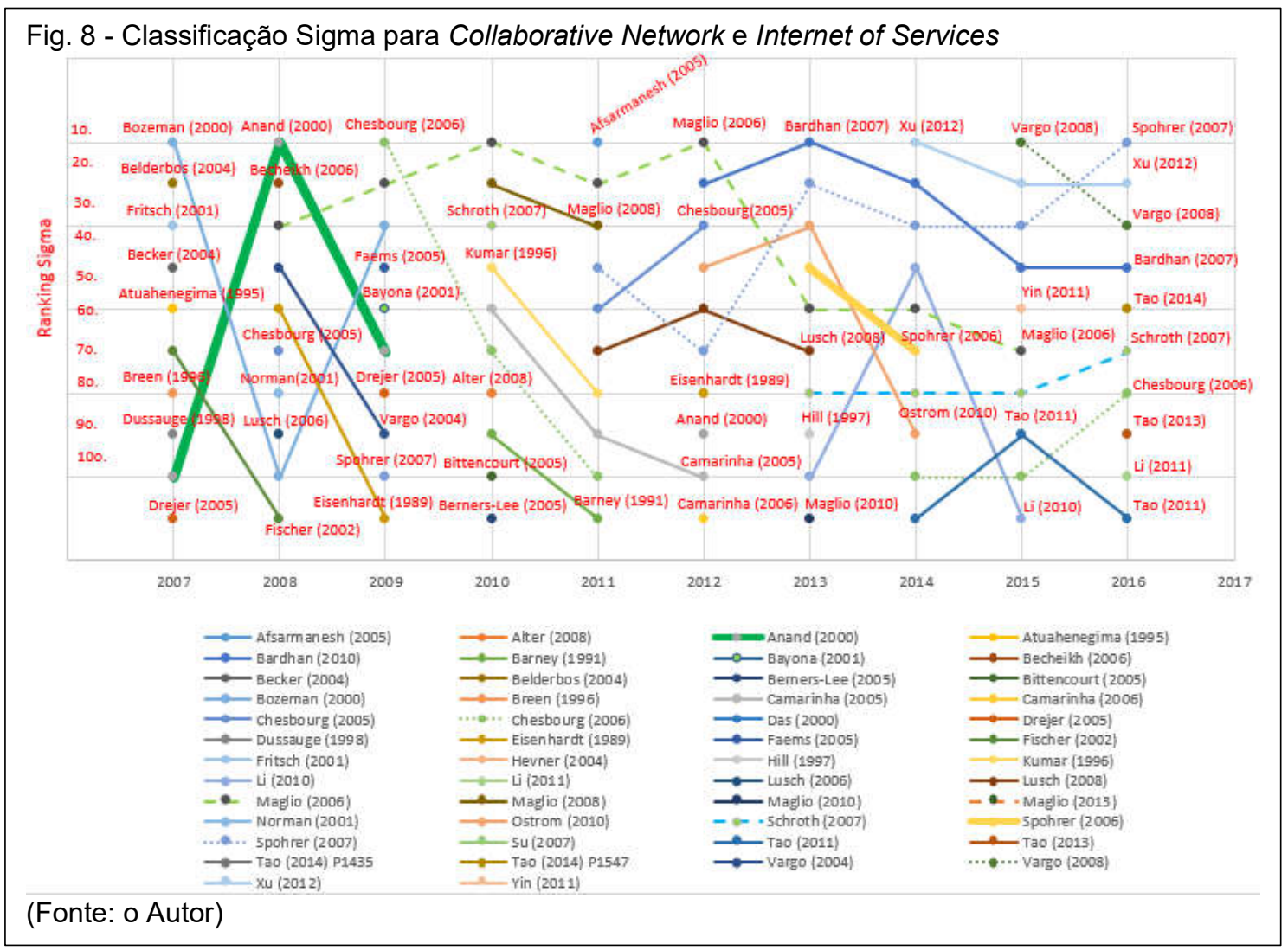

Na Fig. 8 observa-se que trabalhos como o de Anand (2000) discutindo a criação de valores através de alianças intercorporativas começam a se destacar em torno de 2008. Em seguida, de 2008 a 2015 surge o trabalho de Maglio (2006) tratando Sistemas de Serviços como redes de criação de valor compostas de pessoas, tecnologias e organizações. Chesbroug \& Spohrer (2006) surge de 2009 a 2011 e depois de 2014 a 2016 discutindo ciência de serviços. Argumentam que avanços em TIC melhoram a automação e nos conectam nos mercados de trabalho globais, resultando em uma migração de pessoas do setor de manufatura para indústrias de serviços com uso intensivo de conhecimento que apoiam a fabricação e a inovação.

Bardhan (2007) aparece em destaque no fator sigma de 2012 a 2016 inter relacionado Gestão de Serviços de Tecnologia de Informação com ciência de serviços 
argumentando que a ciência de serviços é a área fundamental de pesquisa para Sistemas de Informações.

O trabalho de Schroth \& Janner (2007) que se destaca de 2013 a 2016 trata da convergência de Web 2.0 com a Arquitetura Orientada a Serviços como habilitadores para a Internet de Serviços.

O trabalho de Spohrer et al. (2007) que se destaca de 2011 a 2016 discute os passos em direção a ciência de sistemas de serviços e argumenta que com a evolução de Arquitetura Orientada a Serviços e Web Services é possível vislumbrar uma forte relação entre o estudo de Sistemas de Serviços e o estudo de Sistemas Computacionais.

Ainda em destaque de 2014 a 2016 aparece o trabalho de Xu (2012) com a discussão sobre como Cloud Computing está transformando a manufatura para Cloud Manufacturing através da disponibilização de recursos virtuais dinamicamente escaláveis colocadas na internet como serviços.

\subsubsection{Análise da Estruturação do Conhecimento PSIA e Collaborative Network}

Com isto, pode-se, através desta análise bibliométrica, responder às questões bibliográficas propostas no início do item 2.3.1.

a) Quais são as maiores áreas de pesquisa, baseado no conjunto de dados (lista de artigos coletados na WoS)? - A maior área de pesquisa com relação às mudanças de paradigmas em automação industrial estão em torno do conceito 14.0, seguido de estudos sobre a aplicação de arquitetura SOA para automação industrial em busca de Sistemas de Produção Evolutivos que são tecnologias que sustentam a plataforma 14.0.

b) Como estas áreas estão conectadas e através de quais contribuições acadêmicas (artigos)? - O trabalho de referência para as mudanças de paradigmas em automação têm sua base no trabalho de Jammes e Smit (2005) com a proposição de arquitetura SOA para controle distribuído em automação industrial. Este trabalho juntamente com a proposição de web services que tem Kalogeras et al. (2006) como referência, permitiram a evolução para o conceito de loT que tem o trabalho de Atzori et al. (2010) como referência. A partir do conceito de IoT, surgem outros como Smart Factory (ZUEHLKE, 2010) e IloT (EVANS \& ANNUNZIATA, 2012) que permitiram a evolução para o conceito de plataforma 14.0 (KAGERMANN et al., 2013). 
c) Onde estão as áreas mais ativas? - As áreas mais ativas atualmente podem ser identificadas pelos Bursts de citação mais atuais (Fig. 6) que indicam temas como 14.0 (KAGERMANN et al., 2013; DRATH \& HORSH, 2014; HERMANN et al, 2015, BRETTEL et al., 2014), Big Data e Analíticos (LEE \& KAO, 2014; CHEN, 2014), IoT (ATZORI et al., 2010), IloT (EVANS \& ANNUNZIATA, 2012), CPS (LEE, 2008), CPPS (MONOSTORI, 2014), Manufatura Colaborativa baseada em Nuvem (COLOMBO, 2014), Smart Factory (ZUEHLKE, 2010; LEE, 2015; DAVIS et al., 2012).

d) Do que tratam estas áreas de pesquisa? Quais os trabalhos mais relevantes de cada área? - Todas as áreas com destaque atual em Bursts de citação tem relação com a plataforma 14.0 e os trabalhos mais relevantes são exatamente os citados anteriormente.

e) Quais são as transições críticas na história do desenvolvimento de uma área? Onde estão os pontos de mudança? - As transições mais relevantes são representadas pelos nós com alta centralidade na rede de citações. Destacamse os trabalhos de Zuehlke (2010), Kagermann et al. (2013), Atzori et al. (2010), Brettel et al. (2014), Evans \& Annunziata (2012) dentre outros.

A evolução da pesquisa e os trabalhos mais relevantes identificados no estudo bibliométrico sobre paradigmas em automação industrial estão ilustrados na Fig. 9.

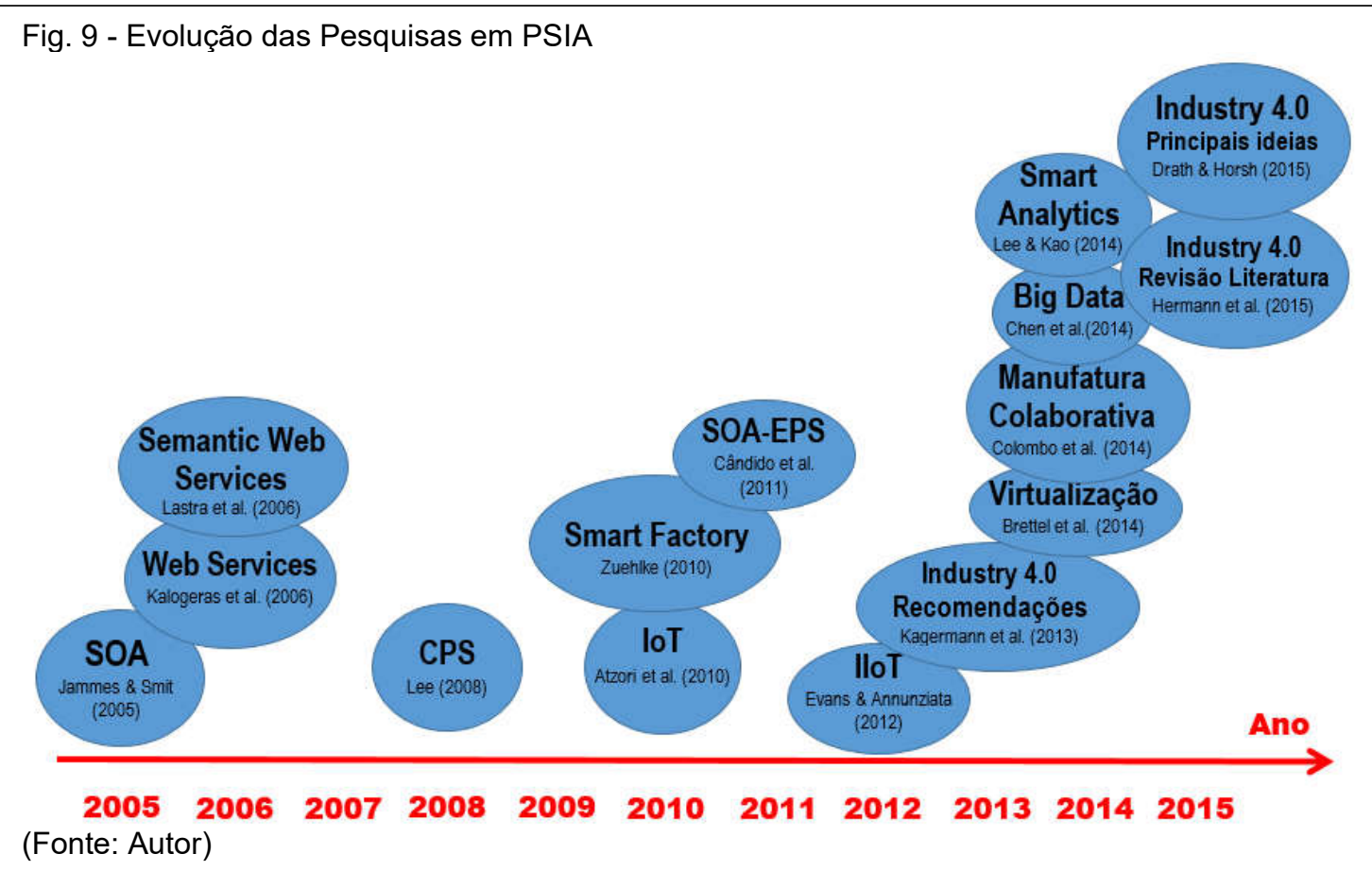

A Fig. 9 mostra como a base de conhecimento evoluiu de I3.0 até o conceito de 14.0. Comparando as análises de Burst e Sigma (Fig. 7), observa-se que a métrica 
Sigma é um pouco mais lenta do que a métrica de Burst para detectar tendências e inovações. As detecções de Burst listadas na Fig. 6 mostram que há muito mais atividade em torno do conceito de 14.0. Na detecção de ruptura, há identificação de artigos como Kagermann et al. (2013), Drath \& Horch (2014), Lee \& Kao (2014) e Evans \& Annunziata (2012). Analisando a evolução do Índice de Sigma apresentado na Fig. 7 juntamente com a detecção de Burst na Fig. 6, é possível perceber como a PSIA está evoluindo da arquitetura CIM para a quarta revolução industrial - 14.0. Ao mesmo tempo, a GE propõe uma plataforma IIOT semelhante, baseada nas mesmas tecnologias loT, mas com uma aplicação mais abrangente, que vai além da indústria de manufatura (DRATH \& HORSH, 2014).

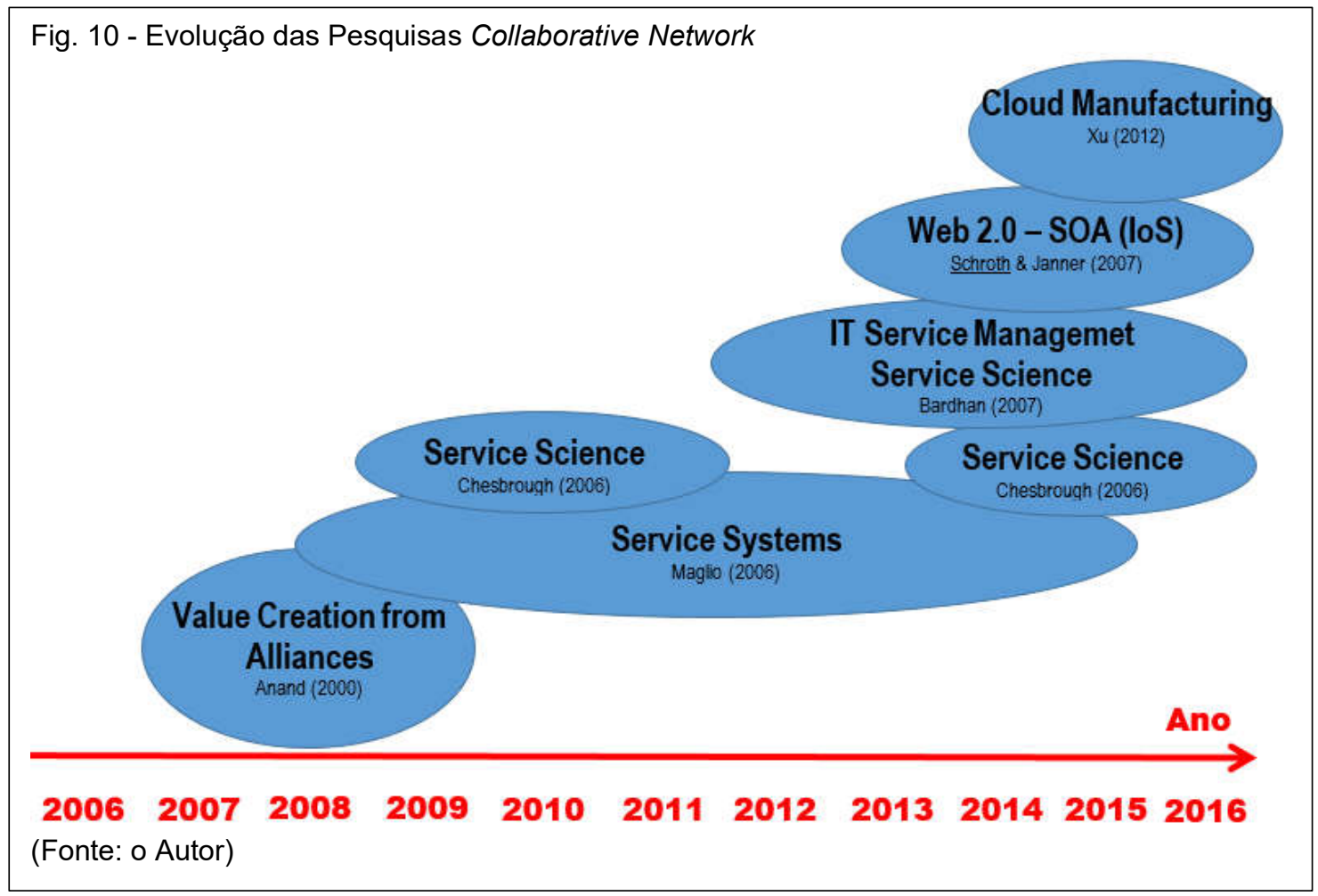

A Fig. 10 mostra como as pesquisas evoluiram desde a ideia de criação de valor através da aliança inter empresarial (cadeias de produção) até a manufatura colaborativa, Cloud Manufacturing ou Redes Colaborativas (Collaborative Network).

\subsection{REVISÃO DA LITERATURA}

Para se poder entender o contexto destas mudanças de paradigma na automação da manufatura e consequentemente na CFSAM, é interessante rever um 
pouco do histórico de como estas mudanças vêm acontecendo e qual é o estado da arte nesta área.

\subsubsection{Histórico}

A automação da manufatura e sua integração com sistemas de negócio são questões que remontam a mais de uma década de tentativas. A Plataforma Integrator Aspect da empresa ABB, apresentada por García et al. (2003), já tinha o propósito de integrar os vários níveis hierárquicos da automação da manufatura (Fig. 11). Esta plataforma fazia parte de um conjunto de produtos que proporcionariam os meios para modelar, controlar e supervisionar processos contínuos ou discretos em vários domínios do mercado. Cada produto atuaria em um nível diferente do processo de manufatura, tendo requisitos distintos de tempo real e de segurança, mas todos dependendo de uma arquitetura comum para a interoperabilidade. A arquitetura propunha um conjunto de componentes que poderiam ser reutilizados em diferentes produtos. A implementação da arquitetura proporcionaria bastante flexibilidade em termos de informações de domínio de modelagem e para modificá-lo de forma dinâmica em run-time (GARCÍA et.al., 2003). Esta plataforma se concentraria no nível de controle de processos (Fig. 11). A funcionalidade básica de uma plataforma de automação como esta consiste de processos de supervisão, que envolve aquisição e apresentação de informações sobre o estado do processo, controle local e remoto do processo, tratamento de eventos / alarmes e gestão de históricos. 
Fig. 11 - Pirâmide da Automação Industrial

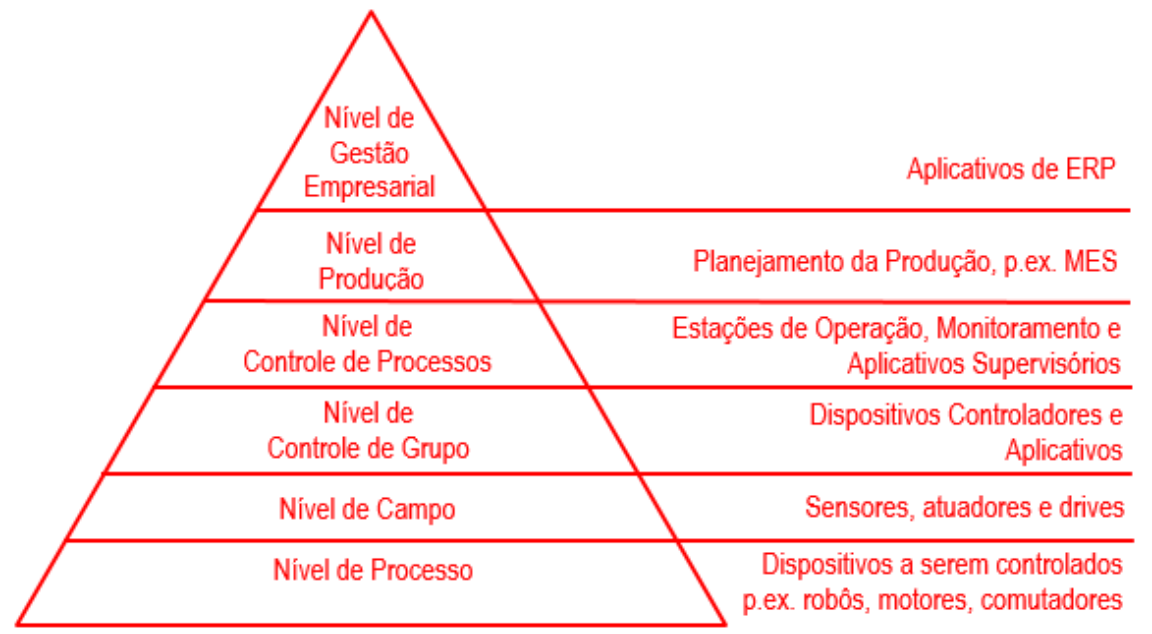

(Fonte: García et.al., 2003)

Uma vez que esta funcionalidade básica não varia muito entre os diferentes domínios do mercado, a principal motivação para a construção de uma plataforma de software para um sistema de automação distribuído era fomentar a ideia de reutilização, evitando desenvolvimentos paralelos em diferentes empresas, harmonizando interfaces para aplicativos de terceiros, e focando em linhas de produtos para diferentes segmentos de mercado. García et.al. (2003).

Porém haviam muitas dificuldades a serem superadas. Jammes \& Smit (2005) relatavam que o modelo de infraestrutura de automação industrial na época (e até hoje) era composto de hardware e software de diversos fabricantes que na maioria das vezes não se comunicavam entre si, dificultando o trabalho daqueles que realizam a implantação e manutenção destes sistemas. Ainda de acordo com os mesmos autores, um terço do custo total da planta ao longo de sua existência, eram gastos com a implantação e configuração, e o custo com a manutenção consumia outra porção considerável das despesas operacionais. Quando uma instalação precisava ser adaptada para novos processos, introduzindo novos equipamentos ou substituindo os obsoletos por equipamentos fornecidos por fabricantes diversos, o custo de instalação e parada da fábrica aumentava ainda mais, principalmente por conta de uma infraestrutura de comunicação inflexível entre os componentes do processo de manufatura e pela dificuldade de portabilidade de software de um equipamento para outro. 
Descreviam ainda que o controle das máquinas era feito de acordo com suas funcionalidades físicas (controladores programáveis, controle de movimentação, reguladores, etc.), que eram programados independentemente, com linguagem própria, e executavam sequencias e comandos como funções primitivas, embora a comunicação entre os controles individuais pudesse, na época, ser facilitada por um sistema central, através de uma rede hierárquica, como exemplificada na Fig. 12. Esta infraestrutura tradicional apresentava sérios entraves quando se pretendia usá-la como base para estrutura de controle de manufatura inteligente (JAMMES \& SMIT, 2005):

"Um ambiente aberto, flexível e ágil com conectividade "plug-and-play" é desejado desesperadamente" (JAMMES \& SMIT, 2005)

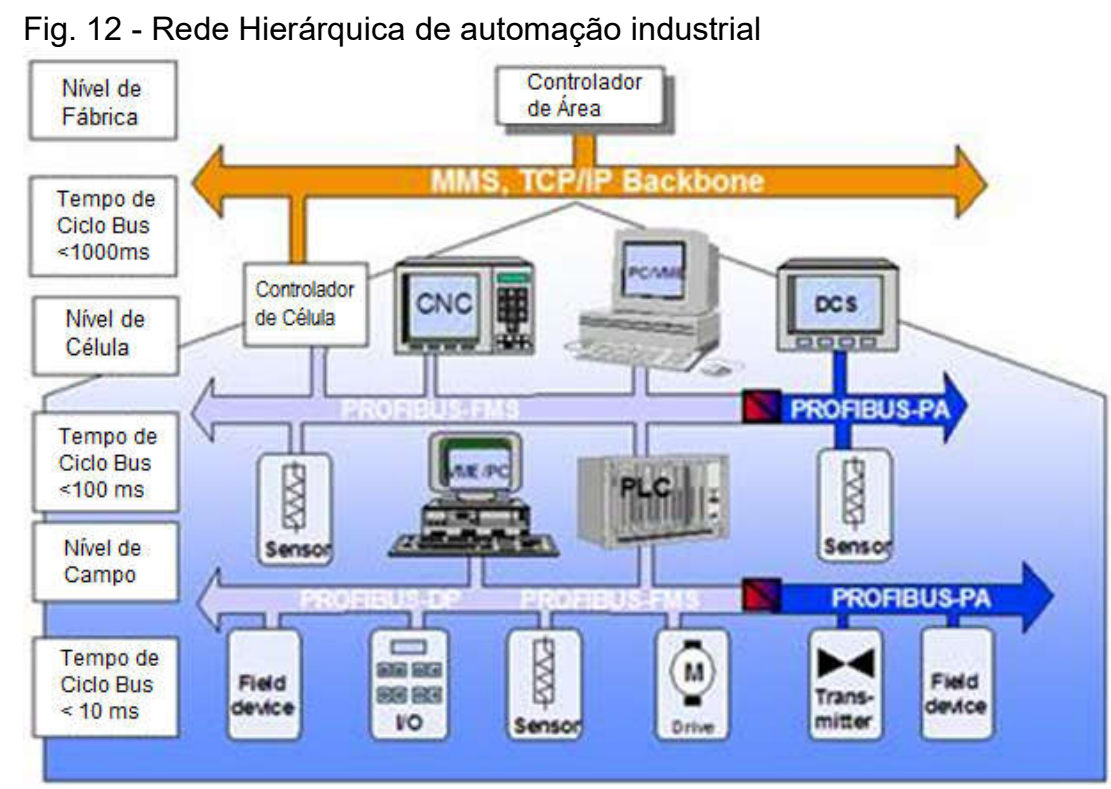

(Fonte: Adaptado de Jammes \& Smith, 2005)

\subsubsection{Tecnologia de Redes em Automação da Manufatura}

Passados mais de dez anos desde o estudo de Jammes \& Smit (2005), o que se vê ainda na maioria das indústrias brasileiras e no mundo é que este modelo de diversidade de padrões ainda persiste. Embora houvesse muitas iniciativas, por parte de fabricantes de equipamentos e por associações como a ISA (International Society of Automation), em padronizar protocolos de redes industriais e linguagens de 
programação, o que se vê na prática é que ainda há vários protocolos proprietários, de fabricantes diversos, bem como de equipamentos e software que não conversam entre si apresentando ainda grande incompatibilidade entre os diferentes fornecedores de equipamentos e sistemas legados. (CÂNDIDO et al., 2011; WANG, 2010; REINHART, 2010). Enquanto o ambiente de negócios juntamente com a internet, possui um protocolo de comunicação altamente padronizado que permite a troca de informações, o ambiente fabril encontra-se na grande maioria como ilhas de tecnologia isoladas dentro de seus padrões proprietários que não se comunicam entre si (CUCINOTTA et al. 2009; SAUTER, 2007) e muitas vezes, mesmo com sistemas corporativos.

Nos tempos atuais, a globalização, a crescente variedade de produtos, a diminuição dos ciclos de vida dos produtos, a necessidade de melhorar continuamente a produtividade e a qualidade demandam maior agilidade dos sistemas de manufatura. Princípios como encapsular funcionalidade em sistemas mecatrônicos para permitir a reutilização e padronização são abordagens básicas para ganhar agilidade em ambientes de produção. No entanto, há falta de uma arquitetura de comunicação global para os sistemas de manufatura, e um conceito global para organizar os processos de planejamento e controle da produção que estão em constante mudança (OLLINGER et al. 2011). De acordo com Ollinger (2011), o controle distribuído seria ainda importante como base para o paradigma de automação sobre arquitetura orientada a serviços (SOA).

O controle distribuído é defendido também por Leitão (2009) na sua proposta de controle através de inteligência artificial distribuída, através de sistemas multiagente seguindo os princípios da manufatura holônica. Porém, um sistema distribuído implica em necessidade de comunicação e sincronismo entre os vários dispositivos para que o mesmo funcione como um sistema. Para satisfazer a demanda de comunicação vários padrões de rede industrial proprietárias foram criados, num processo competitivo entre os grandes fabricantes de equipamentos para automação, cada qual buscando impor seu padrão. Assim, o cenário que se criou é uma mistura de vários padrões, com redes como Modibus, Fieldbus, Profibus, Profinet, Ethernet/IP (Industrial Protocol), AS-i, etc. que não se conversam entre si.

Sauter (2010) apresenta um resumo cronológico das três gerações de redes de campo (field level networks) e de como estas tecnologias de redes estão se 
encaminhando de um padrão de várias redes proprietárias para um padrão internacional. Embora várias redes sejam apresentadas, a tendência é para um padrão único entre o ambiente de negócios e o chão de fábrica. Paralelamente, apresenta também a evolução das redes em outros contextos, além da industrial, conforme ilustrado na Fig. 13.

Fig. 13 - As três gerações de Redes de Campo (Field Networks)

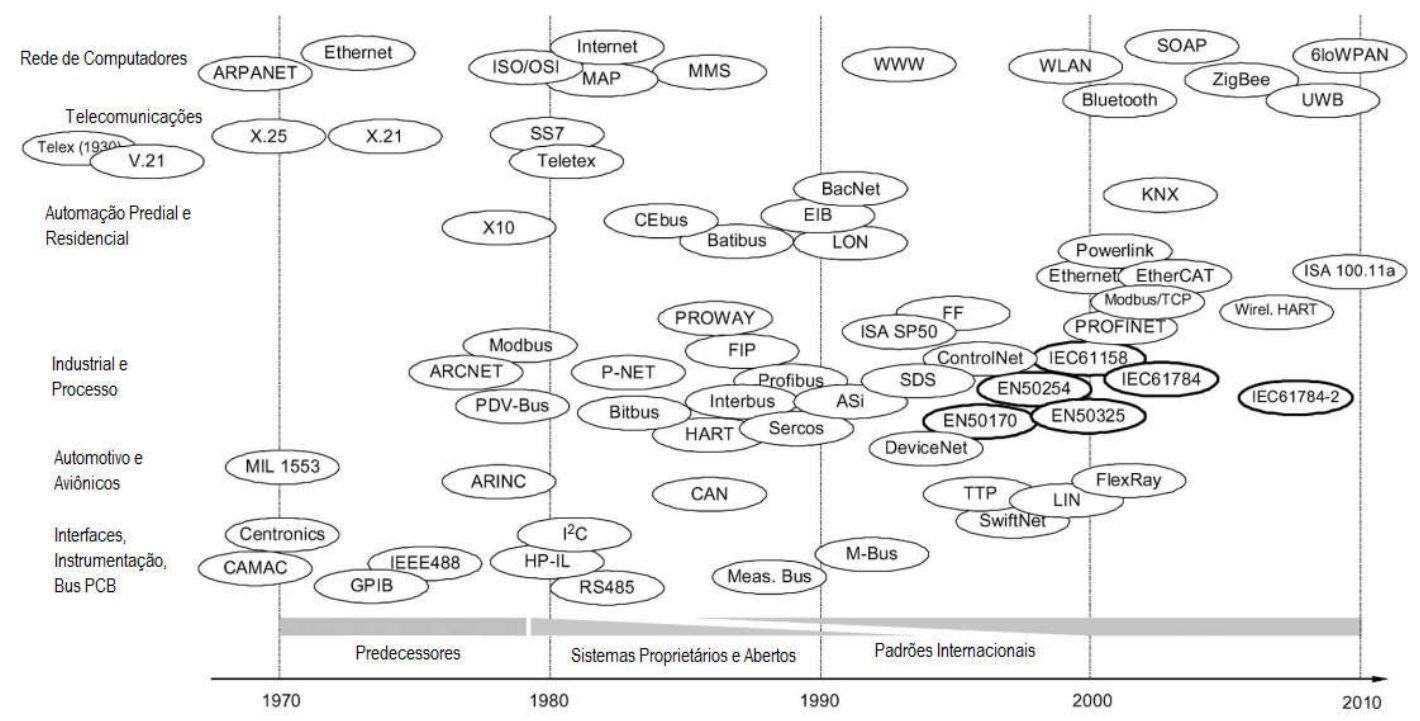

(Fonte: SAUTER, 2010)

Sauter (2007) ainda apresenta a evolução cronológica da tecnologia de comunicação industrial, em paralelo com outras tecnologias de informação empresarial, tais como os sistemas MRP (Material Resource Planning), ERP (Enterprise Resource Planning) e SCM (Supply Chain Management), conforme ilustrado na Fig. 14. 


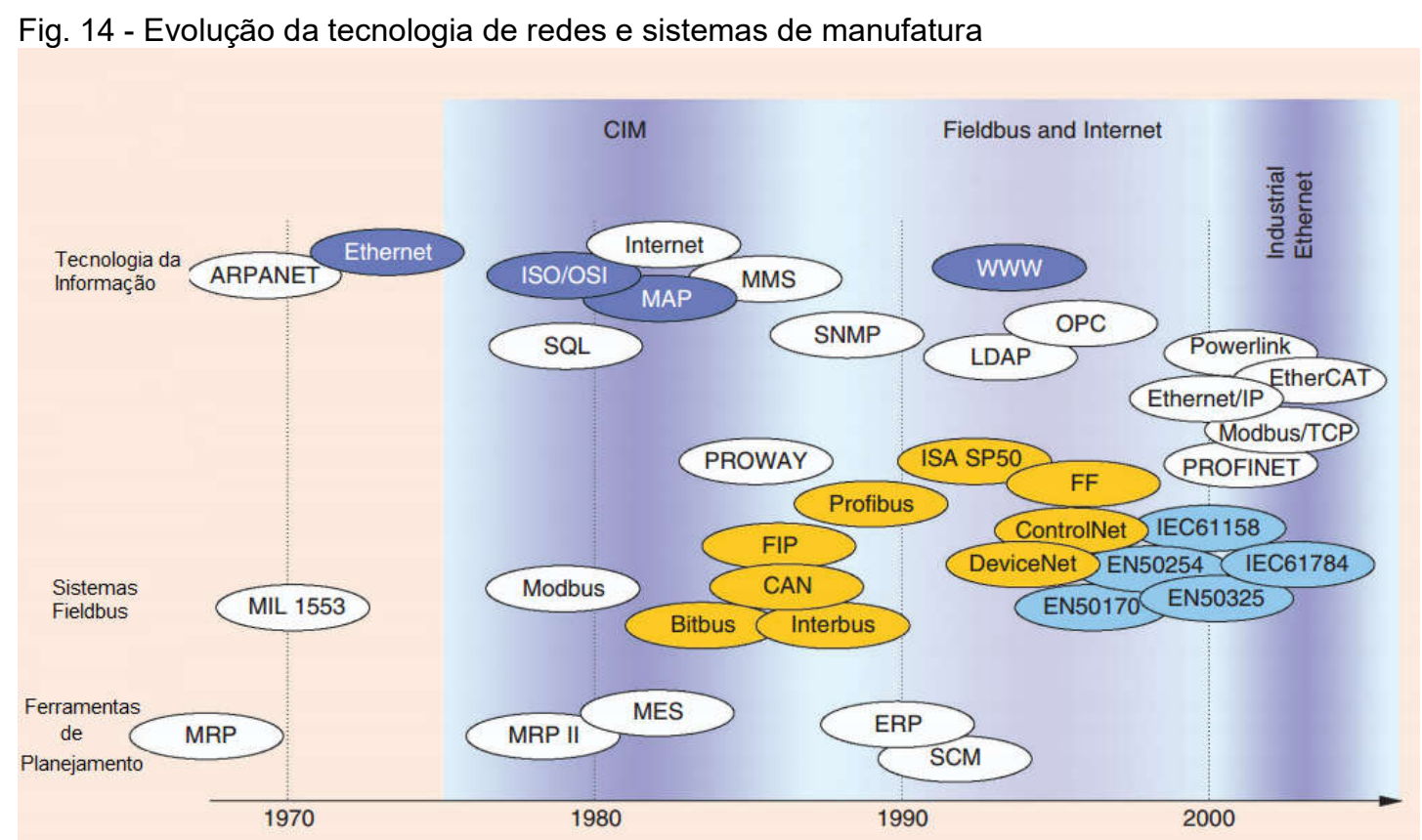

(Fonte: SAUTER, 2007)

$\mathrm{Na}$ era da Internet, características como familiaridade, disponibilidade, baixo custo, dentre outras, da rede Ethernet/IP (Industrial Protocol), têm tornado esta alternativa bastante atrativa como um padrão único de integração entre o mundo dos negócios (TI) e o da automação industrial (TO), especialmente considerando a possibilidade de melhor explorar tecnologias de informação comerciais tais como aplicativos baseados em TCP/IP (Transmission Control Protocol / Internet Protocol) como o XML, Java, entre outros (PEREIRA et al., 2004). A implementação prática desta teoria está sendo desenvolvida através da linguagem B2MML (Business to Manufacturing Markup Language) como parte do padrão ISA-95. B2MML é uma implementação da integração da empresa com o sistema de controle, conhecidos internacionalmente como IEC/ISO 62264 e consiste de um conjunto de esquemas escritos em XML, usando-se a linguagem XSD (XML Schema Definition) da world wide web, que implementam os modelos de dados no padrão ISA-95. Theorin (2013) também cita que há uma pressão cada vez maior de integração do chão de fábrica com sistemas corporativos e mesmo com a World Wide Web (Internet) e considera que o padrão mais promissor para o meio físico é a Ethernet/IP, uma vez que este padrão está largamente difundido no ambiente de negócios e na internet. 
Ethernet/IP, assim como outras redes Common Industrial Protocol (CIP), segue o modelo Open Systems Interconnection (OSI), que define uma estrutura para a implementação de protocolos de rede em sete camadas: física, de enlace de dados, rede, transporte, sessão, apresentação e aplicação. Redes que seguem este modelo definem um conjunto completo de funcionalidades de rede desde a implementação física até a camada de interface com o aplicativo ou o usuário. A rede Ethernet tem uma base instalada na casa dos bilhões de nós, e ao aproveitar a economia de escala nesta tecnologia comercial comprovada, Ethernet/IP proporciona aos usuários ferramentas para implantar a tecnologia Ethernet comercial, em aplicações de manufatura, permitindo conectividade com a internet e redes corporativas, para acessar dados a qualquer hora, de qualquer lugar (ODVA, 2014).

Embora seja o mais promissor e muito tenha sido feito para melhorar a questão temporal para resolver a falta de determinismo, muitas funções críticas em máquinas e processos requerem uma comunicação determinística. Assim, no momento, as redes Ethernet/IP ainda são dedicadas apenas para comunicações, nas quais a falta de determinismo não implique em risco para segurança das máquinas e processos. Mesmo em automóveis, é esperado que a Ethernet entre primeiramente em domínios que não envolvam segurança, pois ainda apresenta algumas questões a serem resolvidas no domínio de tempo real (BELLO, 2011). Conclui-se então, que mesmo sendo uma forte tendência para a padronização e unificação da comunicação comercial com a industrial, garantir a pontualidade destes sistemas ainda constitui um problema em aberto, como se observa através de discussões como de Robert (2012).

\subsubsection{Redes de Sensores Industriais sem fio (IWSN)}

Paralelamente, soluções para melhorar a conectividade surgem, por exemplo, com a proposta de tecnologia Industrial Wireless Sensor Network (IWSN), citado por Gungor \& Hancke (2009) e Christin (2010) que poderia trazer inúmeras vantagens sobre as tecnologias cabeadas. A IWSN com a diminuição de custos de Wireless Sensor Network (WSN), estaria se mostrado cada vez mais viável (AKYILDIZ, 2007). Porém, para que se pudesse desenvolver IWSN comercialmente, novamente ressaltase a importância de prover serviços de busca pela rede de maneira que se possa 
coletar informações úteis de qualquer lugar, a qualquer hora. Por esta razão, seria necessário que houvesse uma integração do IWSN com a arquitetura de protocolos de comunicação IP (Internet Protocol) para que pudessem ser acessados remotamente pela internet. Além disso, arquitetura flexível e escalável bem como protocolos eficientes seriam necessários, acomodados todos numa mesma infraestrutura (GUNGOR \& HANCKE, 2009). Zuehlke (2010) cita que a mudança de paradigma na arquitetura de automação da manufatura, da tradicional arquitetura orientada à função para arquitetura SOA (além da comunicação sem fios e construção modular das instalações industriais) é uma progressão lógica em direção ao conceito "plug'n work" que facilita a substituição ou adição de componentes individuais para a modificação ou extensão de processos de produção. Estas são características que proporcionam Flexibilidade e Escalabilidade na Smart Factory.

\subsubsection{Sistemas Ciberfísicos (CPS)}

Yu et al. (2015) definem CPS como a computação integrada a processos físicos, ou seja, sistemas formados com componentes físicos com capacidade computacional através dos processadores embarcados. Burmeister et al. (2015) citam que CPS são redes de microcomputadores, sensores e atores que podem ser incorporados em materiais, dispositivos ou máquinas, sendo conectados através da Internet (BURMEISTER et al., 2015 apud BMBF, 2013). A pilha de tecnologia consiste em uma camada de dispositivo clássica, ou seja, o dispositivo físico e a capacidade lógica agregada de sensores e atores incorporados, uma camada de rede para transmissão e transporte de informações, uma camada de conteúdo que contém os dados e meta dados e uma camada de serviço para a funcionalidade do aplicativo. De acordo com Wahlster (2012), a redução do custo dos processadores tem possibilitado a disseminação do seu uso embarcados em dispositivos com recursos de conectividade para comunicação (CPS) permitindo a distribuição da inteligência ao nível de dispositivos que é fundamental para permitir a disseminação de controles distribuídos em sistemas complexos. Contudo, apenas a conectividade física não é suficiente para que os dispositivos possam se achar e comunicar-se de forma autônoma. Lee (2008) alerta sobre os desafios em projeto de sistemas CPS com 
relação às tecnologias atuais de computação e infraestrutura de rede que não seriam adequadas para atender às necessidades destes sistemas. Argumenta que não basta melhorar os processos de projeto dos sistemas, mas é necessário reconstruir as abstrações de computação e de rede envolvendo as dinâmicas físicas e a computação de maneira unificada para que sejam adequados às demandas dos CPS.

\begin{abstract}
"Os sistemas ciberfísicos (CPS) são sistemas de engenharia construídos a partir da integração perfeita de algoritmos computacionais e componentes físicos. Os avanços no CPS permitirão capacidade, adaptabilidade, escalabilidade, resiliência, segurança, seguridade e usabilidade que superarão de longe os atuais sistemas embarcados. A tecnologia CPS transformará o modo como as pessoas interagem com sistemas modificados - assim como a Internet transformou o modo como as pessoas interagem com a informação. O novo CPS inteligente impulsionará a inovação e a concorrência em setores como agricultura, energia, transporte, projetos e automação prediais, saúde e manufatura" (NSF, 2012).
\end{abstract}

Os CPS como base para os sistemas de produção permitiriam elevá-los para o patamar de Sistemas de Produção Ciberfísicos (CPPS), que segundo Monostori (2014) possibilitaria a convergência dos sistemas de automação da manufatura (TO) com sistemas de negócios (TI) que vinham evoluindo paralelamente e independentemente até hoje, nos seus mundos físicos e virtual respectivamente.

\title{
2.4.5 Arquitetura Orientada a Serviço (SOA)
}

A Arquitetura Orientada a Serviços (SOA) é considerada como uma filosofia onde as lógicas dos aplicativos são encapsuladas como serviços com uma interface uniformemente definida, disponibilizados publicamente através de mecanismos de busca (MACKENZIE et al., 2006)

Segundo Bloomberg \& Schmelzer (2006, p.3), no mundo dos negócios, em que a única constante são as mudanças, a flexibilidade é uma habilidade fundamental para lucratividade, longevidade e sucesso nos negócios. No entanto, pessoas tendem a ser menos flexíveis pelas próprias características humanas: o medo do desconhecido, a resistência à mudança, a atenção limitada e motivações pessoais para perseguir o interesse próprio e evitar o desconforto e risco. Estas características institucionalizam a inflexibilidade na cultura corporativa e no comportamento da organização como todo à medida que as empresas crescem. Bloomberg \& Schmelzer (2006) em seu trabalho sugerem que a TI pode ajudar as empresas a se tornarem mais flexíveis e apontam que a Orientação a Serviços permite abordar tanto a questão da flexibilidade em TI 
como a flexibilidade nas organizações com TI. Erl (2005), em seu livro define a Orientação a Serviços como um meio de separar as coisas em unidades independentes e lógicas, que por si só é um conceito bastante antigo. Porém, contextualizado no clima competitivo dos negócios, em que é necessário reduzir esforços redundantes e maximizar a conveniência para atingir metas estratégicas, a maneira como uma organização automatiza seus negócios é fator crítico que determina o nível de eficiência em que opera. É neste contexto que a SOA se torna tão valiosa e inovadora. Ao configurar a lógica de automação através da orientação a serviços, os investimentos existentes podem ser alavancados, a inteligência de negócios pode ser expressa com precisão e a agilidade inerente da automação pode ser alcançada. Quando associada à plataforma de tecnologia de web services, a SOA oferece um potencial de benefício significativo e real que pode transformar a tecnologia e as perspectivas de uma organização (ERL, 2005).

De acordo com Erl (2005), a arquitetura SOA deve ater-se aos seguintes princípios:

- Acoplamentos livres: serviços devem manter relações de forma a minimizar dependências e requeiram apenas o conhecimento um do outro.

- Contrato de serviço: serviços deverem aderir a um acordo de comunicação, definido coletivamente através de um ou mais descrições de serviço e documentos relacionados

- Autonomia: serviços devem ter controle sobre a lógica que encapsula.

- Abstração: serviços não expõem as lógicas de execução ao mundo externo além do que está descrito no contrato de serviço.

- Reusáveis: as lógicas são divididas em serviços com a intenção de promover o reuso.

- Componíveis: conjunto de serviços podem ser coordenados e montados para formar uma composição de serviços.

- Desvinculado: os serviços devem minimizar a retenção de informações específicas de uma atividade.

- Descoberta: serviços devem ser capazes de serem descobertos.

Estes serviços devem expor seus membros através de um contrato formal em que são definidas quais operações são disponibilizadas e nele deverá também estar presente a interface técnica. Estas interfaces técnicas são as ligações entre um serviço e as aplicações que irão servir-se dele, expondo apenas as operações desejadas.

Com um conhecimento dos componentes da arquitetura básica e um conjunto de princípios de design que se pode usar para moldar e padronizar esses 
componentes, tudo o que falta é uma plataforma de implementação que permitirá reunir essas peças para construir as soluções de automação orientada a serviços. 0 conjunto de tecnologias de web services oferece essa plataforma.

Erl (2005) cita ainda que o conceito SOA vinha sendo proposto anteriormente em vários modelos, mas apenas com a chegada da Web Service é que SOA se mostrou um avanço realmente bem-sucedido. Atualmente as principais plataformas de fornecedores de sistemas de TI suportam a criação de soluções orientadas a serviços, e a maioria faz isso com o entendimento de que o suporte à arquitetura SOA é baseado no uso de web services. Hoje o conceito SOA é fundamental para plataformas de computação orientada a serviços. SOA permite melhorar a qualidade do serviço, é autônoma e baseada em padrões abertos. Permite ainda a diversidade de fornecedores de sistemas e promove a interoperabilidade intrínseca, a descoberta, a federação, a componibilidade arquitetural, a reusabilidade inerente, acoplamentos livres ao longo da empresa, e a agilidade organizacional.

Dentro desta filosofia, Jammes \& Smit (2005) propuseram um modelo de controle distribuído na automação da manufatura, orientado a serviços através de dispositivos com inteligência embarcada e conectados através de redes. Propuseram ainda que plataformas abertas (que já vinham sendo utilizadas em ambientes de $\mathrm{TI}$ ) poderiam ser utilizadas também no domínio da automação industrial. Isto proporcionaria duas características chaves aos sistemas de automação da manufatura: autonomia e interoperabilidade.

Sistemas autônomos representam sistemas que são criados isoladamente de outros e que operam independentemente do ambiente e possuem uma funcionalidade própria (que pode ser útil por si só). Sistemas interoperáveis são aqueles favorecidos pela abstração clara da interface que um serviço expõe ao seu ambiente e que podem acoplar a outros sistemas de maneira solta, através de sua interface padronizada, dentro de um contexto mais amplo de processos de negócios. Jammes \& Smit (2005) citam ainda que o modelo SOA, aplicado no nível de dispositivos no chão de fábrica, poderia se utilizar também de infraestrutura de comunicação baseada em protocolos de web services. Com tais protocolos, estendidos a dispositivos e definido um conjunto de requisitos mínimos para implementação de dispositivo para web services (DPWS), a comunicação, quer relacionada com descoberta, controle ou notificação de evento, irá basear-se em SOAP (Simple Object Access Protocol) 
(JAMMES \& SMIT, 2005). Cândido et al. (2011) também consideram que a arquitetura SOA é mais promissora para integração de dispositivos como web services em sistemas industriais. Nesta arquitetura os dispositivos podem ter suas funções encapsuladas de forma que uma linguagem de comunicação padrão permita trocar informações entre eles e também com outros sistemas.

O paradigma SOA já está presente em muitos ramos da tecnologia, não somente nas camadas originais da TI. Sua influência e adoção estão em vários domínios de aplicação tais como plataformas de negócios, telecomunicações, saúde, transporte, construção, casa e também seu uso poderia estender se às aplicações industriais simplificando o trabalho de integração (CÂNDIDO et al., 2011). Guinard et al. (2010) também endossam que a arquitetura SOA que tradicionalmente vinha sendo utilizada para conectar funcionalidades entre grandes empresas, está se tornando cada vez mais aplicável também para conectar objetos físicos com processadores embarcados (CPS).

SOA estabelece um modelo de arquitetura que tem como objetivo aumentar a eficiência, agilidade e produtividade de uma empresa, posicionando serviços como o principal meio, através do qual a solução lógica é apresentada como apoio, para atingir os objetivos estratégicos associados à computação orientada a serviços. Em SOAAT, os aspectos físicos e lógicos dos recursos são desacoplados, permitindo uma abordagem holônica para resolver o problema. Desta forma, todos os meandros do dispositivo estão escondidos atrás de interfaces de serviços. Segundo Cândido et al. (2011), uma das abordagens mais promissoras é a sua aplicação ao nível de pequenos dispositivos inteligentes, nos quais o uso da infraestrutura de comunicação baseada em serviços de alto nível permite oportunidades completamente inovadoras. Um dispositivo com capacidade SOA ganha em interoperabilidade, autonomia e abertura para aplicação como um "tijolo" importante sobre o qual aplicações completas podem ser baseadas. Não apenas fornecendo uma tecnologia e ferramentas de comunicação comuns, de fundo, mas também conferindo um valor agregado sobre o qual, aplicativos mais complexos podem ser implementados mais rapidamente e ainda permanecem suficientemente evolutivos para lidar com os requisitos dinâmicos do sistema. Equipamentos legados podem também, ser diretamente integrados através da aplicação de um invólucro de software que irá abstrair a natureza e habilidades do equipamento, seguindo o modelo do dispositivo atual. Um dispositivo físico já irá 
incorporar alguns serviços internos que apoiarão a implantação de aplicações baseadas em SOA, e também outros serviços de valor agregado que permitirão, por exemplo, que o integrador descubra, configure, monitore e diagnostique aquele determinado dispositivo (CÂNDIDO et al., 2011).

Muitas iniciativas têm criado projetos para tentar implementar a arquitetura SOA-AT no chão de fábrica das indústrias manufatureiras, conforme citado por Cândido et al. (2009) e resumidos no Quadro 9, liderados principalmente por empresas europeias como a Schneider Electric (fabricante de equipamentos para automação) e SAP (desenvolvedora de sistemas corporativos ERP). 
Quadro 9 - Iniciativas para implementação da SOA em Automação Industrial.

Projeto

IST SOCRADES

(SOCRADES,

2008)

ITEA SODA

(SODA, 2007)

OPC-UA

(OPC, 2008)

STREP InLife

(InLife, 2007)

RI-MACS

(RI-MACS, 2007)

STREP CoBIS

(COBIS, 2006)

SIRENA

(SIRENA, 2006)

\section{Descrição}

Composto de 15 parceiros de 6 países europeus, liderados pela Schneider Electric e incluindo os principais operadores europeus no setor de automação industrial. O seu principal objetivo era desenvolver uma plataforma de projeto, execução e gestão de sistemas de automação industrial de última geração, explorando o paradigma SOA tanto no dispositivo como no nível de aplicativo.

O objetivo principal do projeto era a implementação de um ecossistema completo para concepção, construção, implantação e execução de aplicativos baseados em dispositivos, alavancando as descobertas orientadas para o serviço, desenvolvidos pelo projeto SIRENA, em diferentes domínios de aplicação, incluindo automação industrial.

A Fundação OPC iniciou a criação de uma arquitetura unificada (OPC-UA), um design completamente novo do sistema, escrito para ser plataforma aberta. OPC-UA irá substituir, modernizar e melhorar toda a funcionalidade das interfaces definidas pelo OPC existentes. Web Services, sendo a única tecnologia de comunicações de alto nível entre aplicativos, para ser adotado por praticamente todos os fornecedores de plataformas, incluindo Microsoft, IBM, Sun e Linux.

Focado na aplicação de tecnologias de inteligência de ambiente e gestão do conhecimento para assegurar uma utilização sustentável e segura de linhas de manufatura e sua infraestrutura ao longo do seu ciclo de vida. Os objetivos científicos e tecnológicos do projeto RI-Macs eram a definição de uma arquitetura aberta de controle de fabricação radicalmente inovador, baseado em tecnologias estado-da-arte em informação e comunicação e mecatrônica modulares. Controle distribuído inteligente, arquiteturas abertas, tecnologia sem fio, ferramentas de engenharia virtuais e metodologias de projeto eram o principal foco tecnológico deste projeto.

Liderados pela empresa SAP, este projeto europeu visava uma nova abordagem SOA para processos de negócios envolvendo físicos (bens, ferramentas, etc.) em ambientes corporativos. A intenção era aplicar os avanços em sistemas em rede para incorporar a lógica de negócios nas entidades físicas para construir sistemas automatizados de identificação de itens e rastreamento.

Com o rápido crescimento do uso de SOA para a construção de aplicações baseadas na web, o projeto SIRENA provou que esta abordagem popular pode ser aplicada com sucesso em microdispositivos de baixo custo. Os avanços tecnológicos gerados pelo projeto SIRENA permitiram a integração de maior inteligência em pequenos dispositivos, enquanto dispositivos embarcados se tornam onipresente e redes IP atingem os níveis mais baixos de dispositivos na hierarquia da automação.

(Fonte: Adaptado de Cândido et al., 2009)

\subsubsection{Web Services}

Kalogeras et al. (2006) endossam a necessidade de interoperabilidade em ambiente industrial onde diferentes aplicativos e sistemas são encontrados na infraestrutura de dados desde o chão de fábrica aos sistemas corporativos. Argumentam que a interoperabilidade é necessária para proporcionar uma 
uma nova arquitetura baseada em três tecnologias: workflow, ontologias e web services para abordar este problema e atender à necessidade crescente das empresas de maior flexibilidade e integração. Zuehlke (2010) cita que as primeiras tentativas de integração da manufatura com computadores, na década de 1980, através de sistemas CIM (Computer Integrated Manufacturing) fracassaram devido à grande complexidade da infraestrutura e dos sistemas de controle da automação da manufatura, que eram caracterizados por sistemas de controles centralizados, inflexíveis e monolíticos, que se mostraram extremamente complexos no planejamento, na construção, na operação e na manutenção. No novo paradigma citado por Kalogeras et al. (2006), as “web services” permitem criar aplicativos de vários desenvolvedores, soltos, que podem se acoplar uns aos outros permitindo uma integração mais fácil entre sistemas, através de interfaces e protocolos padronizados e abertos. Com a gestão de workflow pode-se ter o controle e a coordenação automática dos processos empresariais, juntando os três aspectos fundamentais da empresa: processos industriais, recursos humanos e TI. Por fim, as Ontologias representam um conjunto de termos estruturados hierarquicamente que descrevem um domínio que pode ser usado como base para o conhecimento artificial. A característica principal da Ontologia é que este conhecimento pode ser acessado por usuários diferentes, independente de plataforma. Os autores destacam ainda que com a evolução da web semântica, a necessidade de representação de ontologias em semântica introduziu várias linguagens de mark-up semânticas baseadas no padrão XML. A ontologia introduz semânticas relacionadas aos processos enquanto workflow define os passos para sua execução. A associação do workflow com as informações ontológicas encapsula os reais aplicativos e sistemas que precisam ser chamados, ampliando a interoperabilidade ao nível de engenharia de sistemas (KALOGERAS et al., 2006).

A definição de Web Services, de acordo com a W3C, é um sistema de software responsável por proporcionar a interação entre duas máquinas através de uma rede. Para possibilitar essa interação uma interface descrita em um formato específico, WSDL (Web Services Description Language), permite que sistemas interajam com um Web Service usando essa interface e enviando mensagens SOAP (Simple Object Access Protocol) ou utilizando outros protocolos. As mensagens SOAP basicamente são documentos XML serializados seguindo o padrão W3C enviados em cima de um 
protocolo de rede. O WSDL é uma linguagem para descrever Web Services, é como um índice dos métodos disponíveis em um certo Web Service. Qualquer aplicação pode requisitar esse índice para saber como deve enviar as suas requisições. Independente de tecnologios bastando essas terem acordado quanto a descrição do serviço.

Nota-se que para se criar uma arquitetura distribuída e orientada a serviços para que sistemas físicos (CPS) possam se comunicar e atuar de forma autônoma e interoperável, ainda faltavam muitas questões de linguagem e padronizações a serem resolvidas. Lastra \& Delamer (2006) abordam o emprego de Web Services Semânticas na automação da manufatura como forma de proporcionar rápida reconfiguração das instalações permitindo evoluir e adaptar para a customização em massa. Propõem a criação de sistemas baseados em conhecimento usando arquitetura orientada a serviço (SOA) para facilitar as interações e web semântica para proporcionar capacidade de inferência e semânticas interpretáveis por máquinas. $A$ convergência destas duas tecnologias resulta em Web Service Semântica, que é por sua vez proposta para aplicações na automação da manufatura (LASTRA \& DELAMER, 2006). Bell (2008) em seu livro trata sobre as técnicas para modelamento de descoberta de serviços e análise de problemas dentro de uma arquitetura orientada a serviços através de uma linguagem de modelagem simples sobrepondo as barreiras de comunicação entre os profissionais de negócios e de TI. Puttonen et al., (2013) apresentam uma abordagem do uso de web services baseada em semântica para encapsular processos de automação de fábrica o que facilitaria descobrir, invocar e compor tais processos como serviços independentes de plataforma. Mesmo sobre sistemas legados uma interface web service poderia encapsular sua heterogeneidade tecnológica. Citam que linguagens de execução de processos de negócios (BPEL) poderiam ser aplicados também na prescrição do workflow em processos de manufatura e anotações semânticas poderiam ser usadas para encontrar web services correspondentes, declaradas no processo BPEL, e compor automaticamente os serviços necessários para atingir objetivos mesmo complexos.

Segundo Shelby (2010), a web vinha sendo usada tradicionalmente por seres humanos para acessar hipertexto (HTML) e outros meios de comunicação através de navegadores web. No entanto, cada vez mais a web está sendo usada para comunicação entre máquinas. Comunicações de interoperabilidade entre as 
máquinas na Internet é muitas vezes conseguida usando web services. Para que a IoT possa estender sobre a arquitetura da web convencional, os web services serão indispensáveis na criação de comunicações interoperáveis entre as máquinas na Internet, dentro do novo paradigma de automação da manufatura baseada em arquitetura orientada a serviços.

Cândido et al. (2011) que estudam a arquitetura SOA aplicada em automação industrial, argumentam que com esta arquitetura a complexidade de HW do dispositivo pode ser simplificada através de um componente de SW denominado de web services que irá encapsular uma função ou comportamento sob sua interface. Ele pode ser descoberto e explorado por outra entidade de rede, a fim de executar uma determinada tarefa ou obter algum tipo de informação.

Mora et al. (2012) também citam a utilidade de componentes de serviços, contendo informações de dispositivos, tais como a web services na implementação da integração vertical baseada em padrão ISA95, permitindo uma comunicação perfeita, intercamadas e integrando os níveis superiores (ERP) com os níveis inferiores (CLP) chegando até mesmo aos níveis de dispositivos (sensores).

De acordo com Tan \& Yuan (2005), web services é uma tecnologia baseada em linguagem XML, de padrões abertos, leve e simples o suficiente para ser utilizado sobre a infraestrutura de internet existente. Juntamente com tecnologias como Business Process Management (BPM) e WS-Securitiy, é seguro o suficiente para ser usado e ainda é capaz de integrar e coordenar diferentes sistemas.

Puttonen \& Lobov (2013) também citam que a adoção de tecnologias baseadas em Web Services é uma das tendências atuais em automação industrial. Em particular a arquitetura orientada a serviço permitirá o desenvolvimento de sistemas de manufatura flexíveis que evitam o problema tradicional de controle centralizado. Uma das principais vantagens da SOA é que ela é baseada em padrões de Web Services abertos que permitem que Web Services individuais se comuniquem completamente independente da plataforma. Além disso, o desenvolvimento de interfaces para Web Services é fácil, até mesmo para a maioria dos sistemas legados. Sistemas que abrangem vários Web Services heterogêneos podem apresentar problemas de interoperabilidade, porém estes podem ser resolvidos através de descrições de serviço Web Semântica. 


\title{
2.4.7 Web Semântica (Smart Network)
}

Berners-Lee (2001) cita que o conteúdo da internet convencional é desenhado para serem lidos por humanos e não por programas de computadores de maneira que pudesse ser manipulado de forma efetiva. O autor argumenta que a Web Semântica trará estrutura para o conteúdo significativo de páginas da web, criando um ambiente onde os agentes de software possam navegar de página em página e facilmente realizar tarefas sofisticadas para os usuários. Explica ainda que a Web Semântica não é uma rede separada, mas sim uma extensão da atual em que as informações recebem significados bem definidos, permitindo que computadores e pessoas possam trabalhar melhor em cooperação. Assim como a internet, a Web Semântica será o mais descentralizado possível. Para que a Web Semântica funcione, é necessário que os computadores tenham acesso às coleções de informações e conjunto de regras de inferência para que possam realizar avaliações automáticas.

De acordo com Top Quadrant (http://www.topquadrant.com),

\begin{abstract}
"A tecnologia semântica (software) permite que o significado e as associações entre as informações sejam conhecidos e processados no momento da execução. Para que uma tecnologia semântica funcione verdadeiramente dentro de um sistema, deve haver um modelo de conhecimento de alguma parte do mundo (uma ontologia ativa) que é usada por uma ou mais aplicações em tempo de execução".
\end{abstract}

De acordo com Berners-Lee (2001), duas tecnologias importantes para o desenvolvimento da Web Semântica já estão implementadas: XML (Extensible Markup Language) e o RDF (Resource Description Framework). O XML permite que todos criem suas próprias etiquetas - rótulos ocultos como ou que anotar páginas da Web ou seções de texto em uma página. Scripts, ou programas, podem fazer uso dessas tags de maneiras sofisticadas, mas o roteirista tem que saber o que o escritor de página usa cada tag para. Em resumo, o XML permite aos usuários adicionar estrutura arbitrária aos seus documentos, mas não diz nada sobre o que as estruturas significam. O significado é expresso por RDF, que o codifica em conjuntos de triplos, sendo cada triplo algo como o sujeito, verbo e objeto de uma sentença elementar. Esses triplos podem ser escritos usando tags XML. No RDF, um documento faz afirmações de que determinadas coisas (pessoas, páginas da Web ou qualquer outra coisa) possuem propriedades (como "é uma irmã de", "é o autor de") com determinados valores (outra pessoa, outra página da Web). Esta estrutura acaba por 
ser uma maneira natural de descrever a grande maioria dos dados processados pelas máquinas. Assunto e objeto são identificados por um identificador de recurso universal (Universal Resource Identifier - URI), tal como usado em um link em uma página da Web. (Uniform Resource Locators -URLs são o tipo mais comum de URI). Os verbos também são identificados por URIs, que permitem a qualquer pessoa definir um novo conceito, um novo verbo, apenas definindo um URI para ele em algum lugar na Web.

Berners-Lee (2001) acrescenta ainda que duas bases de dados podem usar identificadores diferentes para o que é de fato o mesmo conceito, como por exemplo o "CEP" e "Código Postal". Um programa que quer comparar ou combinar informações através dos dois bancos de dados tem que saber que estes dois termos estão sendo usados para significar a mesma coisa. Idealmente, o programa deve ter uma maneira de descobrir esses significados comuns para os bancos de dados que encontra. Uma solução para este problema é fornecida pelo terceiro componente básico da Web Semântica: coleções de informações chamadas de ontologias. Em filosofia, uma ontologia é uma teoria sobre a natureza da existência, de que tipos de coisas existem. A ontologia como uma disciplina estuda tais teorias, mas os pesquisadores de inteligência artificial e da Web têm adotado o termo para seu próprio jargão e, para eles, uma ontologia é um documento ou arquivo que define formalmente as relações entre os termos. O tipo mais comum de ontologia para a Web tem uma taxonomia e um conjunto de regras de inferência. Com as páginas de ontologia na Web, começam a surgir soluções para problemas terminológicos (e outros). O significado dos termos ou códigos XML usados em uma página da Web pode ser definido por ponteiros da página para uma ontologia. Naturalmente, os mesmos problemas como antes agora surgem se um elemento apontar para uma ontologia que define endereços como contendo um "CEP" e o outro apontar para um que usa o "Código Postal". Esse tipo de confusão pode ser resolvido se ontologias (ou outros serviços da Web) fornecerem relações de equivalência: uma ou ambas as ontologias podem conter as informações de que o "CEP" é equivalente ao "Código Postal".

O verdadeiro poder da Web Semântica será percebido quando as pessoas criarem vários programas que coletam conteúdo da Web de diversas fontes, processarem a informação e trocarem os resultados com outros programas. A eficácia desses agentes de software aumentará exponencialmente à medida que mais conteúdo da Web, legíveis por máquina e serviços automatizados (incluindo outros 
agentes) estiverem disponíveis. A Web Semântica promove essa sinergia: mesmo agentes que não foram expressamente projetados para trabalhar juntos podem transferir dados entre si quando os dados vêm com semântica. Muitos Web Services automatizados já existem sem semântica, mas outros programas, como agentes, não têm como localizar um que irá executar uma função específica. Esse processo, chamado descoberta de serviço, só pode acontecer quando houver uma linguagem comum para descrever um serviço de uma forma que permita que outros agentes "entendam" a função oferecida e como aproveitá-la. Serviços e agentes podem anunciar sua função, por exemplo, depositando tais descrições em diretórios análogos às Páginas Amarelas.

Embora o conceito de Web Semântica tenha sido proposto inicialmente visando ambientes de TI, Lastra \& Delamer. (2006), propuseram o uso de Web Services Semânticos como solução para proporcionar capacidade de rápida reconfiguração em sistemas de manufatura para evoluir e se adaptar à customização em massa. Segundo os autores, o uso de ontologias e semânticas explícitas permite que o raciocínio lógico implique um conhecimento suficiente sobre a classificação dos processos que as máquinas oferecem e sobre como executar e compor esses processos para realizar a orquestração de manufatura de forma autônoma.

\subsubsection{Padrão OPC-UA}

Outro aspecto citado por Jammes \& Smit (2005) para a integração de fábricas já instaladas com um parque de equipamentos legados, era a heterogeneidade das tecnologias e protocolos de rede, formando verdadeiras ilhas tecnológicas. Mahnke et al. (2009) abordam esta questão com o emprego de OPC-UA. Sugerem que este protocolo deverá se tornar o novo padrão para comunicação de dados em automação de processos pelo fato de ser independente de plataforma e utilizar a tecnologia web service. A expectativa é que a OPC-UA seja aplicada em setores mais amplos que a OPC clássica, sendo aplicável em dispositivos e sistemas DCS, MES e ERP. Os autores ainda destacam que os serviços disponíveis na OPC-UA são concebidos de maneira orientada a serviços, sempre oferecendo operações em massa. OPC-UA juntamente com o padrão ISA-95 é visto por Brandl et al. (2013) também como uma solução que irá permitir interoperabilidade para sistemas MES. 


\subsubsection{Internet das Coisas (IoT)}

A combinação das tecnologias de CPS e infraestrutura baseada em SOA e Web Services permite vislumbrar novas e amplas possibilidades para a internet, em que não apenas pessoas, mas também dispositivos físicos podem se conectar autonomamente entre eles ao que se tem denominado de loT. Isto significa que a loT é composta de CPS conectada por uma rede inteligente semântica (Smart Network ou Smart Web ou Web 3.0) (HE et al., 2012).

Segundo Atzori et al. (2010), a loT terá alto impacto no dia-a-dia das pessoas no uso doméstico e no trabalho. Sob perspectiva de negócios, as consequências mais visíveis são em campos como automação, manufatura industrial, logística, administração de negócios e processos, bem como em transporte inteligente de bens e pessoas.

Sundmaeker et al. (2010), definem a loT como uma infraestrutura de rede global e dinâmica com capacidades de autoconfiguração com base em protocolos de comunicação padrão e interoperáveis, em que "coisas" físicas e virtuais têm identidades, atributos físicos, personalidades virtuais e usam interfaces inteligentes, e estão perfeitamente integradas na rede de informação.

Camarinha-Matos et al. (2013) argumentam que a loT é um assunto multidisciplinar e que ainda requer a integração de contribuições de várias tecnologias. Apontam, conforme ilustrado no Quadro 10, as tecnologias mais relevantes e as principais questões a serem abordadas em cada uma. 


\begin{tabular}{|c|c|}
\hline Tecnologia & Problemas Chave ilustrativos \\
\hline $\begin{array}{l}\text { Tecnologia da } \\
\text { Comunicação }\end{array}$ & $\begin{array}{l}\text { Comunicação bidirecional eficiente em energia, Rede de sensores } \\
\text { sem fio multifreqüenciais, Comunicação baseada em fila de } \\
\text { mensagem objetivando ambiente em nuvem, etc. }\end{array}$ \\
\hline Tecnologia de rede & $\begin{array}{l}\text { Gateway de protocolos, Arquiteturas escaláveis, Protocolos de } \\
\text { comunicação sem fio seguro e confiável, Redes baseadas em } \\
\text { serviços, etc. }\end{array}$ \\
\hline Descoberta de Rede & $\begin{array}{l}\text { Mecanismos de descoberta automática e capabilidades de } \\
\text { mapeamento ("coisas" novas continuamente aparecem / } \\
\text { desaparecem, algumas "coisas" evoluem) }\end{array}$ \\
\hline Software e Algoritmos & $\begin{array}{l}\text { Microssistemas operacionais, Computação orientado a serviços, } \\
\text { Aplicativos em ambiente de nuvem, Software autoadaptativos } \\
\text { (sistemas autonômicos), Algoritmos bioinspirados, Sistemas } \\
\text { atentos à energia, Software atentos ao contexto, Gestão de } \\
\text { eventos, Balanceamento entre inteligência local versus na nuvem e } \\
\text { tomada de decisões, Representação de objetos (serviços, agentes) } \\
\text { etc. }\end{array}$ \\
\hline Dispositivos de Hardware & $\begin{array}{l}\text { Dispositivos inteligentes nano eletrônicos, Colheita de energia, } \\
\text { Eletrônica de polímeros, Inteligência embarcada, Tags de baixo } \\
\text { custo, Dispositivos inteligentes, Protocolos multipadrões, } \\
\text { Arquitetura heterogênea, Dispositivos de baixo custo, etc. }\end{array}$ \\
\hline $\begin{array}{l}\text { Tecnologia de Dados e } \\
\text { Processamento de Sinais }\end{array}$ & $\begin{array}{l}\text { Interoperabilidade semântica, Compartilhamento de dados, } \\
\text { Agregação de dados, Processamento de fluxo, Processamento de } \\
\text { Big Data, etc. Interpretação de dados massivos gerados pelos } \\
\text { dispositivos inteligentes, (big data) é um dos componentes chave } \\
\text { da loT. }\end{array}$ \\
\hline $\begin{array}{l}\text { Tecnologias de descoberta } \\
\text { e máquinas de pesquisa }\end{array}$ & $\begin{array}{l}\text { Descoberta de dispositivos, Repositórios distribuídos, Localização } \\
\text { e posicionamento, Mapeamento terrestre, Alerta de localização, } \\
\text { etc. }\end{array}$ \\
\hline $\begin{array}{l}\text { Tecnologias de } \\
\text { armazenamento de } \\
\text { energia }\end{array}$ & $\begin{array}{l}\text { Baterias / Microbaterias, Colheita de energia, Mapeamento de } \\
\text { consumo de energia, Agendamento prioritário baseado em energia, } \\
\text { Tarifas dinâmicas, etc. }\end{array}$ \\
\hline $\begin{array}{l}\text { Tecnologia de Segurança } \\
\text { e Privacidade }\end{array}$ & $\begin{array}{l}\text { Privacidade para dispositivos heterogêneos, Confiança e } \\
\text { autenticação decentralizada, Criptografia eficiente em energia, } \\
\text { Mecanismos de anonimato, Propriedade de dados, etc. }\end{array}$ \\
\hline Padronizações & $\begin{array}{l}\text { Padrões para interoperabilidade cruzada, Padrões para dispositivos } \\
\text { inteligentes, Linguagens para interação entre coisas, Arquitetura de } \\
\text { infraestrutura padronizadas, etc. }\end{array}$ \\
\hline $\begin{array}{l}\text { Tecnologia de } \\
\text { gerenciamento de redes de } \\
\text { relacionamento }\end{array}$ & $\begin{array}{l}\text { Gestão de identidade, Relacionamento e reputação, Estruturas } \\
\text { organizacionais, Modelos colaborativos e funções, Inteligência } \\
\text { coletiva, Rastreabilidade de tomada de decisões distribuída, etc. }\end{array}$ \\
\hline
\end{tabular}

(Fonte: Camarinha Matos et al., 2013)

\section{A Gartner (2015) aponta em suas estimativas de tendências tecnológicas que}

a loT ainda levará algum tempo para atingir o platô da produtividade conforme mostra

a Fig. 15. No caso, a expectativa é que a loT atinja o platô da produtividade entre 2020 e 2025. 
Fig. 15 - Platô da Produtividade para loT

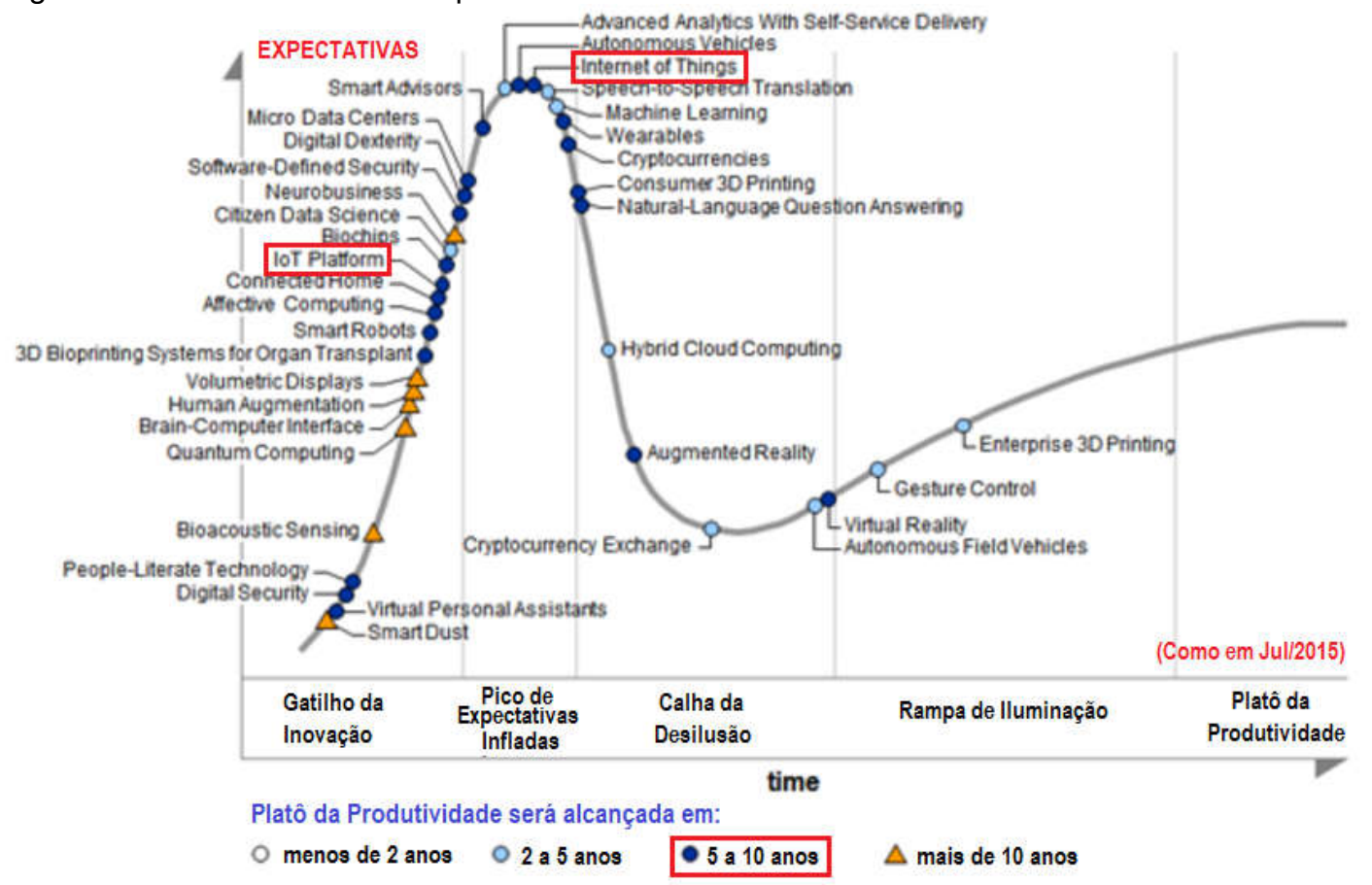

(Fonte: Gartner, 2015)

\subsubsection{Internet Industrial (IIoT)}

Evans \& Annunziata (2012), pesquisadores da GE vislumbram a aplicação da IoT no domínio industrial chamando-a de Internet Industrial ou IloT e citam a importância de três elementos fundamentais: máquinas inteligentes, analíticos avançados e pessoas conectadas e consideram-na uma nova etapa nas revoluções industriais. Segundo os autores, a primeira onda revolucionária está relacionada à introdução de energia mecânica no lugar de energia muscular. A segunda onda revolucionária está relacionada à introdução de força computacional e internet global que resultou em mudanças radicais no tratamento das informações e na tecnologia de comunicação. E atualmente presencia-se a revolução na internet através de dispositivos inteligentes, redes inteligentes e sistemas decisórios inteligentes ao que se está chamando de convergência para Internet Industrial. De acordo com Bruner (2013) a IloT traz as características chaves (modularidade, abstração e software acima do nível de simples dispositivo) da internet para as instalações físicas industriais, permitindo aos inovadores resolver grandes problemas através da distribuição em pequenas partes (BRUNER, 2013). Zuehlke (2010) complementa ao 
citar que a lloT permitiria simplificar as complexidades da integração vertical das fábricas viabilizando a Smart Factory que é um dos componentes básicos para elevação ao próximo conceito proposto por Kagermann et al. (2013) chamado de Industria 4.0 (14.0) e considerado pelos mesmos como a quarta revolução industrial diferentemente de Evans \& Anunziatta (2012) e Rifkin (2012) que consideram a IloT como a terceira revolução industrial. A proposta da plataforma 14.0, com incentivo do governo alemão tem dois objetivos: trazer de volta ao país as atividades de manufatura transferidas para regiões com custos de mão de obra mais baixos e vender tecnologias para a implantação desta plataforma.

De acordo com Camarinha-Matos et al., (2013), a Internet Industrial se concentra em aplicações industriais, que visa uma rede global para conectar pessoas, máquinas e dados com a finalidade de facilitar a gestão, operação e manutenção de instalações industriais e melhorar sua performance. Porém, a General Electric (EVANS \& ANNUNZIATA, 2012) ressalva que todo o potencial da tecnologia digital baseado na Internet ainda não está plenamente realizado através do sistema global da indústria. Os dispositivos inteligentes, sistemas inteligentes, e sistemas decisórios inteligentes representam as principais formas em que o mundo físico de máquinas, instalações, frotas e redes podem se fundir mais profundamente com a conectividade, analíticos de Big Data e o mundo digital.

Camarinha-Matos at al. (2013) considera que a Internet industrial é um subconjunto de Internet das coisas, que por sua vez é um subconjunto de sistemas cíberfísicos, argumentando que CPS abrange não apenas coisas conectadas à internet, mas também outros sistemas com poder computacional embarcado conforme ilustrado na Fig. 16, adaptado de Camarinha-Matos et al. (2013). 
Fig. 16 - Internet Industrial, loT e CPS

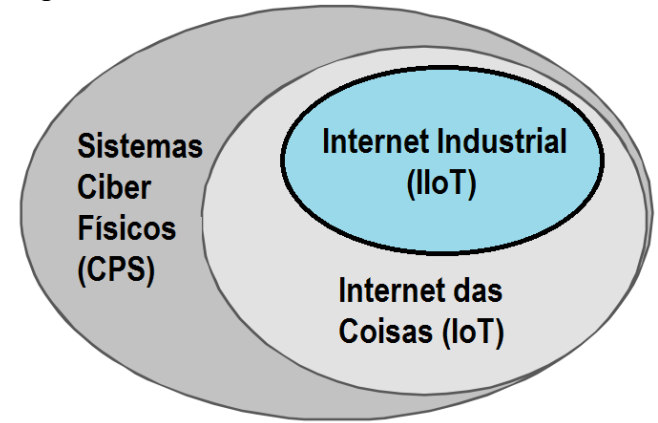

(Fonte: Adaptado de Camarinha Matos et al., 2013)

\subsubsection{Sistemas de Produção Ciberfísicos (CPPS)}

Segundo Monostori et al. (2014) o CPPS consiste de elementos e subsistemas autônomos e cooperativos que estão se conectando entre si de maneira dependente da situação, em todos os níveis de produção, desde processos através de máquinas até redes de produção e logística. Posada et al. (2015) e Spath et al. (2013) citam que CPPS é uma especialização de CPS aplicada à produção e, portanto, pode-se concluir que CPPS é um subsistema de CPS. Weyer et al. (2015) citam que Smart Machines são máquinas se tornando CPPS que serão capazes de se comunicarem com outros dispositivos de campo, módulos de produção e produtos de forma mais autônoma através de redes abertas e semânticas. Wahlster et al. (2014) citam que as Smart Factories usam CPPS, comunicação semântica M2M e memórias de produtos semânticos para produzir Smart Products. Esses Smart Products são a base para Smart Services que os usam como uma plataforma física. Como os Smart Products e as Smart Factories incluem muitos sensores, os fluxos de dados coletados por estes sensores podem ser fundidos e transformados em dados inteligentes que, por sua vez, podem aumentar a eficiência de Smart Factory, Smart Products e Smart Services.

Shrouf et al. (2014) citam que a flexibilidade em redes de criação de valor no contexto da 14.0 é incrementada com o uso de CPPS, permitindo que máquinas e plantas adaptem seu comportamento diante de variações nos pedidos e condições de operação, através de auto-otimização e reconfiguração. O foco principal está na capacidade dos sistemas de perceber a informação, derivar descobertas dela e mudar 
seu comportamento de acordo, e armazenar o conhecimento adquirido com a experiência. Sistemas e processos de produção inteligentes, bem como métodos e ferramentas de engenharia adequados, serão um fator chave para implementar com êxito instalações de produção distribuídas e interligadas nas Smart Factories do futuro.

\subsubsection{Integração Vertical na 14.0}

A ideia da integração vertical entre o chão de fábrica e os sistemas de TI já é um tema que vem sendo desenvolvido desde os anos $80 \mathrm{com}$ o modelo CIM (ZUEHLKE, 2010). Contudo o modelo CIM mostrou-se extremamente complexo e inflexível, tornando o processo de evolução destes sistemas um processo demorado e oneroso, bem como sua implantação e manutenção (JAMMES \&SMIT, 2005). Os entraves que são citados para justificar esta dificuldade são a heterogeneidade de tecnologias e protocolos envolvendo máquinas e equipamentos industriais, bem como as redes proprietárias que não se conversavam entre si. Novas demandas de mercado tais como ciclos de vida cada vez mais curto dos produtos e a individualização dos produtos requerem que a fábrica integrada seja facilmente adaptável para novas condições de produção, pois conforme Bloomberg \& Schmelzer (2006, p.3) citam, a única constante no mundo dos negócios são as mudanças. Neste contexto, a mudança de paradigma para um sistema decentralizado com inteligência distribuída e conectado através de uma rede semântica (Smart Network) em arquitetura orientada a serviços permitirá novas possibilidades tecnológicas de se integrar a manufatura (TO) com os sistemas de negócios (TI) de maneira mais simples, adaptativa e econômica.

A integração de negócios e manufatura é um processo chave para as empresas de manufatura. A integração exige que o processo de negócios e o processo de fabricação troquem informações relevantes, mas isso deve ser realizado sem impacto desnecessário aos processos de negócios ou processos de fabricação existentes. A palavra chave para resolver este entrave à integração é padronização. Os padrões ANSI / ISA-95 Enterprise / Control System Integration definem um modelo efetivo para atingir essas metas.

\subsubsection{O modelo ISA-95}


A Sociedade Internacional de Automação ANSI/ISA (American National Standard Institute / International Society of Automation), trabalha no desenvolvimento de um padrão de arquitetura através do modelo ISA-95, no sentido de se criar um padrão único, aberto, para integração do chão de fábrica com o topo de fábrica, buscando definir o domínio entre DCS e ERP (CLARK, 2010). A ISA juntamente com outras organizações, como a MESA e MIMOSA, trabalham para definir as ferramentas e métodos para a transferência de dados entre os vários níveis de empresa integrada de hoje (VERHAPPEN, 2010). A Fig. 17 ilustra estes níveis do modelo ISA-95.

\begin{tabular}{|c|c|c|c|c|}
\hline \multicolumn{5}{|c|}{ Fig. 17 - Níveis do modelo ISA-95 } \\
\hline \multicolumn{5}{|r|}{ Modelo ISA-95 } \\
\hline Nivel & Sistemas & Gestão e Controle & Prazos & Funções \\
\hline Nivel 4 & $\begin{array}{l}\text { Sistema Logistico de } \\
\text { Negócios (ERP) }\end{array}$ & $\begin{array}{l}\text { Planejamento de Negócio e } \\
\text { Logistica (Planejamento da } \\
\text { produçăo, geståo de negócios, } \\
\text { etc.) }\end{array}$ & 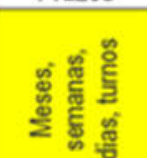 & $\begin{array}{l}\text { Estabelecimento do plano de produçã́c } \\
\text { básico, uso de material, expediçăo, niveis } \\
\text { de estoque. }\end{array}$ \\
\hline Nivel 3 & $\begin{array}{l}\text { Sistemas de Operaçס̄es } \\
\text { de Manufatura (MES, } \\
\text { Lote, LIMS, AM, etc.) }\end{array}$ & $\begin{array}{l}\text { Gestão de Operaçōes de } \\
\text { Manufatura (Despacho de } \\
\text { produçð̃o, planejamento } \\
\text { detalhado da produçăo, } \\
\text { garantia de confiabilidade, etc.) }\end{array}$ & 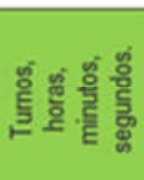 & $\begin{array}{l}\text { Fluxo de trabalho, controle de receitas } \\
\text { para fabricaçăo do produto final } \\
\text { Manutençăo de registros e otimizaçăo dc } \\
\text { processo de produçăa. }\end{array}$ \\
\hline Nivel 2 & $\begin{array}{l}\text { Sistemas de Controle } \\
\text { (PLC, DCS, PAC, etc.) }\end{array}$ & \multirow{2}{*}{$\begin{array}{l}\text { Controle da Manufatura } \\
\text { (Controle Básico, Controle } \\
\text { Supervisorio, Manipulaçato de } \\
\text { Processos) }\end{array}$} & \multirow{2}{*}{ 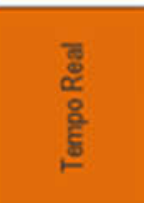 } & \multirow{2}{*}{$\begin{array}{l}\text { Monitoramento, controle supervisório } \epsilon \\
\text { controle automático do processo de } \\
\text { produçăo. } \\
\text { Sensoriamento e manipulação do } \\
\text { processo de produçăo. }\end{array}$} \\
\hline Nivel 1 & $\begin{array}{l}\text { Dispositivos Inteligentes } \\
\text { (Fluxo, Visão, Pressâo, } \\
\text { etc.) }\end{array}$ & & & \\
\hline Nivel0 & \multicolumn{4}{|c|}{ Nivel Fisico do Processo de Produçào } \\
\hline \multicolumn{5}{|c|}{ (Adaptado de VERHAPPEN, 2010) } \\
\hline
\end{tabular}

Enquanto o padrão predecessor ISA-88 era focado em controle de produção, em especial na produção por lotes, o ISA-95 tem seu foco na troca de informações entre os sistemas ERP e os sistemas MES, conforme ilustrado na Fig. 18. 
Fig. 18 - Comparação entre o escopo e foco dos padrões ISA-88 e ISA-95.

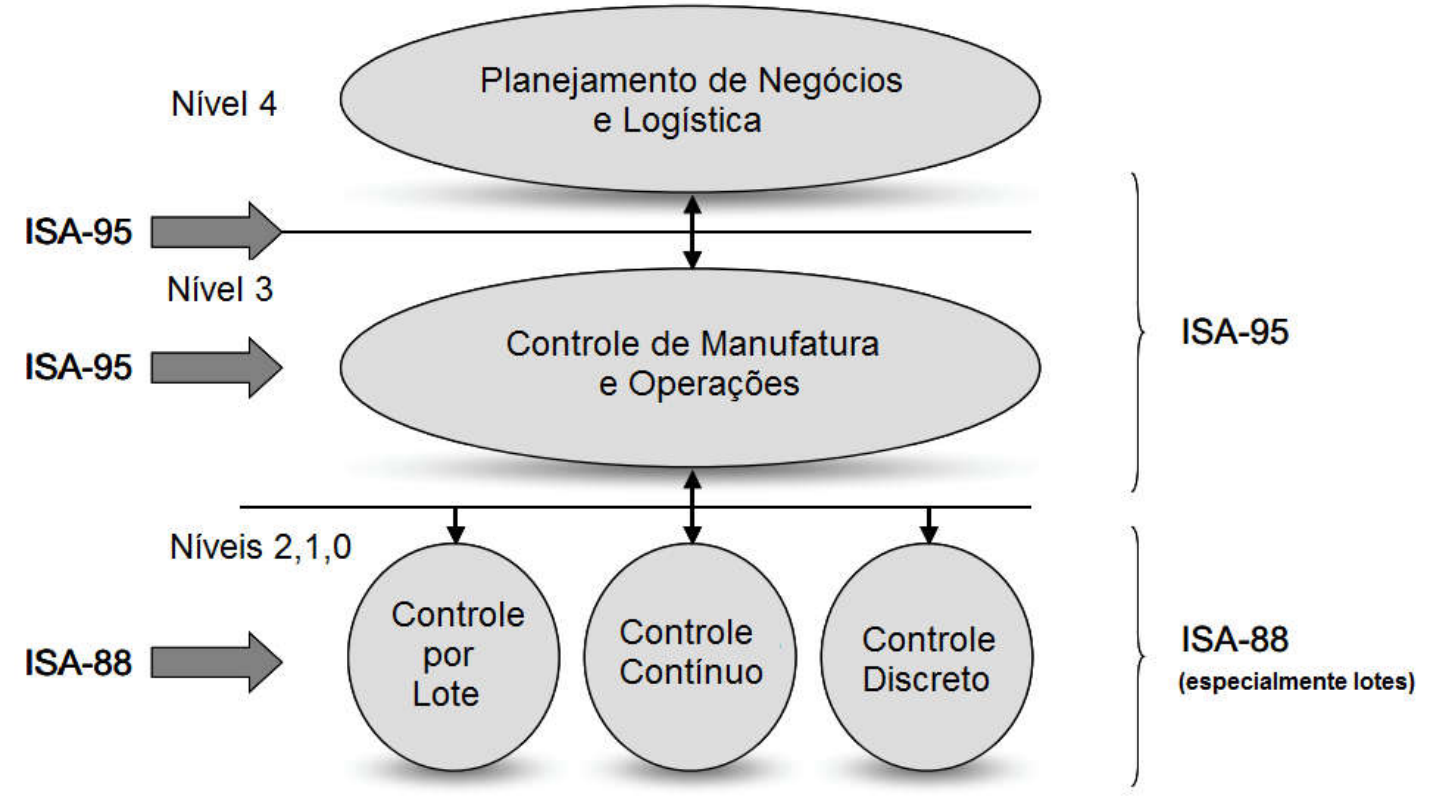

(Fonte: SCHOLTEN, 2007).

Estes modelos fornecem uma categorização hierárquica e modular para as máquinas e dispositivos que conduzem o processo e também para as receitas que descrevem como fabricar o produto. Eles formam a base para a gestão de processo de produção e, portanto, garantem a padronização dentro da automação do processo de produção. Estes padrões diferem em termos de objetivos, o que significa que empresas de manufatura podem usar ambos os padrões. Usa-se ISA-88 para automatizar os controles de máquinas e dispositivos e ISA-95 para a troca de informações entre os sistemas ERP e MES (SCHOLTEN, 2007).

Ainda de acordo com o modelo ISA, os processos produtivos são classificados em três grupos: Produção discreta, produção por lote e produção contínua, como se vê na Fig. 18. A contextualização do processo produtivo influi no processo de integração dos sistemas por apresentarem parque de máquinas com características diferentes. Nos modelos de produção discretos, geralmente, há uma diversidade de máquinas e equipamentos maiores e consequentemente um número maior de padrões de redes, equipamentos e softwares de controle, e isto tende a diminuir à medida que os processos produtivos passam por modelos de produção por lotes em direção ao modelo de produção contínuo. Pode-se supor que os modelos de processos contínuos teriam maior facilidade de integração com os sistemas de negócios que os modelos de produção discretos. Contudo, os produtos que mais 
demandam customização, flexibilidade, adaptabilidade e evolução na manufatura são aqueles produzidos sob modelo discreto ou por lotes e, portanto, é imprescindível uma solução de integração entre os níveis de sistemas de negócios e o nível de sistemas de controle neste ambiente diversificado, inclusive considerando sistemas e equipamentos legados.

Embora a realidade das industrias, mesmo de países mais desenvolvidos, seja ainda um parque de máquinas com padrões heterogêneos de hardware de controle e protocolos de comunicação, já existem soluções de integração baseados em OPC. Estas soluções têm sido desenvolvidas pela OPC Foundation (https://opcfoundation.org/) para facilitar a conectividade entre os dispositivos legados. Esta tecnologia adapta-se bem aos prazos necessários para a aquisição de dados. $A$ última versão, UA (Unified Architecture), é independente de plataforma e, portanto, aplica-se a uma ampla gama de produtos e a OPC está se tornando rapidamente o padrão de fato para a transferência de dados entre as camadas 1 a 3 do modelo ISA95 (BRANDL \& OWEN, 2003, MAHNKE et al., 2009) da Fig. 19. Enquanto isso, alguma variante do SQL (Structured Query Language) provavelmente deve surgir como o padrão de fato para o nível 3 e acima. Nestes níveis o prazo (time frame) é da ordem de minutos, horas ou dias - de modo que a definição de "tempo real" é relativa. O que é importante, no entanto, é a integração bidirecional contínua de dados (VERHAPPEN, 2010). Fabricantes de equipamentos como a Siemens já oferecem sistemas compatíveis com a linguagem OPC através de plataformas como o TIA Portal e WinCC Flexible que permitem integrar seus produtos com o de outros fabricantes e também com aplicativos (MES, ERP, etc.) compatíveis com a linguagem OPC, através da rede Ethernet usando o protocolo TCP/IP (SIEMENS, 2013 p.26). 
Fig. 19 - Arquitetura Física nos níveis 1, 2 e 3 do modelo ISA-95

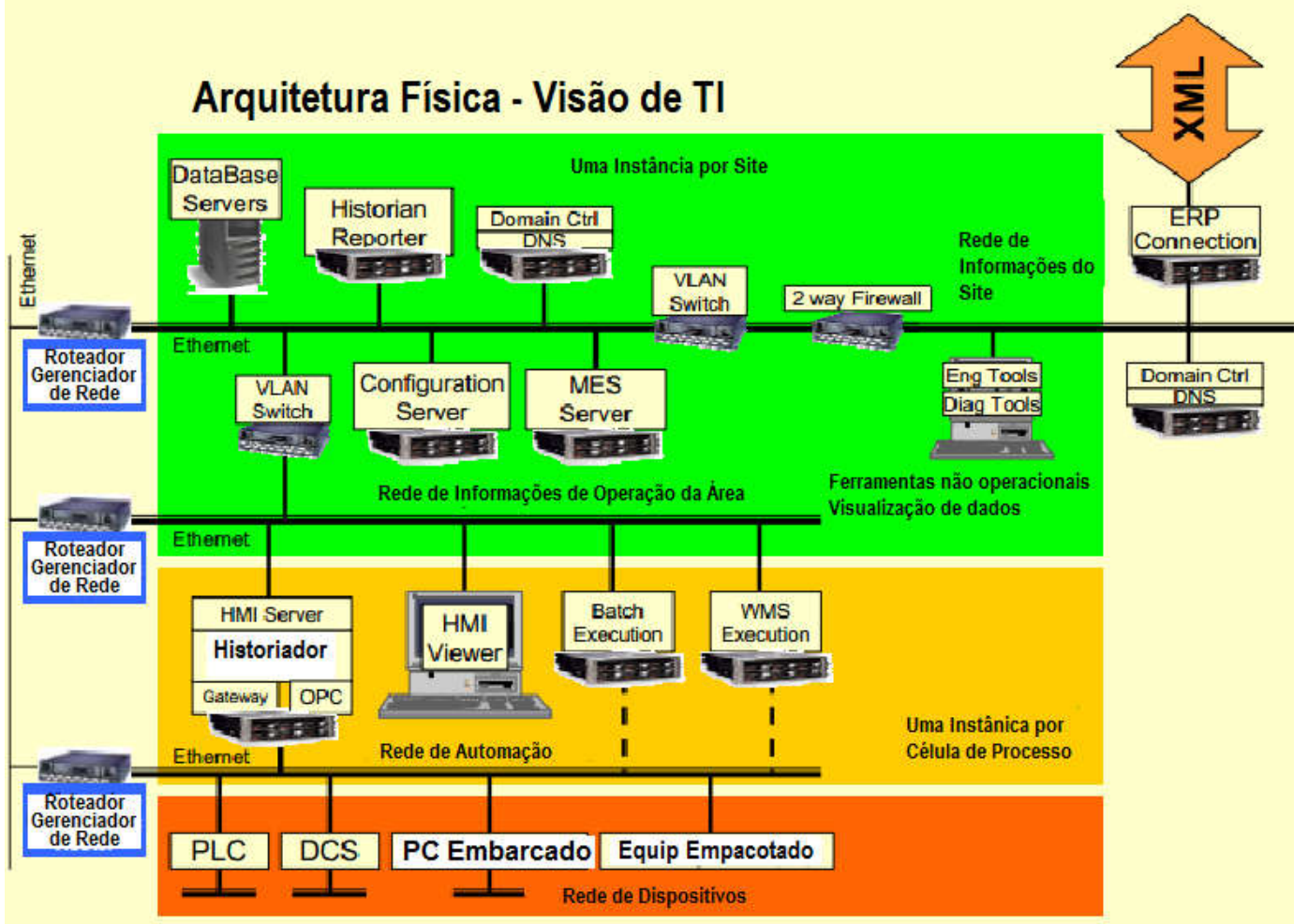

(Fonte: Brandl \& Owen, 2003)

A ISA-95 é uma tentativa de se criar um padrão aberto de infraestrutura de comunicação objetivando a integração da manufatura com o sistema corporativo. As camadas do modelo ISA-95 são baseadas nas camadas da hierarquia da automação, também conhecida como a pirâmide da automação (Fig. 1). O paralelo das camadas entre o modelo ISA-95 e a pirâmide da hierarquia da automação está ilustrado na Fig. 20. 
Fig. 20 - Padrões ISA-88 e ISA-95.
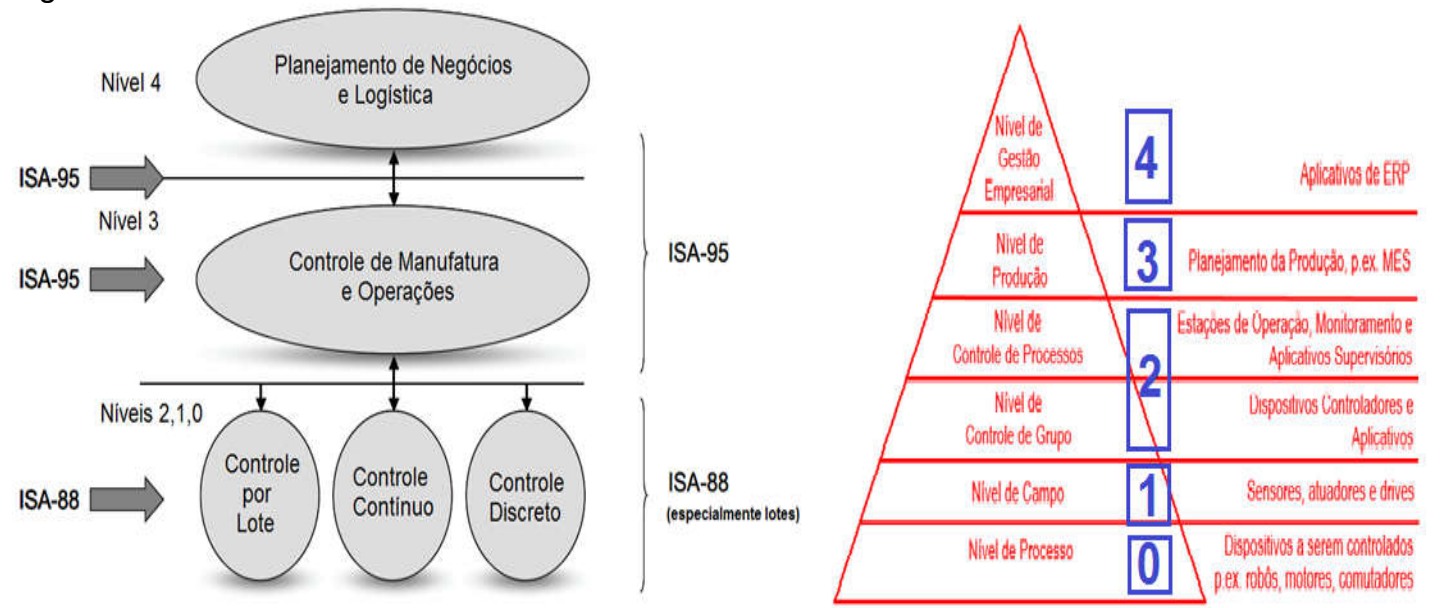

(Fonte: Adaptado de SCHOLTEN, 2007 e García et al., 2003)

Existe ainda a série de normas IEC-62264 que padronizam os modelos de sistemas de integração da manufatura, já traduzidos também para as normas BS (British Standard) e DIN. Algumas destas normas podem são citadas no Quadro 11.

\section{Quadro 11 - Normas IEC62264}

Norma IEC 62264

IEC 62264-1 Ed. 2.0 b:2013

IEC 62264-2 Ed. 2.0 b:2013

IEC 62264-3 Ed. 1.0 b:2007

ISA 95.00.03-2013

IEC 62264-5 Ed. 1.0 b:2011

(Fonte: IEC)

\section{Descrição}

Enterprise-control system integration. Models and terminology

Enterprise-control system integration - Part 2: Object and attributes for enterprise-control system integration

Enterprise-control system integration - Part 3: Activity models of manufacturing operations management

Enterprise-Control System Integration, Part 3: Models of Manufacturing Operations Management (IEC 62264-3 Modified)

Enterprise-control system integration - Part 5: Business to manufacturing transactions

Conforme Brandl \& Owen (2003), a proposta de arquitetura física no modelo ISA-95 já previa em 2003, a utilização das redes Ethernet até o nível 2 (conforme ilustrado na Fig. 19). A Schneider Electric por exemplo, já apresentava em sua brochura datada de 2005, soluções de Ethernet e web em seus produtos.

"Os produtos Telemecanique "Transparent Ready ${ }^{\mathrm{TM}}$ " são baseados na tecnologia universal Ethernet TCP/IP e na tecnologia Web. O protocolo aberto Modbus TCP/IP, que é o protocolo Ethernet industrial líder, está em conformidade com IEC internacional e os padrões fieldbus chinês SAC" (SCHNEIDER ELECTRIC, 2005).

Atualmente, a maioria dos fabricantes de equipamentos de controle e automação (fabricantes de CLPs, computadores industriais, drivers de motores, inversores de frequência, etc.) já dispõem de módulos adaptadores nos equipamentos 
para comunicação, no protocolo Ethernet. Desta forma máquinas novas que integram o parque fabril poderão ter maior conectividade com a rede corporativa. Contudo, uma arquitetura SOA, que permita uma fácil integração e comunicação com e entre os equipamentos (M2M), ainda necessita que alguns desafios tecnológicos sejam transpostos, como a implementação prática da web semântica.

\subsubsection{Sistemas ERP na Fábrica Inteligente 14.0}

Segundo MacDougall (2014) a 14.0 gerou um debate dentro da indústria de software alemã sobre qual sistema, se o ERP ou MES, se estabeleceria como força dominante em sistema de software em ambiente de produção. Algumas vozes da indústria acreditam que o ERP estará diretamente ligado aos sistemas de controle de processo no nível de chão de fábrica, tornando desnecessário o MES. Por outro lado, um contingente significativo considera que o MES está muito bem situado para a implementação da 14.0. Na conclusão de MacDougall (2014), ainda não há uma resposta clara, pois, a própria 14.0 representa uma transformação significativa no campo de software de gestão da produção. Contudo, como as funcionalidades ERP e MES tradicionais continuam a ser indispensáveis para a gestão da produção, o autor considera que é improvável que um sistema de software substitua o outro. Em sua opinião, um cenário mais provável é que haja crescente convergência entre os dois sistemas, tornando a linha divisória entre TI e TO mais difusa. Este cenário corresponde à essência da integração interdisciplinar e às etapas de implantação da 14.0 (MACDOUGALL, 2014).

Todavia, Honeywell (2010) aponta, conforme ilustrado na Fig. 21, que ainda há uma lacuna de funcionalidade nos sistemas atuais de integração entre o nível de sistemas de negócios ( $\mathrm{TI}$ ) e o nível de sistemas de controle em tempo real (TO). Esta lacuna está hoje, conectado com inúmeros aplicativos ad-hoc. Isto significa que sem uma solução integrada, operações de processos neste nível não são otimizados e, portanto, esses processos e ciclos de realimentação de informações operam muito abaixo do nível de eficiência e desempenho que poderiam ser alcançados. 
Fig. 21 - Ciclo de realimentação de informações no sistema de produção.

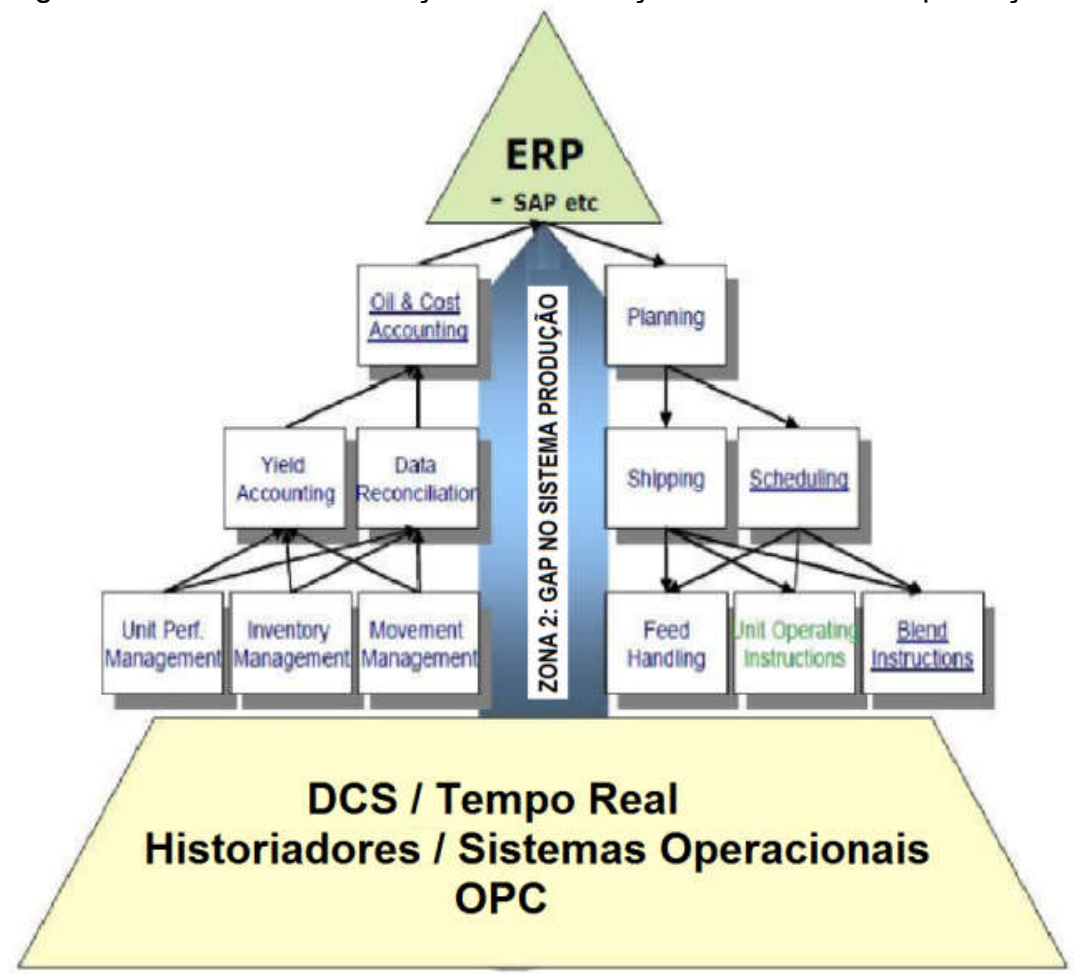

(Fonte: Honeywell, 2010)

Muitas vezes ao se tratar informações dentro de uma empresa, dá-se grande ênfase na visualização ou na apresentação dessas informações, porém o objetivo principal destes sistemas é fechar o ciclo de informações, partindo dos objetivos do negócio. Estes objetivos de negócio é que estabelecem metas de produção para os processos operacionais seguintes, causando ações sobre os ativos da fábrica e material, que por sua vez são monitorados e reportados com o objetivo de verificar se a empresa está cumprindo suas metas. Desta forma, a gestão em tempo real, demanda aplicativos integrados que possam suportar este ciclo de negócio.

O que Honeywell (2010) aponta é que embora os sistemas ERP permitam integrar verticalmente o chão de fábrica (TO) com os sistemas de TI corporativos, esta integração não tem permitido o nível de eficiência que poderia ser alcançado devido à inflexibilidade dos sistemas atuais como o ERP e MES que adotam uma estrutura centralizada e monolítica (DITTES, 2015). Ou seja, o nível de integração atual ainda não permite uma comunicação bilateral eficiente entre os níveis de chão de fábrica e os sistemas de negócio. 
Assim como no CIM, os sistemas ERP atuais possuem uma estrutura monolítica e centralizada, tornando os processos de adaptação a novas demandas muito complexas. Para que este ciclo de realimentação no sistema de produção citado por Honeywell (2010) possa ser fechado de maneira efetiva é necessário que o sistema seja adaptável às necessidades de cada empresa de uma forma mais rápida, simples e econômica. Lembrando ainda que a única constante nos negócios são as mudanças, o Sistema de Produção precisa também seguir uma arquitetura aberta, distribuída, modular, orientada a serviços para que novas funções possam ser facilmente acopladas ou desacopladas e processos possam ser adaptados segundo as necessidades particulares de cada empresa e das demandas do mercado. Dittes (2015) acredita que a 14.0 poderá mudar este cenário através da conectividade com sistemas cíberfísicos (CPS) e loT com uma comunicação direta entre o sistema ERP e CPS incluindo os Smart Products do nível de produção. O acesso direto aos dados de produção a partir do sistema ERP garantiria a transparência dos processos de negócio para além das fronteiras dos aplicativos individuais. De acordo com Dittes (2015) da SAP, os sistemas ERP e os sistemas MES atuais apresentam grandes dificuldades na integração e processamento de informações devido à estrutura inflexível e heterogênea da instalação fabril e a estrutura monolítica do software de ERP. A falta de padronização na infraestrutura de comunicação com o chão de fábrica torna a integração e a implementação de mudanças um processo demorado e oneroso. O mesmo se aplica a SW de ERP que devido à sua arquitetura monolítica tornam as mudanças e a adição de funcionalidades, em especial módulos de outros fabricantes, um processo demorado e oneroso. Portanto, para se alinhar com o conceito 14.0, será necessário que juntamente com a conversão da fábrica em Sistemas Cíberfísicos (CPS), o ERP também seja convertido para uma nova geração denominada Smart ERP (SERP) que deverá ter uma arquitetura orientada a serviços (SOA), permitindo assim usar funções e serviços de outros provedores de SW através de interfaces padronizadas. A loT permitirá uma comunicação direta entre o ERP e os CPS e Smart Products. A nova geração de ERP permitirá ainda o uso de Computação em nuvem para acessar a loS através de componentes de SW baseados na nuvem (DITTES, 2015). 


\title{
2.4.13 Smart Factory
}

Radziwon et al. (2014), relatam diferentes visões encontradas sobre o conceito de Smart Factory. Embora citado por profissionais do ramo e acadêmicos, vários termos são utilizados de forma indistinta: Ubiquitous Factory, Factory-of-Things, Realtime-Factory e Intelligent Factory of the future. Além disso, os acadêmicos referem-se à Smart Factory como uma tecnologia, uma abordagem ou um paradigma. Após analisarem várias referências, Radziwon et al., propõem a seguinte definição para a Smart Factory:

\begin{abstract}
"Smart Factory é uma solução de manufatura que fornece processos de produção flexíveis e adaptativos que resolverão problemas que surgem em uma unidade de produção com condições de fronteira dinâmicas e em rápida mudança num mundo de complexidade crescente. Esta solução especial poderia, por um lado, estar relacionada com a automação, entendida como uma combinação de software, hardware e / ou mecânica, que deveria levar à otimização da produção resultando na redução de mão de obra desnecessária e desperdício de recursos. Por outro lado, pode ser visto numa perspectiva de colaboração entre diferentes parceiros industriais e não industriais, em que a inteligência provém da formação de uma organização dinâmica" (RADZIWON ET AL., 2014)
\end{abstract}

Lee (2015) define Smart Factory como sendo a integração dos recentes avanços tecnológicos de loT em redes de computadores, integração de dados e analíticos para proporcionar transparência em toda a indústria de manufatura.

Dittes (2015), define a Smart Factory como uma solução que transforma a tradicional fábrica inflexível em uma instalação de produção mais inteligente e flexível através de dois elementos: IoT + Smart ERP (SERP), conforme ilustra a Fig. 22.

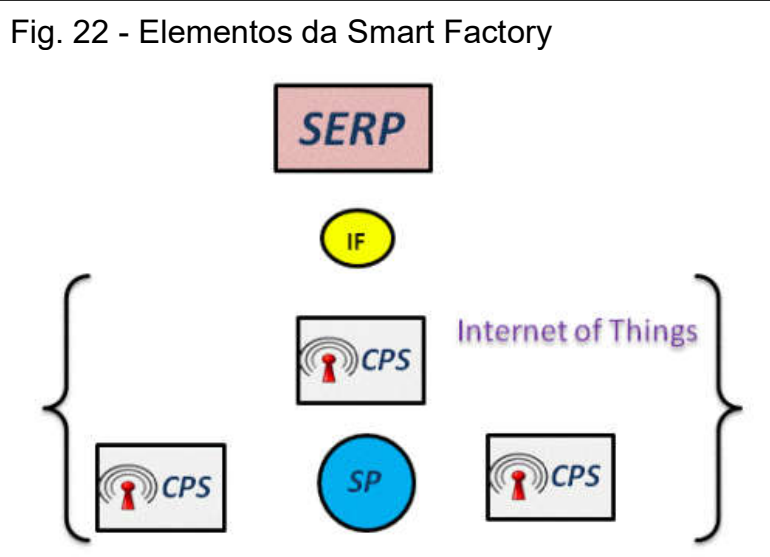

(Fonte: Dittes (2015) 
Wahlster (2012) sugere ainda que a Fábrica do Futuro (Smart Factory) será uma fábrica all-IP, em que os planejamentos dos sistemas empresariais poderão ser feitos independente do HW, através de uma arquitetura SOA na qual os dispositivos físicos serão vistos apenas como prestadores de serviços virtual, conforme ilustrado na Fig. 23.

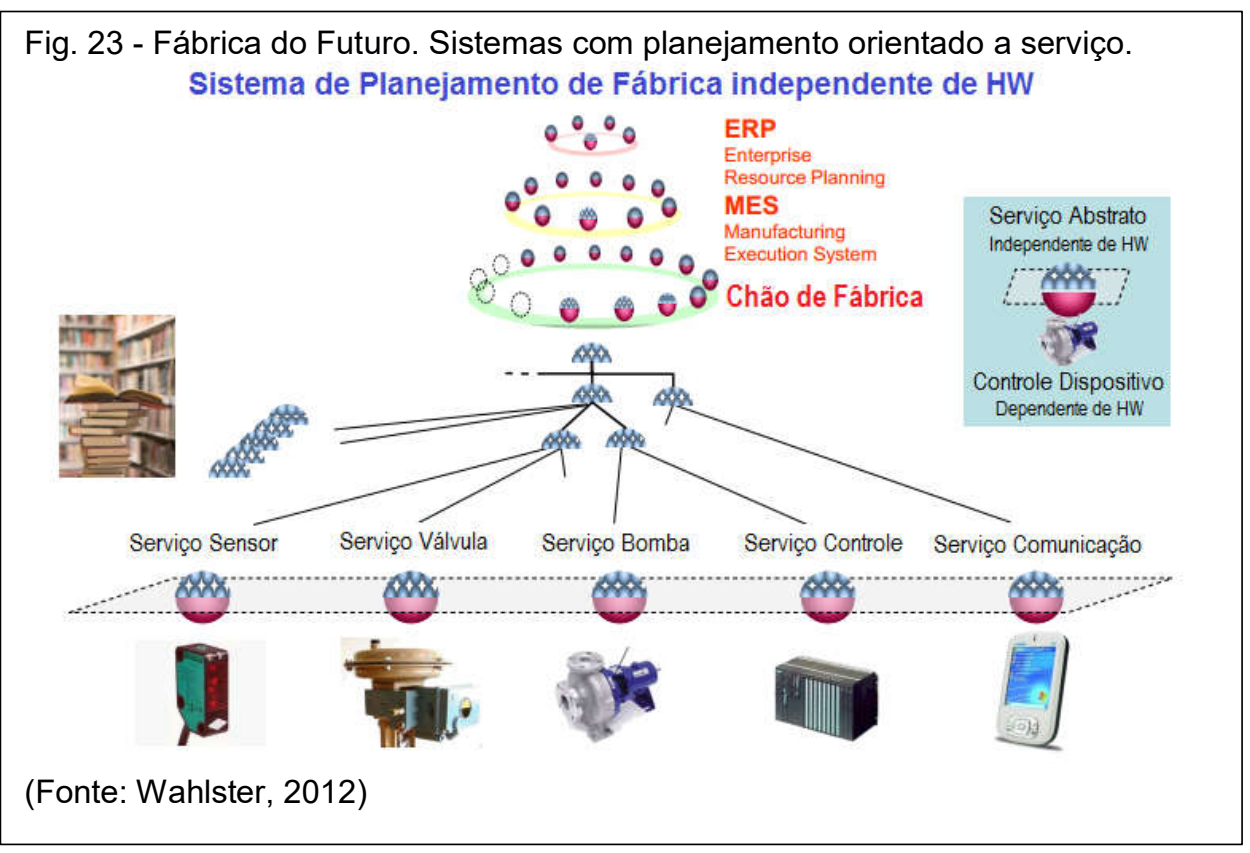

Zuehlke (2010), baseado nas mudanças e desafios experimentados na iniciativa Smart Factory KL 6 (fábrica experimental fundada em parceria entre a academia e indústria), cita que a Smart Factory precisa ainda de muitos avanços multidimensionais para que seja possível sua implementação. Estas dimensões incluem: tecnológica, organizacional, planejamento, segurança e humana.

Destaca que a dimensão tecnológica é a que representa menor desafio, porém os avanços nesta dimensão devem se basear em modelos tecnológicos desenvolvidos para bens de consumo, adaptados para uso industrial por motivos econômicos. Recomenda que no processo, deve-se esforçar para usar as normas existentes do mundo do mercado de consumo, pois é aí que os altos volumes de produção levam a custos aceitáveis (ex. protocolos Ethernet, PC industriais, tablets e smartphones para aplicações industriais, etc.). Contudo estes padrões precisam ser

\footnotetext{
${ }^{6}$ SmartFactoryKL (Smart Factory Kaiserlautern) é uma associação não lucrativa fundada em 2005 com parceria entre indústria e instituições de pesquisa com o propósito de desenvolver tecnologias comercializáveis para a Indústria 4.0
} 
adequados para as condições industriais considerando-se as diferenças de requisitos em confiabilidade e ambiente industrial.

Zuehlke (2010) cita que, as mudanças na dimensão organizacional, através da adoção de modelo de arquitetura orientada a serviços é fundamental para simplificar o projeto de sistemas complexos. Isto pode ser o maior desafio para os planejadores experientes de fábrica, acostumados com pensamento hierárquico que terão que mudar seu pensamento para compor complexos sistemas técnicos de serviços baseados em ontologias comuns. Isto requer muito mais que simplesmente renomear as funções de controle atuais de "serviços" e deixar tudo como está. O que torna sua implementação difícil é que é necessário inicialmente definir semanticamente os serviços a nível corporativo e só depois definir progressivamente aos níveis inferiores até o chão de fábrica. Além disso SOA não é uma estrutura hierárquica como é típico nas plantas atuais, ao contrário, ela é uma rede distribuída com conexões livres. Isto implica em satisfazer a necessidade de novos métodos e ferramentas de engenharia antes de qualquer implementação em ambiente industrial. Zuehlke (2010) prevê que como os usuários neste setor não querem uma revolução, mas uma evolução previsível, com melhorias contínuas, será difícil promover este modelo completo de uma vez. Estruturas antigas, com décadas de experiências acumuladas não serão substituídas da noite para o dia, mas as vantagens deste novo modelo conduzirão os aplicativos em SOA do nível de ERP (onde já é empregada em larga extensão) aos níveis inferiores de MES e dispositivos de chão de fábrica, onde os CLPs do futuro serão vistos como objetos complexos de serviços pelos níveis superiores de MES. Por sua vez, os PLCs do futuro traduzirão os pedidos de serviço aos dispositivos de nível inferior através do modelo hierárquico tradicional de bits e bytes.

Na dimensão de planejamento, Zuehlke (2010) destaca que o planejamento atual é auxiliado por vários sistemas CAx (Computer Aided $x$ ) e baseados em modelos. Contudo, o autor diz que estes sistemas frequentemente apresentam falta de integração de dados. Embora internamente sejam baseados em modelos, os modelos muitas vezes são incompatíveis. E é precisamente esta integração baseada em modelos que irá fazer a diferença no processo de planejamento enxuto do futuro. Hoje já se tem a maioria dos dispositivos industriais entregues aos clientes com dados de CAD e produto em formato STEP internacional. No futuro estes dados devem ser 
transformados em modelos de dispositivos mais abrangentes incluindo dados de serviço e comunicação. Na visão futura, o planejamento da planta é denominado "Fábrica Digital" e grandes atores da indústria de equipamentos juntaram se a empresas de TI para oferecer ferramentas de desenvolvimento, planejamento e controle. (Por ex. PLM da Siemens). Estas ferramentas integram planejamento, simulação, operação e mesmo funções de MES e ERP, apoiando o ciclo de vida completo do produto e isto requer modelos de sistemas abrangentes e consistentes que será o ponto crucial para o sucesso (ZUEHLKE, 2010). Por outro lado, Dittes (2015) acredita que a Smart Factory pode fazer com que o MES se torne desnecessário, ao mesmo tempo que os atuais sistemas monolíticos ERP seriam substituídos por um sistema ERP inteligente (Smart ERP - SERP), modular e orientado a serviço.

Na dimensão segurança, é necessário que os sistemas industriais sejam mais seguros e confiáveis que os equipamentos destinados ao consumo, nas quais falhas e eventuais ataques cibernéticos podem levar a situações extremamente graves. Como caso de ataque cibernético industrial pode-se citar o exemplo do vírus Stuxnet (KARNOUSKOS, 2011).

Na dimensão humana Zuehlke (2010) alerta que qualquer que seja o sistema técnico desenvolvido, o homem deve ser sempre considerado ao centro, pois a intervenção humana será necessária em todas as fases de operação da planta, desde o planejamento até operação, manutenção e reparos. Portanto, os sistemas futuros deverão focar no homem e não o contrário, em que o homem precise se ajustar às tecnologias. As novas possibilidades tecnológicas irão permitir ao homem uma mobilidade jamais alcançada anteriormente desacoplando cada vez mais o homem do seu ambiente físico de trabalho.

Wang et al. (2015) apresentam um comparativo entre as características da Smart Factory e a Linha de Produção tradicional que pode ser visto no Quadro 12. 


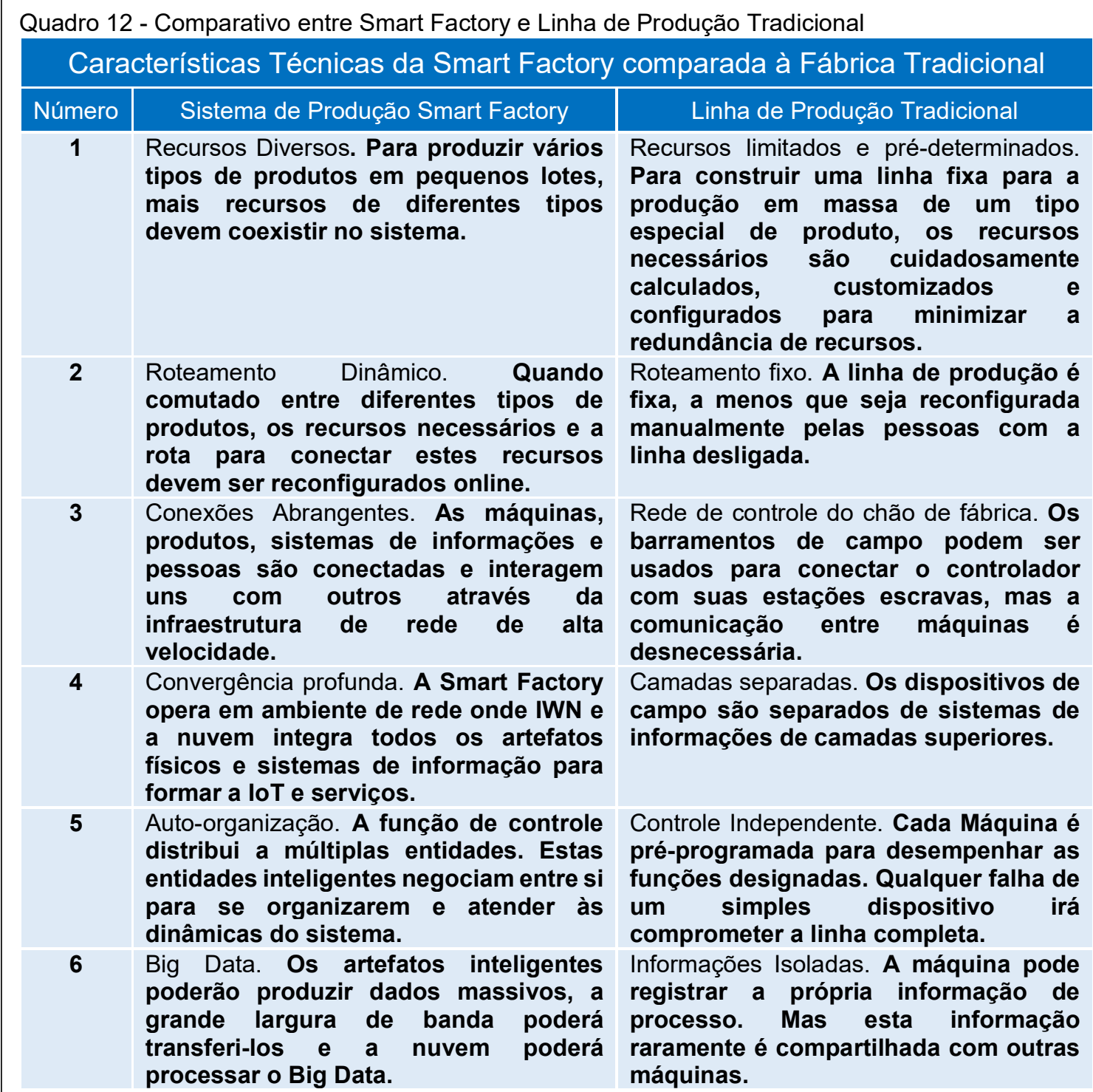

(Fonte: Wang et al., 2015)

\subsubsection{Integração Horizontal}

De acordo com o Wahlster (2012), o número de processadores embarcados deve crescer vertiginosamente conforme a Fig. 24, que é a base para os CPS, que irão criar ambientes cada vez mais inteligentes com a loT e loS, que, por sua vez, juntamente com Smart Factory construirão a infraestrutura para a 14.0 conforme Fig.

25. 

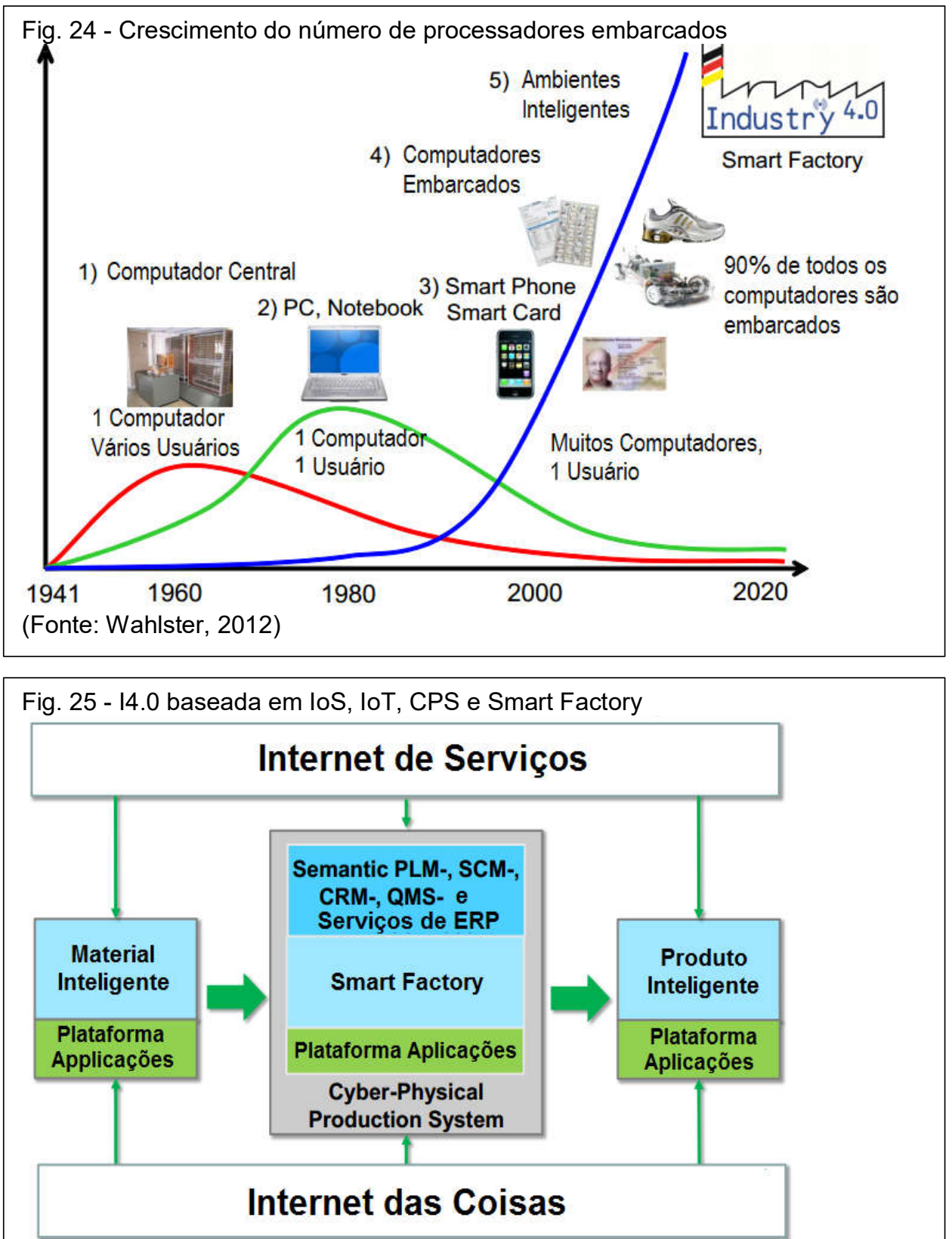

(Fonte: Wahlster 2012)

Contudo a loT e loS irão permitir que a manufatura não dependa apenas de recursos internos da empresa, permitindo a integração com toda a cadeia de produção de valor. A ideia central da 14.0 é usar as novas tecnologias da informação para implementar a loT e loS, de modo que processos de negócio e processos de engenharia estejam profundamente integrados fazendo com que a produção opere de forma flexível, eficiente e sustentável com alta qualidade e baixo custo de maneira constante (WANG et al., 2015). De acordo com Wang et al. (2015), a 14.0 é fundamentada em três tipos de integração, conforme ilustrado na Fig. 26: 
a) Integração Vertical entre subsistemas hierárquicos dentro de uma fábrica para criar um sistema de manufatura flexível e configurável;

b) Integração Horizontal representando a colaboração interempresariais e;

c) Integração ponta a ponta na engenharia, através de toda a cadeia de valor apoiando a customização de produtos.

Fig. 26 - Três tipos de integração na 14.0

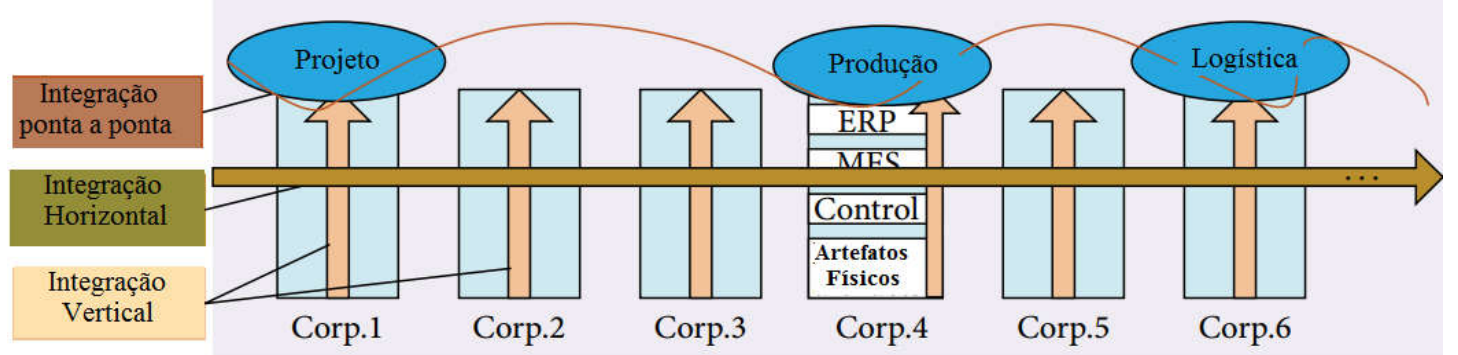

(Fonte: Wang et al., 2015)

Isto mostra que para que a 14.0 aconteça, é necessária toda uma infraestrutura para a integração horizontal entre empresas, além da integração vertical.

Tapscott e Williams (2006) explicam que o desenvolvimento de redes colaborativas resulta em novos modelos de negócios baseados em colaboração em massa. Com a colaboração em massa há uma transferência de poder do tradicional modelo hierárquico para o modelo colaborativo. Estes modelos de negócio tradicionais não poderão mais sustentar uma inovação bem-sucedida:

"Numa época em que a colaboração em massa pode transformar uma indústria de um dia para o outro, as velhas formas hierárquicas de organizar o trabalho e a inovação não proporcionam agilidade, criatividade e conectividade que as empresas necessitam para se manterem competitivas no ambiente de hoje".

Simplificando, uma empresa terá que repensar os modelos tradicionais de operação de negócios, uma vez que a quantidade de conhecimentos internos que detêm é reduzida por aqueles detidos pela massa global de povos conectados através da Globalização.

A integração horizontal pode ser fixa entre os atores da cadeia de valor, porém seguindo o modelo de serviços desacoplados em arquitetura aberta, surgem novas possibilidades com o Cloud Manufacturing.

\subsubsection{Cloud Manufacturing (CM)}


Como já visto anteriormente, a revolução da manufatura está ocorrendo com a aplicação das tecnologias de Internet aos elementos do chão de fábrica (DRATH \& $\mathrm{HORCH}, 2014$ ). Assim, tem-se vislumbrado o uso das tecnologias de Computação em Nuvem (CN) também para a Manufatura. Xu (2012) cita que a adoção de computação em nuvem na manufatura pode ser sugerida de duas formas: fabricando com adoção direta de tecnologias de Computação em Nuvem e através do Cloud manufacturing - a versão manufatura da $\mathrm{CN}$.

A adoção da CN como ela é na manufatura utiliza-se do principal impulso da $\mathrm{CN}$ que é fornecer serviços de computação sob demanda com alta confiabilidade, escalabilidade e disponibilidade em um ambiente distribuído para o propósito de manufatura. Na CN (Fig. 27), "tudo" é tratado como serviço (XaaS), por exemplo: Software como Serviço (SaaS), Plataforma como Serviço (PaaS) e Infraestrutura como Serviço (laaS). Esses serviços definem uma estrutura de sistema em camadas para a computação em nuvem. Na camada de infraestrutura, processamento, armazenamento, redes e outros recursos de computação fundamentais são definidos como serviços padronizados pela rede. Os clientes dos provedores de nuvem podem implantar e executar sistemas operacionais e software para suas infraestruturas subjacentes. A camada intermediária, isto é, a PaaS fornece abstrações e serviços para desenvolver, testar, implantar, hospedar e manter aplicativos no ambiente de desenvolvimento integrado. A camada de aplicação fornece um conjunto completo de aplicativos de SaaS. A camada de interface do usuário na parte superior permite uma interação perfeita com todas as camadas subjacentes do XaaS. A implementação de tecnologias de CN na manufatura é considerada por Wu et al. (2013) como de baixo investimento comparado à $\mathrm{CM}$ pois a $\mathrm{CN}$ em já vem sendo utilizada em várias aplicações empresariais. 
Fig. 27 - "Tudo" como serviço na Computação em Nuvem

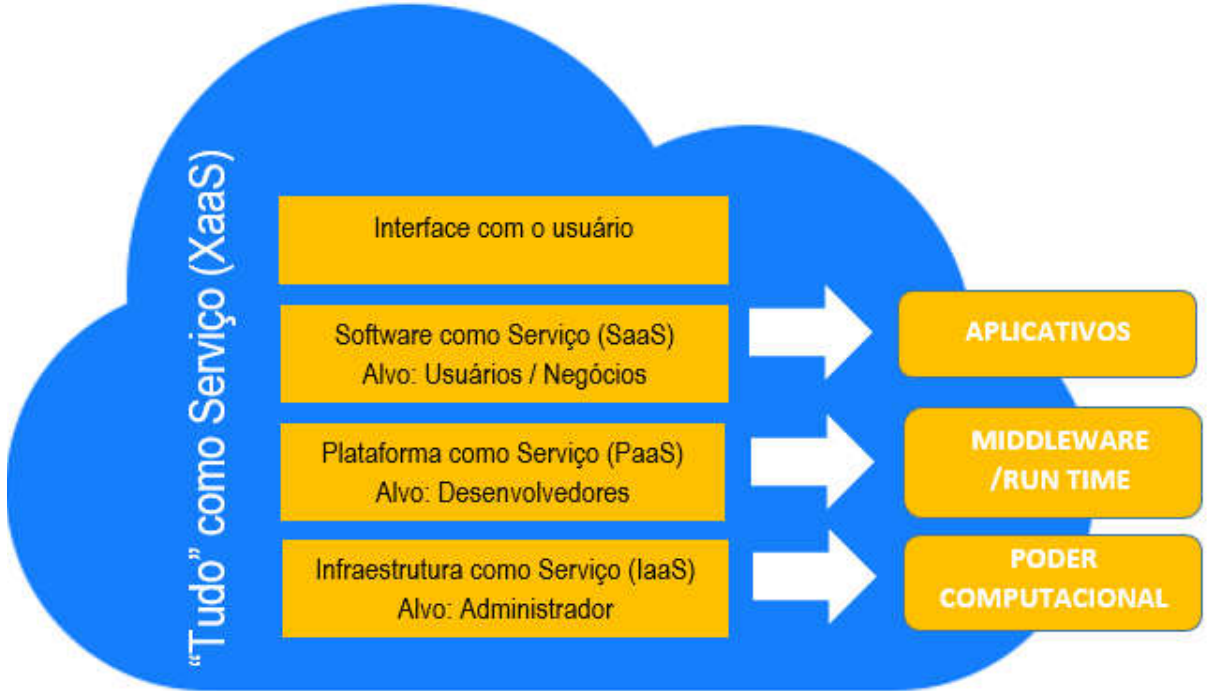

(Fonte: adaptado de $\mathrm{Xu}, 2012$ )

Na CM (versão manufatura da CN), utiliza-se da replicação do conceito de $\mathrm{CN}$, porém com a utilização de recursos físicos de manufatura no lugar de recursos de computação (WU et al., 2013). Wu et al. (2013) definem CM como um modelo de manufatura centrado no cliente que explora o acesso sob demanda a uma coleção compartilhada de recursos de fabricação diversificados e distribuídos para formar linhas de produção temporárias e reconfiguráveis que aumentam a eficiência, reduzem os custos do ciclo de vida do produto e permitem carregamento otimizado de recursos em resposta a demanda de tarefa variável gerado pelo cliente.

A CM é, portanto, uma expansão da loS através dos recursos disponíveis na nuvem, proporcionando escalabilidade de recursos de manufatura. A utilização de serviços na nuvem permite que aplicativos baseados na nuvem ofereça acesso universal a qualquer hora a dados fundamentais. Isto simplifica também a coleta e análise de dados, o monitoramento e distribuição, não somente entre fábricas, mas ao longo de toda a cadeia de valor (DELOITTE CONSULTING, 2015). Isto também muda o escopo de atuação dos participantes da CFSAM em relação à atuação corrente. 
Colombo et al. (2014) citam ainda que através do projeto IMC-AESOP7, abriuse o caminho desde sistemas habilitados por WebService até CPS industriais baseados em nuvem, e demonstrou-se com casos de aplicações industriais reais, vários aspectos do que será a próxima geração de controle, supervisão e aquisição de dados (SCADA) que podem tornar possível a concretização de sistemas industriais colaborativos. Colombo et al. (2013) mostram como a arquitetura de sistemas SCADA vêm se desenvolvendo de uma estrutura monolítica (primeira geração) para uma arquitetura distribuída (segunda geração), evoluindo para uma configuração em rede (terceira geração) e agora para uma arquitetura em nuvem (próxima geração) (Fig. 28).

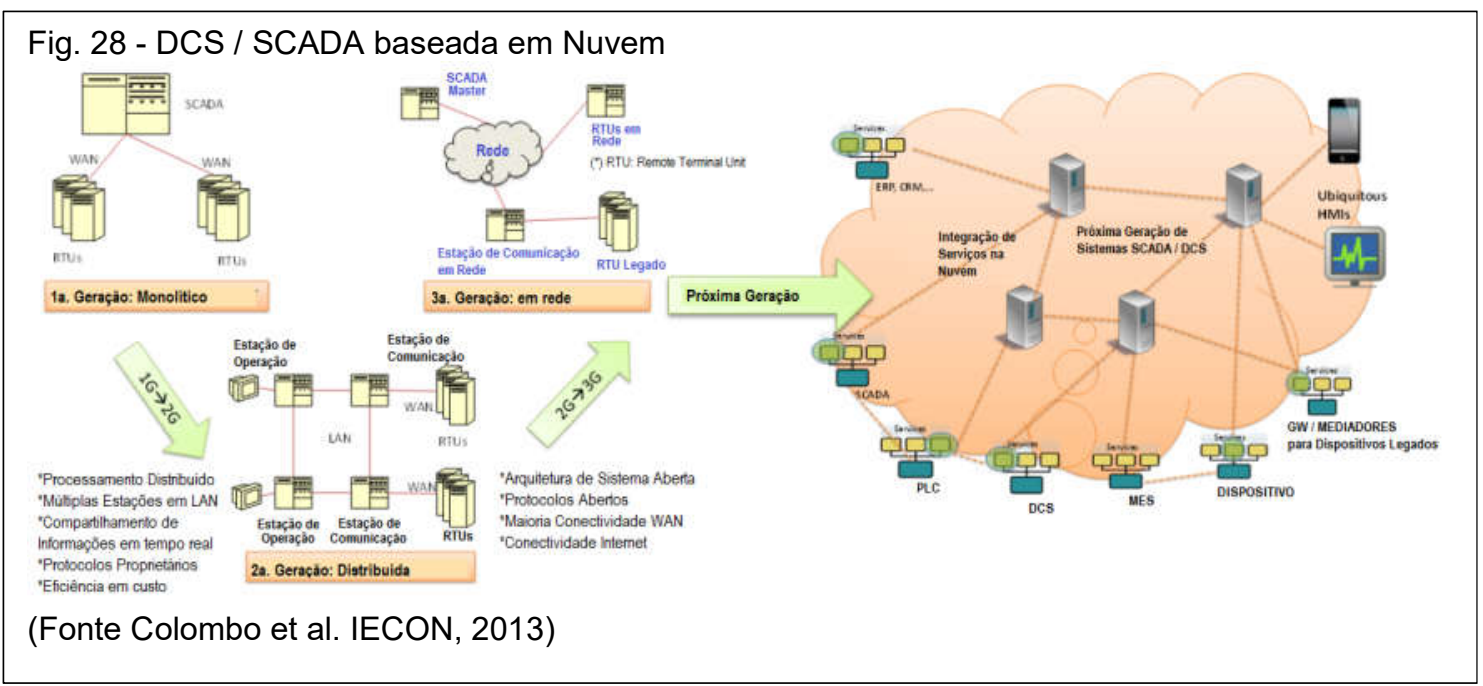

A arquitetura em nuvem é basicamente uma arquitetura SOA, em que as entidades são vistas como serviço e, portanto, pode-se dizer que a arquitetura em nuvem é uma arquitetura suportada pela Internet de Serviços (IoS). Em outras palavras CM é uma possibilidade tecnológica suportada pelas tecnologias de loS. Contudo, Wu et al. (2013) alertam que CM ainda é um campo de estudo vagamente

\footnotetext{
${ }^{7}$ O projeto IMC-AESOP iniciado em setembro de 2010 faz parte do 7th Framework Program da União Europeia, com uma duração total de 40 meses. O Consórcio IMC-AESOP foi composto por 18 parceiros de 7 países europeus, tendo sido liderado por Schneider Electric, e inclui alguns dos principais intervenientes europeus da cadeia de valor de automação industrial e a participação de instituições de pesquisa e universidades mundialmente reconhecidas. O projeto foi coordenado pelo Prof. Dr. Armando Walter Colombo da Schneider Electric Automation GmbH e University of Applied Sciences Emden I Leer da Alemanha.
} 
definido e demanda ainda pesquisas em várias áreas. Citam que mesmo no tocante aos modelos de negócios na $\mathrm{CM}$, a definição de que atividades são viáveis na $\mathrm{CM}$, ainda é indeterminada. Além disso há questões sobre como os valores agregados devem ser pagos quando o valor entregue é resultado de trabalho de vários colaboradores ou de interesse de vários usuários, ou de como lidar com a propriedade intelectual, etc.

\subsubsection{Indústria 4.0 (14.0)}

Anderl (2014) define 14.0 como uma abordagem estratégica para a integração de sistemas de controle avançados com tecnologia de internet que permite a comunicação entre as pessoas, produtos e sistemas complexos. A abordagem principal é equipar futuros produtos e sistemas de produção com sistemas embarcados como base para o sensor inteligente e atuadores inteligentes para possibilitar a comunicação e controle de operação inteligente.

Hermann et al. (2015) em sua revisão bibliográfica, definem 14.0 como sendo um termo coletivo para as tecnologias e conceitos de organização da cadeia de valor. Dentro das Fábricas inteligentes da 14.0, estruturadas modularmente, a CPS monitora processos físicos, cria uma cópia virtual do mundo físico e toma decisões descentralizadas. Ao longo da loT, CPS comunica e coopera uns com os outros e com os homens em tempo real. Através da loS, tanto os serviços internos como inter organizacionais são oferecidos e utilizados pelos participantes da cadeia de valor.

A 14.0 é uma plataforma que se diferencia da lloT por vislumbrar não somente a integração das coisas, mas também a virtualização de processos e da cadeia de produção promovendo uma operação harmoniosa entre as empresas, permitindo acesso em tempo real às informações relevantes sobre produtos e produção a todos os participantes da cadeia (BRETTEL et al., 2014). Embora haja várias definições para 14.0 bem como perspectivas tecnológicas que a caracterizam, de acordo com Hermann et al. (2015), a 14.0 integra quatro componentes chaves - CPS, IoT, IoS e Smart Factory para criar uma plataforma colaborativa de manufatura. Argumentam que a comunicação $\mathrm{M} 2 \mathrm{M}$ e produtos inteligentes não são considerados como componentes independentes da 14.0, pois M2M é um facilitador da loT, e produtos inteligentes são subcomponentes de CPS. Os autores veem ainda Big Data e 
Computação em Nuvem como serviços de dados que utilizam os dados gerados pelas implementações da 14.0, mas não como componentes independentes da 14.0

A 14.0 abrange não apenas uma única fábrica inteligente (Smart Factory), mas integra horizontalmente todas as empresas participantes da cadeia colaborativa de produção e do ambiente colaborativo de desenvolvimento. Nesta cadeia surgem oportunidades, especialmente paras as PMEs com recursos limitados. A organização em redes colaborativas multiplica a capacidade disponível sem a necessidade de investimentos adicionais e por isso, as empresas em rede colaborativa podem se adaptar a mercados voláteis e produtos com ciclos de vida menores com maior agilidade. Por outro lado, o desacoplamento e a separação espacial, de processos ao mesmo tempo em que integra dados de produção de múltiplos locais de produção, requerem uma coordenação e comunicação muito mais eficientes. Isto muda o modelo de negócio das empresas de manufatura que ofereciam produtos de qualidade superior para empresas de manufatura que oferecem capacidade de manufatura superior (BRETTEL et al., 2014).

No entanto, Drath \& Horsh (2014) lembram que a 14.0 ainda está no futuro pois muitas questões ainda precisam ser resolvidas antes que ela possa ser implementada. Gartner (2015) prevê que a loT (um dos elementos da 14.0) que está no momento em seu pico de expectativas, deverá levar ainda de 5 a 10 anos para atingir o platô da produtividade. Consoante com esta previsão a Rockwell Automation (2014) prevê que a automação na Manufatura deve mudar radicalmente nos próximos cinco anos que nos vinte anos anteriores.

Embora esta mudança de paradigma prevista na automação industrial, desencadeada pelas tecnologias de internet esteja sendo interpretada como a Quarta Revolução Industrial pelos alemães e seguido por outros países europeus, vale citar que há uma divergência de opiniões com relação às revoluções industriais. Os americanos (RIFKIN, 2012) referem-se a estas mudanças como parte da Terceira Revolução Industrial (TIR) o que tem confundido a Terceira Revolução Industrial europeia (I3.0) com a TIR americana.

Segundo a visão alemã, as revoluções industriais caracterizam-se pela introdução de avanços tecnológicos conforme ilustrado na Fig. 29 abaixo. 
Fig. 29 - Revoluções Industriais

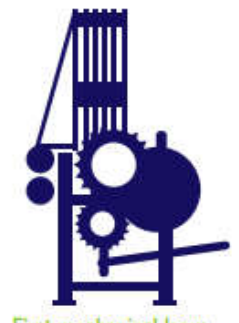

First mechanical loom 1784

1.Revolução Industrial Segue Energia Vapor e Hidráulica. Facilidades Mecânicas para Manufatura

Final do

Século 18

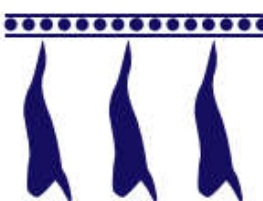

First production line,

Cincinnati slaughterhouses 1870

2.Revolução Industrial Segue Introdução da Produção em Massa Energia Elétrica Divisão do Trabalho

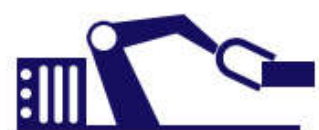

First programmable logic controller (PLC), Modicon 084 1969

3.Revolução Industrial usa a eletrônica e TI para incrementar a automação da manufatura

(Fonte: KAGERMANN et al., 2013)

Já na visão de Rifkin (2012), os eventos, conforme ilustrado na Fig. 30, caracterizam as principais revoluções na indústria e presencia-se agora, a Terceira Revolução Industrial (TIR) com o advento da Internet.

Fig. 30 - As Revoluções Industriais segundo Rifkin (2012)

Terceira Revolução Industrial

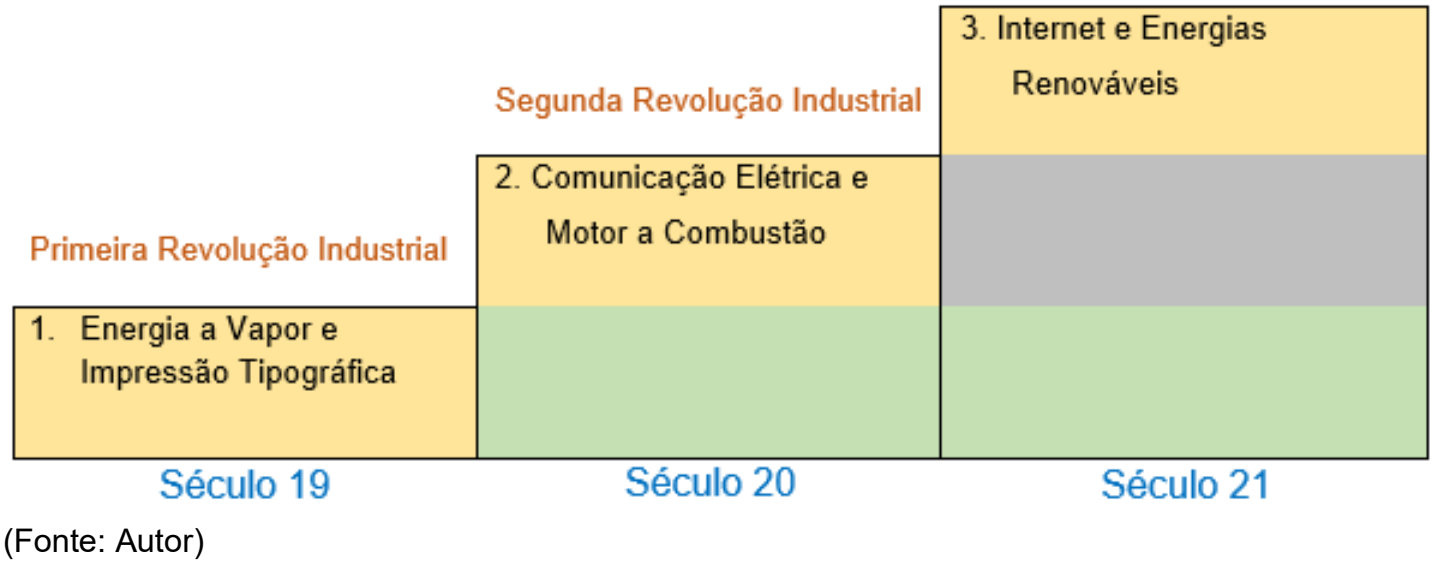


Independente da divergência de opiniões, este novo paradigma está sendo visto por todos como uma grande mudança na engenharia industrial e de manufatura, impulsionado pela convergência de máquinas, dados inteligentes, impressoras 3D, robótica e avanços na ciência dos materiais, tendo como pano de fundo a internet e outros avanços na TI (IEEE CG\&A, 2014). Da mesma forma Rifkin (2015) caracteriza a Terceira Revolução Industrial (TIR) pela existência de sensores em todos os lugares (nos campos agrícolas, nas fábricas, nas estradas, nos carros, nos centros de distribuição, etc.), permitindo a conexão de tudo com todos.

Assim, o estado da arte na automação industrial está relacionado ao ambiente todo conectado, impulsionado pela loT, onde o controle será cada vez mais distribuído através de dispositivos com inteligência embarcada e suas funções poderão ser encapsuladas através de software dentro de uma arquitetura orientada a serviços. Contudo esta arquitetura requer um ambiente padronizado e conectado através de internet, ao qual empresas como a GE denominaram Internet Industrial (BRUNER, 2013).

Neste trabalho aceita-se a visão da $\mathbf{3}$.0 como a Terceira Revolução Industrial desencadeada pelo uso do processamento digital na indústria e a 14.0 como a Quarta Revolução Industrial desencadeada pelo uso de tecnologias de comunicação digital (tecnologias de Internet) na indústria, e principalmente pela mudança de paradigma associada à adoção de arquitetura distribuída baseada em SOA e Web Semântica.

A diferença de infraestrutura na fábrica entre a 13.0 e 14.0 estão baseadas em três tecnologias: CPS, Smart Network e Smart ERP que compõem a Smart Factory (DITTES, 2015). Porém, uma empresa para estar imersa na 14.0 não basta a infraestrutura de Smart Factory. É necessária também a inserção na rede colaborativa através da loS conectados através da Nuvem conforme ilustra Dittes (2015) na Fig. 31. Tal estrutura inclui a integração horizontal ao longo da cadeia de criação de valor (WANG et al., 2015) bem como a possibilidade de Cloud Manufacturing (XU, 2012) já citada em 2.4.14.1. 


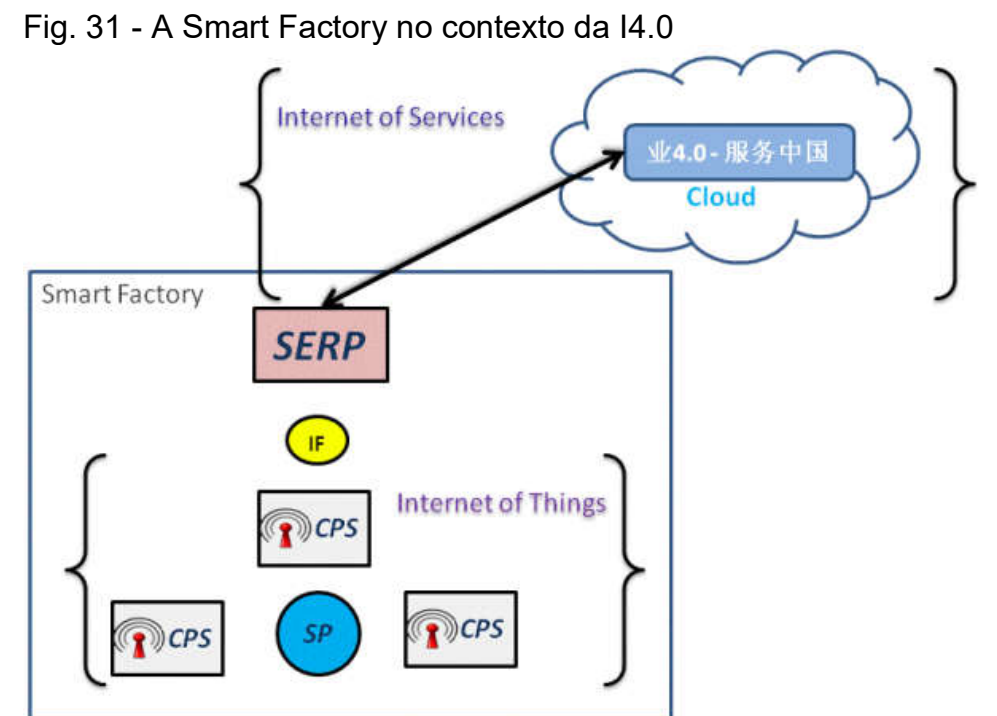

(Fonte: Dittes, 2015)

Segundo Bosch Rexroth (2013), os produtos na 14.0 não mais serão meros elementos passivos, mas um agente ativo que por si só, pode decidir como deve ser fabricado. Dentro de sistemas de 14.0, tanto os produtos como as máquinas serão capazes de comunicar-se e monitorar-se, descobrindo falhas, usando cálculos independentes, determinando quando a manutenção será necessária. Estas mudanças tornarão a produção e a logística mais flexíveis, uma vez que a informação não será mais processada por uma única unidade central. Bosch Rexroth (2013) enfatiza que no momento, a questão é, principalmente, criar a tecnologia da informação necessária para a 14.0, principalmente através de métodos para auferir inteligência aos produtos que estão sendo fabricados por tecnologias tais como os códigos de resposta rápida ( $Q R$ code) e chips de identificação por rádio frequência (RFID's). Estes meios são apenas parte de um sistema de produção mais amplo chamado de ciberfísicos (CPPS), que são nada mais que uma rede de produção na qual máquinas inteligentes, sistemas de armazenamento e recursos de operação trocam informações de maneira autônoma e disparam ações se necessário. Embora estes sistemas estejam sendo testados, ainda não há nenhum padrão de software definido, para serem aplicados nestes meios ciberfísicos. A comunicação entre máquinas e produtos claramente requer protocolos de comunicação completamente novos, uma vez que não se tratará mais de uma simples questão de transmissão de dados. Os novos protocolos deverão ser capazes de descrever os dados de forma que sejam inteligíveis para as máquinas. Isto permitirá que outras máquinas e 
sistemas tomem ações com base nestas informações. Tecnologias semânticas como estas serão essenciais para garantir a interoperabilidade de cada um destes sistemas (BOSCH REXROTH, 2013).

Bosch Rexroth (2013) ainda comenta que muitas das tecnologias que pavimentam o caminho para a 14.0 tem surgido ao longo dos últimos 10 a 15 anos. Estas tecnologias estarão embarcadas nos materiais, componentes e máquinas que trabalham com eles de maneira que podem se comunicar entre si em tempo real e trocar comandos à medida que o produto caminha ao longo da linha de manufatura. Até então, não havia meios para conectar elementos isolados da cadeia de produção. Hoje, as tecnologias de rede de dados tais como chips de RFID, mini transponders, oferecem oportunidades para coleta de mais dados e mapear a unidade completa de produção abrangendo desde o fornecedor até o cliente. Se a descontinuidade de dados entre o que o sistema ERP claramente identifica como pedidos de cliente até o agendamento da produção e necessidade de materiais, for solucionada, então a habilidade de produzir bens customizados será altamente impulsionado em termos de fator de escala. No entanto, a 14.0 requer um certo grau de abertura para todos os atores do mercado, representado pela padronização, em particular com relação à troca de informações. Quando iniciativas como a Ethernet IP, ISA 95 etc. se tornam relevantes para a formatação de um padrão.

Kagermann et al. (2013) citam que a ACATECH através de seu grupo de trabalho, Industrie 4.0 Working Group, diante das mudanças de paradigma na automação industrial impulsionados pelos avanços na Tecnologia de Internet, trabalham na iniciativa Industrie 4.0, apontando o cenário para novas oportunidades e modelos de negócios. O cenário é de uma plataforma promovendo um ambiente altamente conectado e dinâmico, favorecendo negócios em rede. Nesta rede várias empresas poderão participar promovendo a "fabricação em rede" e "logística adaptável, auto-organizável”. A 14.0 irá dar origem a novas plataformas de Sistemas Ciberfísicos (CPS) voltadas para apoiar os processos de negócios industriais de colaboração e as redes de empresas associadas para todos os aspectos de fábricas inteligentes e ciclos de vida dos produtos inteligentes.

De acordo com Kagermann et al. (2013), os serviços e aplicativos fornecidos por essas plataformas deverão conectar pessoas, objetos e sistemas um com o outro. Citam ainda a mudança de paradigma na interação tecnologia-humano para humano- 
ambiente provocada pela 14.0, com novas formas de trabalho na fábrica de colaboração que podem ser realizadas fora da fábrica, em locais de trabalho móveis ou virtuais. No contexto das redes de negócios, haverá oportunidades de trabalho de desenvolvimento em $\mathrm{TI}$, principalmente relacionado à orquestração de serviços e aplicações em plataformas compartilhadas com CPS. Esta plataforma compartilhada é o lugar onde surgirão os requisitos específicos para a integração horizontal e vertical do CPS, aplicações e serviços em processos de negócios. Particularmente, será necessário que o setor de TI (que está acostumado a ciclos de inovação curtos) trabalhe em estreita colaboração com fabricantes de máquinas e instalações além de fornecedores de sistemas mecatrônicos (que tendem a pensar em termos de ciclos de inovação mais longos), a fim de desenvolver modelos de negócios que sejam aceitáveis para todos os parceiros. Atualmente os processos de negócios na manufatura ainda são na maioria, estáticos e implementados através de sistemas de software extremamente inflexíveis. No entanto, eles não podem simplesmente ser substituídos da noite para o dia por sistemas orientados a serviços. Desta forma, será essencial integrar novas tecnologias nos sistemas legados, e sistemas antigos terão de ser atualizados para sistemas habilitados em tempo real. Contudo, deve-se ter em mente que implementação de soluções através de CPS habilitados em tempo real, por sua vez, traz novas exigências de disponibilidade de serviços e infraestrutura de rede em termos de espaço, qualidade técnica e confiabilidade.

\subsubsection{Industria 4.0: Revolução ou Evolução?}

Enquanto pesquisadores como Kagermann et al. (2013) consideram que a 14.0 representa a quarta revolução industrial, outros como Rüttimann \& Stöckli (2016) entendem que a 14.0 é uma evolução natural da CIM e não uma revolução. Diante desta divergência de entendimentos, a questão que se trata neste item é: o que muda tão radicalmente da 13.0 para a 14.0 a ponto de ser considerada uma nova revolução industrial?

A definição da Plataforma Indústria 4.0 é dada por Koch et al. (2014) citando a tradução da versão em alemão da Platform Industrie 4.0.

"O termo Indústria 4.0 representa a quarta revolução industrial. Melhor entendida como um novo nível de organização e controle sobre toda a cadeia de valor do ciclo de vida dos produtos. A 14.0 é voltada para necessidades 
cada vez mais individualizadas dos clientes. Este ciclo começa na ideia do produto, abrange a colocação do pedido e se estende até o desenvolvimento e fabricação, até a entrega do produto para o cliente final, e conclui com a reciclagem, abrangendo todos os serviços resultantes. A base para a quarta revolução industrial é a disponibilidade de todas as informações relevantes em tempo real, conectando todas as instâncias envolvidas na cadeia de valor. A capacidade de obter o fluxo ótimo de valor agregado a qualquer momento a partir dos dados também é vital. A conexão de pessoas, coisas e sistemas cria conexões dinâmicas, auto-organizadas, em tempo real e otimizadas, dentro e entre empresas. Estes podem ser otimizados de acordo com diferentes critérios tais como custos, disponibilidade e consumo de recursos" (Koch et al., 2014 apud Platform Industry 4.0)

Por esta definição, a inteligência distribuída através de sistemas ciberfísicos (CPS) e disponibilidade de informações relevantes em tempo real através da conectividade são citados como características desta plataforma. Ainda são citadas características como flexibilidade e sistemas auto-organizáveis orientadas à individualização da produção. Contudo, há uma dificuldade de se caracterizar os elementos que distinguem a plataforma 14.0 da 13.0 pois muitas destas características já estavam presentes em sistemas da I3.0 na Manufatura Integrada por Computador (CIM). Brettel et al. (2014) também citam que o termo 14.0 é um termo usado para descrever mudanças iminentes no cenário industrial, particularmente na manufatura, mas que é aplicado em diversos contextos e carece de uma definição mais explicita.

Yu et al. (2015) definem a Manufatura Integrada por Computador (CIM) como a aplicação da tecnologia da Computação à empresa manufatureira com o propósito de fornecer as informações corretas no local apropriado e no tempo certo permitindo atingir os objetivos de produção. É a integração total da manufatura através da tecnologia de informação juntamente com uma filosofia de gestão, que permite melhorar a eficiência organizacional e de pessoas. Esta integração é feita através de sistemas ERP que integram verticalmente a manufatura física com os negócios. Ainda de acordo com Yu et al. (2015), CIM pode ser considerado uma das principais forças propulsoras da 13.0. De acordo com os autores, CIM foca a integração da computação com tecnologias avançadas de manufatura tais como máquinas de controle numérico (CN) e sistemas de manufatura flexível (FMS), porém em recursos localizados, sobre uma arquitetura de negócios mais estruturada e estática que é uma peculiaridade dos atuais sistemas ERP. Desta forma, CIM apresenta grandes restrições em adaptabilidade às variações dinâmicas de produção. Pode-se dizer que a CIM mantém o foco em sistemas conectados enquanto CPS foca dispositivos conectados e Cloud Manufacturing foca empresas conectadas (YU et al., 2015). 


\subsubsection{Mudanças de Paradigmas na Integração Vertical}

As contribuições mais relevantes para a evolução da pesquisa PSIA identificadas na Fig. 9 do estudo bibliométrico, mostram como a base de conhecimento evoluiu de I3.0 até 14.0. Nela é possível perceber como a PSIA está evoluindo da arquitetura CIM para a quarta revolução industrial - 14.0. Baseado nas pesquisas mais relevantes apontados pelas métricas de Sigma e Burst no estudo bibliométrico é possível construir a narrativa para a evolução da pesquisa sobre PSIA conforme segue:

A Automação de Manufatura inicia sua mudança de paradigma ao quebrar o conceito de arquitetura monolítica e centralizada do CIM, propondo em seu lugar uma arquitetura de automação industrial orientada a serviço (JAMMES \& SMIT, 2005) por meio de sistemas distribuídos em rede com capacidade de computação embutida (CPS). Nesta arquitetura, uma interface de software encapsularia as complexidades e particularidades de cada dispositivo tornando-as autônomas e interoperáveis. No entanto, todos esses dispositivos precisariam ser integrados em um sistema. Kalogeras et al, 2006 propuseram para isso, o uso de tecnologia Web Services para a integração vertical das empresas industriais.

Igualmente, Lastra \& Delamer (2006) propuseram a utilização de Web Service semânticos para permitir que estes dispositivos se encontrem e se comuniquem de forma autônoma viabilizando comunicações entre máquinas (M2M). Em 2010, o livro de Bloomberg \& Schmelzer (2006) surge com destaque em sigma nas pesquisas de PSIA, discutindo a necessidade de orientar o negócio para serviços, alertando para o risco de cair na armadilha da inflexibilidade. Os autores enfatizam que a inflexibilidade é a mãe de todos os problemas porque a única constante em negócios é a mudança. O livro sugere SOA com acoplamentos livres como a solução para superar este problema. Embora o foco esteja nos sistemas de TI no contexto de negócios, a ideia é a mesma proposta por Jammes \& Smit (2005) no contexto da automação industrial. O livro de Bell (2008) que discute padrões de modelagem de SOA para descoberta e análise orientada a serviços" é apontado em 2011, como possível inovação em PSIA. Candido et al. (2010) destaca-se em sigma em 2012 discutindo o uso de SOA a nível de dispositivo apoiando Sistemas de Produção Evolutivos. A partir de 2014, o trabalho 
de Candido et al. (2011), ainda discutindo o uso de infraestrutura SOA para a implantação de EPS recebe o destaque no ranking de sigma (inovação potencial). Todos esses destaques indicam claramente que, uma vez que a mudança de paradigma de controle centralizado para controle distribuído foi proposta, os pesquisadores estão trabalhando ativamente na implementação deste conceito sobre SOA usando tecnologias de web semântica.

Considerando que a métrica Sigma é pouco mais lenta que a métrica Burst para identificar a novidade, vê-se que os artigos relacionados a loT e 14.0 emergem em relevância somente em 2016. A técnica de fatiamento de tempo analisando a classificação sigma mostrou que SOA, Web Services e Web Service Semânticos, desenvolvidos principalmente para ambientes de TI, pavimentaram o caminho para a concepção de loT (ATZORI et al., 2010) e IloT (EVANS \& ANNUNZIATA, 2012). Embora as pesquisas em CPS (LEE, 2008) tenham sido destacadas como novidade em Burst somente em 2016, o conceito de dispositivos com computadores embutidos é proposto desde 2005 por Jammes \& Smit (2005).

Complementando a análise Sigma com a detecção de Burst, é possível ver ainda a evolução do IloT e do loT para a Smart Factory (ZUEHLKE, 2010) e Rede Colaborativa (COLOMBO, 2014). Que por sua vez permitem a visão do conceito de Plataforma 14.0 (KAGERMANN et al., 2013). Paralelamente, a GE propõe uma plataforma IloT semelhante, baseada nas mesmas tecnologias loT, mas com uma aplicação mais abrangente, que vai além das indústrias de manufatura (DRATH \& HORSH, 2014).

\subsubsection{Mudança de Paradigma na Integração Horizontal}

Paralelamente à mudança de paradigma na estrutura da automação industrial verifica-se também uma mudança de paradigma na forma como a cadeia de produção muda de um conceito de Marketing de Bens para Marketing de Serviços (Sistemas de Serviços).

Maglio et al. (2006) contribuem com o conceito de Sistemas de Serviços como redes de criação de valor, sobre a ideia de Anand \& Khann (2000) de criação de valor através de alianças interempresariais. 
Junto com a Ciência de Serviços discutido por Chesbrough \& Spohrer (2006) Bardhan et al. (2007) destaca a importância da Ciência de Serviços como área fundamental para pesquisas em Sistemas de Informações.

Schroth \& Janner (2007) por sua vez tratam da convergência da Web 2.0 (redes sociais colaborativas) com a Arquitetura Orientada a Serviços como habilitadores para a Internet de Serviços, que por sua vez evoluiu para Cloud Manufacturing discutido por Xu (2012) ilustrando a evolução da integração horizontal das cadeias de produção para as redes colaborativas baseadas em serviços.

Esta estrutura evolutiva segundo dois pilares de integração vertical e integração horizontal é mostrada na Fig. 32 onde é possível perceber a evolução da infraestrutura tecnológica da 13.0 para a 14.0. Nesta infraestrutura tecnológica nota-se que a Arquitetura Orientada a Serviços e Serviços de Web Semântca são a base para estas mudanças de paradigma. São eles que irão facilitar a abertura e modularização da arquitetura monolítica do CIM e são eles que irão permitir que serviços da loS possam ser disponibilizados na Rede Colaborativa.

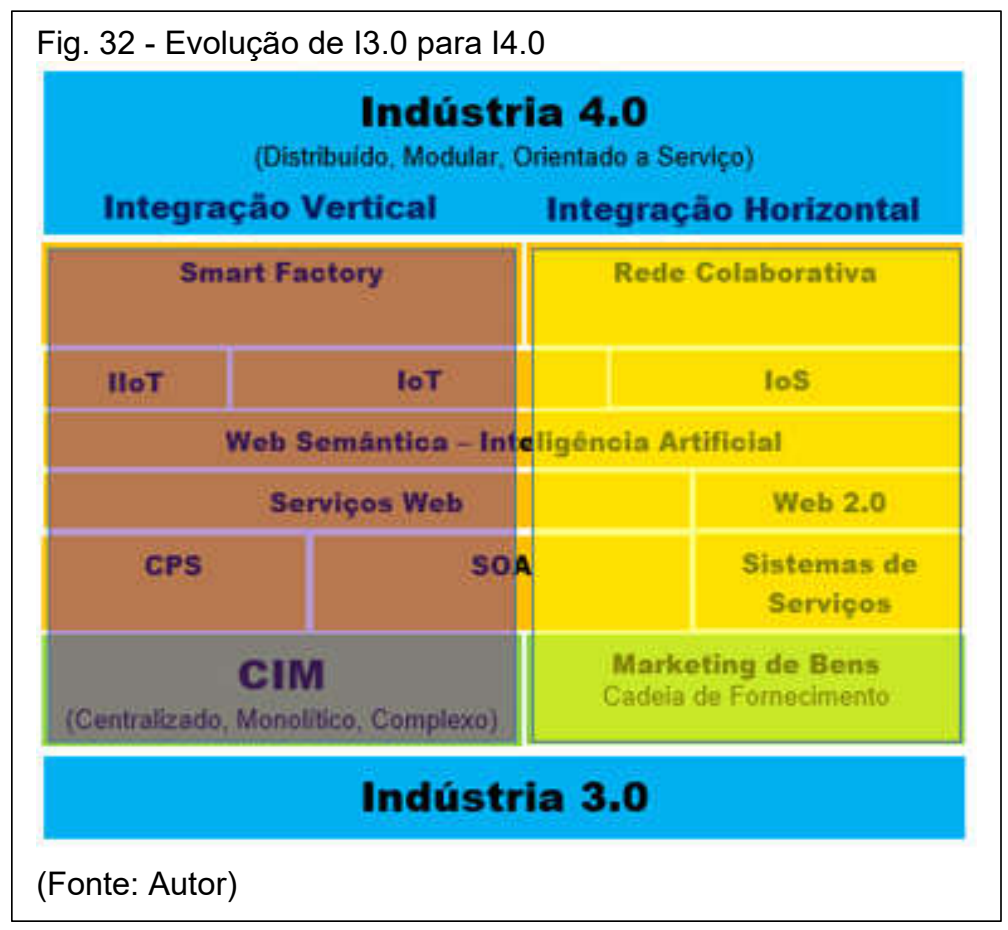

Outros temas como Big Data, Smart Analytics (LEE et al., 2013, LEE et al., 2014, CHEN, 2014) e Virtualização (BRETTEL et al., 2014) aparecem com destaque 
em Burst, mas Hermann et al. (2015) consideram que estes elementos são serviços de dados que utilizam os dados gerados pela plataforma 14.0. Na verdade, a plataforma 14.0 possibilita múltiplas possibilidades tecnológicas, que são mal interpretadas como características da 14.0. Percebe-se pela análise da evolução nas pesquisas que o paradigma de automação industrial está seguindo basicamente os paradigmas de TI de arquitetura SOA e Web Services, para trazer mais simplicidade e flexibilidade por meio de sistemas distribuídos e livremente acoplados, conectados por uma web semântica em que "coisas" são capazes de encontrar uns aos outros e se comunicar de forma autônoma (M2M). Esta plataforma permitiria que a instalação industrial fosse interoperável, reutilizável e adaptável para se tornar um EPS flexível, e é vista como solução para demandas de personalização em massa. O ambiente todo conectado em loT, permitiria uma coleta maciça de dados em tempo real e coordenação em um ambiente de produção colaborativa. Isso traria outra possibilidade relacionada à melhoria da eficiência através de Big Data e Smart Analytics. A virtualização ou a digitalização da fábrica e processos permitiriam maior agilidade nos processos de simulação, mudanças ou desenvolvimento de novos produtos. Estas são na verdade, algumas das muitas possibilidades tecnológicas habilitadas pela plataforma $\mathbf{1 4 . 0}$ conforme ilustrado na Fig. 33.

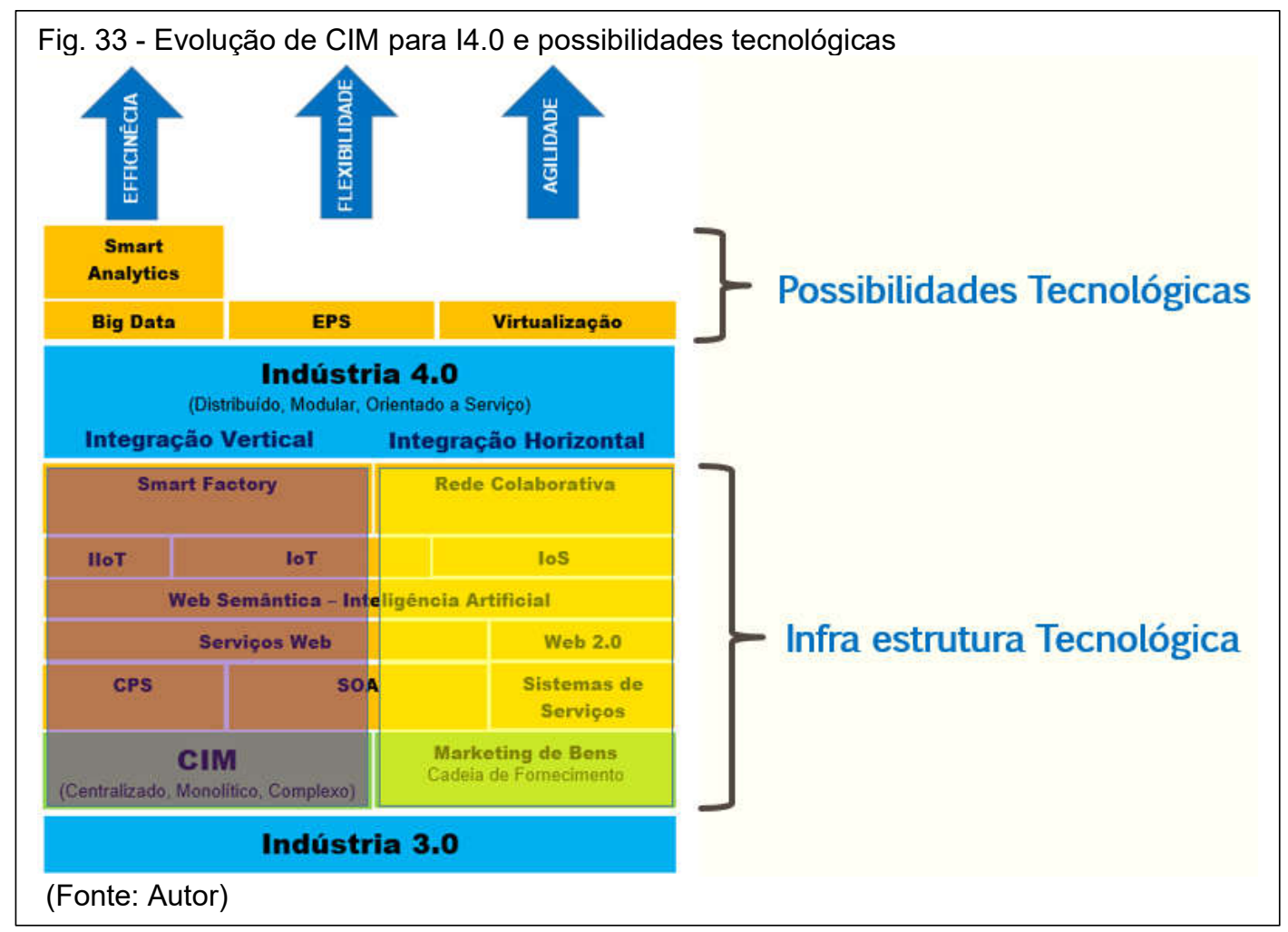


As possibilidades tecnológicas criadas sobre a plataforma 14.0, identificadas pelas literaturas destacadas no estudo bibliométrico podem ser resumidas em três categorias: eficiência, agilidade e flexibilidade. O Quadro 13 inclui outras possibilidades tecnológicas identificadas em outras literaturas e sites de internet, buscando classifica-las nestas categorias de benefícios.

\begin{tabular}{|c|c|c|}
\hline Benefícios & Possibilidades Tecnológicas & O que proporciona \\
\hline Eficiência & $\begin{array}{l}\text { Big Data } \\
\text { Smart Analytics } \\
\text { Inteligência nos Negócios } \\
\text { Controle Preditivo } \\
\text { Comunidades de Negócios } \\
\text { Comunidades Sociais } \\
\text { Data mining }\end{array}$ & $\begin{array}{l}\text { Rastreabilidade } \\
\text { Monitoramentos } \\
\text { Decisões assertivas } \\
\text { Redução de desperdícios } \\
\text { Aproveitamento melhor de recursos } \\
\text { Custos menores }\end{array}$ \\
\hline Agilidade & $\begin{array}{l}\text { Virtualização } \\
\text { Fábrica Digital } \\
\text { PLM } \\
\text { Realidade Aumentada } \\
\text { Wearables } \\
\text { BYOD } \\
\text { Engenharia Colaborativa } \\
\text { Comunidades de Negócios } \\
\text { Manufatura Aditiva }\end{array}$ & $\begin{array}{l}\text { Simulações } \\
\text { Prototipagem } \\
\text { Mobilidade aos trabalhadores } \\
\text { Tempos de desenvolvimento mais } \\
\text { curtos }\end{array}$ \\
\hline Flexibilidade & $\begin{array}{l}\text { Customização em massa } \\
\text { EPS } \\
\text { Manufatura Aditiva } \\
\text { Plug \& Produce } \\
\text { Robô autônomo } \\
\text { SW como Serviço } \\
\text { Cloud Manufacturing }\end{array}$ & $\begin{array}{l}\text { Escalabilidade } \\
\text { Adaptabilidade } \\
\text { Reusabilidade } \\
\text { Interoperabilidade } \\
\text { Individualização da produção } \\
\text { Customização em massa. }\end{array}$ \\
\hline
\end{tabular}

O entendimento deste trabalho, baseado na análise bibliográfica é que o que muda radicalmente da 13.0 para 14.0 é a quebra de paradigma da arquitetura centralizada, monolítica e complexa do CIM para adoção de uma arquitetura distribuída, modular e orientada a serviço da 14.0, que começou com Jammes \& Smit (2005). A visão desta arquitetura distribuída e modular foi possível graças à queda de preços e miniaturização de processadores cada vez mais potentes viabilizando sistemas com processadores embarcados (CPS) com conectividade em rede. Porém, para que estes sistemas possam usufruir de toda a potencialidade de comunicação, adaptabilidade e interoperabilidade são necessárias ainda a adequação a outras tecnologias de internet como Web Services e Web Semântica. Autores como Drath \& Horsh (2014) e Brettel et al. (2014) citam a introdução das tecnologias de internet como evento desencadeador da 14.0. Pela análise das literaturas 
destacadas no estudo bibliométrico, os avanços em PSIA tem como base muitos conceitos e tecnologias inicialmente destinadas a ambientes de TI. Com isto, pode-se dizer que o que se presencia agora é a extensão destas tecnologias de internet aos ambientes de TO através da loT para permitir a simplificação de sistemas complexos.

Ollinger et al. (2011) ilustram esta extensão da aplicação da SOA originalmente concebido para TI para TO e citam as diferenças entre SOA-TI e SOA-TO, conforme mostra o Quadro 14.

\begin{tabular}{|c|c|c|}
\hline \multicolumn{3}{|c|}{ Quadro 14 - SOA-TI e SOA-TO } \\
\hline & SOA-TI & SOA-TO \\
\hline $\begin{array}{l}\text { Campo de } \\
\text { aplicação }\end{array}$ & Processos de negócio & Processos Técnicos \\
\hline $\begin{array}{l}\text { Definição de } \\
\text { serviço }\end{array}$ & Encapsulamento de SW & $\begin{array}{l}\text { Encapsulamento de } \\
\text { funcionalidades } \\
\text { mecatrônicas }\end{array}$ \\
\hline Localização & $\begin{array}{l}\text { Independente de } \\
\text { localização e provedor de } \\
\text { serviço }\end{array}$ & $\begin{array}{l}\text { Dependente de localização } \\
\text { e provedor de serviço }\end{array}$ \\
\hline $\begin{array}{c}\text { Acoplamento } \\
\text { solto }\end{array}$ & $\begin{array}{l}\text { Programação modular } \\
\text { com alta coesão }\end{array}$ & $\begin{array}{c}\text { Programação modular + } \\
\text { desenho mecatrônico }\end{array}$ \\
\hline $\begin{array}{l}\text { Especificação de } \\
\text { serviço }\end{array}$ & Funcionalidade de SW & $\begin{array}{l}\text { Funcionalidade } \\
\text { mecatrônica + descrição de } \\
\text { HW + Localização }\end{array}$ \\
\hline Objetivo & Computação distribuída & $\begin{array}{l}\text { Execução de processo } \\
\text { Técnico }\end{array}$ \\
\hline \multicolumn{3}{|c|}{ (Fonte: Traduzido de Ollinger et al., 2011) } \\
\hline
\end{tabular}

Neste quadro, os autores propõem o encapsulamento das funcionalidades dos CPS como serviços, simplificando suas complexidades técnicas e representadas apenas como um agente de serviço na rede.

\subsubsection{Caracterização da Plataforma I4.0}

As diferenças de infraestrutura de fábrica entre a 13.0 e 14.0 estão baseadas em três elementos: CPS, Smart Network e Smart ERP que compõem a Smart Factory (DITTES, 2015). Porém, para uma empresa estar imersa na 14.0 não basta possuir infraestrutura de Smart Factory. É necessária também a inserção na rede colaborativa através da IoT, loS e outros CPS conectados através da Nuvem conforme ilustra a Fig. 34. 


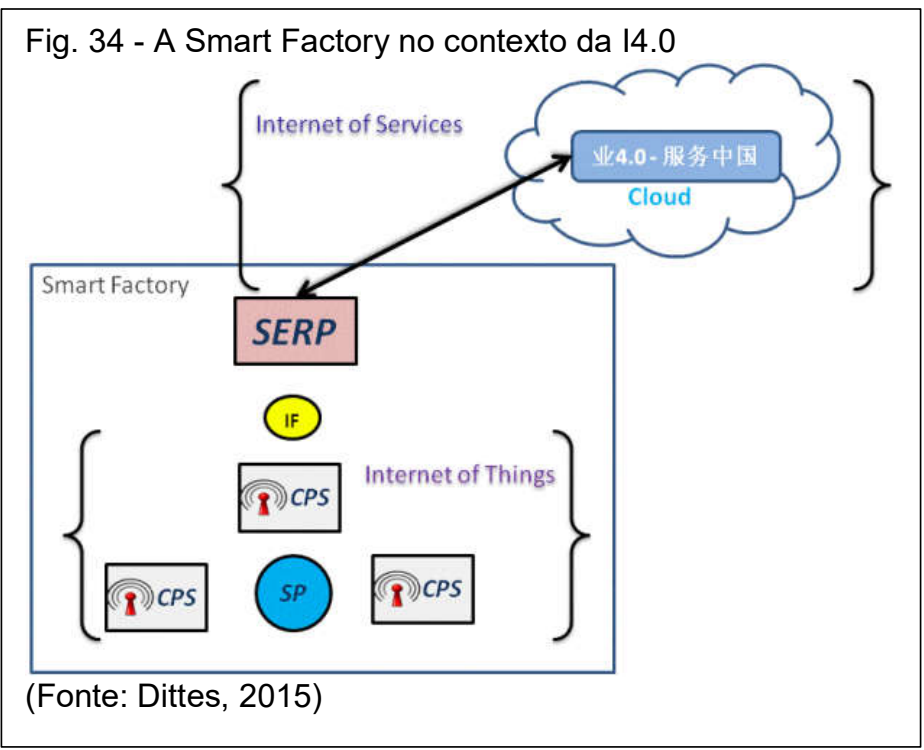

Shrouf et al. (2014) citam ainda que a ideia básica da loT são componentes físicos enriquecidos com capacidade computacional (CPS) conectadas à internet. Em outras palavras, loT baseia-se em Smart Objects e Smart Network (Web Semântica) (LASTRA \& DELAMER, 2006, WAHLSTER et al., 2014).

Hermann et al. (2015) resumem a plataforma 14.0 em quatro elementos básicos: CPS, IoT, loS e Smart Factory), porém Camarinha-Matos et al. (2013), consideram a IoT como subconjunto de CPS pois os objetos físicos com capacidade computacional embutida não precisam necessariamente estar conectados na internet, mas como na 14.0 interessam apenas os CPS conectados na loT entende-se que IoT já engloba os CPS e os quatro elementos de Hermann et al. (2015) poderiam ser resumidos em apenas três: IoT, loS e Smart Factory. Contudo, Dittes (2015) ainda define a Smart Factory como uma composição de loT e SERP (Fig. 34). Considerando que a 14.0 inclui a integração horizontal de outros atores da cadeia de valor que não praticam necessariamente funções de manufatura o elemento Smart Factory poderia ser melhor representado pela sua composição loT + SERP e os quatro elementos básicos de Hermann et al. poderiam ser representados de outra maneira por apenas três elementos: IoT, IoS e SERP.

Além destes elementos, quando os produtos são formados por Smart Objects e a infraestrutura é composta de Smart Machines tem-se um Sistema de Produção Ciberfísico - CPPS (MONOSTORI et al., 2014) que conectados por Smart Network passa a compor a IloT, que integrados verticalmente através de um software Smart 
ERP (DITTES, 2015) compõem uma Smart Factory (ZUEHLKE, 2010). A Smart Factory, que é o núcleo da 14.0, integrada horizontalmente a Smart Services através da Smart Network, compõe a rede colaborativa de valor inteligente - Smart Value Chain (COLOMBO et al., 2014; BELYH, 2015).

Para um melhor entendimento das relações entre os elementos da 14.0 descritos anteriormente tentou-se definir estes elementos através de relações deduzidas a partir das conceituações feitas anteriormente como ilustradas no Quadro 15.

\begin{tabular}{|c|c|c|}
\hline Elementos & Definição & Referência \\
\hline $\begin{array}{l}\text { Smart Object }= \\
\text { CPS }\end{array}$ & Objeto Físico $+\mu \mathrm{P}+$ Conectividade & Lee, 2008; Shrouf et al., 2014 \\
\hline Smart Network & $\begin{array}{l}\text { Internet + Tecnologia Semântica } \\
=\text { web semântica }\end{array}$ & $\begin{array}{l}\text { Lastra \& Delamer, 2006; Wahlster et } \\
\text { al., } 2014\end{array}$ \\
\hline loT & CPS + Smart Network & $\begin{array}{l}\text { Lastra \& Delamer, 2006; Atzori et al., } \\
\text { 2010, Camarinha Matos et al., } 2013 .\end{array}$ \\
\hline loS & Serviços + Smart Network & Wahlster et al., 2014 \\
\hline Smart Product & $\begin{array}{l}\text { Produto }+\mu P+\text { Conectividade } \\
\text { (Subconjunto de CPS) }\end{array}$ & $\begin{array}{l}\text { Radziwon et al., 2014; Weyer et al., } \\
\text { 2015; Weitlaner et al., 2015; Cronin; } \\
2010\end{array}$ \\
\hline Smart Machine & Máquina baseada em CPS & Weyer et al., 2015 \\
\hline CPPS & CPS aplicado à manufatura & $\begin{array}{l}\text { Monostori et al., 2014; Burmeister et } \\
\text { al., 2015, Posada et al., 2015) }\end{array}$ \\
\hline IloT & $\begin{array}{l}\text { loT Industrial = CPPS + Smart } \\
\text { Network } \\
=\text { Smart Products + Smart Machines } \\
+ \text { Smart Network }\end{array}$ & $\begin{array}{l}\text { Evans \& Annunziata, 2012; Bruner, } \\
2013\end{array}$ \\
\hline Smart ERP & ERP para Smart Factory & Dittes, 2015; Gilchrist, 2016 \\
\hline Smart Factory & $\begin{array}{l}\text { CPPS + Smart Network + Smart ERP } \\
=110 T+\text { Smart ERP }\end{array}$ & $\begin{array}{l}\text { Zuehlke, 2010; Shrouf et al., 2014; } \\
\text { Lee, 2015; Wang et al., 2015, Dittes, } \\
2015\end{array}$ \\
\hline $\begin{array}{l}\text { Cloud } \\
\text { Manufacturing }\end{array}$ & $\begin{array}{l}\text { Manufacturing Service + Smart } \\
\text { Network } \\
\text { (Subconjunto de loS) }\end{array}$ & $\begin{array}{l}\text { Xu, 2012, Wu et al., 2013, Colombo } \\
\text { \& Karnouskos, } 2013 .\end{array}$ \\
\hline $\begin{array}{l}\text { Smart Value } \\
\text { Chain }\end{array}$ & Smart Factory + loS & Belyh, 2015 \\
\hline 14.0 & $\begin{array}{l}\text { CPS+loT+loS+Smart Factory } \\
=10 T+\text { loS +SERP }\end{array}$ & Hermann et al., 2014 \\
\hline \multicolumn{3}{|l|}{ (Fonte: Autor) } \\
\hline
\end{tabular}

Esta representação permite perceber a relação de contingências destes elementos com os demais. A partir destas relações de contingências construiu-se uma representação gráfica da estrutura da plataforma Industria 4.0 conforme pode ser vista na Fig. 35, que é composta não apenas pela estrutura da Smart Factory mas também do conjunto de atores que participam da cadeia colaborativa de produção de valor. 
Estas definições permitem ainda visualizar a diferença entre loT e 14.0, bem como permite perceber que a abordagem americana de Internet Industrial (IloT) é diferente da abordagem alemã de 14.0. A 14.0 está mais focada na manufatura e inclui toda a rede colaborativa de produção através de loS e loT enquanto a IloT, tem uma abordagem focada em conectividade entre equipamentos industriais e com abrangência maior. A lloT inclui outros segmentos industriais além da manufatura tais como setor de energia, saneamento, etc. enquanto a 14.0 foca especificamente em sistemas integrados de manufatura, incluindo sistemas como Smart ERP, IoS e outros objetos conectados pela loT.

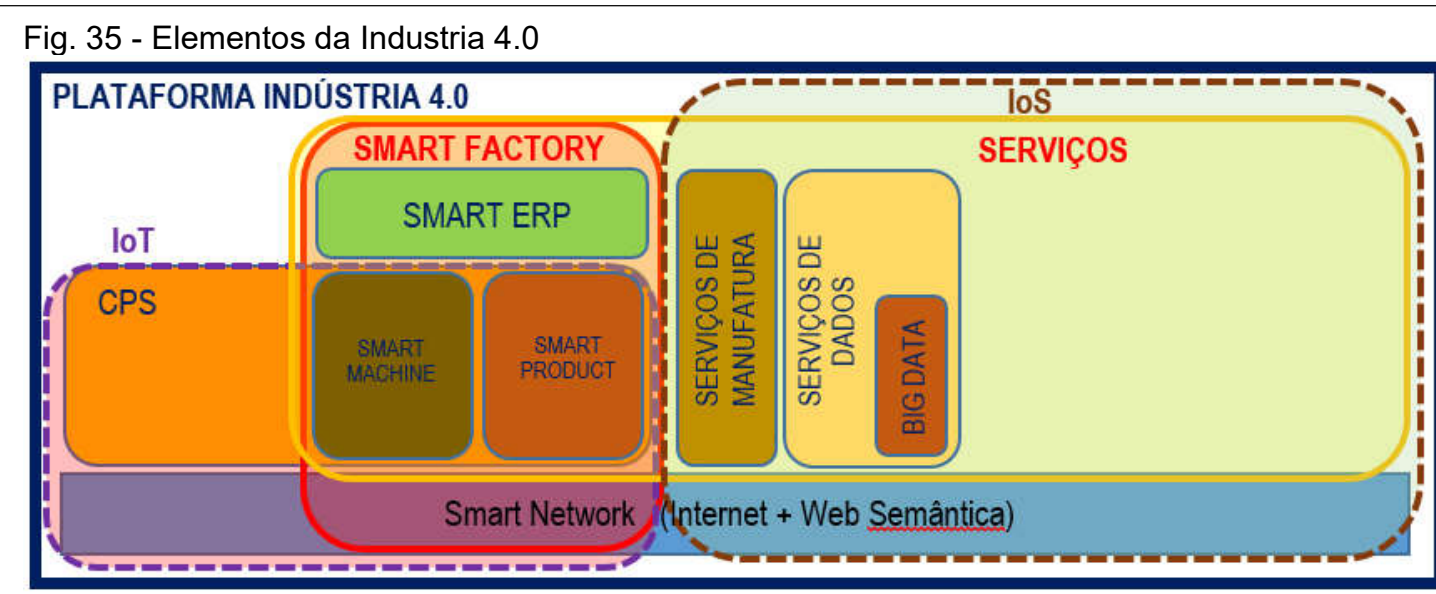

(Fonte: Autor)

A estrutura da Fig. 35 ainda pode ser simplificada para os três elementos básicos: IoT, loS e Smart ERP, baseado nos elementos básicos definidos por Hermann et al. (2015).

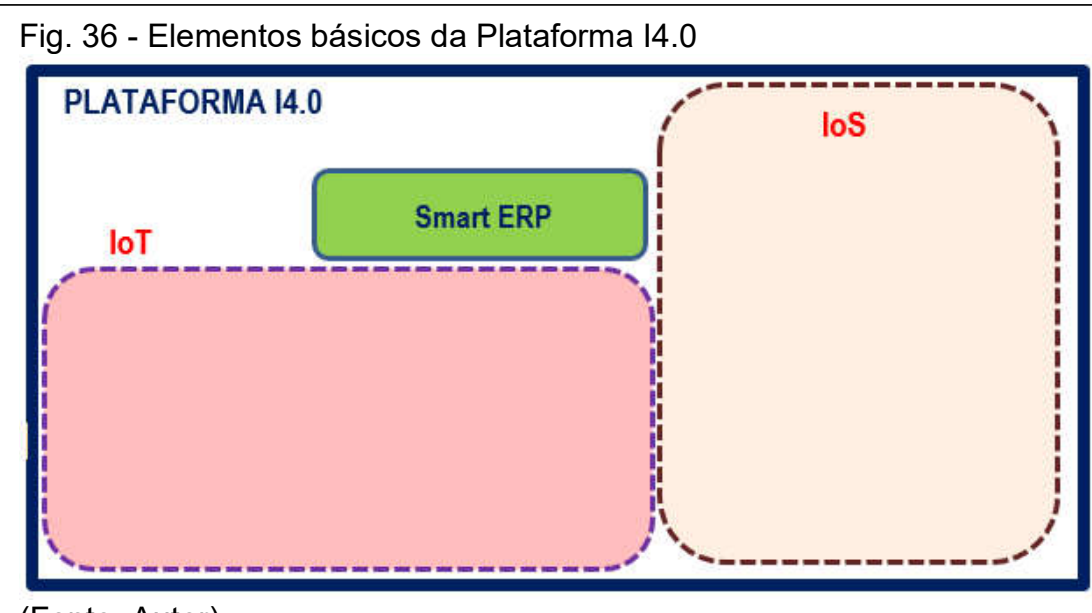

(Fonte: Autor) 
Embora a 14.0 possa ser representada como uma composição de apenas três elementos tecnológicos, a caracterização da 14.0 é baseada em dois conceitos fundamentais: SOA + Web Service Semântica conforme esclarecido na revisão bibliográfica. Isto significa que para que a plataforma 14.0 esteja implementada em toda sua potencialidade é necessário que sobre um backbone de Web Semântica (Smart Network) dispositivos e sistemas sejam implementados encapsulados como serviços (XaaS) segundo conceito de SOA ao longo de todo o caminho de integração vertical e horizontal (ou seja, entre os dispositivos físicos do chão de fábrica, entre os componentes de SW na integração vertical e entre as entidades de negócios na integração horizontal e engenharia de ponta a ponta) para que as várias perspectivas tecnológicas e benefícios possam ser vislumbradas. Com isto, a implementação da plataforma 14.0 pode ter vários graus de implementação. Como estas tecnologias e conceitos foram vislumbradas inicialmente para ambientes de TI é razoável esperar que o grau de implementação da plataforma 14.0 seja mais avançada nos níveis de negócio (TI) que nos níveis de chão de fábrica (TO).

\subsubsection{Outras Iniciativas}

Embora as iniciativas americana e alemã sejam as mais citadas na literatura, outros países também têm suas iniciativas similares (RUNKLER, 2013; PATHFINDER, 2014). Enquanto na Alemanha promove-se a 14.0, tem-se iniciativas similares nos Estados Unidos chamadas Advanced Manufacturing e Smart Manufacturing Leadership Coalition (SMLC) enquanto na China se denomina Intelligent Manufacturing, conforme pode se ver pela Fig. 37. 
Fig. 37 - 14.0 e Iniciativas Similares

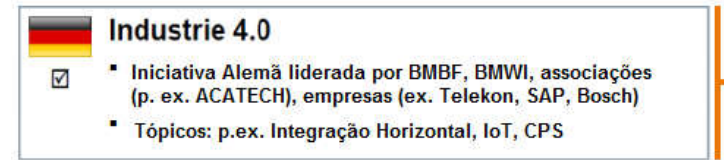

\section{Advanced manufacturing}

- Iniciativa do Governo americano, comunidades envolvendo universidades (p.ex. MIT, CMU), empresas (p.ex. General Electric, Honeywell, IBM)

- Tópicos: p.ex. Inovações em TI, novos materiais

Smart Manufacturing Leadership Coalition

- Organização sem fins lucrativos fundada em 2012. Membros: associaçōes (p.ex. MESA), fabricantes (p.ex. General Motors), fornecedores (Rockwell, Honeywell)

- Tópicos: p.ex. plataformas comunitárias para empresas com plantas virtuais

\section{Intelligent manufacturing}

- Programa Nacional liderado pelo Ministério de Ciências e

Tecnologia, lançado em 03/212.

- Tópicos: robótica industrial, planta digital, IloT

\section{Nㅏㄴ.}

(
Foco:

- Integraçäo Horizontal através de redes de valor

Engenharia ponta a ponta através de redes de valor

Integração Vertical e sistemas de produçäo em rede

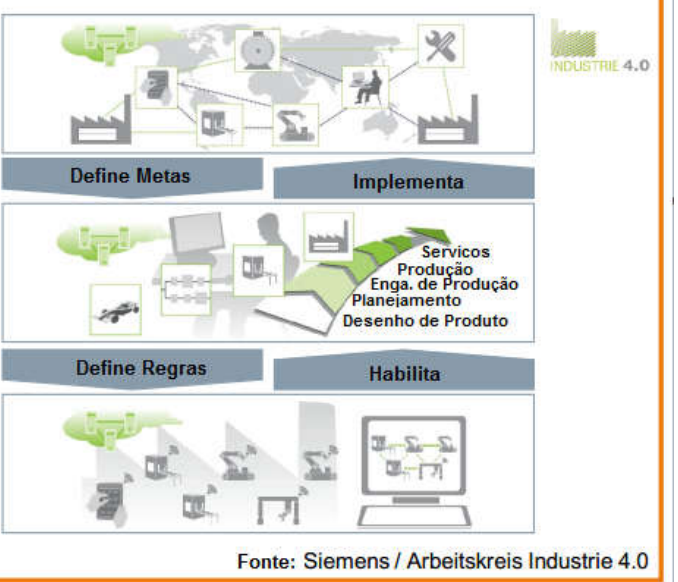

(Fonte: RUNKLER, 2013)

Pathfinder (2014) cita outras iniciativas similares nos países europeus, como ilustrados no Quadro 16. 


\begin{tabular}{|c|c|c|c|}
\hline País & Título & Link & Lançamento \\
\hline Áustria & $\begin{array}{l}\text { BMVIT (Austrian } \\
\text { Ministry for Transport, } \\
\text { Innovation and } \\
\text { Technology) Innovation: } \\
\text { Solutions for the future. }\end{array}$ & $\begin{array}{l}\text { http://www.bmvit.gv.at/en/service/publi } \\
\text { cations/downloads/bmvit_innovation_s } \\
\text { olutions.pdf }\end{array}$ & $10 / 2009$ \\
\hline Dinamarca & $\begin{array}{l}\text { Manufacturing 2025: } \\
\text { Five future scenarios for } \\
\text { Danish manufacturing } \\
\text { companies }\end{array}$ & $\begin{array}{l}\text { http://www.manufuture.dk/digitalAssets } \\
\text { /15/15567_manufacturing-2025_down } \\
\text { load.pdf }\end{array}$ & $05 / 2010$ \\
\hline Finlândia & $\begin{array}{l}\text { Finland's regional } \\
\text { development strategy } \\
2020\end{array}$ & $\begin{array}{l}\text { https://www.tem.fi/files/27807/TEM_53 } \\
\text { _2010_netti.pdf }\end{array}$ & $09 / 2010$ \\
\hline França & $\begin{array}{l}\text { France Europe 2020: } \\
\text { A strategic agenda for } \\
\text { research, technology } \\
\text { transfer } \\
\text { and innovation }\end{array}$ & $\begin{array}{l}\text { http://cache.media.enseignementsupre } \\
\text { cherche.gouv.fr/file/FranceEurope_202 } \\
\text { 0/18/3/AgendaStategique02-07-2013- } \\
\text { EnglishLight_262183.pdf }\end{array}$ & $02 / 2013$ \\
\hline Alemanha & $\begin{array}{l}\text { Recommendations for } \\
\text { implementing the } \\
\text { strategic } \\
\text { initiative INDUSTRIE } 4.0\end{array}$ & $\begin{array}{l}\text { http://www.plattformi40.de/sites/default } \\
\text { /files/Report_Industrie\%204.0_ } \\
\text { engl_1.pdf }\end{array}$ & $04 / 2013$ \\
\hline Irlanda & $\begin{array}{l}\text { Making it in Ireland: } \\
\text { Manufacturing } 2020\end{array}$ & $\begin{array}{l}\text { http://www.djei.ie/enterprise/support/Fi } \\
\text { nalForfasReport.pdf }\end{array}$ & 2012 \\
\hline Letônia & $\begin{array}{l}\text { Sustainable } \\
\text { Development } \\
\text { Strategy of Latvia until } \\
2030\end{array}$ & $\begin{array}{l}\text { http://www.cbs.nl/NR/rdonlyres/B7A58 } \\
\text { 65F-0D1B-42AE-A838-FBA4CA316 } \\
\text { 74D/0/Latvia_2010.pdf }\end{array}$ & $06 / 2010$ \\
\hline Holanda & $\begin{array}{l}\text { Global Challenges } \\
\text { Dutch } \\
\text { Solutions }\end{array}$ & $\begin{array}{l}\text { http://english.rvo.nl/sites/default/files/2 } \\
\text { 014/01/Global\%20Challenges-Dutch\% } \\
\text { 20Solutions_ENG_2.pdf }\end{array}$ & 2011 \\
\hline Holanda 2 & $\begin{array}{l}\text { Smart Industry - Dutch } \\
\text { industry fit for the future }\end{array}$ & $\begin{array}{l}\text { http://www.clicknl.nl/wpcontent/uploads } \\
\text { /2014/06/Smart-Industry-.pdf }\end{array}$ & $04 / 2014$ \\
\hline Suécia & $\begin{array}{l}\text { Swedish Production } \\
\text { Research } \\
2020\end{array}$ & $\begin{array}{l}\text { http://www.teknikforetagen.se/Docume } \\
\text { nts/FoU/Swedish_production_research } \\
\text { _2020.pdf }\end{array}$ & 2008 \\
\hline $\begin{array}{l}\text { Reino } \\
\text { Unido }\end{array}$ & $\begin{array}{l}\text { The future of } \\
\text { manufacturing: a } \\
\text { new era of opportunity } \\
\text { and } \\
\text { challenges for the UK }\end{array}$ & $\begin{array}{l}\text { http://www.ifm.eng.cam.ac.uk/uploads/ } \\
\text { Resources/Future_of_Manufacturing__ } \\
\text { Report.pdf }\end{array}$ & 2013 \\
\hline \multicolumn{4}{|c|}{ (Fonte: Pathfinder, 2014) } \\
\hline
\end{tabular}

A versão japonesa da 14.0 foi lançada em 2015 com o nome Industrial Value Chain Initiative (IVI) como contrapartida à 14.0 Alemã para conectar os negócios via Internet. Segundo Pühringer (2016) o objetivo da IVI é estabelecer uma estrutura que conecte mesmo pequenas e médias empresas além das filiais e entre setores. Pühringer (2016) acredita que embora a indústria japonesa esteja avaliando cuidadosamente os conceitos levantados pelos Estados Unidos, Alemanha e outros países sobre a "indústria conectada", que apenas os grandes players globais darão 
início à implantação real da lloT e 14.0 no Japão. E em sua opinião, isto deve acontecer no Japão através de uma abordagem pela TO com adaptação e conectividade para TI, e não o contrário, como parece mais provável nos EUA. Dressler (2016) cita que a IVI é baseada em dois princípios:

a) Manufatura Conectada, que tem o propósito de eliminar "muri" (esforço demasiado), "muda" (desperdício) e "mura" (irregularidades) através de empresas e fábricas conectadas digitalmente, criando cadeia de valor baseada em automação e habilidade humana ao mesmo tempo.

b) Padrões soltos que significa o emprego de modelos adaptáveis ao invés de sistemas inflexíveis. Padrões rígidos, como comumente se encontram hoje, enfrentam, muitas dificuldades em instalações de manufatura complexas com novos e velhos elementos. No seu lugar, padrões soltos proporcionam maneiras de conectar caso a caso. IVI trabalha no desenvolvimento de um modelo de referência para padrões soltos.

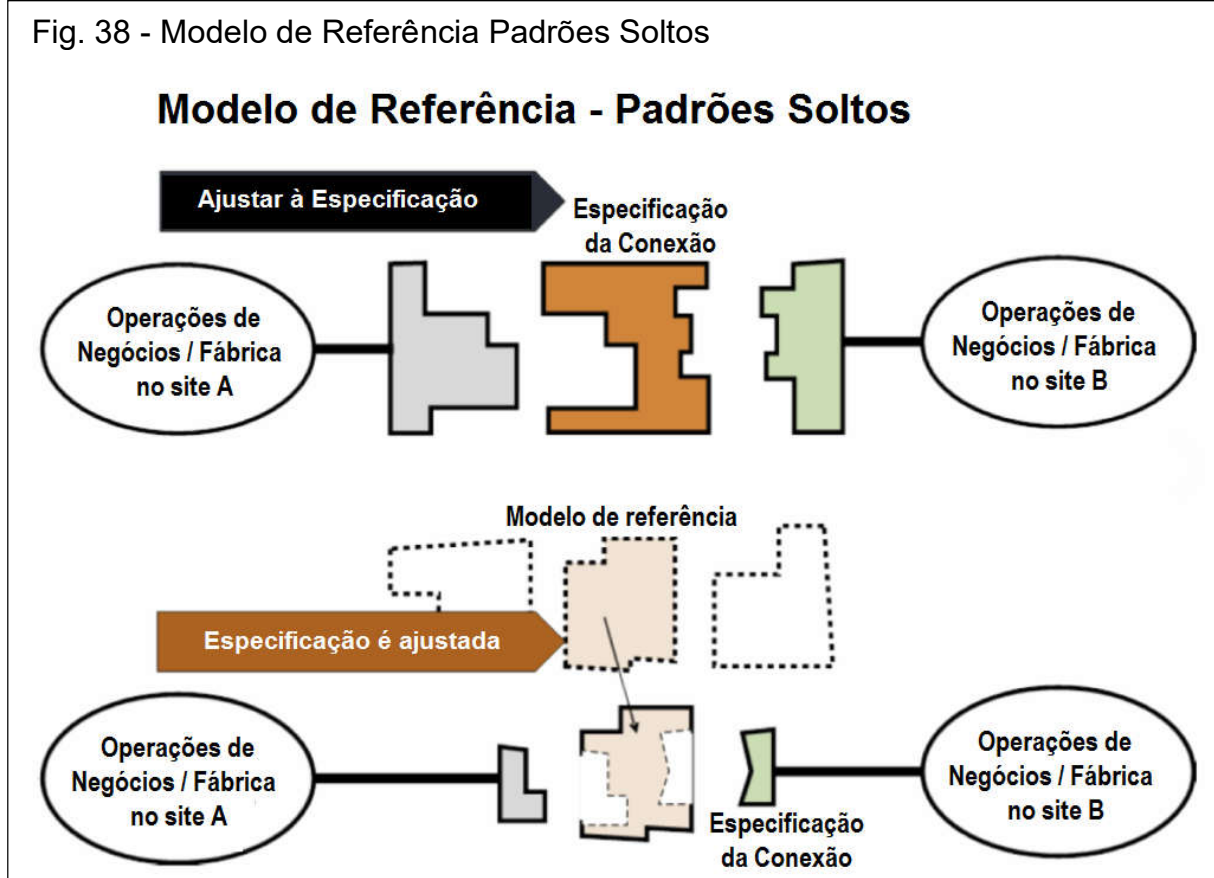

(Fonte: Dressler, 2016)

No Brasil, a iniciativa governamental até o momento, em busca de capacitação e qualificação para este novo paradigma da manufatura ainda é tímida. Com relação ao estado atual da automação da manufatura no Brasil especialistas do setor comentam:

"O consenso entre os especialistas é de que a indústria nacional ainda se encontra em grande parte na transição do que seria a Indústria 2.0 [caracterizada pela utilização de linhas de montagem e energia elétrica] para 
a Indústria 3.0 [que aplica automação através da eletrônica, robótica e programação]. Para termos uma ideia da defasagem brasileira, precisaríamos instalar cerca de 165 mil robôs industriais para nos aproximarmos da densidade robótica atual da Alemanha. No ritmo de hoje, cerca de 1,5 mil robôs instalados por ano no país, levaremos mais de 100 anos para chegar lá" (HAHN FILHO, 2015 - Revista Amanhã)

"A boa notícia é que não precisaremos passar por todo o processo de modernização fabril ocorrido nos países desenvolvidos nas últimas décadas para só então poder abraçar as tecnologias da Indústria 4.0. Podemos e devemos queimar etapas. O que não podemos é ignorar essa revolução, se quisermos preservar a indústria presente no Brasil e prepará-la para este novo panorama competitivo. Um cenário no qual as tecnologias de informação e de automação, e não a mão de obra de baixo custo, é que gerarão as vantagens competitivas para as nações com setor de manufatura relevante" (HAHN FILHO, 2015 - Revista Amanhã).

“...enquanto a nova fase industrial é realidade em modernos complexos da Europa e dos Estados Unidos, no Brasil a mudança ainda é um conceito, pouco conhecido". (DANGEL, 2015 - Diário Catarinense)

“...Pesquisa realizada em 1,5 mil empresas de diferentes setores do Rio Grande do Sul revela que a maioria das indústrias gaúchas está ainda entre a segunda e a terceira revolução industrial" (DANGEL, 2015)

"Apesar de ainda ser mais um conceito do que uma realidade, aqui no Brasil já existe um movimento significativo em investimento, porém pequeno comparado a outros países. Aqui, a grande tendência são máquinas e sensores conectados que trocam informações por meio da rede. É possível descobrir falhas e corrigi-las instantaneamente. Estas mudanças tornam a produção mais flexível, já que equipamentos e máquinas estão conectados em redes e disponibilizando informações de forma única, facilitando o controle e gestão industrial" (COELI - PHISYSTEMS, 2015)

\subsection{IMPACTOS DA I4.0 PARA OS ATORES DA CFSAM}

Embora as pesquisas e desenvolvimentos para mudanças em direção a 14.0 já venham acontecendo há algum tempo, Gartner (2015) e Rockwell Automation (2014) preveem que a manufatura irá sofrer mais mudanças radicais nos próximos cinco anos que nos últimos vinte anos. Roland Berger Consultants, (2014) descrevem um cenário de grandes mudanças para a 14.0 , em que haverá uma fábrica profundamente transformada. E haverá também novos competidores com modelos de negócio industrial radicalmente novos. Citam que tecnologias de transformação como Internet ou telefones celulares não foram bem-sucedidos apenas por serem uma tecnologia nova, mas porque eles também foram seguidos por transformações sociais, e sugerem que o mesmo deverá acontecer com a 14.0 trazendo novas funcionalidades que irão modificar as regras do jogo para os atores do setor.

De acordo com os estudos feitos pela Roland Berger Consultants (2014), três grupos de atores são identificados na 14.0 conforme Quadro 17. 
Quadro 17 - Grupos de Atores da 14.0

Grupo de Ator

CFSAM
Função

Fornece Tecnologia chave para Produção de tecnologias

Provedores de infraestrutura

Usuários industriais
Lidam com estruturas de apoio e serviços tais como computação em nuvem, armazenamento e processamento de big data

Usam tecnologias como prototipagem rápida, ou prédios de energia inteligente para otimizar seus processos produtivos

(Fonte: ROLAND BERGER CONSULTANTS, 2014)

Os consultores destacam que estes grupos de atores serão essenciais para que a 14.0 aconteça. À medida que se movem para a 14.0 as empresas serão capazes de responder mais rapidamente e flexivelmente às demandas dos clientes e mudanças rápidas nas especificações dos clientes. Observam que esta mudança é nítida em logística, por exemplo, mas que empresas de engenharia mecânica, engenharia médica e fábrica de motores também estão caminhando em direção à implantação de processos de produção inteligente e produtos customizados.

Analisando-se estes três grupos de atores percebe-se que estes são na realidade os atores da CFSAM, dos quais os dois primeiros são os fornecedores dos Sistemas de Automação da Manufatura e o último é o consumidor final que também faz parte da cadeia.

\subsubsection{Benefícios Pretendidos pela I4.0}

De acordo com a revisão bibliográfica identificaram-se três categorias de benefícios almejados com a implementação da plataforma 14.0 conforme Quadro 13 apresentado no item 2.4.16.

a) Eficiência

b) Agilidade

c) Flexibilidade

\subsubsection{Aumento da Eficiência}


Aumento da Eficiencia Gernecial: A 14.0 através de CPS que integra vários sensores, permite a coleta farta de dados da produção que por sua vez, auxilia na melhoria da eficiência e confiabilidade. Tecnologias e algoritmos correspondentes a cada camada hierárquica a arquitetura organizacional colaboram com a estrutura unificada e percebem as funcionalidades desejadas do sistema global para melhorar a eficiência do equipamento, a confiabilidade e a qualidade do produto (LEE et al., 2015).

A eficiência gerencial está ligada à integração vertical que permite que dados coletados dos sistemas CPS sejam transferidos para os sistemas corporativos apoiando a tomada de decisão gerencial e a Manufatura Flexível e reconfigurável (WANG et al., 2015).

Aumento da Eficiência Produtiva: Schuh et al. (2014) apresentam uma pesquisa para identificar os mecanismos que contribuem para aumentar a produtividade no contexto revolucionário da 14.0 e apontam que a produtividade colaborativa pode ser eventualmente, a maior fonte de aumento da produtividade na 14.0. O significado de colaboração para estes autores vai além da colaboração homem-homem abrangendo a colaboração homem-máquina e máquina-máquina. Destaca ainda que a base para aumento da produtividade é a melhoria da habilidade para tomada de decisões. Os autores propõem a criação de quatro precondições necessárias para o sistema de produção aos quais denomina de habilitadores para a produtividade colaborativa conforme ilustra a Fig. 39.

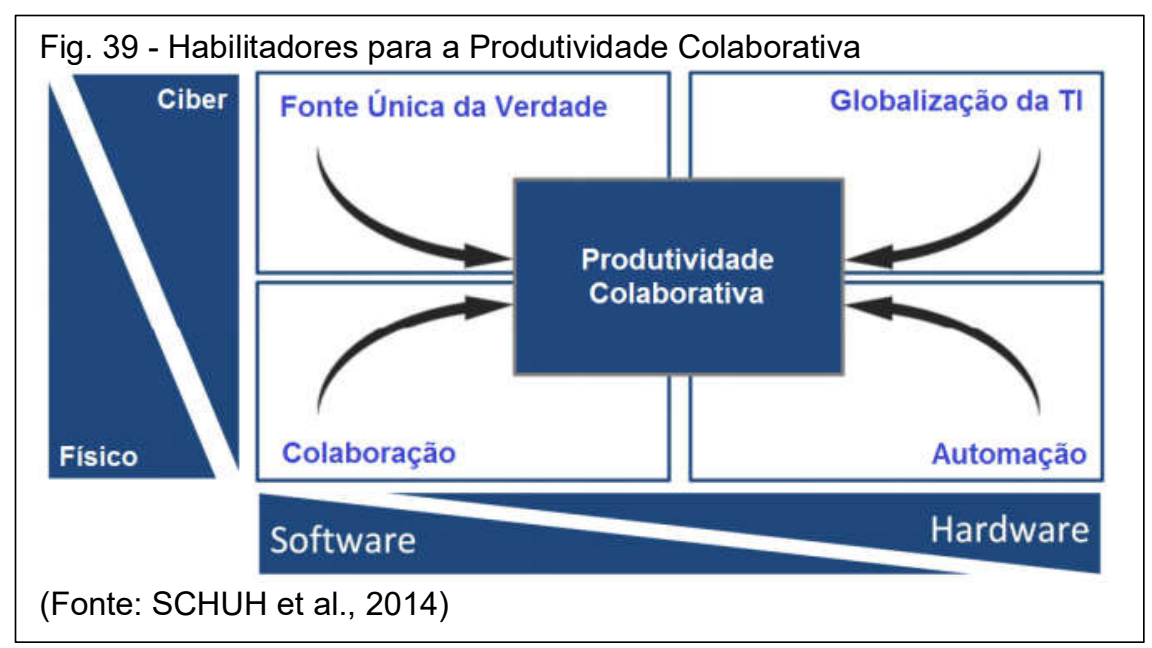

\subsubsection{Agilidade}


De acordo com Erl (2004) a orientação a serviço em empresas estabelece um novo ambiente que pode responder aos requisitos de negócio com agilidade sem precedente (ERL, 2004 p.476). Cândido et al. (2011) citam também que Sistemas de Produção Evolutivos (EPS) baseado em infraestrutura SOA, têm por objetivo melhorar a eficiência e agilidade na manufatura. Assim, é de se esperar que a 14.0 que tem em SOA a sua principal característica disruptiva, proporcione também agilidade na manufatura.

Brettel et al. (2014) explicam que a organização em redes colaborativas multiplica a capacidade produtiva disponível sem a necessidade de novos investimentos e permitem que as empresas participantes possam se adaptar com maior agilidade a mercados voláteis e produtos com ciclos de vida mais curtos.

Outra possibilidade tecnológica que a plataforma 14.0 possibilita através de sua rede colaborativa é a Integração da Engenharia Ponta a Ponta (BRETTEL et al., 2014; WANG et al., 2015) em processos de desenvolvimento e customização de produtos. Esta possibilidade é vista também como uma forma de reduzir os tempos de lançamento de novos produtos e consequentemente de auferir agilidade a estes processos.

A Virtualização (BRETTEL et al., 2014) também identificada como outra possibilidade tecnológica sobre a plataforma 14.0 também tem como objetivo proporcionar maior agilidade através de processos de simulação e redução de custos de desenvolvimento. Ainda pode-se citar as técnicas de visualização avançada de dados sensíveis ao contexto através da realidade virtual (também chamado de Realidade Aumentada) também como uma possibilidade tecnológica sobre a plataforma 14.0 que pode proporcionar agilidade em processos de manutenção, treinamentos, estudos de ergonomia, etc.

Enfim, são várias as possibilidades tecnológicas vislumbradas através da implantação da plataforma 14.0 no sentido de auferir maior agilidade aos processos industriais e de negócio.

\subsubsection{Flexibilidade na Manufatura}


Um dos maiores benefícios que é reivindicado pelo conceito 14.0 é a flexibilização da manufatura sem perder a lucratividade. Significa que será permitida a manufatura de pequenos lotes, com alta customização bem como a escalabilidade dos recursos de produção. A 14.0 espera que subsistemas hierárquicos sejam integrados verticalmente, para transformar a fábrica tradicional no sistema de produção altamente flexível e reconfigurável, que significa implementar a fábrica inteligente. Isto é essencial para apoiar pequenos lotes e demandas personalizadas de consumo (WANG et al., 2015).

No cenário de alta conectividade em que a tecnologia sem fio permite fácil conectividade além de escalabilidade, Islam et al. (2012) abordam a utilização dos recursos de rede de sensores sem fio (Wireless Sensor Network - WSN) aplicados em larga escala em um ambiente de virtualização de sensor. Apresentam desafios e oportunidades de pesquisa no campo de virtualização da rede de sensores, bem como ilustram o estado atual da pesquisa neste domínio.

Outro aspecto é a necessidade de equipamentos e instalações que sejam cada vez mais flexíveis e escaláveis. Arumugam et al. (2013), citam a robótica sem fio como uma das áreas emergentes no setor de automação e abordam em seu estudo oportunidades, desafios de pesquisa e problemas de padronização em robótica sem fio, com foco nos aspectos de rede e wireless.

A Manufatura Colaborativa é suportada pela integração horizontal, permitindo a formação de um ecossistema eficiente de empresas (WANG et al., 2015). Desta forma a eficiência produtiva está mais ligada à integração horizontal entre as empresas.

Através da conectividade em rede e pela internet, a 14.0 traz também a possibilidade de uma integração maior entre empresas participantes da cadeia de valor, num conceito mais colaborativo de produção. A manufatura colaborativa está mais ligada à integração horizontal entre as empresas que compõem a cadeia de valor na rede colaborativa (WANG et al., 2015)

À medida que a profundidade de valor agregado dentro de uma fábrica e empresa geralmente diminui, enquanto aumenta a complexidade dos produtos e processos, a Manufatura Colaborativa e Ambientes Colaborativos de Desenvolvimento ganham importância especialmente para as pequenas e médias 
empresas (PMEs) com recursos limitados. Dentro de uma rede colaborativa, os riscos podem ser balanceados e recursos combinados podem aumentar o leque de oportunidades de mercado. A organização em redes multiplica a capacidade disponível, sem a necessidade de novos investimentos. Por isso, as empresas em redes colaborativas podem se adaptar a mercados voláteis e encurtamentos de ciclos de vida dos produtos com grande agilidade (BRETTEL et al., 2014).

\subsubsection{Outros Impactos para os atores da CFSAM}

Além dos benefícios hipotéticos pela adoção da plataforma 14.0 previstos na literatura, existem ainda outros impactos colaterais. Os impactos mais citados na literatura são comentados a seguir.

\subsubsection{Emergência das PMEs}

MacDougall (2014) comenta que do ponto de vista da economia global, as PMEs em especial são responsáveis por uma parte significativa da criação de emprego e de valor na Alemanha e, como tal, são de importância central para a estrutura econômica. Lembra ainda que a 14.0 também é de extrema relevância para as PMEs, pois a próxima revolução industrial será caracterizada pela conectividade em rede e a internet. As cadeias de valor tornam-se em redes de valor. Como consequência da 14.0 , as tecnologias de informação, de automação e de produção serão mais interligados do que nunca. MacDougall (2014), cita ainda que segundo a SAP, com a 14.0 as cadeias de fornecimento irão evoluir para redes altamente adaptáveis. Dentro deste contexto, as PMEs desempenham um papel importante em tais redes de valor agregado. Ao integrar os conceitos e tecnologias da 14.0, elas poderão fornecer produtos e serviços individualizados e serão altamente adaptáveis para mudanças.

Segundo a Festo (2015), para operar na plataforma 14.0 a agilidade na manufatura é um ponto chave e cita que plantas de produção grandes e centralizadas estão se tornando dinossauros. Defende que as fábricas do futuro serão pequenas, flexíveis, móveis e locais (uma das ironias da globalização é que no final elas retornarão para produção local). Este conceito está alinhado com a ideia principal da 
mudança para o paradigma 14.0, em que as grandes estruturas monolíticas e centralizadas dão lugar a estruturas distribuídas, com elementos menores, proporcionando funcionalidades modulares com maior agilidade. Este princípio é aplicável ao longo de toda a cadeia de integração da 14.0, desde instalações físicas do chão de fábrica aos sistemas de SW e entidades que compõem a cadeia de valor.

Brettel et al. (2014) citam que as PMEs com recursos limitados ganham valor principalmente nas redes colaborativas de manufatura e ambientes de desenvolvimento onde os riscos podem ser balanceados e recursos combinados podem expandir a percepção de oportunidades no mercado.

Rifkin (2012) argumenta que a terceira revolução industrial (TIR) está democratizando a produção, e permitirá que na nova era, todo mundo poderá, potencialmente, ser o seu próprio fabricante, bem como a sua própria empresa de site de internet e energia através do processo de impressão 3D. Argumenta ainda que a democratização da manufatura está sendo acompanhado pela queda nos custos de marketing. Devido à natureza centralizada das tecnologias de comunicação da primeira e segunda revolução industrial (jornais, revistas, rádio e de televisão) os custos de Marketing Industrial eram elevados na época e favoreciam empresas gigantes que podiam dedicar fundos substanciais para comercializar os seus produtos e serviços. A internet transformou o marketing de um patamar de custo substancial para um custo insignificante, permitindo que novas, PMEs pudessem comercializar seus produtos e serviços em sites da internet ao longo do espaço virtual, permitindoIhes competir mesmo com empresas gigantes de negócios do século 21. Com isto Rifkin (2012) sugere que empresas de pequeno e médio porte têm as mesmas oportunidades, que as gigantes de negócios tradicionais. O crescimento lateral da Terceira Revolução Industrial permite que as pequenas e médias empresas floresçam. Porém, isto não significa que as empresas globais estão desaparecendo, em vez disso, eles estão se transformando, cada vez mais, de produtores primários e distribuidores para agregadores. Na nova era econômica, o seu papel será o de coordenar e gerir as várias redes que movem o comércio e o negócio ao longo de toda a cadeia de valor.

La Regina (2015), na pesquisa realizada sobre os desafios comuns entre Europa e Japão para a digitalização da economia, aponta que indústrias no setor de manufatura, a maioria nas mãos de PMEs que tanto na Europa como no Japão 
ocupam grande espaço nas respectivas economias, são obsoletas e ineficientes na maioria dos processos de controle e produção. Estas indústrias poderiam ser melhoradas com a adoção de modelos de manufatura inteligente habilitado pelas tecnologias de Informação e Comunicação, porém as soluções disponíveis de grande escala não são compatíveis com as necessidades de investimento e customizações devido à grande variedade de empresas e suas especializações.

Radziwon et al., (2014) discutem os desafios (tais como custo de aquisição e manutenção destes sistemas) para as potenciais aplicações da Smart Factory em empresas PMEs e cita que uma das lacunas na literatura sobre Smart Factories é a falta de conceitos aplicáveis a PMEs. Os autores, argumentam ainda que inicialmente as soluções discutidas focavam sistemas para grandes empresas de manufatura fornecidos por grandes empresas de automação. Porém, baseados em sua pesquisa exploratória conduzida na Dinamarca, concluem que mesmo com o vasto conhecimento, experiência e habilidades que detém estas grandes empresas de automação, há necessidade de um profundo conhecimento sobre os problemas, necessidades e capacidades das PMEs, principalmente de "custo percebido" pelas PMEs que seria maior que para as grandes empresas devido à desproporcionalidade entre elas conforme explica Westhead \& Storey (1996). Portanto, seria mais apropriado que tais soluções para as PME's fossem desenvolvidas também por PMEs para não haver esta desproporcionalidade entre as partes. Além disso a democratização da manufatura citada por Rifkin (2012) bem como a simplificação para arquitetura SOA deverão permitir a implantação destes sistemas mais customizáveis e com menor custo, tornando mais acessíveis para as PMEs.

\subsubsection{Novas demandas de Qualificação Profissional}

Festo Didactic (2015) entende que para a implantação de uma plataforma 14.0 em uma empresa, o treinamento e as qualificações dos trabalhadores devem ser adaptados de acordo com os novos requisitos de uma abordagem interdisciplinar. Por exemplo, manutencionistas precisam não apenas de experiência em mecatrônica, mas também em infraestrutura de TI de forma que eles possam recolocar as máquinas em funcionamento o mais rápido possível. Como as tarefas dos trabalhadores na 14.0 se tornarão mais exigentes tanto em termos organizacionais como tecnológicos, 
competências interdisciplinares se tornarão cada vez mais importantes e, portanto, haverá necessidade de adaptar as habilidades de vários ofícios. Ainda segundo Festo Didactic (2015), à medida que os limites entre os diferentes níveis funcionais se tornam cada vez mais fluidos, a necessidade de adaptação afeta todas as profissões técnicas.

Para avaliar o impacto das mudanças sobre as qualificações e habilidades necessárias aos trabalhadores operários da fábrica do futuro (atores do grupo de usuários industriais), um esforço conjunto entre VDI (Associação de Engenheiros Alemã) e a ASME (American Society of Mechanical Engineers) discutiram o impacto da inovação industrial 14.0 sobre o papel destes trabalhadores (VDI \& ASME, 2015). O estudo foi feito baseado em três níveis de cenários futuros:

- Primeiro nível de ferramentas, tecnologias, organização, estrutura e ambiente de trabalho;

- Segundo nível de tarefas a serem executadas sobre este contexto e

- Terceiro nível de qualificações e habilidades necessárias para executar tais tarefas.

A conclusão a que chegaram é que embora sejam necessárias novas habilidades, os conhecimentos básicos como conhecimento em materiais e processamento de metais continuarão a ser necessários. As qualificações complementares previstas neste estudo basicamente são habilidades e conhecimentos relacionados à TI, estatística e interação com IHM modernas, que não chega a ser nenhuma surpresa radical.

Contudo, quando se trata de profissionais no grupo de integradores de sistemas (atores do grupo de fornecedores de tecnologia e do grupo de fornecedores de infraestrutura), Knowles-Hall \& Van der Veer (2014) argumentam que há uma grande brecha entre a qualificação de engenheiros de integração de sistemas atuais e o que será necessário no futuro. A fusão de TI com TO significa que enquanto os engenheiros de integração de sistemas estão atualmente focados primeiramente em automação, eles precisarão conduzir seus clientes para a Fábrica Inteligente com conhecimento e habilidades crescentes não somente em automação, mas também em TI, redes Ethernet e Segurança Cibernética. Empresas de Manufatura irão buscar empresas com solução tecnológica e seus parceiros de integração de sistemas para obter conselhos sobre como aproveitar novas oportunidades para construir a Fábrica 
Inteligente 14.0. Alertam ainda que de acordo com o relatório da 14.0 novos métodos serão precisos para melhorar a capacidade de atender as necessidades individualizadas dos clientes; para a introdução de processos dinâmicos de negócios e engenharia, e para satisfazer as demandas por maior eficiência e produtividade. Engenheiros de integração de sistemas que trabalham na indústria precisarão mudar a maneira de executar projetos. A fusão de TI com TO significa que enquanto os engenheiros de integração de sistemas estão atualmente focados primeiramente em automação, eles precisarão conduzir seus clientes para a Fábrica Inteligente com compreensão e habilidades crescentes não somente em automação, mas também em TI, Ethernet e Segurança Cibernética.

Empresas de Manufatura irão buscar empresas com solução tecnológica e seus parceiros de integração de sistemas para obter conselhos sobre como aproveitar novas oportunidades para construir a Fábrica Inteligente 14.0. No contexto de convergência de TI e TO, a rede baseada em Ethernet é essencial. Engenheiros de automação, portanto, precisam expandir seus conhecimentos, e se tornar especialistas em fornecimento e instalação desse tipo de rede para atender às demandas dos clientes industriais. A abertura fornecida pela conectividade da rede Ethernet aumenta a necessidade de engenheiros de automação de dominar também as questões relativas à segurança cibernética e como lidar com ameaças através de tecnologias avançadas. Segurança cibernética é parte integrante de convergência entre TI e TO, mas não deve ser considerada apenas como mera adição no topo da implantação do projeto, mas como parte essencial do projeto inicial. Enquanto a conectividade já é uma característica presumida na indústria, a segurança do sistema precisa ser inerente, e os engenheiros de integração devem conduzir seus clientes a Fábricas Inteligentes seguras através de habilidades e conhecimentos avançados nesta área (KNOWLES-HALL \& VAN DER VEER, 2014).

Os autores destacam ainda que o Desenvolvimento Profissional Contínuo (Continuous Professional Development - CPD) é um dos 8 fatores chave de sucesso delineados pelo Working Group Industrie 4.0. O CPD aborda a exigência de planos específicos e dedicados em matéria de formação e educação continuada durante toda a carreira dos profissionais. Como as funções existentes irão mudar radicalmente e novos papéis serão necessários, fornecedores de tecnologia, parceiros e usuários precisarão adotar uma abordagem de aprendizado contínuo ao logo da vida. CPD é a 
maneira de fazer com que os profissionais mantenham e melhorem seus conhecimentos e habilidades ao longo de suas carreiras. No novo mundo convergente de TI e TO não mais será suficiente que o profissional simplesmente tenha completado um curso de graduação e tenha uma experiência prática em uma empresa. Será necessário que o profissional se mantenha engajado em projetos de educação e crescimento profissional continuado. O CPD é um elemento-chave na força de trabalho de hoje e irá certamente aumentar em importância no futuro próximo.

Opinião contrária é da B\&R Automation (2015) que argumenta que ao mesmo tempo que a 14.0 trará maior complexidade, novas tecnologias poderão simplificar seu uso de forma semelhante como aconteceu na operação de PC's, máquinas copiadoras, dispositivos móveis, etc.

\subsubsection{Redução de Offshoring da Produção}

Offshoring é um termo utilizado para se referir ao deslocamento de várias operações de uma empresa para outro país por razões tais como custos trabalhistas mais baixos ou condições econômicas mais favoráveis nesse outro país (http://www.businessdictionary.com/definition /offshoring.html).

O aumento do offshoring e o crescimento das cadeias de abastecimento sofisticadas permitiram que as empresas de todo o mundo utilizassem países como a China, Índia e outros de baixos salários para a execução da manufatura. Contudo, diante da crise financeira global, alguns países estão traçando estratégias para trazer a manufatura de volta, a fim de criar postos de trabalho e impedir que mais habilidades de manufatura sejam exportadas (THE ECONOMIST, 2013). Sugerem ainda, que a manufatura digital poderá trazer alguns empregos de volta aos países com custo de mão-de-obra mais altos, à medida que a automação da manufatura tende a reduzir a necessidade de pessoas no chão de fábrica. A digitalização da manufatura através da ampla conectividade permitirá fabricar produtos em menor escala, com maior flexibilidade e com menos mão de obra, ao que Rifkin (2012) chama de "democratização da manufatura".

MacDougall (2014) cita que segundo a SAP, para países altamente industrializados como Alemanha, a 14.0 é uma grande oportunidade para manter empregos industriais no país e garantir o crescimento e força inovadora a longo prazo. 
Salienta que muitos fabricantes alemães são altamente especializados e muitas vezes, líderes mundiais em sua área. Com a 14.0, estes fabricantes poderão aumentar ainda mais a sua vantagem competitiva, tornando-se mais eficientes e sensíveis às mudanças do mercado com a introdução de novas ofertas de serviços com base em dados mais ricos de produtos e máquinas inteligentes. Esta visão concorda com a opinião da Festo (2015) de que a globalização no final retornará para a produção local.

\subsubsection{Maior Risco Cibernético para o Ambiente Industrial}

Com a abertura dos sistemas industriais através da conectividade proporcionada pela loT, dos CPS, a segurança é um ponto indispensável para a implementação do conceito 14.0 (Lee, 2014). De acordo com a survey realizada pela Rockwell Automation (2015 - Manufacturing Connectivity and Data Integration) a segurança é considerada a segunda maior barreira para a introdução de máquinas conectadas pela internet, atrás apenas do seu custo para a implantação. Embora alguns fornecedores (Rockwell Automation, 2015; Oracle, 2015) argumentem que possuem soluções para prevenir ataques cibernéticos aos equipamentos industriais, TÜV Rheinland (2015) não apenas ressalta a importância da segurança, mas afirma que é uma questão ainda não resolvida para a implementação da 14.0. Exemplo de ataque cibernético a sistemas industriais como o Stuxnet em meados de 2010 (KARNOUSKOS, 2011), Night Dragon e Duqu (BYRES \& CUSIMANO, 2012) reforçam ainda mais a preocupação com a segurança cibernética.

Os dispositivos sem fio, em especial a rede de sensores wireless e dispositivos móveis para operação do sistema servindo de IHM entre máquina e usuários, facilitam a escalabilidade através da expansão ou redução de funcionalidades no sistema. 0 emprego de dispositivos sem fio ainda incrementa a flexibilidade do sistema reduzindo o tempo necessário para implementação de infraestruturas. Por outro lado, cria-se vulnerabilidades para ataques cibernéticos. Ainda segundo Wang et al. (2015), as Smart Factories sofrem de problemas de segurança cibernética bem maiores que as aplicações tradicionais de internet.

Por estas razões a Cibersegurança é uma necessidade extremamente relevante, emergente e uma questão ainda não resolvida (ou pelo menos discutível 
na sua eficácia) e, portanto, representa também uma área que demanda reação por parte dos atores da CFSAM.

\subsubsection{Maior Oferta de Produto como Serviço}

A 14.0 é baseada em quatro elementos segundo Hermann et al. (2015), dos quais a loS é uma delas. Desta forma, claramente disponibilização de produtos como serviços (Servitização) através de recursos virtuais é uma das tendências previstas na 14.0. Servitização é um termo cunhado por Vandermerwe \& Rada (1988) e é definido como uma estratégia competitiva em que os fabricantes buscam diferenciação através da agregação de serviços aos produtos. Os termos "Servitização" e "Servicização" são utilizados indistintamente por vários autores (BAINES \& LIGHTFOOT, 2013).

A Cloud Manufacturing também é uma forma de prestação de serviços através de recursos disponibilizadas na nuvem na forma de Infraestrutura como Serviço (laaS), Plataforma como Serviço (PaaS) e SW como Serviço (SaaS) (WANG et al., 2015).

Xu (2012) cita que a computação em nuvem está mudando a forma como as empresas fazem negócios através da disponibilização de recursos virtualizados de forma dinamicamente escalável. A computação em nuvem também está emergindo como um dos grandes habilitadores para a indústria de manufatura. Ele é capaz de transformar o modelo de manufatura tradicional através da criação de uma rede inteligente de fábrica encorajando a colaboração. Segundo o autor, a manufatura ainda pode utilizar a computação em nuvem de duas maneiras. Através da adoção direta das tecnologias da computação em nuvem, utilizando-se de serviços da nuvem ou através da Cloud Manufacturing - uma versão de manufatura da computação em nuvem. Na Cloud Manufacturing, os recursos distribuídos de manufatura estão encapsulados como serviços de nuvem, que vão desde desenho de produto, manufatura, testes e demais fases do ciclo de vida dos produtos, os quais podem ser requisitados pelo usuário da nuvem.

YEN et al. (2014) citam seis benefícios e desafios fundamentais da Cloud Manufacturing: 
- Redução de ociosidade e aumento da utilização de recursos.

- Redução de investimento inicial principalmente para empresas PMEs

- Proporciona redução de infraestrutura e custos administrativos; economia de energia e redução de custos de atualização e manutenção.

- Facilita a vida das empresas de manufatura, quer pequenas ou grandes, permitindo dimensionar a sua produção e negócios de acordo com a demanda.

- Pode gerar novos tipos e classes de modelo ou processo de negócio não previsto anteriormente.

- Pode otimizar a distribuição industrial e promover a divisão especializada da manufatura pois o usuário da Cloud Manufacturing não precisa arcar com o ciclo de vida completo da manufatura.

Da mesma forma Deloitte Consulting (2015) cita que a Cloud Manufacturing é uma das possibilidades de expandir a loS, utilizando-se recursos disponíveis na nuvem, proporcionando escalabilidade e fazendo uso eficiente do grande volume de dados gerados (Big Data). A utilização de serviços na nuvem permite que aplicativos baseados na nuvem ofereça acesso universal a qualquer hora a dados fundamentais. Isto simplifica a coleta de dados, o monitoramento, distribuição e análise de dados, não somente entre fábricas, mas ao longo de toda a cadeia de valor.

Com a tecnologia de impressão 3D (Manufatura Aditiva), a disponibilização de produtos como serviços, através de meios digitais também poderão ser favorecidos e representam uma oportunidade para oferecer novos produtos como serviços através da web (THE ECONOMIST, 2013)

\subsection{TRABALHOS SIMILARES}

Um dos trabalhos mais relevantes com relação ao novo cenário e às novas oportunidades é a pesquisa feita pela Platform Industrie 4.0 (2014) - Neue Chancen für Unsere Produktion que apresenta 17 teses elaboradas pelo Comité Científico da Platform Industrie 4.0, conforme citadas no Quadro 18.

Este trabalho elaborado pela Academia Alemã de Ciência e Tecnologia descreve um panorama decorrente da implementação do conceito 14.0 nas indústrias alemãs através das 17 teses que ilustram o cenário de oportunidades sob perspectiva de pessoas, tecnologias e organizações. 
Quadro 18 - 17 Teses da Working Group Industrie 4.0

Novas Oportunidades para a Produção na 14.0 - 17 Teses

Pessoas

1 Serão criadas variadas possibilidades de forma humanizada da organização de trabalho, também no sentido de auto-organização e autonomia. Principalmente abrem-se possibilidades para uma formação de trabalho personalizada, adequada ao envelhecimento e à idade.

2 A 14.0, como sistema técnico-social, oferece aos colaboradores oportunidades de ampliar o espectro de suas atribuições, aumentar suas qualificações e amplitude de atuação e melhorar nitidamente o seu acesso ao conhecimento

3 Meios de trabalho de incentivo ao estudo (learn instruments) e formas de trabalho comunicativos propiciam a melhoria da produtividade do ensino e do aprendizado. São criados novos conteúdos de treinamento com crescimento de um alto teor de habilidades em TI.

4 Testemunhos de aprendizagem - artefatos utilizáveis e que promovem o aprendizado demonstram, automaticamente, a sua funcionalidade ao usuário

\section{Tecnologia}

5 Sistemas 4.0 industriais são assimilados facilmente pelo usuário, operados intuitivamente, são indutores ao aprendizado e reagem confiavelmente.

6 Esquemas de soluções de acesso aberto possibilitam a muitos usuários desenvolver sistemas 4.0 industriais, realizá-los e operacionalizá-los (Industrie 4.0 by Design).

7 A interconexão e individualização dos produtos e processos de negócios criam complexidade que é gerenciada p.ex. pela modelagem, simulação e auto-organização. Um maior ambiente de soluções pode ser analisado em menor tempo e soluções encontradas mais rapidamente.

8 A eficácia e eficiência dos recursos podem ser planejados, implementados, monitorados e otimizados continuamente e de forma autônoma.

9 Produtos inteligentes são portadores de informações ativos e são passiveis de endereçamento e identificação em todas as fases do seu ciclo de vida.

10 Componentes de sistemas também são passiveis de identificação e endereçamento dentro dos meios de produção. Eles ajudam no planejamento virtual de sistemas e processos de produção.

11 Novos componentes de sistema possuem, no mínimo, as capacidades dos substituídos e podem assumir suas funções com compatibilidade.

12 Componentes de sistema oferecem suas funcionalidades como serviços que outros podem acessar.

13 Uma nova cultura de segurança conduz a sistemas I 4.0 confiáveis, resilientes e de aceitação social.

\section{Organização}

14 Tanto as redes de valoração novas como as já estabelecidas, com valor agregado, integram produto, produção e prestação de serviços, permitindo a variação dinâmica da divisão do trabalho.

15 Cooperação e competição (coopetition) levam a novas estruturas econômicas e legais

16 Estruturas de sistemas e processos de negócios são demonstráveis dentro dos quadros jurídicos válidos em cada caso; novas soluções jurídicas permitem novos modelos de contrato.

17 São criadas oportunidades à transferência de iniciativas de valoração regional - também em mercados em desenvolvimento.

(Fonte: Traduzido de Kagermann et al. (2014) com a colaboração do Sr. Willy Bernd Unger)

Há ainda trabalhos similares como a do VDI \& ASME (2015) que têm estudado também os impactos das inovações industriais no papel do ser humano no futuro da manufatura.

Whitepapers como do projeto Pathfinder (2014), financiado pela comunidade europeia também discutem os desafios para o desenvolvimento da fábrica do futuro 
diante dos avanços de $\mathrm{TI}$, reconhecendo o elo entre a produtividade e o investimento em TI. Neste trabalho são citadas várias iniciativas de países europeus com relação à manufatura do futuro conforme já ilustrado no Quadro 16.

Outro trabalho similar foi feito por Koch et al. (2014) em sua pesquisa intitulada "Industry 4.0 Opportunity and challenges of the industrial internet" em que uma survey foi realizada pela instituição de pesquisa TNS Emnid envolvendo 235 indústrias alemãs. Os principais resultados desta survey estão ilustrados na Fig. 40.

Fig. 40 - Principais Resultados da Survey pela TNS Emnid na Alemanha. Descobertas Chave da Survey

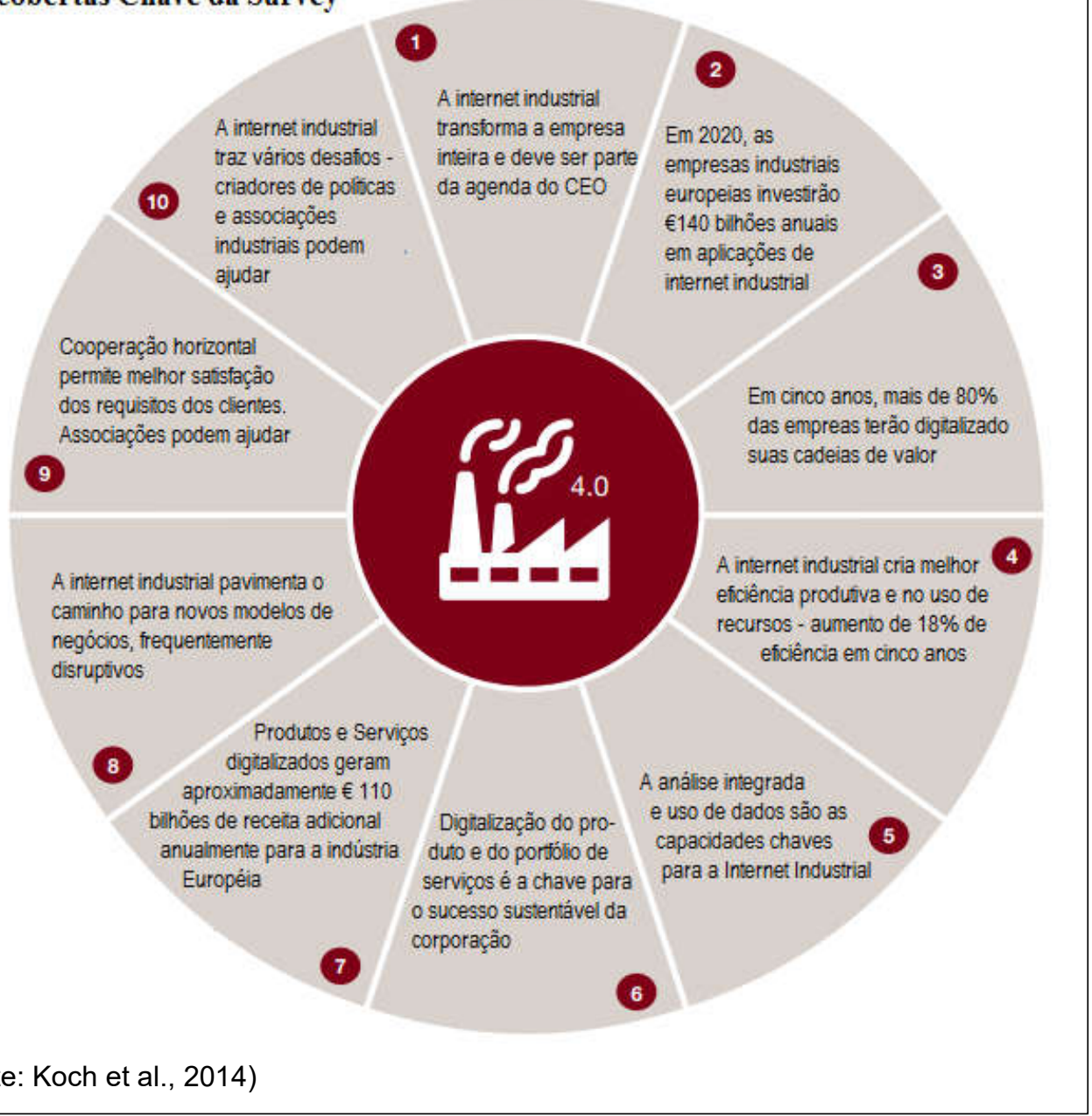

Burmeister et al. (2015) apresentam um estudo qualitativo empírico através da abordagem pelo processo de Inovação do Modelo de Negócio (Business Model Innovation - BMI) no contexto da 14.0. Com foco especialmente em processos dedicados, estruturas organizacionais, e ferramentas para BMI, os autores fornecem uma perspectiva do estado atual da BMI em 14.0 e concluem que as práticas atuais 
de desenvolvimento de produtos e serviços ainda precisam ser complementadas através de uma abordagem sistemática pelo BMI, construindo capacidade fundamental para explorar as oportunidades da 14.0.

\subsection{COMPARAÇÃO DOS RESULTADOS COM OUTRAS PESQUISAS}

Entende-se que as oportunidades de atuação para os participantes da CFSAM no Brasil residem principalmente nas brechas existentes entre o estado da arte no cenário mundial e o estado da prática no Brasil. Desta forma, é de fundamental importância entender como as empresas brasileiras participantes da CFSAM estão reagindo a estas mudanças de paradigma apontadas pelo estado da arte no setor de automação da manufatura.

A estrutura para comparação será entre o resultado da pesquisa que caracterizará o estado da prática através da análise de como as empresas brasileiras estão reagindo diante das mudanças de paradigma em automação da manufatura e as pesquisas existentes que caracterizam o estado da arte em automação da manufatura.

A comparação permitirá vislumbrar a brecha tecnológica entre os dois estados que por sua vez permitirá identificar possíveis oportunidades de atuação para as empresas participantes da CFSAM.

Os atores típicos da CFSAM no cenário atual, estão representados na Fig. 41, em que o usuário industrial é o proprietário destes sistemas. O que se verifica na prática atual, é que a integração completa da fábrica desde o nível 0 até o nível 4 do modelo ISA-95, envolve produção de software que demandam expertises distintos para os diferentes níveis, de maneira que é necessária uma equipe multidisciplinar para desenvolver tais projetos. Assim, é usual termos vários atores participando da cadeia de fornecimento de tais sistemas. 


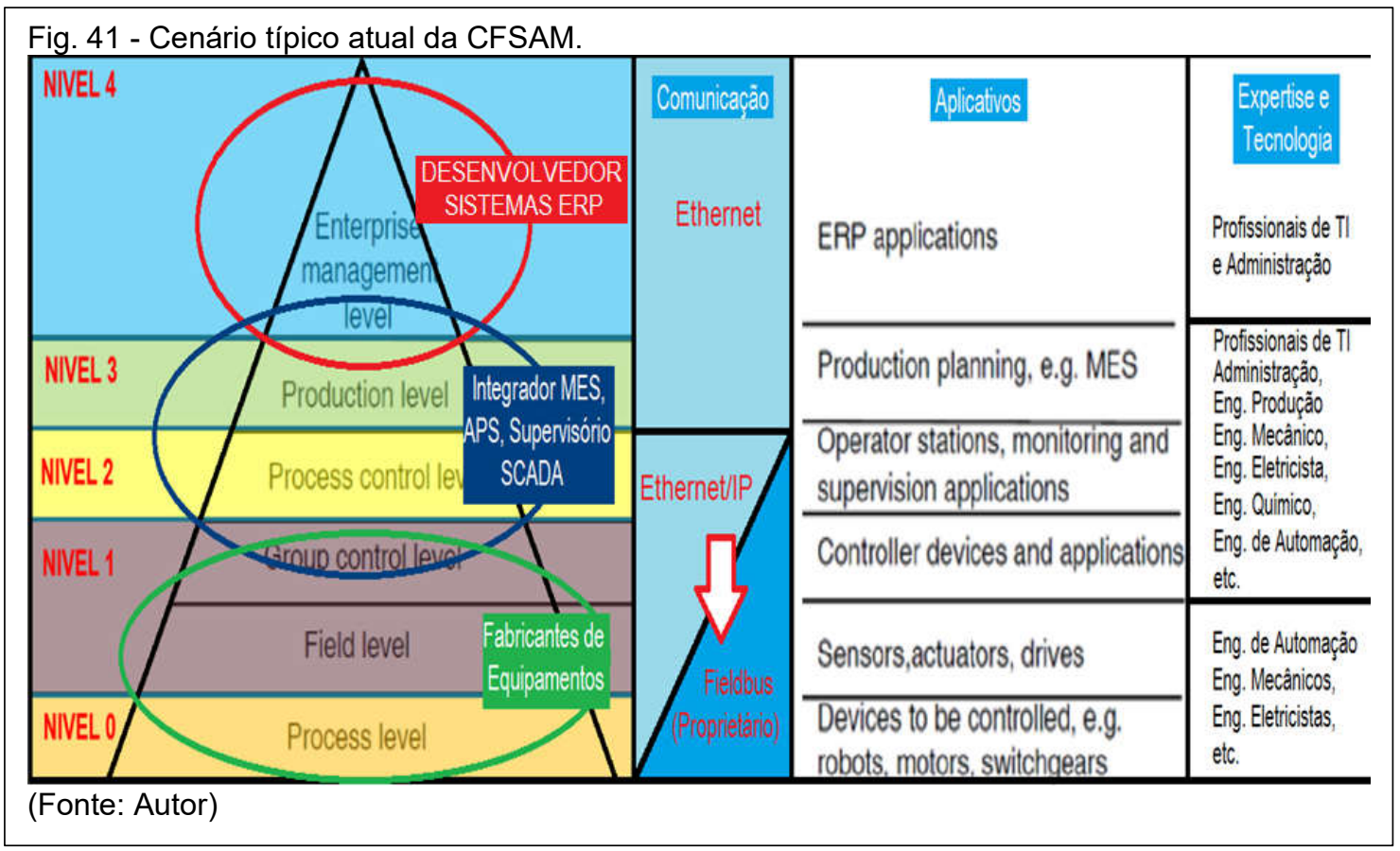

Com a mudança para o modelo de arquiteturas SOA para TO, nas quais os dispositivos terão suas funcionalidades encapsuladas como serviços, este panorama poderá sofrer mudanças por não necessitarem mais de middleware ${ }^{8}$ para estabelecer pontes de comunicação entre os vários pedaços de software que compõem o sistema. Usando-se a tecnologia web services, a interoperabilidade, integração e a reutilização de componentes do aplicativo serão bastante facilitadas. Ao usá-la com base em protocolos padrões nos diferentes níveis do sistema de produção, será possivel proporcionar uma comunicação direta e transparente entre níveis de dispositivos e de TI. (CÂNDIDO et al., 2009; OLLINGER et al. 2011). Brettel et al. (2014) ilustra esta tendência através da Fig. 42.

\footnotetext{
${ }^{8}$ Middleware: programa intermediário que faz a mediação entre o software e demais aplicativos em plataformas ou protocolos de comunicação diferentes
} 


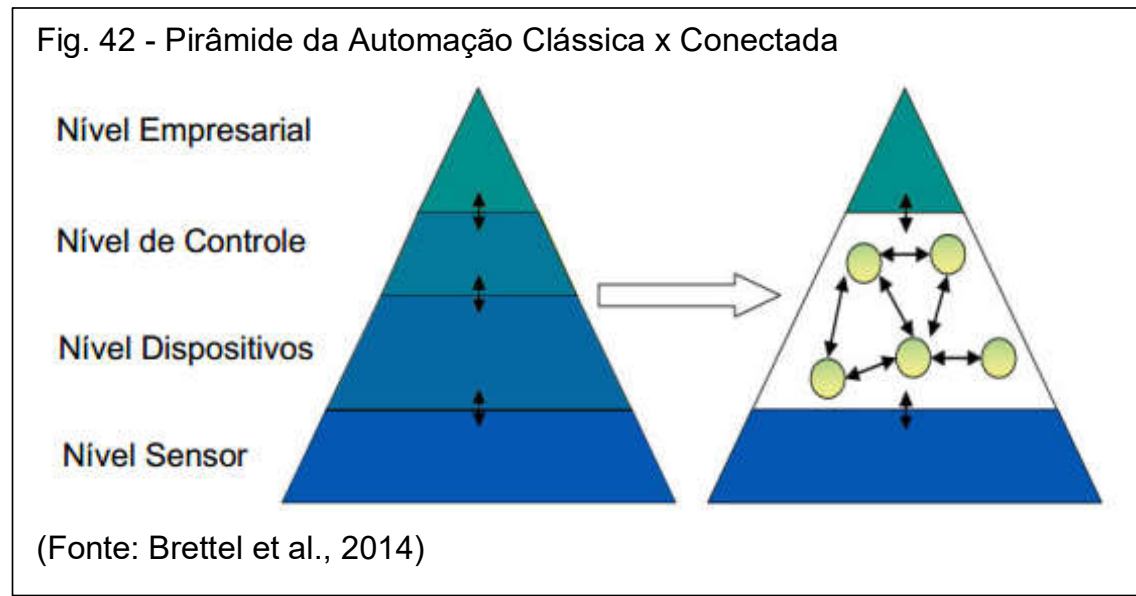

Para esta comparação do cenário nacional com o estado da prática mundial, utilizou-se o questionário - ANEXO , extraído de Kagermann (2013), que foi aplicado em empresas alemãs e o questionário - ANEXO extraído de Deloitte Consulting (2015) que foi aplicado em empresas Suíças para a aplicação de uma Survey nas empresas brasileiras.

Para a comparação do cenário nacional com o estado da arte, avaliou-se os impactos hipotéticos com as percepções dos dirigentes das empresas brasileiras avaliados pelas questões complementares incluídas nos questionários do ANEXO e ANEXO através da Survey e do Estudo de Múltiplos casos. 


\section{METODOLOGIA DE PESQUISA}

Este capítulo trata da definição das variáveis de pesquisa, no item 3.1, a partir da questão principal da pesquisa identificando a 14.0 como variável independente e seus impactos aos sistemas de manufatura como variáveis dependentes desta pesquisa. Diante das principais variáveis dependentes identificadas, apresenta-se, no item 3.2, o constructo que mostra a relação entre a variável independente e a variável dependente. Constructo em que os três grupos de atores da Cadeia de Fornecimento de Sistemas para Automação da Manufatura (CFSAM) são apresentados transversalmente criando-se uma matriz cujas células representam segmentos de reação para cada grupo de ator em relação a cada um dos impactos. O estudo destes segmentos é o objetivo desta pesquisa e o seu planejamento é ilustrado no item 3.3 através de fluxograma de atividades.

\subsection{VARIÁVEIS DA QUESTÃO DE PESQUISA}

Conforme o objetivo enunciado no capítulo introdutório deste trabalho, reescreve-se a questão de pesquisa:

Quais impactos a 14.0 está causando na CFSAM no Brasil e que oportunidade de atuação estão surgindo para os atores desta cadeia?

A metodologia identifica os tipos de variáveis (CRESWELL, 2012) a partir da questão principal conforme ilustra a Fig. 43. 


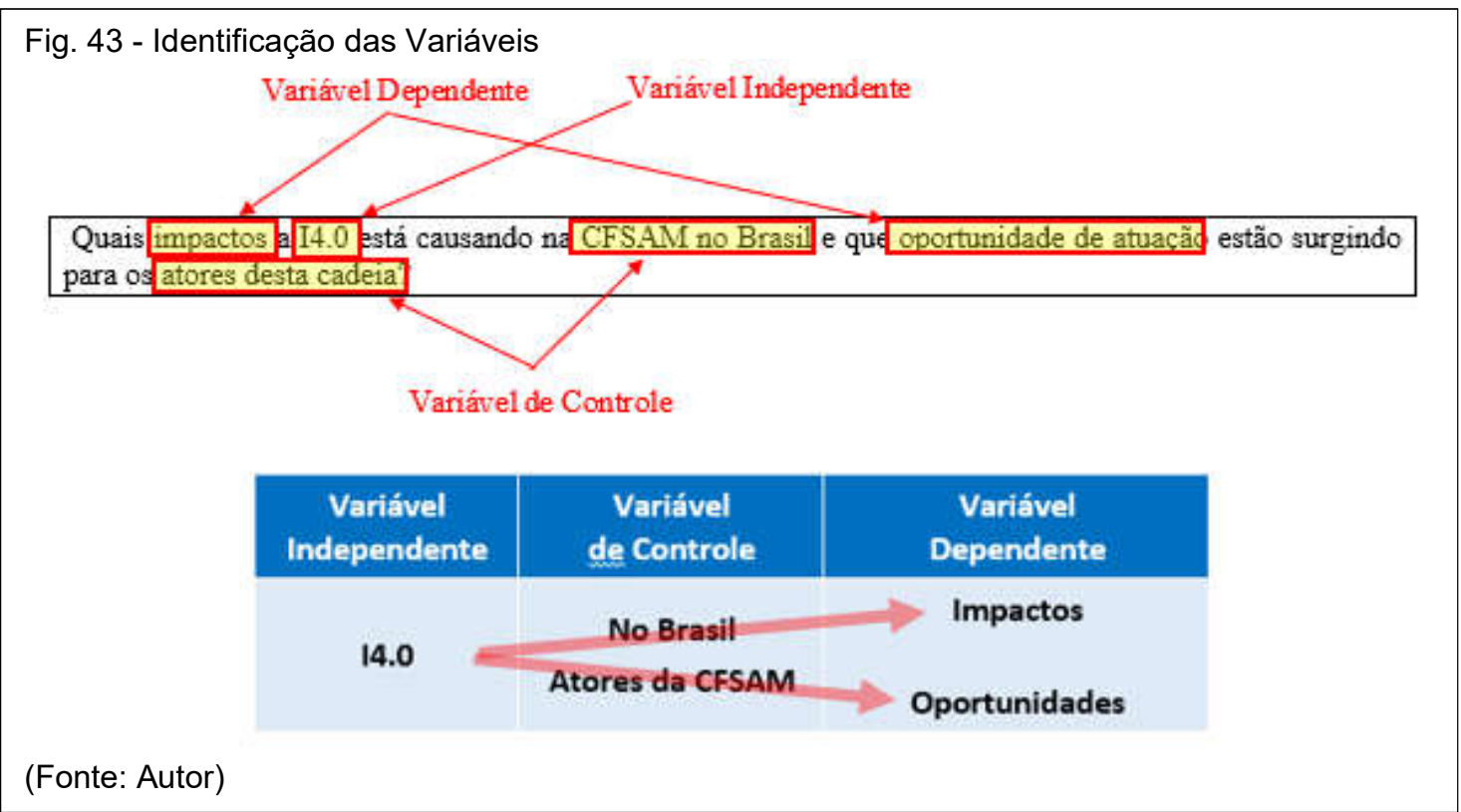

Uma pesquisa típica procura definir a relação entre variável dependente observada e a variável independente hipotética através de uma teoria dentro de um contorno definido pelas variáveis de controle.

$$
V_{d}=F_{\left[V_{c}\right]}\left(V_{i}\right)
$$

Onde, $\boldsymbol{V}_{\boldsymbol{d}}=$ variável dependente, $\boldsymbol{V}_{\boldsymbol{i}}=$ variável independente, $\boldsymbol{V}_{\boldsymbol{c}}=$ Variáveis de Controle e $\boldsymbol{F}_{\left[V_{c}\right]}\left(\boldsymbol{V}_{\boldsymbol{i}}\right)$ é a teoria que explica a relação entre as variáveis.

As variáveis identificadas na questão desta pesquisa estão mostradas na Fig. 43. Neste caso, o ponto de partida é a variável independente representada pelos avanços tecnológicos em TI representados pelo paradigma $\mathbf{1 4 . 0}$ e as variáveis dependentes são os impactos e oportunidades hipotéticas apontadas pelos estudos acadêmicos e visões empresariais.

Pela revisão bibliográfica verificou-se que os avanços em TI representados pelas tecnologias, padrões e conceitos emergentes mais relevantes na Automação da Manufatura estão sendo resumidos num único conceito chamado de Indústria 4.0 (14.0) já tratada em 2.4.15. Conceitos semelhantes existem, também baseados nos mesmos avanços tecnológicos de TI em direção à conectividade das coisas (loT), porém com outros nomes como Internet Industrial e Manufatura Inteligente. Contudo, considerou-se neste trabalho, que a $\mathbf{1 4 . 0}$ resume melhor, como variável independente, os avanços tecnológicos em TI que impactam os sistemas de automação da manufatura. 


\subsection{IMPACTOS DA PLATAFORMA I4.0 SOBRE A MANUFATURA}

Na revisão bibliográfica, identificaram-se os oito impactos hipotéticos mais proeminentes da 14.0 aos atores da CFSAM, conforme ilustrado no Quadro 17. Nele podem-se ver três categorias de benefícios à manufatura reivindicados pela $14.0 \mathrm{e}$ cinco impactos colaterais aos atores da CFSAM.

Contudo, a VDMA 9 , 2015, baseado em estudos da Gartner, 2012 estima que a 14.0 não atingirá o platô da produtividade antes de 2022 conforme mostra a Fig. 44.

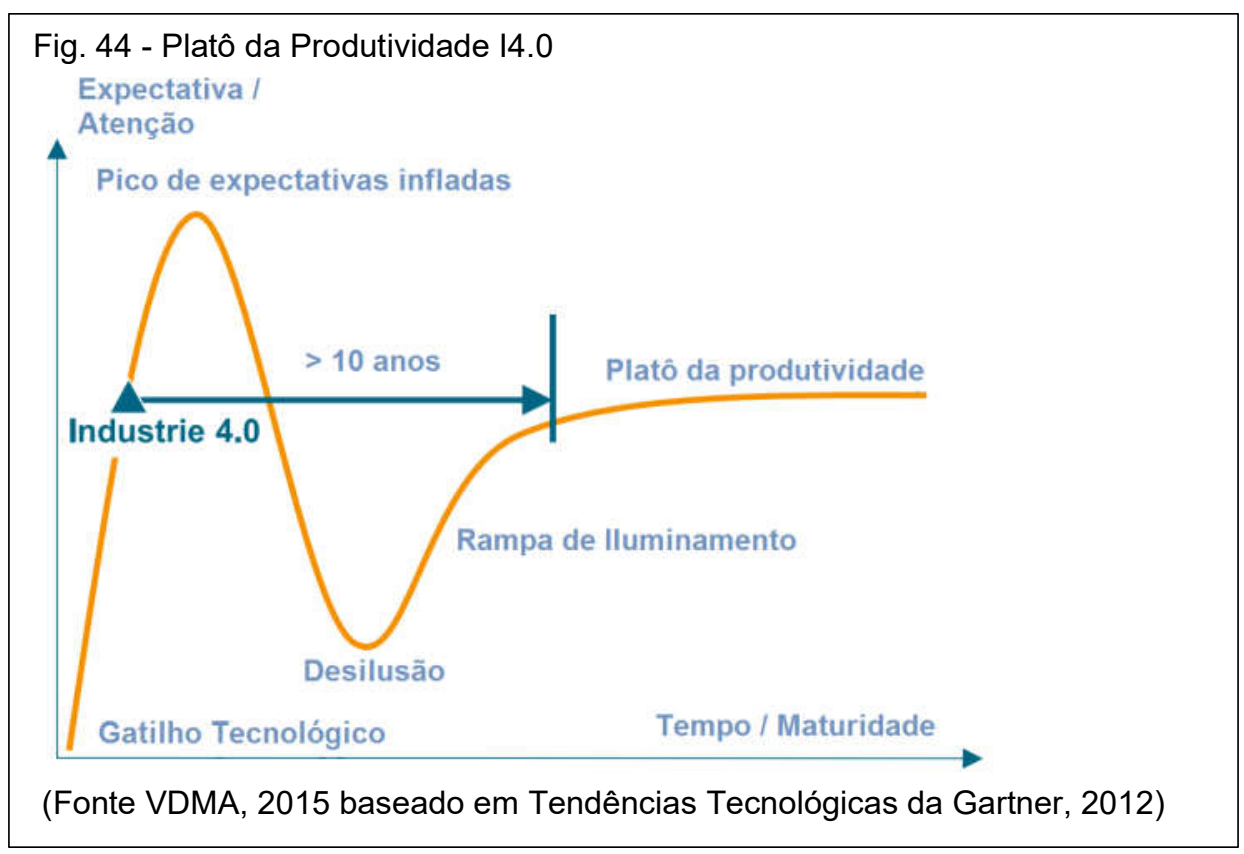

Esta estimativa está em concordância com a expectativa de loT atingir o platô da produtividade entre 2020 a 2025 uma vez que a loT é um dos elementos básicos da 14.0. (Fig. 15).

Assim sendo, era de se esperar que a verificação pragmática plena destes impactos seria algo difícil de se conseguir. No entanto, oportunidades somente tem valor se identificadas com antecipação, antes que os impactos se consolidem, para que os atores da CFSAM possam usufruir das mesmas.

O estudo propõe, a verificação de impactos conforme ilustrado na matriz do constructo na Fig. 45. Este constructo resume os impactos hipotéticos da 14.0 sobre

\footnotetext{
9 VDMA (Verband Deutscher Maschinen- und Anlagenbau) - Associação Alemã de Fabricação de Máquinas e Instalações Industriais
} 
os Sistemas de Manufatura em duas categorias: benefícios diretos para os sistemas de manufatura e outros impactos que afetam a manufatura.

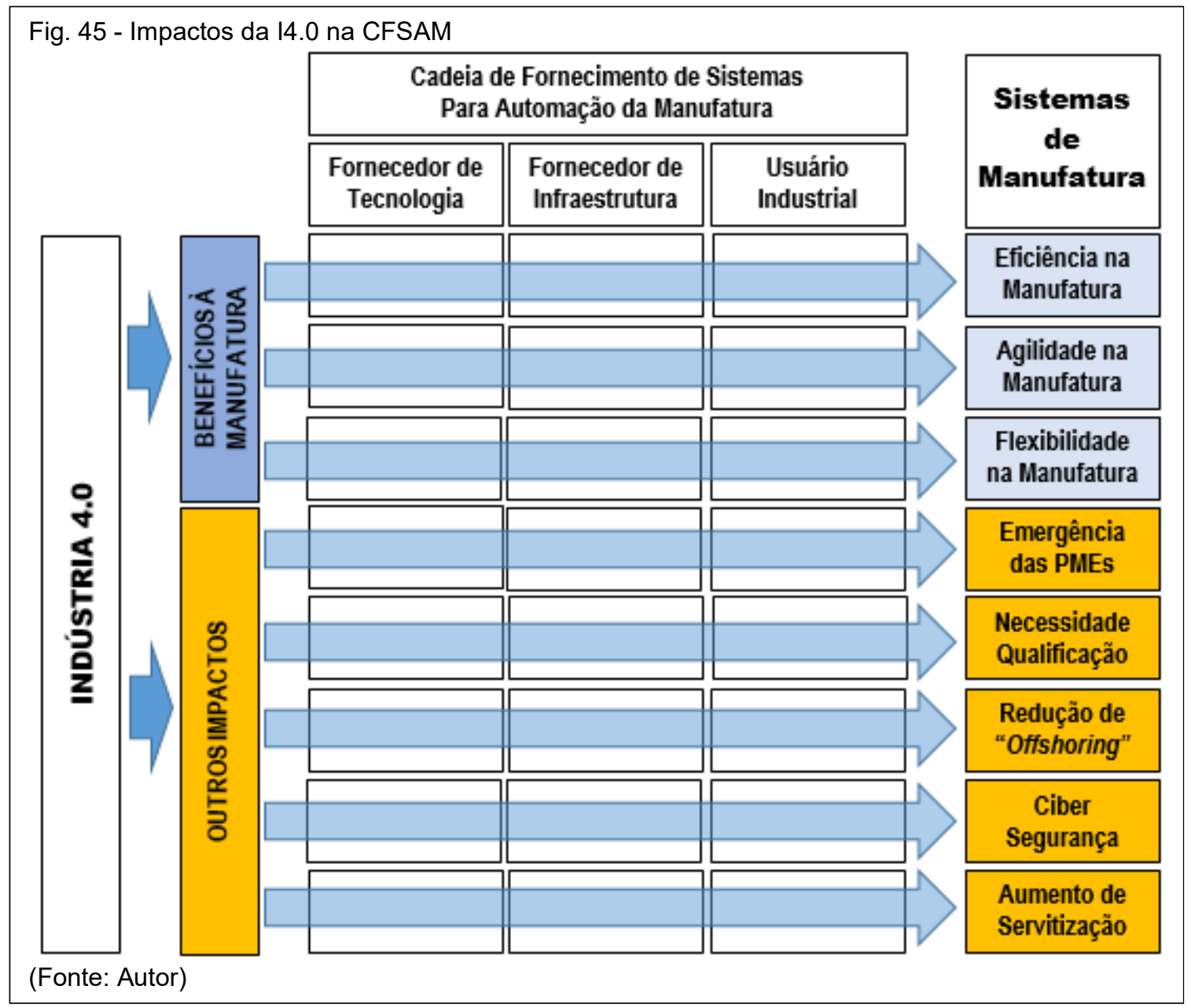

O constructo mostra ainda que, para se atingir os impactos hipotéticos nos sistemas de manufatura, há necessidade de diferentes reações entre os atores CFSAM. A análise da reação nestes segmentos (representados pelos quadros na intersecção entre as linhas e colunas) é o cerne deste trabalho. O estudo mostra que em alguns segmentos as reações não estão ocorrendo simplesmente por que ainda não há padronizações ou tecnologias disponíveis para que os atores possam reagir aos impactos. 


\subsection{ETAPAS DA PESQUISA}

A pesquisa para verificação dos impactos e análise das oportunidades e ameaças para os atores da CFSAM foi feita de acordo com a sequência de estudos ilustrada na Fig. 46.

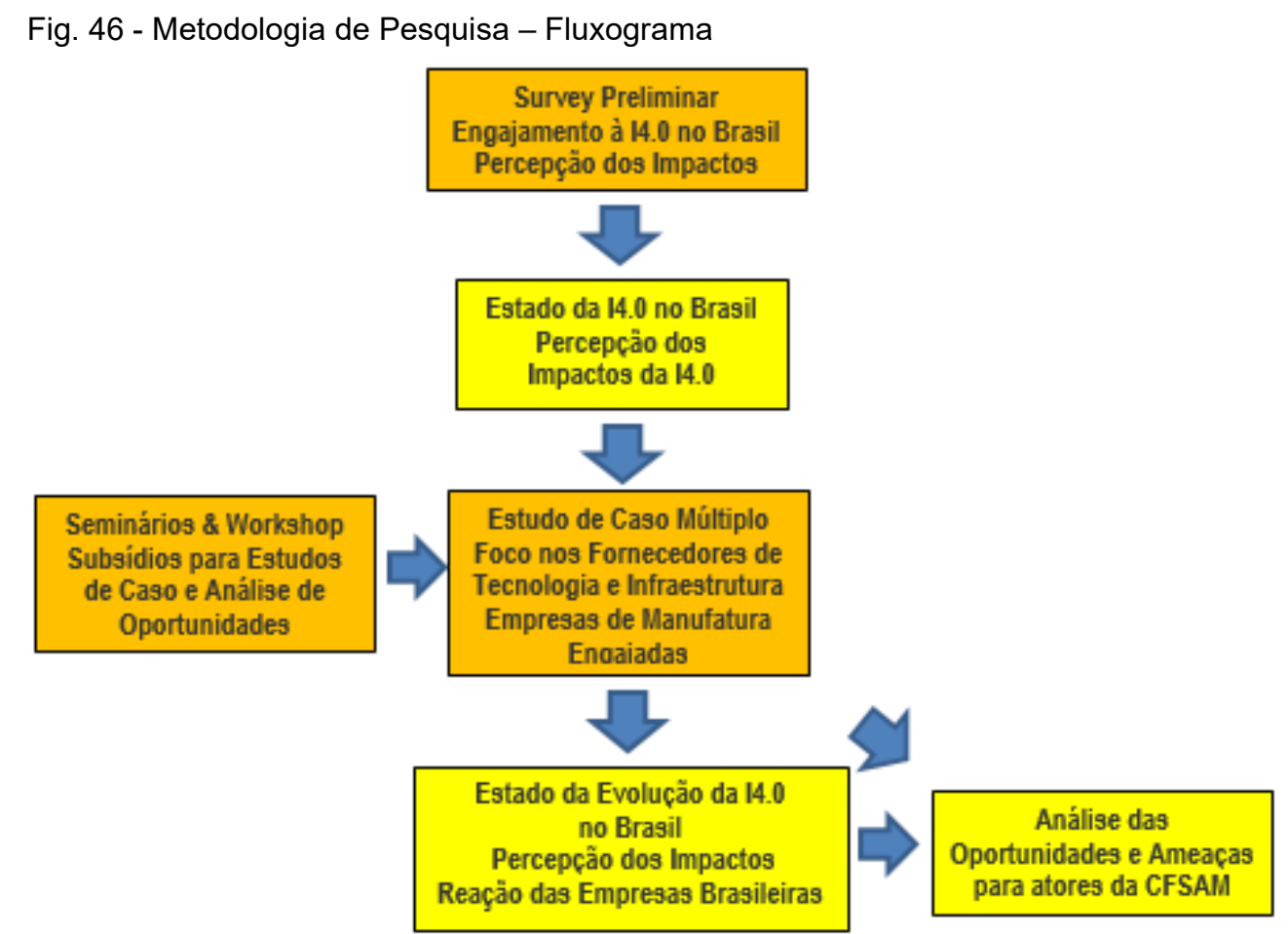

(Fonte: Autor)

A pesquisa iniciou-se com uma Survey, que permitiu verificar o nível de engajamento das empresas brasileiras aos conceitos da 14.0, testar a correlação entre engajamento e as percepções dos impactos hipotéticos, bem como identificar as empresas mais engajadas.

Como já era esperado, o nível de engajamento das empresas brasileiras na implantação da plataforma 14.0 ainda é bastante baixo, confirmando as estimativas da VDMA (2015) e Gartner (2015) na Fig. 44 e Fig. 15. Ainda, recentes pesquisas feitas pela Siemens-IDG (CAMPI - BITMAG, 2016) e CNI (2016) apontavam que a maioria das empresas usuárias industriais no Brasil, ainda não entendiam com clareza a estrutura da 14.0, confirmando o que diziam também os estudos acadêmicos a nível mundial (HERMANN et al., 2015; DRATH \& HORSH, 2014). Portanto, uma Survey como método de pesquisa único, muito provavelmente resultaria em avaliações 
imprecisas pela falta de entendimento e pela falta de casos práticos com inciativas de 14.0 implantados. Assim, a Survey inicial foi utilizada para confirmar o baixo nível de engajamento das empresas brasileiras à 14.0 e para identificar empresas engajadas na implantação dos conceitos da 14.0 .

A partir destas empresas, realizou-se estudo de múltiplos casos para identificar as estratégias de evolução adotadas por estas empresas na migração para a plataforma 14.0 e com isto identificar novas oportunidades para os atores da CFSAM. Paralelamente, Seminários e Workshops também foram utilizados como meio de identificar oportunidades hipotéticas que seriam verificados no estudo de múltiplos casos. 


\section{DESENVOLVIMENTO DA PESQUISA}

Este capítulo descreve o desenvolvimento da pesquisa executada com base no fluxograma da Fig. 46. Iniciou-se a pesquisa com uma Survey para avaliar o nível de engajamento das empresas brasileiras com os conceitos da 14.0. No entanto, fazia-se necessário criar uma métrica para medir o nível de engajamento, uma vez que não se encontrou na literatura nenhuma definição de métrica para medir o engajamento à 14.0. O desenvolvimento desta métrica portanto, é objeto do primeiro item deste capítulo. A seguir, apresenta-se o desenvolvimento da Survey preliminar que foi utilizada para confirmar a falta de entendimento do que é a 14.0 pela maioria dos gestores de manufatura no Brasil e para identificar as empresas mais engajadas na implantação dos conceitos da 14.0 no Brasil. Confirmado o baixo engajamento prático e pouco entendimento dos conceitos da 14.0, a próxima etapa trata de identificar as poucas empresas com algum engajamento prático para a condução de Estudo de Múltiplos Casos. Esta etapa é descrita no item 4.3.

\subsection{MEDINDO O ENGAJAMENTO À 14.0}

Para verificar o nível de engajamento das empresas pesquisadas com a plataforma 14.0 era necessária uma métrica para se medir o engajamento. Nascimento et al. (2014) apresentaram um método para medição do nível de engajamento dos leitores de revistas digitais baseado no modelo de métrica proposto pela Forrester Research (HAVEN, 2007). Este modelo serve a princípio, para medir o engajamento de clientes com uma determinada marca ou empresa do ponto de vista de marketing, porém aproveitou-se o conceito com algumas adaptações para medir o engajamento das empresas com o conceito da I4.0.

Os quatro componentes do engajamento, segundo Haven (2007), estão ilustrados na Fig. 47, na qual estão ilustrados alguns exemplos de métricas utilizadas e como medir. 


\begin{tabular}{|c|c|c|c|}
\hline ENVOLVIMENTO & INTERAÇÃO & INTIMIDADE & INFLUÊNCIA \\
\hline \multicolumn{4}{|l|}{ O QUE RASTREAR } \\
\hline $\begin{array}{l}\text {-Visita a Sites } \\
\text {-Tempo dispendido } \\
\text {-Páginas vistas } \\
\text {-Palavras chave de busca } \\
\text {-Caminhos de Navegação } \\
\text {-Login em sites }\end{array}$ & $\begin{array}{l}\text {-Comentários e contri- } \\
\text { buições aos blogs } \\
\text {-Quantidade/frequencia } \\
\text { de revisões escritas, } \\
\text { comentários no blog } \\
\text { e Conteúdo gerado por } \\
\text { usuário (UGC) }\end{array}$ & $\begin{array}{l}\text {-Rastreamento de sentimen- } \\
\text { tos em sites de terceiros } \\
\text { (blogs, revisões, fóruns, etc. } \\
\text {-Rastreamento de sentimen- } \\
\text { tos de contribuições de clien- } \\
\text { tes internos } \\
\text {-Opiniões expressas em } \\
\text { serviços de atendimento a } \\
\text { clientes }\end{array}$ & $\begin{array}{l}\text {-Nota satisfação Produto / } \\
\text { serviço } \\
\text {-Afinidade com a marca } \\
\text {-Conteúdo encaminhado a } \\
\text { amigos } \\
\text {-Postagens em blogs de } \\
\text { alto perfil }\end{array}$ \\
\hline \multicolumn{4}{|l|}{ COMO RASTREAR } \\
\hline -Analíticos de web & $\begin{array}{l}\text {-Plataforma de comércio } \\
\text { eletrônico } \\
\text {-Plataforma de mídia social }\end{array}$ & $\begin{array}{l}\text {-Monitoramento de marcas } \\
\text {-Serviço de Atendimento ao } \\
\text { Cliente } \\
\text {-Pesquisas }\end{array}$ & $\begin{array}{l}\text {-Monitoramento de marcas } \\
\text {-Serviço de Atendimento ao } \\
\text { Cliente } \\
\text {-Pesquisas }\end{array}$ \\
\hline
\end{tabular}

Envolvimento: é o componente mais básico de medição do engajamento e reflete aspectos mensuráveis da empresa pesquisada com o conceito de 14.0. Embora este componente sozinho não seja suficiente, a medição de atividades neste componente é crítica porque será na maioria das vezes, o primeiro ponto de interação com o conceito e, servirá de base para conexão com outras métricas.

Interação: Este componente mede a profundidade da relação da empresa com o conceito 14.0, na qual a empresa busca aprofundar-se mais sobre os conceitos. Enquanto envolvimento mede contatos com o Conceito 14.0, interação mede ações efetivas.

Intimidade: Este componente vai além da interação e mede o comprometimento e políticas com relação ao conceito. Está relacionado a uma definição de uma opinião e uma postura da empresa com relação ao conceito da 14.0.

Influência: Este componente vai além dos sentimentos da empresa, para determinar tendência da empresa de encorajar parceiros a aderirem a este conceito.

A Fig. 48 apresenta estes quatro componentes adaptados para mensurar o engajamento das empresas com o conceito de 14.0 
Fig. 48 - Quatro componentes para medir engajamento das empresas em 14.0

\begin{tabular}{|c|c|c|c|}
\hline$>$ ENVOLVIMENTO & INTERACÃO & INTIMIDADE & INFLUÊNCIA \\
\hline \multicolumn{4}{|l|}{0 que identificar } \\
\hline $\begin{array}{l}\text { Obtendo Informações, } \\
\text { workshops, seminários... }\end{array}$ & $\begin{array}{l}\text { Participação Grupos de } \\
\text { Pesquisa, testes... }\end{array}$ & $\begin{array}{l}\text { Opinião e postura da } \\
\text { empresa definida }\end{array}$ & $\begin{array}{l}\text { Encoraja empresas } \\
\text { parceiras a aderir à M4.0 }\end{array}$ \\
\hline \multicolumn{4}{|l|}{ Como medir } \\
\hline Questionário & Questionário & Questionário & Questionário \\
\hline
\end{tabular}

(Fonte: Adaptado de Haven, 2007)

Através de características da postura da empresa perante a 14.0 pode-se medir o engajamento de uma empresa em cinco níveis ao incluir o nível 0 em que a empresa não tem nenhum engajamento com a 14.0 (Quadro 19).

\begin{tabular}{|c|c|c|c|c|}
\hline \multicolumn{5}{|c|}{ Quadro 19 - Métrica para Nível de Engajamento em 14.0} \\
\hline Nível & Dimensão & Função & $\begin{array}{c}\text { Engajamento } \\
\text { (Adaptado para loT / } \\
\text { 14.0) }\end{array}$ & $\begin{array}{c}\text { Estilo de } \\
\text { Engajamento }\end{array}$ \\
\hline 0 & - & - & Ainda não engajado & Não engajado \\
\hline 1 & $\begin{array}{c}\text { Métrica } \\
\text { Envolvimento }\end{array}$ & $\begin{array}{l}\text { Ajuda a medir atividades } \\
\text { de descoberta }\end{array}$ & Obtendo informação & Descobrindo \\
\hline 2 & $\begin{array}{l}\text { Métrica } \\
\text { Interação }\end{array}$ & $\begin{array}{l}\text { Rastreia atividades de } \\
\text { avaliação e } \\
\text { envolvimento. }\end{array}$ & $\begin{array}{l}\text { Envolvido em pesquisa, } \\
\text { testes ou protótipos de } \\
\text { loT//4.0 }\end{array}$ & \multirow{3}{*}{ Praticando } \\
\hline 3 & $\begin{array}{l}\text { Métrica } \\
\text { Intimidade }\end{array}$ & $\begin{array}{l}\text { Monitora opiniões } \\
\text { durante e após o uso }\end{array}$ & $\begin{array}{l}\text { Implementando loT e } \\
\text { Smart ERP na } \\
\text { Manufatura }\end{array}$ & \\
\hline 4 & $\begin{array}{l}\text { Métrica } \\
\text { Influência }\end{array}$ & $\begin{array}{l}\text { Avalia a expressividade } \\
\text { à medida que } \\
\text { desenvolve afinidade. }\end{array}$ & $\begin{array}{l}\text { Integrando rede } \\
\text { colaborativa através da } \\
14.0\end{array}$ & \\
\hline (Fonte & Autor) & & & \\
\hline
\end{tabular}

Esta métrica permite apenas medir o quanto uma empresa está engajada ao conceito 14.0, mas não permite avaliar o quanto a 14.0 já está implantada. Para isto seria necessário verificar quais elementos da plataforma 14.0 (Fig. 36) a empresa possui implantada. Como um dos elementos básicos é a loT e, segundo estimativas da Gartner (2015) (Fig. 15), a loT no mundo deve atingir o platô da produtividade apenas em 2020 a 2025, era de se esperar que ainda não houvesse nenhuma empresa com a plataforma 14.0 implantada. Porém isto não significa que não possa haver empresas implementando estratégias de implantação ou migração para a 14.0. 


\subsection{SURVEY}

A survey foi feita com uma amostragem de trinta empresas brasileiras utilizando-se de questionários já aplicados em outros países para confirmar o nível de engajamento das empresas de manufatura brasileiras, e para identificar as empresas mais engajadas na implantação de iniciativas 14.0 .

Tomou-se o cuidado de iniciar a pesquisa com um texto explicativo sobre os conceitos da 14.0 e os propósitos da pesquisa para tentar reduzir as imprecisões por falta de entendimento (CRESWELL, 2012 p.392).

Além das questões dos anexos A e B, a survey incluiu ainda algumas questões para verificar as percepções das empresas engajadas aos impactos hipotéticos identificados no constructo da Fig. 45 conforme anexos C e D.

Creswell (2012) alerta que quando um questionário é elaborado pelo próprio pesquisador, alguns cuidados precisam ser tomados e apresenta algumas orientações, conforme listados no Quadro 20, que devem ser verificados antes de se aplicar o questionário. 


\begin{tabular}{|c|c|c|}
\hline & Pontos & Recomendação \\
\hline 1 & Clareza & $\begin{array}{l}\text { A questão deve ser clara. A falta de clareza decorre de palavras vagas ou } \\
\text { imprecisas. Identifique palavras vagas e imprecisas e substitua-as por } \\
\text { palavras que sejam entendidas pelos participantes da pesquisa. }\end{array}$ \\
\hline 2 & $\begin{array}{l}\text { Questões } \\
\text { múltiplas }\end{array}$ & $\begin{array}{l}\text { Isto ocorre quando uma questão contém duas ou mais questões na mesma } \\
\text { pergunta. Reduza as questões múltiplas em uma questão simples. }\end{array}$ \\
\hline 3 & $\begin{array}{l}\text { Questões } \\
\text { longas }\end{array}$ & $\begin{array}{l}\text { Quando uma questão é demasiadamente longa. Corte as palavras } \\
\text { desnecessárias e simplifique, encurtando as questões. Evite uso } \\
\text { excessivo de preposições (mais que três) ou declarações qualificativos } \\
\text { que tornam a sentença mais longa. }\end{array}$ \\
\hline 4 & $\begin{array}{l}\text { Questões } \\
\text { negativas }\end{array}$ & $\begin{array}{l}\text { As questões estão redigidas negativamente. Se as questões contém um } \\
\text { ou mais negativas tais como "não deve" o significado deixa de ser claro. } \\
\text { Reformular a frase para eliminar conotações negativas. }\end{array}$ \\
\hline 5 & Uso de jargões & $\begin{array}{l}\text { Jargões podem não ser familiares a todos os participantes. Elimine os } \\
\text { jargões e substitua-as por palavras que todos os participantes entendam. }\end{array}$ \\
\hline 6 & $\begin{array}{l}\text { Respostas } \\
\text { sobrepostas }\end{array}$ & $\begin{array}{l}\text { Em questões fechadas, podem haver respostas sobrepostas, ou seja, } \\
\text { situações em que duas alternativas respondem à pergunta. Certifique-se } \\
\text { de que as respostas não se sobrepõem criando alternativas distintas. }\end{array}$ \\
\hline 7 & $\begin{array}{c}\text { Respostas } \\
\text { desbalanceadas }\end{array}$ & $\begin{array}{l}\text { Há respostas alternativas desbalanceadas. As respostas podem estar } \\
\text { desbalanceadas em termos de intervalos naturais. Opções de respostas } \\
\text { podem começar com a palavra "importante" (por ex. "muito importante") e } \\
\text { terminar com a palavra "extensão" (ore x. "para uma pequena extensão") } \\
\text { ao invés de adjetivos como "não importante". Decida sobre uma alternativa } \\
\text { de resposta simples e use-a consistentemente para todas as categorias } \\
\text { de questões. }\end{array}$ \\
\hline 8 & $\begin{array}{l}\text { Respostas em } \\
\text { desacordo com } \\
\text { as questões }\end{array}$ & $\begin{array}{l}\text { As respostas podem não corresponder às palavras de "ação" usadas na } \\
\text { questão. Identifique o verbo ou adjetivo na questão que será a base para } \\
\text { a alternativa de resposta e crie opções usando esta palavra. (Ex. se a } \\
\text { questão diz: "em que extensão", a resposta deve dizer "em grande } \\
\text { extensão") }\end{array}$ \\
\hline 9 & $\begin{array}{l}\text { Linguagem } \\
\text { técnica }\end{array}$ & $\begin{array}{l}\text { A pergunta inclui palavras excessivamente técnicas. Quando isto ocorre, } \\
\text { o respondente pode não ter nível de conhecimento suficiente para } \\
\text { responder à questão. Simplifique a questão de maneira que as pessoas } \\
\text { possam entender as palavras e responder à questão. }\end{array}$ \\
\hline 10 & $\begin{array}{l}\text { Questões não } \\
\text { aplicáveis }\end{array}$ & $\begin{array}{l}\text { Nem todas as questões são aplicáveis para os todos os participantes. } \\
\text { Neste caso inclua ramificações ou questões contingenciais no } \\
\text { questionário. Tais questões devem seguir a questão original e oferecem } \\
\text { alternativas para incluir todos os participantes. }\end{array}$ \\
\hline
\end{tabular}

(Fonte: Adaptado de Creswell, 2012 p.389)

\subsubsection{Hipóteses}

As hipóteses foram formuladas a partir de impactos da 14.0 identificados na literatura e elencadas como variáveis dependentes conforme Quadro 21.

Para verificação destas hipóteses, um questionário foi preparado conforme ANEXO C. As questões deste anexo, foram formuladas de maneira a permitir uma quantificação através de uma escala Lickert de 5 pontos. Na medida do possível, as 
respostas foram direcionadas para serem quantificáveis buscando minimizar o efeito da subjetividade. O questionário assim preparado tem três funções:

Objetivos

a) Verificar o nível de engajamento das empresas brasileiras aos conceitos da 14.0 .

b) Correlacionar os impactos hipotéticos (Quadro 21) com o nível de engajamento (Quadro 19).

c) Identificar as empresas brasileiras mais engajadas à 14.0.

Quadro 21 - Hipóteses para a Questão de Pesquisa

Hipóteses

Benefícios à Manufatura

H1 A 14.0 está sendo implementada visando maior eficiência gerencial e produtiva.

H2 A 14.0 está sendo implementada visando maior agilidade à manufatura e desenvolvimento de produtos através de tecnologias para virtualização e simulação de processos.

H3 A 14.0 está sendo implementada visando maior flexibilidade através de reprogramação, escalabilidade (expansão e redução de recursos), individualização (customização em massa $=$ produzir lote unitário personalizado sem a perda de lucratividade)

Outros Impactos

H4 A implantação da 14.0 tende a gerar mais oportunidades para as PME's

H5 A implantação da 14.0 tende a demandar profissionais com novas qualificações multidisciplinares

H6 A implantação da 14.0 tende a reduzir a migração da produção para outros países com custos menores.

H7 A implantação da 14.0 tende a trazer maior risco cibernético para o ambiente industrial.

H8 A implantação da 14.0 tende a oferecer mais produtos como serviços.

(Fonte: Autor)

\subsubsection{Perfil dos Respondentes}

Conforme já mencionado anteriormente, a população alvo dos respondentes foram os atores da CFSAM conforme já descrito no Quadro 17, que incluem três categorias de empresas (fornecedores de tecnologia, fornecedores de infraestrutura e usuários industriais) que foram utilizados como uma variável de controle nesta pesquisa. O perfil dos respondentes almejou profissionais na função de gestão 
estratégica destas empresas com conhecimento ou engajamento nos conceitos da 14.0 ou iniciativas semelhantes.

\subsection{ESTUDO DE MÚLTIPLOS CASOS}

Prevendo um baixo nível de empresas engajadas em implementação prática, e para obter-se um entendimento mais profundo da reação dos atores da CFSAM planejou-se adicionalmente um estudo de múltiplos casos, com escolha das unidades de estudo por conveniência (Creswell, 2012 p.206).

Se por um lado o engajamento entre os Usuários Industriais ainda é baixo, uma rápida busca na internet permitiu identificar alguns Fornecedores de Tecnologia e de Infraestrutura oferecendo soluções em conectividade loT e 14.0. Isto permite que a pesquisa seja conduzida de forma qualitativa através de uma amostragem por conveniência focada nestes grupos de atores para através de suas experiências, identificar a reação dos Usuários Industriais à iniciativa 14.0.

Selecionou-se desta forma, três empresas de grande representatividade do grupo de Fornecedores de Tecnologia que já oferecem soluções tecnológicas para a implementação da 14.0. Além destes, escolheu-se quatro representantes do grupo de Fornecedores de Infraestrutura que estivessem engajados na implantação dos conceitos da 14.0. E por fim, mais quatro empresas Usuárias Industriais engajadas na implantação de conceitos da 14.0 identificadas na survey.

O estudo de múltiplos casos foi feito através de entrevistas semiestruturadas aproveitando-se o questionário utilizado para survey (ANEXO ). No entanto, a constatação de baixo nível de engajamento prático dos Usuários Industriais no Brasil através da survey trouxe uma questão complementar a ser investigada no estudo de múltiplos casos para entender a reação das empresas brasileiras perante à iniciativa 14.0:

Por que os Usuários Industriais no Brasil ainda apresentam nível de engajamento baixo na implantação prática dos conceitos da 14.0 ?

Esta questão motivou a inclusão de um novo item no questionário base destinado aos Fornecedores de Tecnologia e Infraestrutura com o propósito de 
investigar as barreiras e dificuldades interpostas pelos Usuários Industriais à adoção das soluções ofertadas para a implantação da 14.0. (ANEXO).

\subsubsection{Proposições}

As proposições identificadas para os desafios a serem vencidos na implantação da loT e 14.0 foram obtidas através da revisão bibliográfica e estão listadas no Quadro

22.

Quadro 22 - Proposições sobre Desafios para a Implantação da loT e 14.0

\begin{tabular}{|l|l|}
\hline P1 & \multicolumn{1}{|c|}{ Proposições } \\
\hline & $\begin{array}{l}\text { A falta de padronização em } \\
\text { infraestrutura de comunicação é } \\
\text { um desafio para implantação da } \\
\text { 14.0 }\end{array}$ \\
\hline P2 & $\begin{array}{l}\text { A falta de sistemas capazes de } \\
\text { integrar HW de CPS com TI } \\
\text { para operacionalizar a loT é um } \\
\text { desafio para implantação da l4.0 }\end{array}$ \\
\hline
\end{tabular}

P3 A falta infraestrutura de TIC para operacionalizar Big Data e Sistemas analíticos é um desafio para implantação da 14.0

P4 A falta qualificação requerida para os trabalhadores na plataforma 14.0 é um desafio para implantação da 14.0

Weyer et al. (2015); Koch et al. (2014); Deloitte Consulting (2015); IEEE (2014); Haddara \& Elragal (2015); HCL (2014); Roland Berger Consultants (2015); Belyh (2015); FST Essentials (2015); Acatech (2011);

Mosterman \& Zander, 2015; Gregor et al. (2015); Dittes (2015); Acatech (2011); Wortmann \& Flüchter (2015); Ungurean (2015); Hartweg (2014); Wahlster et al. (2014); Kuehnle (2015); Wu et al. (2013); Wahlster (2013); Brecher (2015);

Yin \& Kaynak, 2015; Deloitte Consulting (2015); IEEE (2014); FST Essentials (2015); Schulz (2015); Wahlster (2013); Brecher (2015);

Koch et al., 2014; Deloitte Consulting (2015); Gregor et al. (2015); HCL (2014); Belyh (2015); FST Essentials (2015); Acatech (2011); Hartweg (2014); Saldivar et al. (2015);

P5 O alto nível de investimento requerido em infraestrutura para loT é um desafio para implantação da 14.0

P6 A dificuldade com novos modelos de negócio e integração horizontal com parceiros de negócio e clientes é um desafio para implantação da 14.0

P7 A segurança e proteção de dados em ambiente loT é um desafio para implantação da 14.0

Koch et al., 2014; Haddara \& Elragal (2015);

Deloitte Consulting (2015); FST Essentials (2015); Acatech (2011);

IEEE (2014); HCL (2014); FST Essentials (2015); Yu et al. (2015); Dacier et al. (2014); Schulz (2015); Brecher (2015);

(Fonte: Autor)

P1: A falta de padronização em infraestrutura de comunicação é um desafio para a implantação da 14.0. 
Segundo Weyer et al. (2015) a padronização global em infraestrutura de comunicação num contexto, em que a fábrica requer uma ampla rede de fornecedores de tecnologias para automação é essencial para assegurar a interoperabilidade entre os diferentes módulos da linha de produção. É necessário ainda que os fornecedores de tecnologia trabalhem em estreita cooperação com outros fornecedores para desenvolver sistemas interativos com componentes de diversos fabricantes num ambiente de rede. A padronização da interface é desejável também para que os dispositivos IoT e gateways possam se comunicar rápida e eficientemente. Os dispositivos precisarão ainda de uma maneira rápida e fácil de descobrir uns aos outros e aprender as capacidades do seu vizinho (IEEE, 2014; DELOITTE CONSULTING, 2015). Koch et al. (2014) da PwC Management Consulting através de uma Survey realizada com 235 empresas industriais na Alemanha apontam também a necessidade de definir padrões como um dos desafios para a implantação da IloT. Roland Berger Consultants (2015) complementam que o maior desafio para a implantação da 14.0 é a padronização e a virtualização de plataformas de TI no contexto do controle de fábrica, porque é aí que os riscos de TI irão afetar o ambiente de produção.

HCL Technologies (2014) cita que padrões de comunicação também representa um desafio na rede colaborativa entre vendedores e clientes ao longo dos diversos setores da indústria desde o desenho de produto até serviços aos produtos precisam ser desenvolvidos. A criação de redes entre empresas exige padrões comuns e uniformes e necessita de uma arquitetura de referência para sua descrição técnica (FST ESSENTIAL, 2015).

P2: A falta de sistemas capazes de integrar HW de CPS com TI para operacionalizar a loT é um desafio para a 14.0.

Embora muitos fornecedores de sistemas ERP considerem que estão aptos para a 14.0, ainda há dificuldades com a comunicação M2M entre máquinas e ERP (HADDARA \& ELRAGAL, 2015).

O acesso à internet móvel e acesso à infraestrutura física incluindo engenharia de sensores e atuadores, algoritmos para o comportamento adaptativo dos sistemas em rede e ontologias para interligar tais sistemas autônomos representam ainda um desafio para a loT e consequentemente para a 14.0. Além disso a necessidade de 
tecnologia semântica relacionada ao armazenamento, procura e organização de grandes quantidades de informações também é citada como desafio para loT (Atzori et al., 2010).

IoT, loS e loD oferecem a infraestrutura técnica para customização em massa, mas apenas a tecnologia semântica pode auferir a flexibilidade, a adaptabilidade, agilidade e interoperabilidade na fabricação, criação e entrega de serviços, bem como de análise de dados que são necessários para a personalização eficiente de produtos, serviços e fontes de dados grandes (Wahlster et al. 2014). Falta de estrutura para compartilhamento de informações e recursos perfeito para facilitar a comunicação e colaboração em sistemas colaborativos e distribuídos (Wu et al., 2013)

P3: A falta de infraestrutura de TIC para operacionalizar Big Data e Sistemas analíticos é um desafio para implantação da 14.0

E consequentemente, é um deasfio para os sistemas analíticos da 14.0 (Yin \& Kaynak, 2015). O grande volume de tráfego de dados na loT requer uma rede de comunicação robusta, de alta capacidade e sempre disponível com o mínimo de congestionamento. Criar valor através de desenvolvimento de algoritmos de análise de dados que possam transformar dados em ações inteligentes é um dos desafios inerentes à Big Data (Schulz, 2015). Brecher (2015) cita também que a 14.0 traz enormes desafios tais como Big Data, processamento destes dados, a segurança de dados e a colaboração homem-máquina. IEEE (2014) argumenta que com muitas conversas entre dispositivos loT e gateways, a própria rede de comunicação precisa ser robusta, de alta capacidade e sempre disponível com um congestionamento mínimo. Sugere ainda que grandes quantidades de tráfego com tamanhos de pacotes relativamente curtos exigirão uma gestão de tráfego sofisticada.

P4: A falta de qualificação requerida aos trabalhadores nas empresas crescentemente digitalizadas é um dos obstáculos para a implantação da 14.0.

Schmitt et al. (2013) citam que um dos aprendizados das tentativas de automação de fábricas isentas de pessoas através do CIM foi que os humanos não são dispensáveis. Diante das complexidades cada vez maiores impostas pelas demandas de mercado, os humanos não apenas são necessários como devem ser otimamente integrados na fábrica do futuro tornando-se a parte mais flexível dos sistemas de produção. Como o elo mais flexível, os trabalhadores da fábrica do futuro 
precisarão lidar com as mais variadas tarefas desde a especificação e monitoramento até a verificação de estratégias de produção através de interfaces sofisticadas de assistência. Isto requer também um novo perfil de trabalhador com qualificação multidisciplinar que ainda não se dispõe no mercado de trabalho. Os respondentes da survey realizada pela PwC Management Consulting consideram ainda que a qualificação requerida de trabalhadores nas empresas cada vez mais digitalizadas é o maior obstáculo para o aproveitamento das novas oportunidades de negócios que a loT irá proporcionar (KOCH et al., 2014). Koch et al. (2014) citam ainda que para que as empresas possam se tornar uma empresa da 14.0 devem dominar suficientemente as habilidades necessárias para lidar com o ambiente digitalizado. Uma vez que os produtos e sistemas de produção estão se tornando cada vez mais complexos, os engenheiros devem ter também métodos e ferramentas especiais à sua disposição para desenvolver um planejamento adequado e modelos explicativos (FST ESSENTIAL, 2015).

A IEEE (2014) cita também que a educação será um desafio permanente em todos os níveis. Tanto para os usuários consumidores, usuários que utilizam no trabalho como para os tecnólogos que estão desenvolvendo sistemas loT.

P5: Alto nível de investimento requerido em aplicativos para Internet Industrial é um dos principais desafios para a implantação da 14.0 .

Segundo uma pesquisa survey realizada por Koch et al. (2014), empresas europeias em 2020 pretendem investir em média 3,3\% de suas receitas anuais em soluções para a IloT, o que representa cerca de $50 \%$ do orçamento planejado para novos investimentos. Os autores destacam ainda que para que o investimento tenha o máximo de retorno, este deverá ser aplicado ao longo de toda a sua cadeia de valor e não apenas na empresa.

Outro desafio relacionado ao investimento na plataforma 14.0 é justificar sua viabilidade através de seu retorno financeiro. Haddara \& Elragal (2015) identificaram em seu estudo de múltiplos casos que frequentemente o retorno do investimento apenas sob foco financeiro se mostra inviável. É necessário que o investimento seja analisado também pelo valor de negócio que a tecnologia traz.

P6: As dificuldades com novos modelos de negócio, integração horizontal com parceiros de negócio e clientes são desafios para a implantação da 14.0 
A integração horizontal, tanto com clientes como parceiros de negócio na 14.0 pode trazer modelos de negócio e modelo de colaboração completamente novos representando um desafio para os envolvidos em termos de responsabilidade, questões legais e propriedade intelectual. Os desafios legais envolvem em grande parte a proteção dos dados da empresa, mas também existem questões relacionadas com a responsabilidade, restrições comerciais e tratamento dos dados pessoais. $\mathrm{O}$ risco de acesso não autorizado também aumenta com o crescimento da rede. Arquiteturas integradas de segurança e controle de acessos são críticos para o sucesso (FST ESSENTIAL, 2015).

P7: A falta de segurança e proteção de dados em ambiente loT é um desafio para a implantação da 14.0

O equilíbrio entre Quadruple Trust (protegido, seguro, privado e salvo) e usabilidade representa um desafio no projeto de redes loT e consequentemente para implantação da 14.0. Sistemas seguros e confiáveis serão o desafio para a implantação da 14.0 .

Estas proposições embora pretendam abranger as mais citadas na literatura, não pretendem ser exaustivas, de maneira que outros desafios para a implantação da IoT e 14.0 podem surgir. Com estas proposições, a ideia é buscar entender melhor a reação dos usuários industriais através de percepções baseadas em experiências reais dos atores da CFSAM, principalmente de fornecedores de tecnologias e infraestruturas para a 14.0. Ao envolver os atores de vários grupos da CFSAM pretende-se desenvolver várias perspectivas sobre estes desafios (Creswell, 2012 p.207).

A amostragem por conveniência deve escolher as unidades de estudo através do critério de riqueza de informações e que possam melhor ajudar a entender o fenômeno pesquisado (Creswell, 2012 p.206). De acordo com Creswell (2012), o intuito de uma pesquisa qualitativa não é o de generalizar os resultados para uma população, mas sim de desenvolver um entendimento mais profundo sobre um fenômeno. 


\subsubsection{Unidades de Estudo}

As unidades de estudo serão escolhidas por conveniência. Escolheu-se as três mais representativas empresas Fornecedoras de Tecnologias para automação industrial: Empresa FT2, Empresa FT3 e Empresa FT1, três empresas integradoras provedoras de infraestrutura: Empresa FI1, Empresa FI3, Empresa FI2 e Empresa FI4 parceira SAP. E quatro empresas usuárias industriais: Empresa UI1, Empresa UI2, Empresa UI3 e Empresa UI4 conforme ilustrado no Quadro 23.

\begin{tabular}{|c|l|r|r|}
\hline \multicolumn{3}{|c|}{ Quadro 23 - Escolha das Unidades de Estudo por conveniência } & \\
\hline & Unidade de Estudo & \multicolumn{1}{c|}{ Grupo de Ator da I4.0 } & Local \\
\hline $\mathbf{1}$ & Empresa FT1 & Fornecedor de Tecnologia & Curitiba - PR \\
\hline $\mathbf{2}$ & Empresa FT2 & Fornecedor de Tecnologia & Curitiba - PR \\
\hline $\mathbf{3}$ & Empresa FT3 & Fornecedor de Tecnologia & São Paulo - SP \\
\hline $\mathbf{4}$ & Empresa FI1 & Fornecedor de Infraestrutura & São Paulo - SP \\
\hline $\mathbf{5}$ & Empresa FI2 & Fornecedor de Infraestrutura & Joinville - SC \\
\hline $\mathbf{6}$ & Empresa FI3 & Fornecedor de Infraestrutura & São Paulo - SP \\
\hline $\mathbf{7}$ & Empresa FI4 & Fornecedor de Infraestrutura & São Paulo - SP \\
\hline $\mathbf{8}$ & Empresa UI1 & Usuário Industrial & Curitiba - PR \\
\hline $\mathbf{9}$ & Empresa UI2 & Usuário Industrial & São Caetano - SP \\
\hline $\mathbf{1 0}$ & Empresa UI3 & Usuário Industrial & Curitiba - PR \\
\hline $\mathbf{1 1}$ & Empresa UI4 & Usuário Industrial & Curitiba - PR \\
\hline (Fonte: Autor) & & \\
\hline
\end{tabular}

O estudo qualitativo foi feito através de entrevistas semiestruturadas baseadas no questionário ANEXO , além de questões abertas que irão verificar as proposições elencadas no Quadro 22. A entrevista foi conduzida através de questões fechadas com alternativas numéricas e questões abertas nas quais o entrevistado poderá discorrer sobre o assunto, apresentando justificativas e complementando a resposta dada.

\subsection{SEMINÁRIOS E WORKSHOP}

Além dos estudos de survey e de múltiplos casos, buscou-se o entendimento complementar através da participação do autor em seminários e workshops conforme listados no Quadro 24 que serviram de subsídios para as investigações no estudo de múltiplos casos. 


\begin{tabular}{|c|c|c|c|}
\hline \multicolumn{4}{|c|}{ Quadro 24 - Seminários e Workshop } \\
\hline Data & Eventos & Instituição & Local \\
\hline $\begin{array}{l}09-03- \\
2016\end{array}$ & Workshop Robot as a Service (4hs) & Pollux & Curitiba - PR \\
\hline $\begin{array}{l}15-04- \\
2016\end{array}$ & Workshop Indústria 4.0 (3hs) & Festo Didactic & Curitiba - PR \\
\hline $\begin{array}{l}03-05- \\
2016\end{array}$ & $\begin{array}{l}\text { Sistemas de Automação "All-In-One", } \\
\text { Cloud e Internet das Coisas (IoT) na } \\
\text { Indústria (4hs) }\end{array}$ & $\begin{array}{c}\text { ISA Curitiba } \\
\text { Novus }\end{array}$ & Curitiba - PR \\
\hline $\begin{array}{l}04-05- \\
2016\end{array}$ & $\begin{array}{l}\text { Seminário Manufatura Avançada e VI } \\
\text { Simpósio Internacional de Excelência } \\
\text { em Produção: Indústria } 4.0 \text { - Curto, } \\
\text { Médio e Longo Prazo (8hs) }\end{array}$ & $\begin{array}{l}\text { Abimaq } \\
\text { Feimec }\end{array}$ & $\begin{array}{l}\text { São Paulo - } \\
\text { SP }\end{array}$ \\
\hline $\begin{array}{l}26-01- \\
2017\end{array}$ & Jornada Digital na Manufatura (8hs) & Rockwell - Cisco & Curitiba - PR \\
\hline $\begin{array}{l}29-03- \\
2017\end{array}$ & $\begin{array}{l}\text { Fórum Academico - Industry 4.0: } \\
\text { Integrated Automation for Research and } \\
\text { Education }\end{array}$ & $\begin{array}{c}\text { National } \\
\text { Instruments }\end{array}$ & Curitiba - PR \\
\hline \multicolumn{4}{|c|}{ (Fonte: Autor) } \\
\hline
\end{tabular}




\section{RESULTADOS}

Neste capítulo relatam-se os resultados das pesquisa Survey no item 5.1 onde se buscou uma correlação entre tendência aos impactos hipotéticos e o engajamento à 14.0. No capítulo 5.2 onde são apresentados os resultados do Estudo de Múltiplos Casos, procurou-se a confirmação ou não destas tendências identificadas na Survey e uma explicação para as mesmas. Com base nestes estudos apresenta-se no item 5.3 a percepção do estado atual da 14.0 e as oportunidades identificadas aos grupos de atores da CFSAM.

\subsection{SURVEY}

Os resultados obtidos na Survey buscam testar as hipóteses de impactos hipotéticos levantados através da revisão bibliográfica.

\subsubsection{Impactos Hipotéticos da $\mathbf{1 4 . 0}$}

Com a Survey buscou-se avaliar ainda a correlação entre a percepção dos impactos hipotéticos e o nível de engajamento na implantação da 14.0 pelos respondentes. Entretanto, deve-se atentar ao fato de haver imprecisões devido à falta de entendimento dos conceitos da 14.0 pelos respondentes e pelo baixo nível de engajamento na implantação de maneira que as tendências entre as variáveis representam apenas a percepção dos respondentes que ainda não tem implantada a 14.0 e, portanto, não retrata uma realidade prática.

A mensuração das variáveis hipotéticas foi feita através das respostas às questões correspondentes de acordo com a escala Likert utilizada. As variáveis que envolveram várias questões tiveram os seus pontos Likert somados ou subtraídos de acordo com a interpretação desejada. A lógica de computação da variável hipotética está indicada ao lado da escala correspondente nos gráficos de tendências apresentados a seguir. 


\subsubsection{Hipótese 1 - Maior Eficiência Gerencial e Produtiva}

Um dos impactos previstos é o aumento da eficiência em todos aspectos na empresa, principalmente a gerencial e a produtiva através da disponibilização das informações em tempo real e através de recursos analíticos. Esta hipótese é confirmada pela linha de tendência ascendente na Fig. 49.

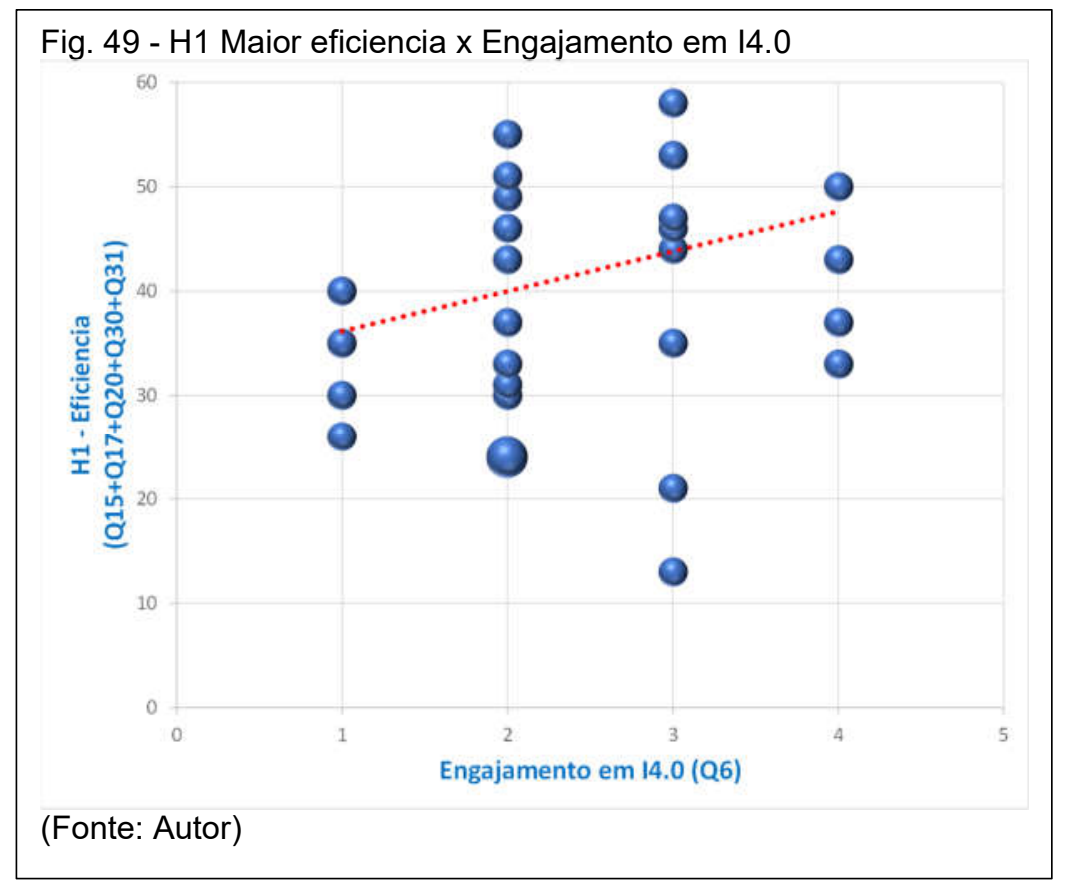

\subsubsection{Hipótese 2 - Maior Agilidade}

O aumento na agilidade para desenvolvimento de novos produtos através de virtualização, simulação e compartilhamento de informações em tempo real era um outro impacto hipotético identificado na revisão bibliográfica. Este impacto não ficou bem evidenciado no gráfico de tendências conforme pode-se ver na Fig. $50 . \mathrm{Na}$ verdade, a agilidade não parece ter qualquer correlação com a 14.0, pelo menos na visão dos entrevistados. 


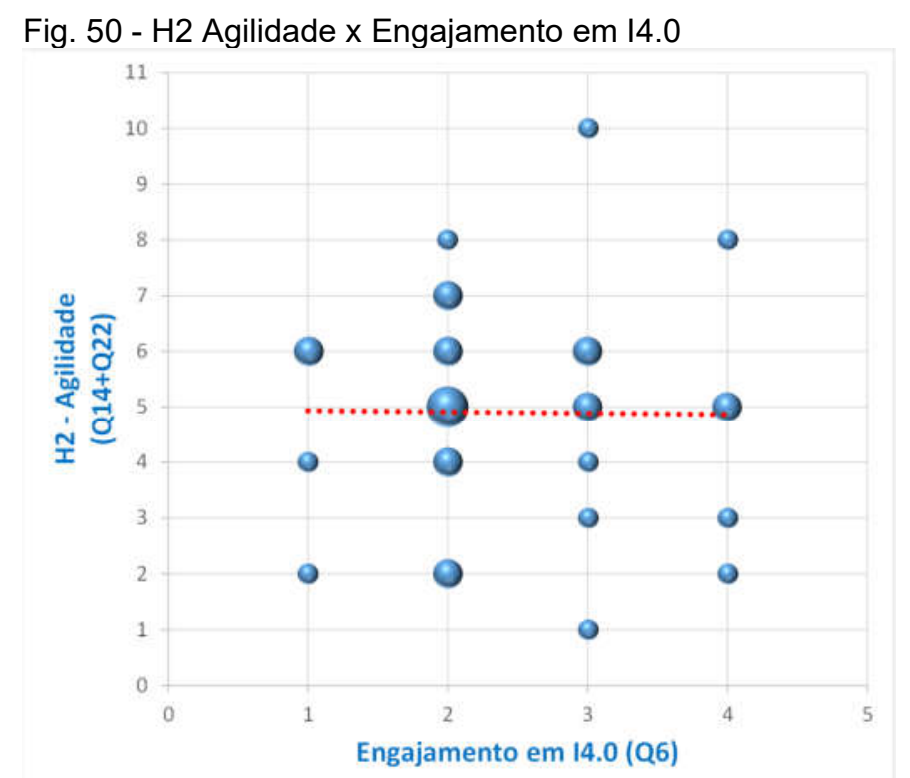

(Fonte: Autor)

Esta falta de comprovação pode ser justificada pelo fato da maioria dos respondentes ter pouco aprofundamento na implantação prática e não conseguir vislumbrar uma aplicação pragmática dos conceitos da 14.0 em suas empresas para atingir este benefício.

\subsubsection{Hipótese 3 - Maior Flexibilidade na Produção}

Um dos impactos mais ventilados na promoção dos conceitos da 14.0 é a melhoria na flexibilidade da manufatura, em que a customização em massa, a adaptabilidade, a escalabilidade das instalações produtivas são as características que poderiam ser atingidas através da implantação dos conceitos da 14.0. No entanto, o gráfico de tendências (Fig. 51) obtido pelo processamento das respostas da Survey aponta justamente o sentido inverso e de forma bastante proeminente.

Esta tendência pode ser justificada pelo fato de não se ter ainda tecnologia e máquinas suficientemente flexíveis nem redes de produção colaborativa tais como o Cloud Manufacturing no platô da produtividade. Na visão tradicional de automação (CIM), a inflexibilidade e a produção em massa estavam associadas com a facilidade de automação e o gráfico de tendência aponta que a visão dos respondentes ainda continua nesta linha. Ou seja, quanto mais engajados na automação e implantação dos conceitos da 14.0, veem a flexibilidade como algo mais difícil de ser alcançado. 
Fig. 51 - H3 Flexibilidade x Engajamento em 14.0

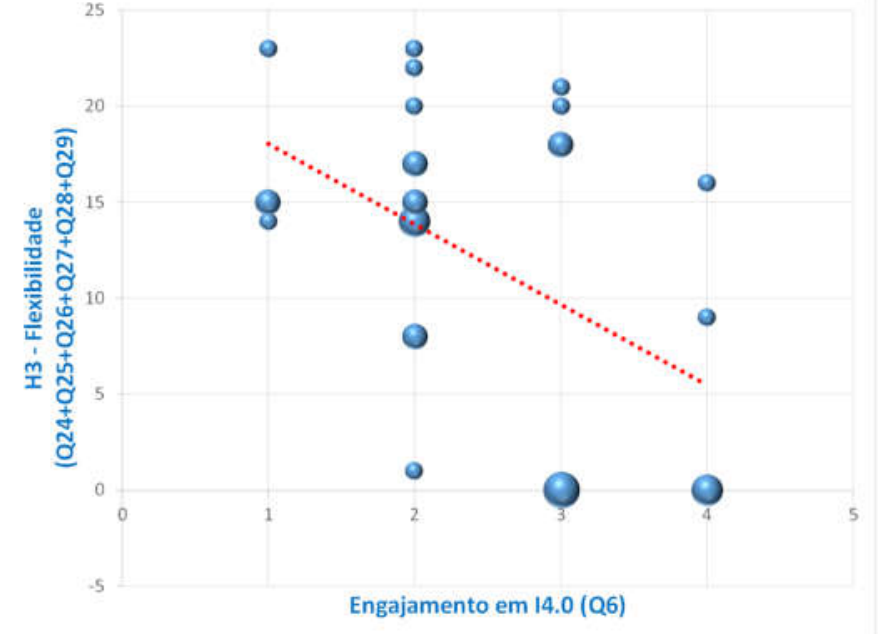

(Fonte: Autor)

\subsubsection{Hipótese 4 - Maior oportunidade para PMEs}

Um dos impactos colaterais previstos na literatura indicavam crescimento das PMEs em importância na rede colaborativa à medida que as estruturas orientadas a serviço passassem a ser mais modulares e distribuídas. No entanto, o gráfico de tendência das PMEs (Fig. 52) não mostra esta correlação com o engajamento com os conceitos da 14.0. $\mathrm{Na}$ visão dos respondentes, quanto mais engajados com os conceitos da 14.0 percebem menos oportunidades para as PMEs.

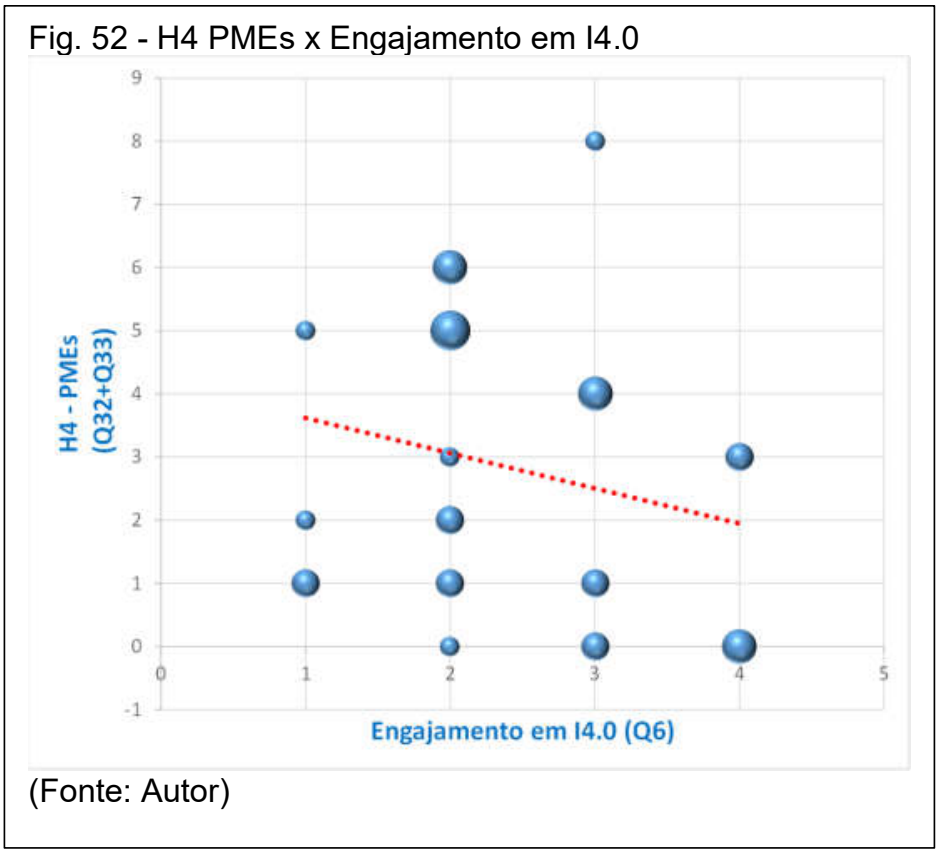




\subsubsection{Hipótese 5 - Novas demandas na Qualificação Profissional}

A quinta hipótese relacionava a necessidade de novas qualificações para os trabalhadores da 14.0 e, portanto, um engajamento maior em 14.0 impactaria em necessidade de novas habilidades multidisciplinares tanto para os operadores como para os fornecedores de infraestrutura e manutencionistas. O gráfico de tendência da Fig. 53 concorda com esta hipótese e aponta que à medida que há um engajamento maior, os respondentes percebem necessidade de maior qualificação dos trabalhadores, quer da produção como dos fornecedores de tecnologia e infraestrutura.

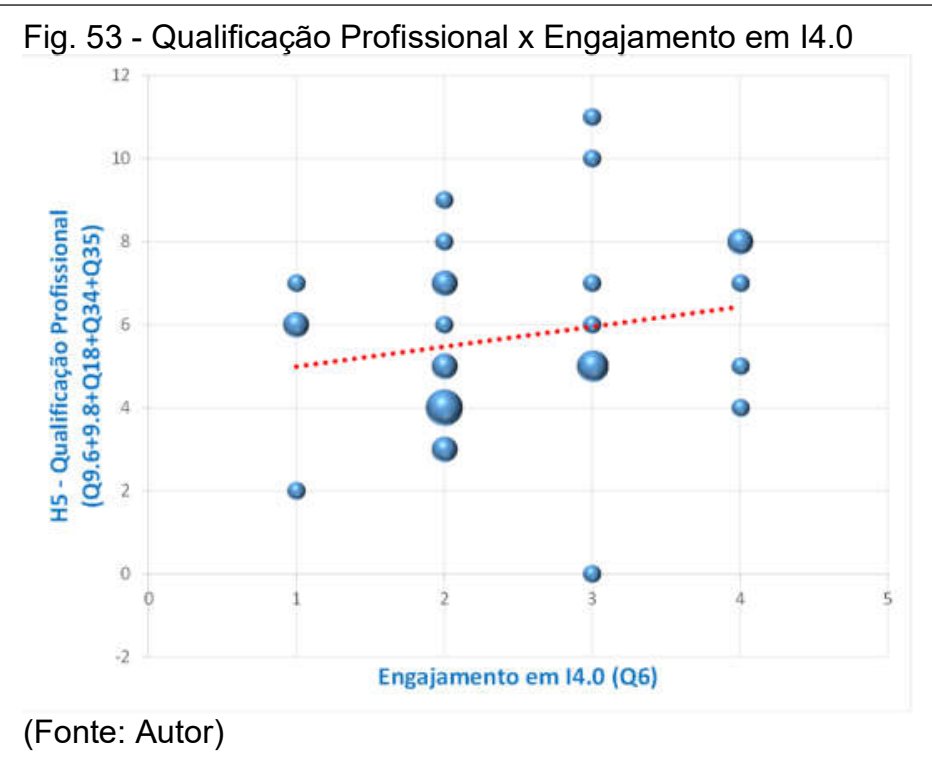

\subsubsection{Hipótese 6 - Redução de Offshoring da Produção}

Um dos objetivos almejados pelos idealizadores do conceito da 14.0 era o de repatriar para a Alemanha os processos produtivos perdidos para países com custos de mão obra mais baixos - processo denominado de offshoring (Kagermann et al., 2013). Nesta survey, a percepção dos respondentes brasileiros também aponta proeminentemente para esta tendência, de que é possível repatriar a produção perdida para países como a China (Fig. 54). Contudo, é importante destacar que há uma diferença significativa entre os contextos brasileiro e alemão e deve-se considerar a possibilidade de que esta percepção por parte dos respondentes esteja 
apenas refletindo os ensinamentos obtidos em seminários e workshops que têm sido atendidos por aqueles que estão ainda apenas em busca de informações ou em fase de experimentações.

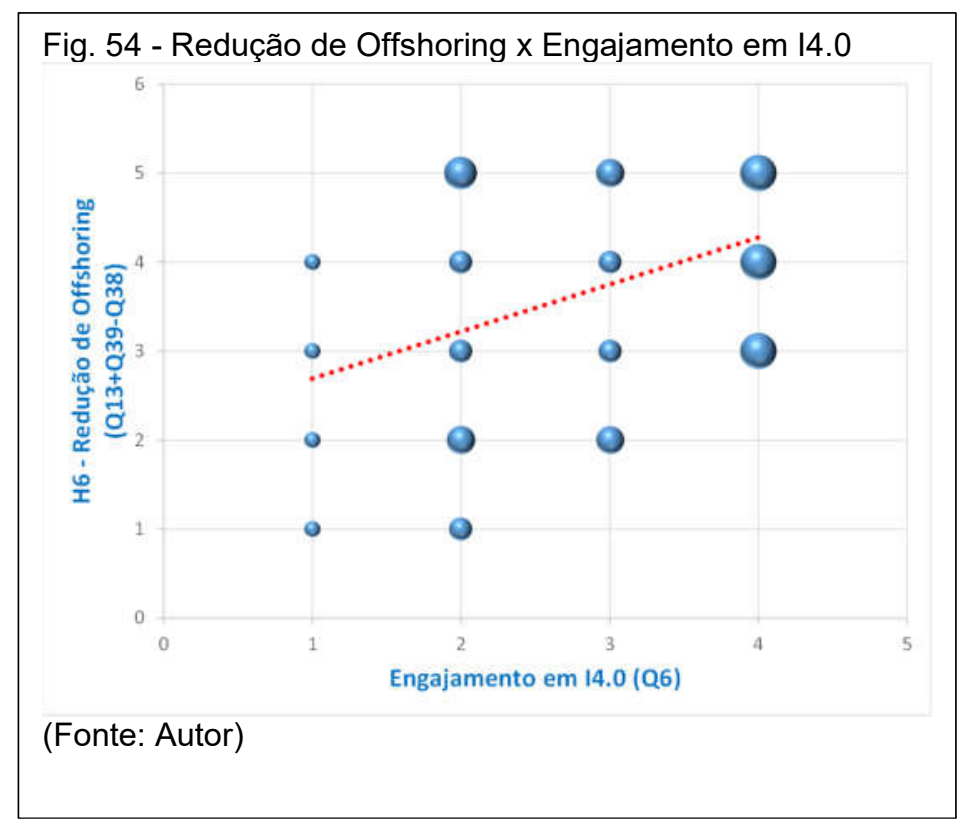

\subsubsection{Hipótese 7 - Maior Risco Cibernético para Ambiente Industrial}

O risco de ataques cibernéticos a equipamentos industriais já foi reportado em estudos acadêmicos e é uma realidade mesmo antes desta conectividade em massa dos dispositivos físicos que pretende a 14.0. Com o aumento da conectividade, é até intuitivo supor que os riscos cibernéticos para o ambiente industrial irão aumentar. $A$ survey confirma esta tendência de acordo com o gráfico da Fig. 55, porém de maneira menos proeminente que nos outros impactos. 
Fig. 55 - H7 Risco Cibernético x Engajamento em 14.0

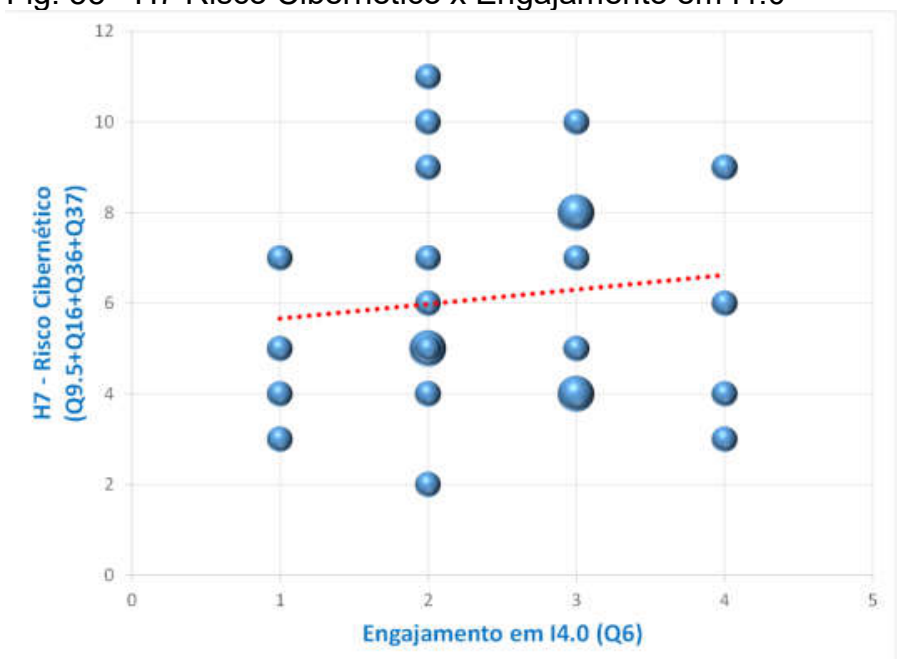

(Fonte: Autor)

\subsubsection{Hipótese 8-Aumento de oferta de Produtos como Serviços}

Outro impacto colateral previsto na literatura é que a 14.0, baseada em uma arquitetura orientada a serviços, favoreça o aumento de ofertas de produtos como serviços, ao que se tem denominado Servitização. Esta hipótese tem sido percebida como indiferente em relação ao nível de engajamento com a 14.0 pelos respondentes da survey conforme se vê pelo gráfico de tendência da Fig. 56.

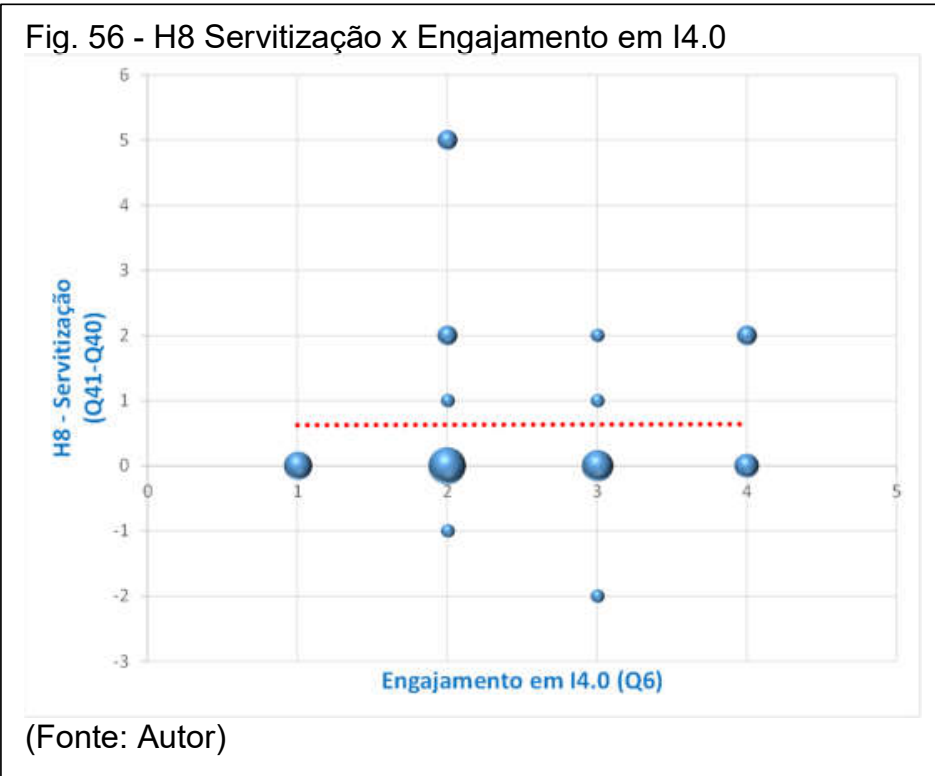




\subsection{ESTUDO DE MÚLTIPLOS CASOS}

Conforme já citado anteriormente este estudo de múltiplos casos tem o objetivo de aprofundar o entendimento das reações das empresas brasileiras de manufatura à iniciativa 14.0. Tem ainda o objetivo de tentar entender com maior profundidade as tendências de percepções apontadas pela Survey no tocante aos impactos hipotéticos, principalmente as hipóteses que foram rejeitadas.

As unidades de estudo foram escolhidas por conveniência e incluíram três empresas fornecedoras de tecnologia mais representativas do mercado brasileiro, quatro fornecedores de infraestrutura (integradores) que estivessem promovendo a implantação da 14.0 e quatro usuários industriais engajadas na implantação dos conceitos da 14.0, nas regiões de Santa Catarina, Paraná e São Paulo, que também são regiões representativas do mercado brasileiro.

O questionário da survey respondidos por e-mail revelou que o cenário da indústria brasileira ainda é de pouco entendimento e pouco engajamento prático dos usuários industriais à plataforma Indústria 4.0, confirmando a sondagem feita pela CNI (2016). Porém, esta dificuldade de entendimento existe mesmo entre os promotores da plataforma Indústria 4.0 (fornecedores de tecnologia e integradores), que não foram concordantes na caracterização do marco de transição da Indústria 3.0 para a Indústria 4.0 na forma de uma mudança radical. Para a Empresa UI1 o que caracteriza a transição para a 14.0 é a conectividade padronizada, já na visão da Empresa FT2 a 14.0 (ou Connected Enterprises) se baseia em três pilares: dispositivos inteligentes, maximização dos ativos e segurança de dados. Já a Empresa FT1 entende que o marco está no momento em que se padronizou a Ethernet para redes industriais.

Segundo Empresa FT2 a implantação da plataforma 14.0 pode ser feita gradativamente em etapas, em que a primeira etapa consiste em criar uma infraestrutura para coletar dados, ou seja, conectar os equipamentos e dispositivos no chão de fábrica. A segunda etapa consiste em coletar os dados das máquinas e dispositivos, a terceira analisar estes dados e a quarta tomar ações sobre elas, fechando um ciclo PDCA. Neste ciclo, os sistemas analíticos são de fundamental importância posicionando-se na camada MES ou na camada ERP que em etapa posterior se estenderia para a rede colaborativa. 
Com relação à tendência de controle distribuído acabar suprimindo a necessidade de CLP's a Empresa FT2 entende que o controle das máquinas não pode ser tão pulverizado e que continuarão a existir CLPs na fábrica do futuro, porém incorporando funcionalidades loT. Isto implica em ter uma interface de encapsulamento de suas funções como Web Service, permitindo uma conectividade autônoma com outros sistemas. Esta tendência pôde ser vista na nova geração de CLP com backbone em Ethernet desenvolvida pela Empresa FT3.

\subsubsection{Desafios para a Implantação da Plataforma I4.0}

Conforme citado no item 4.3, uma questão complementar foi levantada para se compreender o motivo pelo qual o nível de engajamento prático à plataforma 14.0 pelas empresas brasileiras ainda é baixo. Os possíveis motivos foram identificados através da revisão bibliográfica e questionados aos fornecedores de tecnologias e infraestrutura durante o estudo de múltiplos casos. Além das empresas arroladas no estudo de múltiplos casos, cinco outras empresas destes grupos de atores também foram questionadas. A questão colocada no item 10.1 do ANEXO D foi a seguinte:

Quais são as maiores dificuldades colocadas pelos seus clientes industriais para a implantação da $14.0 ?$

As dificuldades percebidas pelos usuários industriais para a implantação da 14.0, segundo fornecedores de tecnologias e infraestruturas estão ilustradas na Fig. 57. Apesar destes resultados estarem quantificados em forma de gráfico, eles não representam resultados de um estudo quantitativo (para o que a amostragem seria insuficiente), mas sim fruto das opiniões verificadas através de estudo de múltiplos casos com as empresas fornecedoras de tecnologia e infraestrutura mais representativas do país. 
Fig. 57 - Desafios para a Implantação da Plataforma 14.0

\section{Desafios à Implantação Plataforma 14.0}

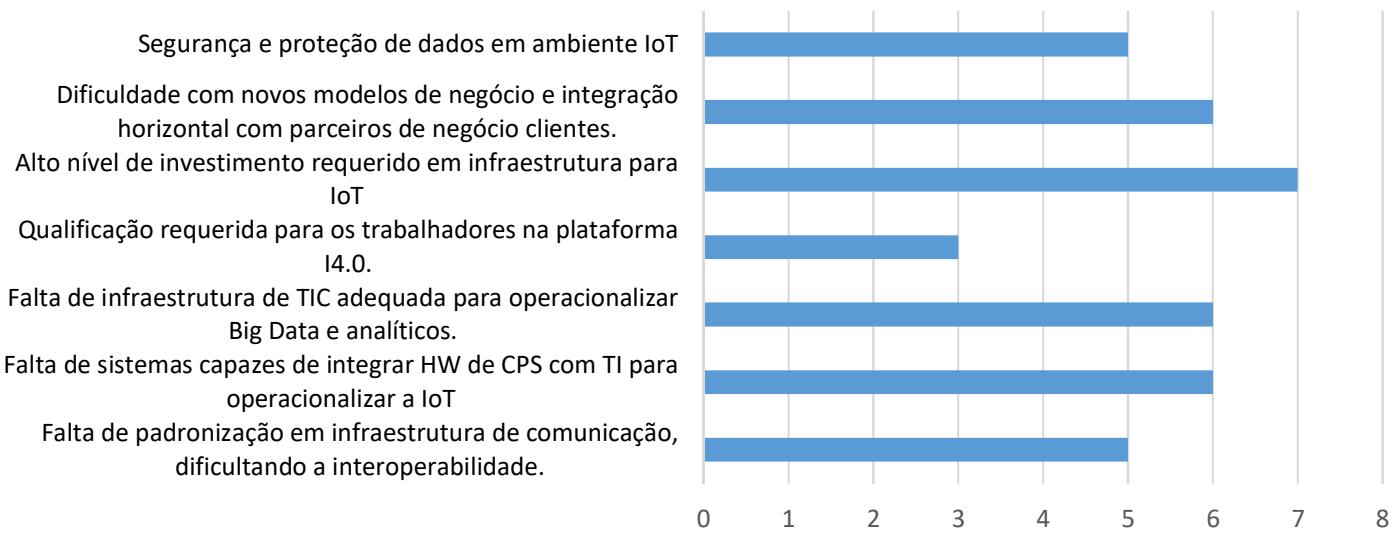

(Fonte: Autor)

Segundo este estudo, as empresas brasileiras em geral relutam em iniciar um engajamento prático à 14.0 devido ao alto nível de investimento requerido e dificuldade em justificar o retorno. Algumas das empresas estudadas citaram também o momento econômico desfavorável e incerto que o país enfrenta como agravante para inibir o investimento nesta área (no período em que se realizou o estudo, várias empresas de grande porte estavam encerrando as atividades no país).

Em segundo lugar foram citadas as dificuldades com novos modelos de negócio, a falta de infraestrutura de comunicação no país e falta de sistemas capazes de integrar os HW de CPS com sistemas de TI. Segundo o estudo de múltiplos casos, a dificuldade com os modelos de negócios se traduzem principalmente no fato de a maioria dos usuários industriais serem incapazes de enxergarem como a 14.0 pode ser utilizada para gerar novos negócios e também por ainda não existir um modelo de implantação pronto que pudesse ser utilizado como referência. Mesmo as empresas usuárias industrias que foram identificadas como "iniciando a implantação" ainda estavam em estágio bastante incipiente, tentando definir padrões.

A infraestrutura de internet do país também foi criticada por alguns dos entrevistados como um obstáculo para sistemas de big data e sistemas em nuvem.

A falta de sistemas que pudessem ser utilizados para integrar o HW CPS com sistemas de $\mathrm{TI}$, citado como outro obstáculo à implantação, reflete o estado incipiente em que se encontra a tecnologia com relação a modelos de sistema e arquitetura para a integração vertical nas empresas. O que se viu nas empresas fornecedoras de 
infraestrutura é que esta integração ainda está sendo feita segundo o modelo CIM e não no modelo SOA. Outras empresas tentam ocupar o mercado de convergência entre TI e TO através de sistemas como o MES e APS. Identificaram-se soluções tecnológicas tais como CLPs com barramento em Ethernet, mas não se encontrou nenhum SW de encapsulamento destes CPS como serviço para que pudessem ser integrados sob uma arquitetura SOA. O que se conclui dos casos estudados é que mesmo as empresas que detém tecnologia não possuem ainda um padrão de integração SOA e de semântica comum com outros fornecedores de tecnologia e infraestrutura.

A segurança de dados, principalmente a proteção da propriedade intelectual em ambiente colaborativo foi apontada como obstáculo significativo embora a Survey tenha apontado uma tendência negativa à percepção de riscos cibernéticos (Fig. 55) com o aprofundamento no engajamento à 14.0. Segundo os entrevistados, o que mais se vê como obstáculo é a segurança de dados e de conhecimentos na rede colaborativa e não com os dispositivos na fábrica, pois para estes acreditam ter soluções como a proposta pela Rockwell - Cisco.

Embora a survey tivesse apontado que o engajamento com a 14.0 traz a percepção de maior necessidade de qualificação profissional (Fig. 53) isto parece ser o menor dos obstáculos para se engajar na implantação prática segundo os entrevistados. Argumentam que muitos jovens já possuem habilidade nata em lidar com este ambiente conectado e acrescentam também que a evolução tecnológica deve criar ferramentas e interfaces que facilitam a usabilidade, a exemplo de sistemas operacionais de computadores e smartphones.

\subsubsection{Reação das Empresas Brasileiras}

Um dos objetivos desta pesquisa era compreender, do ponto de vista de gestão, como as empresas brasileiras estão reagindo às mudanças de paradigma em automação da manufatura lideradas por iniciativas como a 14.0 e similares. Para responder esta questão, retomou-se o constructo da Fig. 45. No constructo temos os impactos hipotéticos da 14.0 nos Sistemas de Manufatura representadas pelas linhas e os grupos de atores da CFSAM representadas nas colunas. As reações são estudadas nestes segmentos localizadas nas intersecções entre linhas e colunas, em 
que se buscou identificar o que cada grupo de atores da CFSAM está fazendo em relação a cada impacto.

O estudo de múltiplos casos revelou que as reações são mais concentradas em alguns destes segmentos, notadamente nos segmentos relacionados ao aumento de eficiência nos sistemas de manufatura. Neste segmento observou-se que há reação por parte dos três grupos de atores no sentido de proporcionar maior conectividade no chão de fábrica e disponibilizar mais informações em tempo real promovendo controles e tomadas de decisão mais precisas na produção.

As reações para cada um dos impactos hipotéticos são discutidas a seguir, baseadas nas constatações feitas durante visitas às instalações, nas entrevistas com os gestores e nos materiais disponibilizados pelas empresas. Nestas análises discutese ainda as divergências encontradas entre o estudo de múltiplos casos e as tendências verificadas através dos dados coletados pela Survey.

\subsubsection{Aumento da Eficiência}

Para atender às demandas de coleta de dados verificou-se que o uso de tecnologias como RFID's, QR Codes e código de barras já são largamente utilizados para rastrear o produto ao longo dos processos de manufatura, mas também ao longo de toda a cadeia de fornecimento. A utilização da rede industrial Ethernet e a OPC como padrões para integrar equipamentos industriais com os sistemas de TI também foi observado como uma tendência, onde cada vez mais máquinas e equipamentos são oferecidos com portas de comunicação Ethernet e funcionalidades de web service. No entanto, verificou-se nas empresas estudadas, que apesar de oferecerem conectividade física, ainda não existe uma interface padronizada de SW voltada a arquitetura orientada a serviços.

Dentre os fornecedores de infraestrutura, alinhados com o objetivo de proporcionar melhor eficiência, observou-se a oferta de sistemas supervisórios e de Business Intelligence $(\mathrm{BI})$ apresentando dados da produção e índices de performance em tempo real. Além disso, sistemas como MES, MON e APS também foram citados, mas na maioria apenas com função de monitoramento.

Dentre os usuários industriais engajados na implantação da plataforma 14.0, a Empresa UI1 adotou a estratégia de se iniciar pela conectividade de máquinas e 
monitoramento de índices de eficiência produtiva em tempo real. Segundo o gestor de TI/TO desta empresa isto traz maior precisão e assertividade nas tomadas de decisão. Cita ainda outras perspectivas futuras de integrar com a cadeia de fornecedores como forma de melhorar a eficiência e melhorar a visibilidade do processo produtivo.

De acordo com as empresas estudadas, dentre os resultados previstos na literatura, as empresas objetivam principalmente, o aumento da competitividade através da eficiência produtiva ao implantar a plataforma Industria 4.0. Este aumento de eficiência é baseado em coleta e análise de informações em tempo real da produção. A Empresa UI1 cita que a automação do processo e coleta de dados através de sistemas conectados podem trazer ainda ganhos pela redução de custos, uma vez que enquanto o custo da mão de obra cresce no Brasil, o custo da tecnologia decresce. A aquisição de dados de chão de fábrica de maneira automática e em tempo real é visto pelas empresas usuárias finais como instrumentos indicadores indispensáveis para "pilotar" a manufatura com assertividade evitando os desperdícios e aumentando a eficiência da produção. É um dos benefícios mais imediatos vislumbrados pelos usuários industriais estudados e que já é uma prática em muitas empresas no Brasil. O que ocorre, no entanto, é que a maioria das empresas possui sistemas conectados através de redes proprietárias ou até mesmo no padrão Ethernet, mas não possuem infraestrutura SOA. Mesmo as empresas que dizem estar implantando a conectividade como a Empresa UI1, ainda não tem implantada a base da 14.0 que é a arquitetura SOA pelo simples fato de a tecnologia loT não estar disponível ainda no platô da produtividade. Mesmo a conectividade com as máquinas e dispositivos requer uma interface que encapsule suas funções como serviço o que ainda não ocorre na maioria das instalações com conectividade. Isto faz com que a conectividade e a coleta de dados ainda sejam uma tarefa bastante complexa, trabalhosa e onerosa como na clássica instalação CIM.

Contudo, a Empresa UI1 entende que a maioria das fábricas com equipamentos legados não irá substituí-los para se ter uma infraestrutura de 14.0 devido aos altos custos envolvidos. Acredita que a solução será promover a conectividade destes equipamentos legados com computadores que poderão desta maneira coletar os dados necessários para os analíticos e indicadores que permitirão pilotar a fábrica com maior assertividade. 
Diante destas experiências árduas de conectividade e coleta de dados a percepção das empresas estudadas é que a 14.0 facilitaria sobremaneira esta conectividade e a coleta de dados. Esta conclusão endossa o gráfico de tendência da Survey e a hipótese de que a 14.0 contribui positivamente para o aumento de eficiência.

\subsubsection{Aumento de Agilidade}

Segundo Erl (2006) a SOA promove maior agilidade organizacional e é possivelmente o benefício mais significativo que esta arquitetura pode proporcionar. Conforme já comentado anteriormente, a literatura identifica a aplicação do conceito SOA como a mudança disruptiva que separa a 13.0 da 14.0 e é a combinação de CPS com SOA que proporciona esta agilidade no ambiente industrial permitindo a comunicação autônoma entre máquinas, reconfigurações e ajustes autônomos. Contudo, em nenhuma das empresas estudadas esta infraestrutura foi identificada. $O$ que se viu foram iniciativas para a implantação da virtualização de fábrica e sistemas simuladores para robôs, que é uma das possibilidades tecnológicas previstas sobre a plataforma 14.0, mas que não depende necessariamente de uma infraestrutura combinada de CPS e SOA. Estas iniciativas visam proporcionar agilidade aos processos industriais e de negócio.

Segundo a Empresa Fl2 alguns clientes brasileiros já têm investido em digitalização da fábrica, conhecido nos Estados Unidos como Digital Twin ou Fábrica Digital, que permite utilizar modelos eletrônicos da fábrica para realizar simulações. Uma das aplicações citadas pela Empresa FI2 foi a possibilidade de simular o trajeto de robôs para verificar previamente o alcance e colisões das ferramentas nas rotas planejadas na programação.

Outras possibilidades observadas foram:

- Estudos de arranjos de lay out de máquinas, rotas de tubulações, etc. permitindo aos planejadores simular as mudanças em modelos digitais antes de sua execução física.

- Utilização de um SW de simulação em realidade aumentada utilizada por uma empresa do segmento automotivo para testar a ergonomia de uma bancada de montagem apenas com o modelo digital antes de sua construção. 
- Uso de modelos digitais utilizados na engenharia concorrente de peças na indústria automotiva para desenvolvimento de processo e meios de produção (moldes, gabaritos de solda, dispositivos de montagem) paralelamente ao desenvolvimento do produto agilizando o tempo de lançamento.

- A Siemens já oferece aos usuários industriais o seu SW de gestão de ciclo de vida dos produtos chamado de PLM no conceito de integração ponta a ponta citado por Wang (2015).

- Outras simulações feitas com modelos digitais para verificar a resistência de peças mecânicas, o funcionamento de lógicas de controladores, etc.

Através destes exemplos verifica-se que a virtualização já está em uso em algumas empresas usuárias industriais no Brasil, mas é uma possibilidade tecnológica que não depende necessariamente da plataforma 14.0. Estas virtualizações que foram percebidos em uso ocorrem todas em ambientes da 13.0 e não da 14.0 uma vez que não aproveitam o potencial de uma infraestrutura conectada e autônoma orientada a serviços. Por este motivo, não se pode dizer que a agilidade proporcionada por estas aplicações são realmente impactos da 14.0.

O desenvolvimento colaborativo e concorrente com o uso de modelos CAD digitais e a produção colaborativa através de sistemas EDI também são realidades na manufatura brasileira, porém também praticada ainda em ambiente 13.0.

Concordante com a survey, não foi evidenciada nenhuma percepção por parte das empresas estudadas, de como um ambiente mais conectado através da plataforma 14.0 poderia melhorar o processo de virtualização ou de digitalização no estágio atual da 14.0. Nem tampouco foram observadas outras iniciativas nestas empresas no sentido de utilizar a plataforma $14.0 \mathrm{com}$ o propósito de obter maior agilidade, excetuando-se a agilidade na coleta de dados, já interpretada como um impacto no aumento da eficiência.

O estudo de múltiplos casos confirma assim a tendência de percepção, já apontada na survey, de que as empresas brasileiras não conseguem relacionar benefícios que possam proporcionar maior agilidade com o engajamento à 14.0. Isto pode ser explicado pelo fato de que a comunicação M2M e integração com os sistemas de $\mathrm{TI}$ ainda estejam numa realidade distante e pelo fato de muitos ainda terem em mente a arquitetura da I3.0 como referência.

\subsubsection{Aumento de Flexibilidade}


Características como flexibilidade e customização já podem ser percebidos em algumas indústrias, porém com restrições. A individualização (customização em massa) e escalabilidades conforme previstos nos conceitos da 14.0 também são vistos como uma realidade bastante distante pelas empresas estudadas, principalmente considerando o parque de equipamentos legados existentes no Brasil. Para que a flexibilidade e a individualização na produção sejam possíveis, não basta a conectividade e sistemas de informação inteligentes. É necessário que haja também equipamentos que permitam essa total flexibilidade, o que com a atual tecnologia ainda é vista como uma realidade distante. Através do estudo de caso de um equipamento adquirido pela Empresa UI4, percebe-se que para auferir maior flexibilidade de forma autônoma aos equipamentos é necessário que os componentes se tornem cada vez mais ciberfísicos, e mesmo assim, com muitas restrições. Dessa forma, seria muito difícil, se não impossível, auferir flexibilidade total aos equipamentos legados mesmo com upgrades tecnológicos. Isto torna o investimento oneroso e os benefícios desta flexibilidade não são tão evidentes e quantificáveis à vista dos entrevistados.

O estudo de caso de um equipamento adquirido pela Empresa UI4 permitiu verificar as diferenças obteníveis em flexibilidade e escalabilidade de produção comparando-se duas concepções diferentes de um equipamento com a mesma função. Trata-se de um equipamento de teste de durabilidade usado em laboratório onde pôde-se constatar duas concepções distintas.

A primeira versão do equipamento consistia de três unidades de teste de durabilidade do produto, controlado por um painel central, no qual um CLP Siemens S7-1200 e IHM Siemens controlavam e monitoravam os parâmetros de teste dos três equipamentos de teste.

A comunicação entre o painel de controle e as unidades de teste eram feitas através de cabos e mangueiras físicas dificultando mudanças de layout e a inclusão mais unidades de teste. A configuração de parâmetros de teste e monitoramento eram realizadas diretamente na IHM do painel central ou na pequena botoeira de comando na unidade de teste. As unidades de teste eram compostas de atuadores lineares pneumáticos de tal forma que o ajuste do deslocamento do cilindro era feito através de batentes mecânicos e o ajuste de velocidade através de válvulas reguladoras mecânicas, diretamente no cilindro pneumático. 
Os sensores magnéticos permitiam verificar a posição inicial ou final do cilindro e um outro sensor eletrônico de proximidade permitia indicar a quebra do produto. Todos estes sinais eram conectados através de cabos até o controlador central. Caso um quarto equipamento precisasse ser incluído o painel de controle deveria ser ampliado com a adição de mais módulos de E/S (entradas e saídas) e bornes para conexão com o quarto equipamento. Além disso, um novo programa incluindo o quarto equipamento no CLP e na IHM seria necessário, o que dificultava sobremaneira a inclusão de novas unidades (escalabilidade). Além disso, quando o painel de controle central apresentava problemas, todas as unidades de teste eram afetadas.

Sendo o teste de durabilidade de longa duração, a interrupção ou falha no equipamento de teste antes da sua conclusão significava a perda completa do teste. Muitas vezes de dias ou semanas de teste, que deveriam ser refeitas. Além disso, o acompanhamento contínuo "in loco" se fazia necessário para detectar uma situação irregular de teste.

Visando uma robustez maior, flexibilidade, escalabilidade e acesso remoto foi desenvolvida uma segunda versão do equipamento.

A segunda versão possuía controle individual com CLP e IHM Omron, com conectividade Ethernet e um Access Point WiFi. O atuador pneumático foi substituído por um atuador linear com servomotor (CPS) o que permitia ajustes de curso, posições de parada, velocidade e força de forma eletrônica através dos parâmetros ajustados na IHM. Através de um web service disponibilizado pela fabricante da IHM foi possível espelhar a IHM, através da rede, em computadores Windows ou mesmo em celulares ou Tablet Android ou iOS. Através dessa interface foi possível ajustar os parâmetros e monitorar o andamento dos testes remotamente por qualquer um destes dispositivos. Adicionar um outro equipamento (escalabilidade) ficou tão simples quanto trazer o novo equipamento ao laboratório e plugá-lo na tomada e ajustar a conectividade WiFi. Configurações de teste tais como velocidade, distância de deslocamento, velocidade e força ficaram tão fáceis quanto ajustar um parâmetro através da interface remota da IHM, sem falar da mudança de layout que também ficou muito facilitada sem a conexão com um painel de controle central. A segunda geração permitiu maior flexibilidade, tanto de operação como de posicionamento físico no laboratório, através de conectividade WiFi, descentralização do controle e implementação de um atuador ciberfísico -conceitos da 14.0 - embora faltasse ainda a 
rede em arquitetura SOA. Com isto, conseguiu-se também uma confiabilidade maior do sistema em virtude da eliminação de um controlador central.

Este caso permite perceber a necessidade de elementos CPS no chão de fábrica (atuadores e sensores com estrutura ciberfísica) e modularizar os equipamentos com interfaces padrões para tornar os sistemas mais flexíveis de forma autônoma. Mostra ainda que mesmo com os CPS, as partes mecânicas remanescentes impõem ainda uma série de restrições para que um sistema se torne completamente flexível e autônomo. Este estudo indica que embora tecnologias disruptivas como a manufatura aditiva estejam surgindo, a escalabilidade, a flexibilidade total e a customização em massa ainda são cenários longe da realidade em virtude da dificuldade, senão da impossibilidade, de desenvolvimento de uma solução de HW que atenda todas as necessidades de flexibilização e customização. Mostrou também que para se obter esta flexibilidade é necessário adquirir novos equipamentos conceitualmente alinhados com os princípios da 14.0, sendo muito difícil, se não impossível adequar equipamentos legados para esta nova funcionalidade.

O segundo caso tratava-se de uma linha de montagem de componente automotivo, onde o controle dos vários postos de montagem era feito através de um único painel central. Outra centralização envolvia a unidade de potência hidráulica que também distribuía o óleo hidráulico para vários dispositivos de movimentação e prensagem ao longo da linha. $\mathrm{Na}$ aquisição de uma segunda linha de montagem os vários postos de montagem foram individualizados cada qual com seu painel de controle com CLPs e unidades hidráulicas menores. Isto permitiu que os postos modularizados pudessem ser retirados ou adicionados de acordo com a necessidade dos vários modelos de produtos proporcionando grau maior de customização e escalabilidade à linha. A coleta de dados e a comunicação destas bancadas modularizadas com o sistema supervisório da linha foram viabilizadas através da utilização de PLCs com conexão Profinet compatível com o padrão Ethernet, permitindo conectar os CLPs diretamente com a rede de computadores da empresa.

No terceiro estudo de caso na Empresa UI2 foi possível estudar-se uma célula de produção protótipo 14.0 construído para fins acadêmicos. Nela constatou-se também uma característica de modularidade, com interfaces padrão, proporcionando facilidades para compor as unidades funcionais na ordem e quantidades desejadas 
permitindo fácil e rápido rearranjo da linha. Embora estes rearranjos precisassem ser feitos manualmente, muitos dos conceitos da 14.0 estavam incorporados neste protótipo de CPPS.

Estes três casos mostram que para permitir flexibilidade na produção, quer para viabilizar uma produção customizada ou auferir escalabilidade, a modularização em blocos funcionais padronizados é essencial. Outro aspecto é que estes módulos precisam utilizar componentes ciberfísicos para que possam responder a comandos digitais e possa fornecer informações também de forma digital. Por exemplo, o uso de atuadores como servomotor e robôs ao invés de atuadores pneumáticos ou hidráulicos que têm maior dificuldade de se comunicar e responder de forma mais flexível aos comandos digitais.

Diante destas constatações percebe-se que o benefício da flexibilidade plena ainda está longe da realidade das empresas brasileiras mesmo com a implantação da plataforma 14.0, principalmente para aquelas empresas com grande parque de equipamentos legados. A reação demonstrada no gráfico de tendências pelos respondentes da Survey retrata, portanto, esta percepção de que o investimento na implantação da plataforma 14.0 não traz este benefício para as empresas brasileiras, pelo menos num futuro próximo.

\subsubsection{Maior Oportunidade para as PME's}

Nos estudos realizados não se constatou a emergência de PMEs como fornecedor de tecnologia. Contudo, constatou-se a presença destes como integradores desenvolvendo infraestruturas e sistemas. Verificou-se também a participação das PMEs na rede colaborativa de desenvolvimento e produção das empresas de manufatura de grande porte.

A oportunidade para as PME's pode surgir ao aderirem às redes de colaboração através da plataforma 14.0 que vão permitir oferecer produtos e serviços no mesmo nível de eficiência que as grandes, segundo alguns dos entrevistados. No entanto, aqui no Brasil as PME's como usuários industriais ainda não veem isso como importantes. Atores como a Empresa FI2 que é uma empresa de médio porte, enxerga a 14.0 como uma oportunidade de se obter vantagem competitiva na função de integrador desta plataforma. Num momento mais imediato, oportunidades que a 14.0 
pode trazer para as as PME's no Brasil são para as empresas que participam da CFSAM como fornecedoras de tecnologia ou de infraestrutura (integradores). As oportunidades para as PME's como usuários industriais tendem a aparecer mais após a consolidação da plataforma 14.0 como participantes das redes colaborativas. E a boa notícia é que as PMEs não precisam necessariamente possuir uma infraestrutura de Smart Factory para participar destas redes. A Empresa FI3 também acredita que a rede colaborativa da 14.0 irá inserir as PMEs no negócio pela possibilidade de compartilhar recursos e consequentemente habilitar-se com investimentos menores.

Conforme citado por Rifkin (2012), a 14.0 irá democratizar a manufatura dando mais oportunidade para as PMEs. Como já visto no item anterior sobre a flexibilidade, a modularização em unidades menores com interfaces padrões permite maior flexibilidade na manufatura, facilitando rearranjos e a escalabilidade e linhas de produção. Com a Cloud Manufacturing um novo horizonte de possibilidades se abre considerando os recursos externos de produção em uma rede colaborativa aberta onde as PMEs poderiam proporcionar esta modularidade com estruturas menores e mais ágeis (FESTO, 2015).

Contudo a Empresa FT2 entende que ainda há muito preconceito por parte das PMEs que acham que a 14.0 é coisa apenas para grandes empresas, mas acredita que a rede colaborativa irá viabilizar muito para as PMEs. No entanto, para que as PMEs possam participar das redes da 14.0 os requisitos principais são a incorporação da loT, loS e Smart ERP pois mesmo não tendo Smart Products e Smart Machines elas precisarão estar conectadas com as demais empresas. No mínimo a Smart ERP terá que estar implantada para conseguirem expor seus serviços ou produtos na rede e conectar de forma automatizada com as demais empresas.

Este preconceito, ou a falta de visão, pode explicar a tendência negativa ao aumento de oportunidade para as PMEs com a disseminação da plataforma 14.0 apontado na Survey (Fig. 52). Contudo, na visão das empresas estudadas, as oportunidades para as PMEs estão nas redes colaborativas e será fundamental que as PMEs tenham pelo menos a conectividade de negócios implantada para poder participar destas oportunidades.

\subsubsection{Novas demandas na Qualificação Profissional}


$\mathrm{Na}$ visão de alguns entrevistados, hoje existe uma separação clara entre programadores focados em dispositivos industriais e programadores de bancos de dados. Em outras palavras, há uma clara distinção entre profissionais da TO e profissionais da TI e é um consenso entre os entrevistados que há uma grande dificuldade em encontrar as duas habilidades em um único profissional. Esta dificuldade é devido ao fato de conceitos e até mesmo termos e jargões serem completamente distintos nestes dois mundos da automação.

Existe ainda a visão de muitas empresas (Honeywell, Empresa FT3, Empresa FT2 etc.) de que a zona de convergência da TO com a TI representa hoje, uma lacuna ainda não preenchida e, portanto, uma oportunidade de atuação para os fornecedores de infraestrutura. Um dos entrevistados cita que hoje as empresas possuem departamentos distintos que cuidam de TO e TI e sugere que para a implantação da 14.0 estes departamentos deveriam ser um único departamento desenvolvendo projetos em conjunto. Esta zona de convergência entre TO e TI ocorre justamente na camada 3 e 4 da ISA-95 da Fig. 3. Visto como uma lacuna, pode-se ver estratégias claras de empresas, tanto de Fornecedores de Tecnologia (TO) como de Fornecedores de Infraestrutura (TI) apressando-se para conquistar este espaço representativamente ocupado por sistemas MES.

As empresas entrevistadas que buscam posicionar a atuação nesta zona preenchem esta falta de qualificação profissional contratando uma equipe multidisciplinar. Uma das empresas que trabalha com o lançamento de uma nova plataforma para IoT e um novo sistema ERP compatível com um ambiente mais conectado revela que mesmo sendo ela especializada em sistemas ERP, os desenvolvedores internos precisam atualizar suas habilidades pois novas ferramentas serão necessárias para atuar nesta nova plataforma. Neste novo ambiente onde se discute o grande valor dos sistemas analíticos como o propulsor da eficiência produtiva e gerencial, o domínio de habilidades em estatística e engenharia de produção também é reconhecidamente importante. Mesmo dentro de TO várias novas tecnologias surgem a cada dia e há dúvida, entre os entrevistados, se um único profissional poderá reunir todas estas habilidades. De qualquer forma, instituições profissionalizantes como SENAI já estão propondo discutir o tema, e estudando o lançamento de cursos preparatórios para formar os profissionais da 14.0, como é o caso da unidade de Mecatrônica de São Caetano do Sul, SP. Há quem aposte também 
na capacidade dos jovens profissionais autodidatas que vão aprendendo na medida da necessidade. Na opinião deste entrevistado, a maior necessidade será de profissionais com perfil para autoaprendizado contínuo pois os avanços tecnológicos serão tão intensos que os cursos profissionalizantes não serão capazes de acompanhar as demandas do mercado. Porém há um consenso entre eles de que o coordenador ou gestor destes projetos deve ser um generalista e ter conhecimento técnico sobre todas as áreas tecnológicas envolvidas.

$\mathrm{Na}$ visão da Empresa UI3 a capacidade de aprendizado dos jovens profissionais motivados é surpreendente com relação a novas tecnologias e no nível de usuário. Acredita que como usuário, a qualificação de pessoal não é o grande problema. Mesmo porque a velocidade de evolução tecnológica é muito alta e os profissionais precisarão estar constantemente se atualizando. Além disso, acredita que o desenvolvimento de novas tecnologias deverá também oferecer ferramentas que facilitem o seu uso.

Através deste estudo de múltiplos casos, confirma-se a tendência apontada na Survey (Fig. 53) de que quanto mais engajada à 14.0, mais se percebe a necessidade de novas demandas na qualificação profissional dos trabalhadores da 14.0.

\subsubsection{Redução de Offshoring da Produção}

Um dos resultados esperados pelo governo alemão com a plataforma $14.0 \mathrm{e}$ pelos americanos com lloT é a repatriação da produção transferida para países com custo de mão de obra mais baixos. Segundo a Empresa FT1, a tendência é de que as grandes empresas de tecnologia levem a produção de volta para os seus países de origem. Considerando que a maioria das empresas de tecnologia não são brasileiras, a tendência é que o Brasil perca estas empresas de tecnologia, que não têm raízes brasileiras. Como estes avanços tecnológicos estão ocorrendo em outros países do mundo, aqueles países que não investirem em tecnologia vão ficar sem as indústrias de manufatura e ficando apenas com as indústrias primárias. Concordante com esta opinião a Empresa UI1 argumenta que o custo da tecnologia no Brasil está caindo, porém ainda é mais cara do que em outros países devido à tributação. Por outro lado, o custo da mão de obra no Brasil incluindo os encargos está subindo. Comparado a outros países, o que a mão de obra brasileira produz por hora é inferior ao que se 
produz em outros países e, portanto, o que puder ser fabricado em outro país irá embora.

Na opinião da Empresa FI1, o Brasil hoje não tem nem mão de obra barata nem tecnologia, então investir em plataforma 14.0 seria uma forma de trazer a produção para o país. Segundo a Festo (2015), as fábricas do futuro serão pequenas, flexíveis, móveis e locais. Isto abre oportunidade para as empresas brasileiras, principalmente as PMEs desde que estejam inseridas na rede colaborativa da plataforma 14.0 e assim poderiam incrementar a produção local. A Empresa FT2 também é da opinião de que com investimento em tecnologia pode-se vencer a concorrência e tornar produtos brasileiros competitivos e desta maneira manter a produção no país.

A Empresa FT3 acredita que as empresas no Brasil ainda estão longe de chegar ao nível da 14.0 e que, portanto, esta redução de Offshoring também está longe de acontecer. Por outro lado, acredita que com a aceleração de outros países na implantação da plataforma 14.0 as empresas no Brasil também deverão começar a investir em tecnologia.

A conclusão que se chega com este estudo é de que embora altamente divulgada em seminários e feiras internacionais de que a plataforma 14.0 pode repatriar a produção de volta ao país de origem, as opiniões entre as empresas brasileiras estudadas estão divididas sobre a influência da 14.0 em trazer a produção para o Brasil. Se por um lado, a Festo (2015) prevê que com a 14.0 a produção tende a ser mais local próximos aos consumidores, outros opinam que a repatriação da produção de alta tecnologia pelos países de origem irá fazer com que mais empresas de manufatura deixem o país. Com isto, a tendência de percepção pelos respondentes da Survey de que haverá uma redução de Offshoring pode estar refletindo mais uma opinião dos países líderes da iniciativa 14.0 e similares do que a realidade brasileira.

\subsubsection{A 14.0 traz maior risco cibernético para o ambiente industrial}

A Empresa FT2 considera a segurança como um dos três pilares fundamentais para um ambiente industrial conectado. Para tanto, associou-se à empresa Cisco para oferecer soluções de conectividade industrial com robustez e segurança. Criou ainda o conceito de fog para processamento de dados em ambiente industrial restringindo o tráfego de dados diretamente à Big Data na Nuvem. 
Rockwell Automation e Cisco (2015), especialistas no segmento de TO e TI respectivamente, formaram uma aliança para oferecer soluções seguras para a integração do chão de fábrica (TO) com sistemas de negócios ( $\mathrm{TI}$ ) através da proposta de uma rede aberta de Sistemas de Automação e Controle Industrial (IACS). Para proporcionar segurança a esta rede, propõem a separação da rede industrial com a rede de negócios através de uma Zona Desmilitarizada Industrial (IDMZ) conforme mostra a Fig. 58. Através desta zona o tráfego de informações seria controlado através de um firewall, não permitindo acesso direto IACS. Isto definitivamente não permitirá uma conexão direta M2M de dispositivos do chão de fábrica com outros dispositivos de outras empresas. Além deste controle, a Empresa FT2 propõe também o conceito de Fog no qual a quantidade massiva de dados seria pré tratada antes de subir aos níveis superiores. Com isto, os dados coletados pelos sensores não seriam transferidos para os chamados Big Data localizado nas nuvens, poupando com isto a necessidade de infraestrutura de internet para o tráfego de dados para a nuvem. Desta forma assegura-se também que o trafego de dados através da zona desmilitarizada será restrito apenas aos dados que interessam.

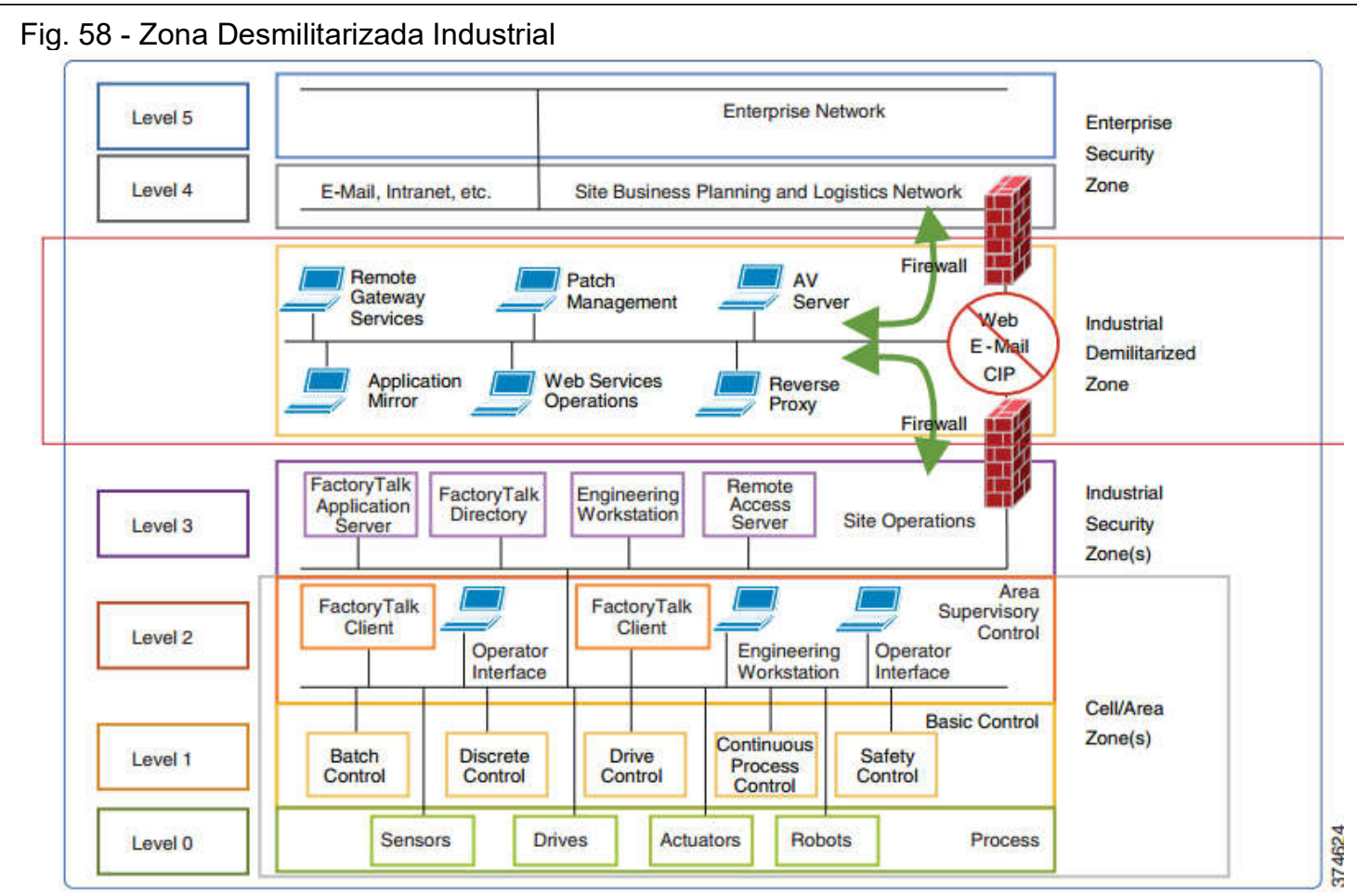

(Fonte: Cisco, 2015) 
Com esta arquitetura a vulnerabilidade ao longo da integração vertical na fábrica é mitigada, porém Ellison et al. (2010b) citam que ainda há a vulnerabilidade em SW nas cadeias de fornecimento e consideram que a eliminação completa das vulnerabilidades de SW é impossível, ou impraticável.

A Empresa FT2 cita que há duas estratégias poderosas para reduzir estes riscos - uma é focada em entender e controlar a superfície de ataque dos sistemas e a outra está em entender as ameaças potenciais. A superfície de ataque é caracterizada pelos vetores potenciais que possam comprometer o sistema. $O$ modelamento de ameaças é caracterizado pelos aspectos da superfície de ataque que estariam mais expostos ao risco. Estes conceitos são importantes, segundo os autores, para o desenvolvimento, implantação, operação e manutenção dos sistemas. Eles ajudam na orientação de que informações devem ser colhidas e como elas podem ser melhor utilizadas para priorizar e mitigar os riscos à segurança em cadeias de fornecimento. Pelo fato da 14.0 prever utilizar-se amplamente das redes de valor abertas - não restrita a parceiros de negócio fixos como nas cadeias de fornecimento convencionais - o risco à segurança é ainda maior.

Esta concepção isola o chão de fábrica não permitindo uma comunicação direta dos recursos nos níveis inferiores com os recursos da camada de gestão e redes colaborativas. Mesmo os dados não são disponibilizados diretamente à Big Data sendo tratados nos níveis de TO através do que a Empresa FT2 denominou de fog. A Empresa FT1 também entende que comunicação M2M entre fábricas é uma possibilidade remota devido à questão de segurança e a comunicação deve ser restrita ao ambiente interno da empresa. Ela também compartilha do conceito que a rede industrial não deve ser aberta às demais empresas da rede de colaboradores. Apenas as informações podem ser disponibilizadas de forma seletiva através dos sistemas ERP em que a TI deve garantir a segurança de dados.

A Empresa FT2, como fornecedor de equipamento, sabe da importância de se garantir a segurança, porém relata que "os clientes ainda não têm esta consciência". Isto pode explicar a tendência negativa da cibersegurança em relação ao engajamento à 14.0 identificado na Survey.

A Empresa Ul1 vê o problema da segurança como importante, porém um assunto já resolvido através da imposição de restrições no sistema de TI. Relata que mesmo na feira de Hannover, cibersegurança foi o tema que menos se ouvia por 
entender que os sistemas poderiam ser isolados e tratados com soluções de segurança atuais. Contudo, entende que padrões mais abertos da 14.0 tendem a trazer mais vulnerabilidade aos sistemas industriais por se tornarem tecnologias conhecidas por todos. O ambiente colaborativo também poderia expor o know-how da empresa a terceiros e que mesmo com contratos de confidencialidade, isto poderia representar dificuldades na proteção do conhecimento, no trato com diversos colaboradores.

A Empresa FI2 entende que a segurança de dados é um dos grandes entraves para que os clientes migrem para sistemas conectados, porém cita que a questão da segurança ainda tem opiniões controversas entre especialistas do ramo.

A Empresa UI3 embora entenda que a segurança de dados seja importante, também não vê isto como problema pois acredita que existem tecnologias para proteção. A Empresa FT3 e Empresa FI1 também concordam que o receio de ataques cibernéticos nas empresas existe, mas não sabe precisar o quanto isto impacta na decisão do cliente de não adotar a plataforma 14.0.

A conclusão que se chega é que há consenso sobre a necessidade de proteção para ataques cibernéticos aos CPS conectados. Porém, a percepção das empresas brasileiras é de que como existem soluções tais como a proposta pela Cisco (Fig. 58) isolando o ambiente de TO do ambiente de $\mathrm{TI}$, o engajamento à 14.0 não traz riscos adicionais. Contudo, existe uma grande preocupação quando se fala em compartilhamento de dados e informações em redes colaborativas no que diz respeito às questões legais e propriedade intelectual, principalmente quando se consideram redes colaborativas abertas onde não estão delimitados os parceiros de negócio.

Desta forma, a tendência da Fig. 55 levantada na survey não é confirmada pelos resultados do estudo de múltiplos casos, que mostram que existe sim uma preocupação maior com a segurança à medida que o nível de engajamento à 14.0 cresce. Acredita-se que a percepção identificada na survey, de que os riscos cibernéticos diminuem com o engajamento à plataforma 14.0 deve-se ao fato de os respondentes serem influenciados pelas empresas fornecedoras de tecnologia que afirmam ter soluções robustas para se garantir esta segurança. Esta percepção condiz ainda com o estudo realizado entre os fornecedores de tecnologia e infraestrutura (Fig. 57) que apontaram o desafio de resolver questões de segurança como dos menores obstáculos para a implantação da 14.0 percebidas pelas empresas usuárias industriais. 


\subsubsection{Maior oferta de produtos como serviços}

Como a conectividade já está mais evoluída na camada de negócios, a 14.0 já está num nível de maturidade mais alta e já se pode ver exemplos como a oferta de robôs como serviço pela Empresa FI2. Empresas fornecedoras de tecnologia e infraestrutura buscam maneiras de oferecer produtos como serviços almejando as verbas de OPEX das empresas usuárias industriais, ao invés das verbas de CAPEX, principalmente em períodos de crise em que as verbas de CAPEX estão bastante restritas. Mesmo empresas grandes como a IBM e Microsoft também estão buscando oportunidades para oferecer produtos como serviços. Oferta de plataformas como serviços (PaaS) tais como a SAP HANA Cloud Platform, GE Predix e Microsoft Azure, já estão disponíveis no mercado. A Empresa FT2 também diz que está adotando a modalidade de oferecer produtos como serviços. No momento podem oferecer SW e infraestrutura como serviço, mas estudam em breve poder passar a oferecer equipamentos como CLP "as service". Tais exemplos são apoiados por um dos elementos básicos da 14.0 que é a loS.

Desta forma, segundo os entrevistados, há muitas outras empresas investindo na oferta de serviços pela internet, e apontam este mercado como uma das oportunidades de atuação para as PME's na 14.0.

Com a 14.0 a tendência é também de reduzir postos de trabalhos na manufatura. A Empresa UI3 enxerga que a 14.0 irá fatalmente reduzir emprego nas indústrias de manufatura e isso fará com que estes trabalhadores migrem na maioria para o setor de serviços. Cita que isto é uma tendência hoje. A Empresa UI3 enxerga que a 14.0 poderá trazer novas oportunidades tecnológicas para oferecer mais serviços aos clientes que agreguem valor aos seus produtos através da conectividade acompanhando o ciclo de vida desde o início da manufatura até o final, fechando o ciclo até uma nova recompra. Para a Empresa UI3, fechar este ciclo de negócio desde a venda até a recompra com acompanhamento online de cada produto que está no campo e agregando valor através de serviços é mais prioritário que a automação desordenada da fábrica.

Assim, a tendência apontada pela Survey (Fig. 56), de que a percepção de aumento da servitização independe do grau de engajamento na 14.0 não se confirmou pelos estudos de múltiplos casos. O estudo de múltiplos casos revela que a 14.0 traz 
grandes oportunidades de servitização, principalmente para as PMEs. Acredita-se que o resultado da survey reflete a percepção da grande maioria das empresas que ainda possuem pouco entendimento dos conceitos da 14.0 e o preconceito de que a plataforma 14.0 é apenas para grandes empresas.

\subsubsection{Posicionamento das Empresas de Manufatura em relação a I4.0}

Para identificar o posicionamento das empresas brasileiras na escala de evolução industrial faz-se necessário citar as várias fases da evolução industrial marcadas pelas revoluções tecnológicas Quadro 25.

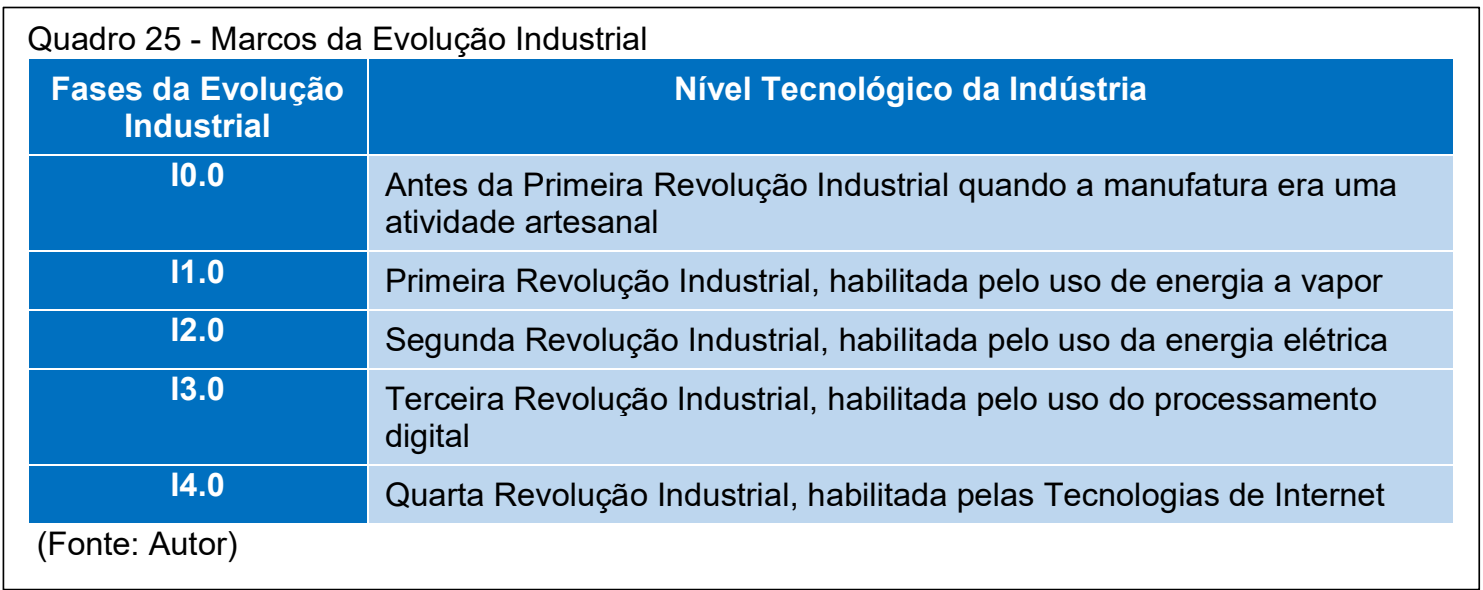

Sobre estas fases de evolução da indústria, procurou-se posicionar a empresa brasileira dentro de uma faixa de maturidade (menos evoluída a mais evoluída) com relação às tecnologias e conceitos da 14.0. O que se concluiu através do estudo de múltiplos casos foi que não é possível atribuir-se um grau único de maturidade para a empresa pois ela varia ao longo dos vários níveis hierárquicos da integração vertical da ISA-95. O estudo mostrou que a maturidade com relação aos conceitos da 14.0 é mais avançada nos níveis superiores da ISA-95, ou seja, nos níveis de negócios.

Este modelo está representado na Fig. 59, na qual a escala horizontal representa os graus de maturidade dos sistemas de automação da manufatura na indústria e mostra os principais marcos da evolução industrial caracterizados por avanços tecnológicos conforme já citados no Quadro 25. A escala vertical representa os níveis hierárquicos da estrutura de automação de uma empresa de manufatura conforme modelo ISA-95. As redes colaborativas e outros mundos externos conectados com a empresa foram considerados como parte do nível 4 de gestão 
empresarial, uma vez que a porta de conexão com o mundo externo deverá ser através deste nível. Conforme visto no estudo de múltiplos casos, a conexão com o mundo externo deverá ser feita através do nível de TI corporativo para garantir a segurança cibernética. Uma conexão direta entre níveis hierárquicos inferiores, como M2M interempresarial, poderia oferecer fragilidades para ataques cibernéticos e segundo o modelo de cibersegurança da Empresa FT2, a IDMZ deverá isolar estes dois níveis.

Este modelo da Fig. 59 mostra claramente que a manufatura brasileira ainda está entre a I2.0 e I3.5 (entre a I3.0 e 14.0) onde notadamente ainda se tem a estrutura hierárquica característica de sistemas de automação da manufatura na I3.0.

No nível 4 de gestão empresarial, as empresas brasileiras mais atrasadas ainda trabalham com planilhas manuais e calculadoras eletrônicas ou planilhas eletrônicas em computadores stand alone, o que as coloca no início da I3.0 no limiar do início do processamento digital. As empresas mais avançadas já possuem sistemas como o ERP internamente à empresa e sistemas como CRM, SCM, PLM, EDI (Electronic Data Interchange), Nuvem, etc. com conexões interempresariais e, portanto, pode-se dizer que já passou a barreira das redes de comunicação digital e se aproximando do cenário da 14.0. Porém, ainda não está num nível pleno da 14.0 pelo fato de não ter a arquitetura orientada a serviços e praticar a loS e loT de maneira ampla e colaborativa com clientes e fornecedores. Para que isso aconteça, ainda seria necessário desenvolver uma linguagem semântica (WAHLSTER, 2014), e ajustar os sistemas ERP para compatibilizar com o contexto da 14.0 (DITTES, 2015). Sistemas como Hana Cloud Platform (HCP) da SAP, Windows Azure da Microsoft e Predix da GE podem ser citados como tentativas de soluções para estas lacunas. 


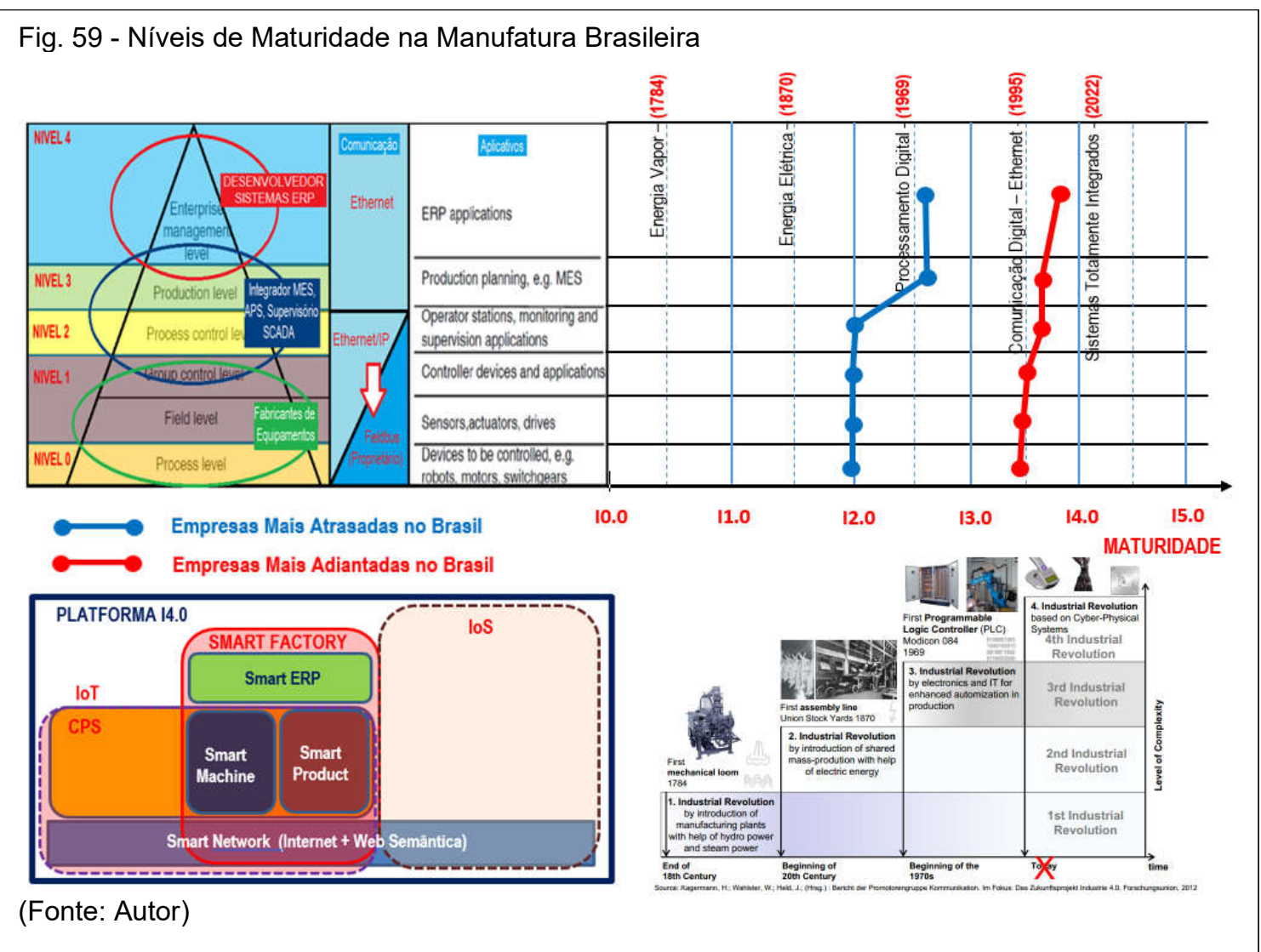

No nível 3 de controle de produção, as empresas mais atrasadas ainda trabalham com planilhas manuais e calculadoras eletrônicas ou planilhas eletrônicas em computadores stand alone, com apontamentos manuais, o que as coloca no início da I3.0 no limiar do início do processamento digital. As empresas mais avançadas já possuem sistemas como o MES, Manufacturing Operations Management (MOM), Enterprise Manufacturing Intelligence (EMI), APS etc. conectados com o chão de fábrica (Empresa FI1). Muitas vezes com conexões feitas através de artifícios como servidores OPC que permitem conectar equipamentos legados. Por estas tecnologias identificadas, pode-se avaliar que as empresas mais adiantadas estão um pouco à frente de uma simples conexão através de redes digitais.

No nível 2 de controle de processos, as empresas mais atrasadas ainda trabalham apenas com sistemas de sinalização elétrica através de lâmpadas, muitas vezes na própria máquina, o que as coloca no início da 13.0 e no limiar do início do processamento digital. Empresas mais avançadas no Brasil já utilizam de sistemas como SCADA e Sistemas Supervisórios que permitem monitorar o processo através da conexão com o chão de fábrica. Isto coloca tais empresas no início do uso da rede 
digital. Contudo, mesmo utilizando-se de sistemas distribuídos como o DCS (Distributed Control Systems), de acordo com a revisão bibliográfica, estes sistemas distribuídos não representam o conceito de inteligência distribuída da 14.0 por não encapsularem seus elementos físicos como serviços, em uma arquitetura orientada a serviços. Portanto, conclui-se que mesmo os sistemas mais avançados presentes na indústria brasileira atual ainda não estão na 14.0.

Algumas empresas já possuem equipamentos industriais conectados para a coleta de dados para geração de indicadores em dashboards (Empresa UI1), alinhados com alguns conceitos das possibilidades tecnológicas da 14.0. Porém, mesmo estas infraestruturas de coleta de dados não podem ser consideradas como infraestruturas da 14.0 por não estarem conectados em uma rede inteligente e em SOA. O que se viu nas empresas visitadas (Empresa UI1 e Empresa UI2) é que estas conexões estão feitas ainda de maneira clássica da 13.0 o que não impede de coletar dados, mas a sua estrutura inflexível dificulta a implantação, bem como evoluções futuras, tanto no aspecto físico como de SW.

No nível 1 de campo, as empresas mais atrasadas ainda possuem chaves eletromecânicas como sensores e dispositivos de acionamento eletromecânico para motores, e painéis de controle a relés, o que as coloca ainda na maturidade 12.0. No outro extremo tem-se empresas com sensores eletrônicos com processamento digital, controle por CLP's, CNC's, computadores industriais, servomotores, interconectadas com a rede digital, produtos com RFIDs, etc. Porém, como ainda não se tem uma conectividade distribuída em SOA, considera-se que ainda esteja na fase inicial da 14.0 .

No nível 0 de processo, em que há dispositivos a serem controlados, as fábricas mais atrasadas possuem apenas motores e dispositivos eletromecânicos. Isso significa início da 12.0. Já as fábricas mais avançadas possuem robôs, servomotores, e produtos com rastreabilidade QR Code, RFID ou Código de barras com conectividade à rede digital, porém ainda sem uma linguagem semântica de comunicação que permita a comunicação M2M, sem soluções de equipamentos que permitam customização em massa, escalabilidade ou flexibilidade nos níveis da 14.0. Considerando ainda que as empresas fornecedoras de tecnologia estão começando a disponibilizar equipamentos com conectividade somente agora, avalia-se que a indústria brasileira de ponta está no limiar de transição da I3.0 para a 14.0. 
Este modelo entende que a loT, loS, Smart Factory, Cloud Manufacturing e todos os demais cenários vislumbrados na 14.0, somente é possível a partir da habilitação das redes de comunicação digital via protocolos ethernet e tecnologias de internet (com fio e sem fio), que permitem a conectividade e a automação da comunicação entre máquinas através das redes de comunicação digital sendo, portanto, o marco inicial para a transição da I3.0 para a 14.0.

O modelo mostra que os níveis hierárquicos de automação em uma empresa de manufatura se encontram em estágios de maturidade diferenciados com relação à 14.0. No nível de gestão empresarial, essa conectividade já está implementada há algum tempo nas grandes empresas brasileiras, porém a disseminação da conectividade no nível de processos está se tornando realidade somente agora com a implementação de objetos ciberfísicos no chão de fábrica, com controle distribuído, incluindo sensores, máquinas e o próprio produto, que estão se tornando elementos com capacidade de memória, processamento e comunicação.

Avanços tecnológicos que envolvem apenas informações estão mais adiantados que naqueles que envolvem equipamentos físicos, possivelmente porque o desenvolvimento de SW é menos oneroso que desenvolvimento de HW. Isto explicaria porque o nível de gestão empresarial está mais avançado que o nível de chão de fábrica que depende mais de soluções em HW, como por exemplo, desenvolvimento de HW para manufatura aditiva ou de HW autoadaptáveis para a produção. Explica porque os benefícios esperados como flexibilidade e escalabilidade da produção ainda são considerados uma realidade distante pelos entrevistados, principalmente considerando-se que muitas dessas funcionalidades requerem a substituição completa dos equipamentos de produção existentes. Ao contrário da aquisição de dados de produção, que é possível com pequenas adaptações e atualizações dos equipamentos legados. Isto significa que coletar dados do chão de fábrica é mais simples que atuar sobre os equipamentos do chão de fábrica de forma autônoma. Por isso as empresas engajadas com a 14.0 estão começando a conectividade com o equipamento legado no desenvolvimento de sistemas de indicadores e analíticos para monitoramento da produção e não de sistemas para execução da manufatura. O estudo mostrou que mesmo os sistemas MES estão sendo utilizados mais para coleta de informações que propriamente para execução da manufatura. 
Dentre os impactos positivos previstos pela aplicação dos conceitos da 14.0, a busca da eficiência produtiva e gerencial através de coleta de dados da produção e geração de indicadores de KPI's (Key Performance Indicators) parece ser percebida pelos usuários industriais brasileiros como a mais viável no momento. Seguindo o princípio de que para se controlar é necessário medir, a coleta de dados é fundamental para a gestão eficiente da produção e a implementação da conectividade em equipamentos legados para coletar dados requer investimentos bem menores que para uma integração funcional. A coleta de dados requer apenas a conexão com pontos estratégicos e não requer mudanças profundas no HW dos equipamentos.

Souza (2014) explica que em sistemas analíticos para cadeias de suprimentos pode-se identificar três tipos de sistemas: descritivo, preditivo e prescritivo. Os sistemas descritivos são baseados em tecnologias como os de GPSs (Global Positioning Sytems), RFIDs (Radio Frequency Identification) e ferramentas de visualização de dados para disponibilizar informações em tempo real, de localização e quantidade de produtos na cadeia aos gestores. Os analíticos preditivos baseiamse em previsão da demanda em níveis estratégicos, táticos e operacionais, que direcionam o processo de planejamento nas cadeias de suprimentos em termos de projeto de rede, planejamento de capacidade, planejamento de produção e gerenciamento de estoque. Finalmente, os analíticos prescritivos se concentram no uso de técnicas de otimização e simulação matemática para fornecer ferramentas de apoio à decisão baseadas em modelos de análise descritiva e preditiva.

Com base neste modelo de Souza, também é possível identificar quatro tipos de controle de produção visando à eficiência em cada uma das fases da evolução industrial. Os tipos identificados são: sem controle, controle corretivo, controle descritivo e controle preditivo conforme ilustrado no Quadro 26.

Nos primórdios da evolução industrial nenhuma ou pouca coleta de informações era possível e o controle da produção se torna algo como dirigir um veículo às cegas (caráter sem controle da produção na I1.0). Na sequência, com a coleta não automatizada de dados da produção, a informação chegava com atraso aos tomadores de decisão, e o controle da produção era algo como dirigir um veículo com base nas imagens do retrovisor (caráter corretivo do controle de produção na 12.0). A automação da coleta de dados da produção através da conectividade por sua vez possibilitou a indicação destas informações relevantes em tempo real permitindo 
tomar ações de forma mais assertiva e tempestiva, algo como dirigir um veículo através das informações do painel de instrumentos (caráter descritivo do controle de produção na 13.0). Num estágio mais avançado, quando esta conectividade ultrapassa os limites corporativos com acesso a dados externos à fábrica e de redes colaborativas, a visibilidade em tempo real é ampliada permitindo prever situações próximas que estão por vir, algo como dirigir um veículo, não apenas pelo painel de instrumentos, mas pelas imagens em tempo real da estrada que vêm à frente (caráter preditivo do controle de produção na 14.0). Contudo, as informações em tempo real do ambiente externo à corporação estão sujeitas a mudanças, tornando-as previsões confiáveis apenas num futuro próximo. Para melhorar a previsibilidade, ainda sobre a plataforma 14.0, apresentam-se possibilidades tecnológicas tais como Big Data e Sistemas Analíticos, em que as informações passam a ter caráter prescritivo, algo como dirigir um veículo com as imagens da estrada e informações de tempo.

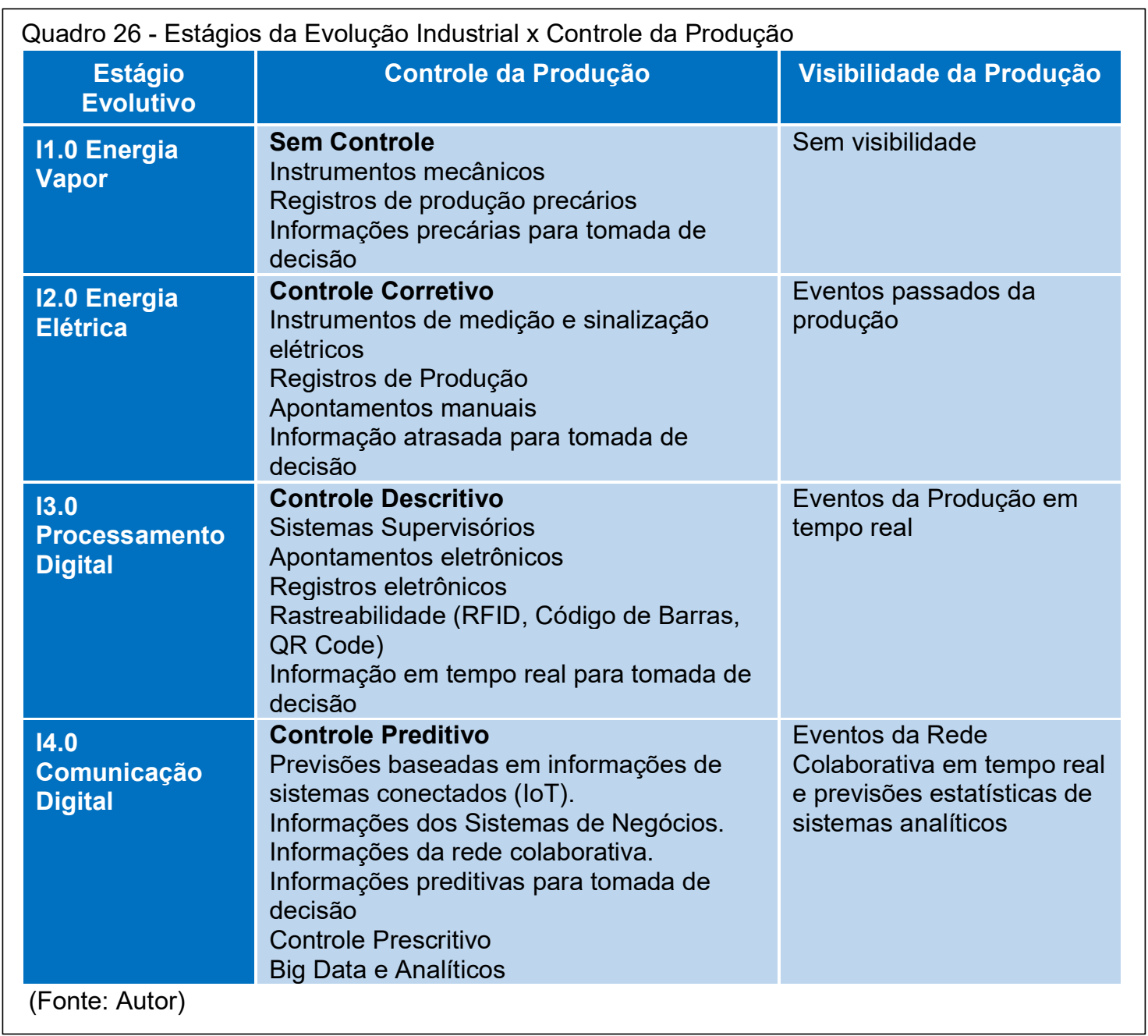


Desde a era da mecanização através da energia a vapor (I1.0), o controle da produção vem evoluindo juntamente com as revoluções tecnológicas. $\mathrm{Na}$ I1.0, os processos industriais foram mecanizados, mas o controle da produção era precário, sem instrumentos ou registros da produção. Pode-se dizer que praticamente não havia controle de produção visando a eficiência. Já com a 12.0, a energia elétrica permitiu a introdução de medidores e sinalizadores de eventos em processos industriais que viabilizaram o registro de informações que ajudaram a evoluir para o controle corretivo da produção. Através das informações de eventos já ocorridos, obtidas por meio de medidores e registradores, poderiam corrigir o processo para que nos próximos lotes a produção pudesse ser conduzida com maior eficiência dandoIhe um caráter corretivo ao controle da produção.

A terceira revolução (13.0) veio com a introdução de processamento digital na indústria, que permitiu monitorar o processo em temo real através de sistemas supervisórios computadorizados. Isto permitiu a tomada de decisões através das informações do que estava acontecendo na produção naquele momento, elevando o nível de visibilidade. Isto caracteriza o controle descritivo na I3.0.

$\mathrm{Na}$ quarta revolução (14.0) a comunicação digital permitiu expandir este nível de visibilidade para além do tempo real, trazendo o cenário de um futuro próximo da produção através de informações em tempo real do ambiente externo e da rede de colaboradores altamente conectados pela IoT. Isto caracteriza o controle preditivo na 14.0. Esta visibilidade do cenário futuro próximo pode ser ainda mais estendida através de analíticos baseados em recursos estatísticos para elevar o controle da produção para um caráter prescritivo. O que se vê aqui é que junto com a evolução industrial a visibilidade do processo industrial vem crescendo cada vez mais em amplitude e precisão, permitindo aos gestores dirigir a produção de forma cada vez mais eficiente conforme ilustrado no Quadro 26.

Avanços tecnológicos como fábrica flexível e escalável, com possibilidade de customização em massa deverão ser mais demorados que os avanços na área de gestão e relacionamentos interempresariais. A implementação de SW de PLM para redução do tempo de lançamento de novos produtos, a oferta de produtos como serviços, a oferta de serviços na Cloud e Big Data são outros exemplos de tecnologias que envolvem mais informações que HW. 


\subsection{ESTADO DA I4.0 NO BRASIL E OPORTUNIDADES NA CFSAM}

Percebe-se pelos casos estudados que o engajamento das empresas no Brasil, no nível de chão de fábrica ainda está no estágio inicial de implantação da 14.0, no qual as empresas ainda estão construindo a infraestrutura de conectividade nos equipamentos legados através de interfaces como servidores OPC que permitem comunicar protocolos diferentes de rede com o padrão Ethernet e assim permitir acesso aos sistemas de TI corporativos. Contudo, a conectividade está sendo realizada justificada com base no retorno pelo aumento de eficiência dos processos produtivos. Esta conectividade está sendo feito nas empresas estudadas de maneira bastante seletiva e restrita, de acordo com critérios de prioridade, que consideram o potencial de retorno através da redução de perdas por meio de indicadores mais precisos. Pode-se dizer ainda que os casos de implantação de conectividade nas máquinas estão sendo feitos como projetos piloto, nos quais vários padrões de conectividade e sistemas adotados ainda estão sendo testados e não são definitivos. A conectividade também não segue modelos de arquitetura SOA nem há padrões semânticos que permitam a interoperabilidade e comunicação autônoma M2M.

Segundo a Empresa FT1, o segmento industrial mais engajado na implantação da plataforma Industria 4.0 é a indústria automotiva em razão da alta competitividade neste mercado. Neste contexto, a plataforma Industria 4.0 é vista como um meio para se obter ganho em competitividade. Industrias de processos como gás e óleo têm se mostrado mais conservadores por receio de que estas novas tecnologias possam trazer riscos operacionais ao processo e tendem a adotar tecnologias mais sedimentadas em seu processo de manufatura.

Outros casos estudados na Empresa FT3 e Empresa Fl1, referem-se a implementações de sistemas MES e OEE na zona de convergência entre TI e TO. Também nestes casos adota-se ainda a arquitetura clássica da I3.0 em que conectamse os equipamentos legados através de interfaces baseadas em CLPs ou placas de aquisição de dados apenas para coletar as informações necessárias. Embora os sistemas MES tenham a função de atuar na execução da manufatura, nos exemplos que foram apresentadas por estas empresas apenas as funcionalidades de monitoramento e relatórios puderam ser identificadas. 
Percebe-se através destes casos que as interfaces implantadas nos equipamentos com o propósito de conectar com sistemas de TI ainda não encapsulam as funcionalidades das máquinas como serviços e tampouco se adota a arquitetura SOA com definições semânticas porque ainda não existem tais padrões definidos. Outro aspecto é que as máquinas e equipamentos legados não possuem estrutura de HW cíberfísicos para responder às demandas de agilidade e autonomia na produção nem modularidade suficiente para se adequar às demandas de flexibilidade. Por este motivo, a conectividade nos casos estudados ainda restringe se apenas à coleta de informações que requer um investimento menor e pode ser justificado pelo retorno proporcionado pelo aumento de eficiência na produção com o monitoramento de índices que permitem controle mais preciso dos processos produtivos.

\subsubsection{Habilitadores para I4.0 segundo perspectivas de empresas}

Durante as entrevistas com os fornecedores de tecnologia, questionando sobre as tecnologias características da 14.0, constatou-se que há uma divergência de perspectivas que diferem de empresa para empresa. Por exemplo, a Siemens enfatiza as suas ferramentas TIA (Totally Integrated Automation) e PLM (Product Lifecycle Management) com ênfase nas funcionalidades de virtualização e simulação no lançamento de novos produtos enquanto a Empresa FT2 enfatiza os seus equipamentos para conectividade loT e Cíbersegurança. A Empresa FT3 e a Empresa FI1 por sua vez focam em loT e loS com ênfase nos sistemas MES. A Empresa FI2 cita as suas linhas de montagem com conectividade e os robôs colaborativos oferecidos como serviço (RaaS).

Buscando outras empresas na internet verificou-se que há ainda várias outras perspectivas conforme mostra o Quadro 27. Nele percebe-se diversas tecnologias são citadas como habilitadores dentre os quais os mais citados são Big Data, Analíticos e IloT/CPS, o que causa uma certa nebulosidade em torno do que é a essência da plataforma 14.0 .

O que pode-se concluir desta constatação e da revisão bibliográfica é que a plataforma 14.0 é apoiada essencialmente nos elementos citados na Fig. 36 (IoT, loS e Smart ERP) e que sobre ela abrem-se várias oportunidades tecnológicas tais como a Manufatura Aditiva, Cloud Manufacturing, Big Data, Analíticos, Realidade 
Aumentada, SWs de PLM, Digitalização da Fábrica, Digital Twins, Simulação, etc. O entendimento após este estudo é que a maioria destas tecnologias citadas pelas empresas são na verdade possibilidades tecnológicas habilitadas pela plataforma 14.0, ou mesmo tecnologias que independem da plataforma 14.0 mas que tentam pegar uma carona promocional com al4.0.

Portanto, o que se conclui é que a adoção da plataforma 14.0 em uma empresa de manufatura requer a implantação dos três elementos básicos que a compõem, lembrando que a Smart Factory implicitamente requer um sistema Smart ERP que permita esta integração vertical e horizontal.

O Quadro 27 agrupa as tecnologias habilitadoras coletadas de White Papers e informações de sites de internet de várias empresas de consultoria e fornecedoras de tecnologias que buscam cada qual inserir a sua tecnologia ou expertises dentro do contexto da 14.0, embora a maioria delas sejam apenas possibilidades tecnológicas sobre a plataforma 14.0 . 


\begin{tabular}{|c|c|c|c|c|c|c|c|c|c|c|c|c|c|c|c|c|}
\hline & 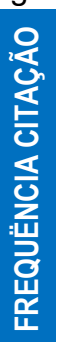 & 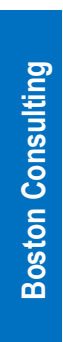 & 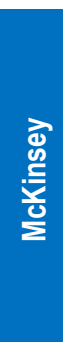 & $\begin{array}{l}\frac{5}{90} \\
\frac{9}{2} \\
\frac{\pi}{4}\end{array}$ & 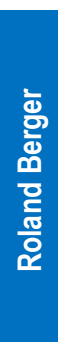 & $\begin{array}{l}\frac{7}{0} \\
\frac{0}{2} \\
\frac{2}{8} \\
\frac{0}{4} \\
\frac{0}{4}\end{array}$ & 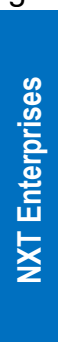 & 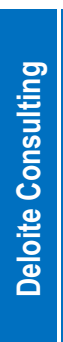 & 㩊 & 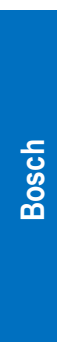 & 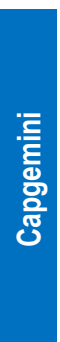 & 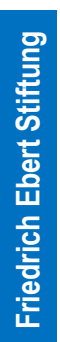 & $\begin{array}{l}\text { 윰 } \\
\stackrel{\$}{4}\end{array}$ & 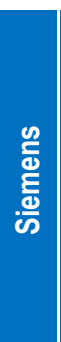 & 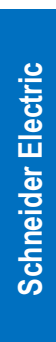 & 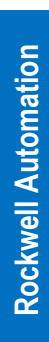 \\
\hline Big Data \& Analíticos & 15 & 0 & 0 & 0 & 0 & 0 & 0 & 0 & 0 & 0 & 0 & 0 & 0 & 0 & 0 & 0 \\
\hline IloT (CPS) & 13 & 0 & 0 & 0 & 0 & 0 & & 0 & 0 & 0 & & 0 & 0 & 0 & 0 & 0 \\
\hline $\begin{array}{l}\text { Comunidades Sociais } \\
\text { Comunidades de } \\
\text { Negócio }\end{array}$ & 7 & & & 0 & 0 & 0 & 0 & 0 & & & 0 & & 0 & & & \\
\hline Cloud Technology & 6 & 0 & 0 & & 0 & & 0 & & & & 0 & & & 0 & & \\
\hline Comunicação M2M & 6 & & 0 & 0 & & 0 & & 0 & & 0 & 0 & & & & & \\
\hline $\begin{array}{l}\text { Robô Autônomo / } \\
\text { Avançado }\end{array}$ & 5 & 0 & 0 & & 0 & & & & & & 0 & & & 0 & & \\
\hline Manufatura Aditiva & 5 & 0 & 0 & & 0 & & & & & & 0 & & & 0 & & \\
\hline $\begin{array}{l}\text { Services Hospedados } \\
\text { (loS) }\end{array}$ & 5 & & & & & 0 & 0 & 0 & & & & & & 0 & 0 & \\
\hline Sistemas ERP-MES & 5 & & & 0 & & 0 & & 0 & & 0 & & & & & 0 & \\
\hline Cibersegurança & 4 & 0 & & 0 & & 0 & & & & & & & & & & 0 \\
\hline $\begin{array}{l}\text { Aplicativos Móveis I } \\
\text { Internet }\end{array}$ & 4 & & & 0 & 0 & 0 & 0 & & & & & & & & & \\
\hline $\begin{array}{l}\text { Interface Touch, IHM, } \\
\text { M2P }\end{array}$ & 4 & & 0 & 0 & & & & & & & & 0 & 0 & & & \\
\hline $\begin{array}{l}\text { Digitalização e } \\
\text { Automação Trabalhos } \\
\text { do Conhecimento }\end{array}$ & 3 & & 0 & & & & & & 0 & & & & & 0 & & \\
\hline PLM & 3 & & & 0 & & 0 & & & & & & & & 0 & & \\
\hline $\begin{array}{l}\text { Adaptação por } \\
\text { sensores }\end{array}$ & 3 & & & 0 & & & & & & & & 0 & & 0 & & \\
\hline $\begin{array}{l}\text { Integração Vertical e } \\
\text { Horizontal de Sistemas }\end{array}$ & 3 & 0 & & & & 0 & & 0 & & & & & & & & \\
\hline Realidade Aumentada & 2 & 0 & 0 & & & & & & & & & & & & & \\
\hline Simulação & 2 & 0 & & & & & & & & & & & & 0 & & \\
\hline Software como Serviço & 2 & & & 0 & & 0 & & & & & & & & & & \\
\hline Broadband, Netwkng & 2 & & & 0 & 0 & & & & & & & & & & & \\
\hline Dispositivos Móveis & 2 & & & & & & 0 & & & & 0 & & & & & \\
\hline $\begin{array}{l}\text { Colheita e Estocagem } \\
\text { de Energia }\end{array}$ & 1 & & 0 & & & & & & & & & & & & & \\
\hline IPV6 & 1 & & & 0 & & & & & & & & & & & & \\
\hline Data Mining & 1 & & & 0 & & & & & & & & & & & & \\
\hline $\begin{array}{l}\text { Flexibilidade e } \\
\text { Escalabilidade }\end{array}$ & 1 & & & 0 & & & & & & & & & & & & \\
\hline Plug \& Produce & 1 & & & 0 & & & & & & & & & & & & \\
\hline BYOD & 1 & & & & & & 0 & & & & & & & & & \\
\hline Wearables & 1 & & & & 0 & & & & & & & & & & & \\
\hline
\end{tabular}




\subsubsection{Afinal, o que é a l4.0?}

Atualmente o termo 14.0 está no centro das atenções dos promotores de tecnologia, usuários industriais e pesquisadores acadêmicos mas existe uma grande nebulosidade em torno de quais tecnologias exatamente ela engloba $\mathrm{e}$ as características que distinguem uma empresa na plataforma 14.0. De acordo com o estudo de múltiplos casos, verificou-se que as perspectivas sobre a 14.0 diferem de empresa para empresa. Por exemplo entre os fornecedores de tecnologia, há maior ênfase em soluções tecnológicas ou estratégias adotadas por cada uma delas. A Siemens (2013) enfatiza as soluções em torno de TIA (Totally Integrated Automation) na automação de fábrica e o SW de PLM para desenvolvimento de novos produtos com ênfase em digitalização e simulação. Já a Empresa FT2 enfatiza suas soluções em conectividade através do protocolo Ethernet IP e HW de conectividade desenvolvidos em parceria com a Cisco, com ênfase na segurança cibernética. Compartilha ainda do conceito de convergência de TI com TO da Empresa FT3 que estrategicamente busca a liderança de atuação nessa região de convergência. Além desses fornecedores, outras empresas e academias podem ser citadas cada qual com perspectiva diferente do que será o cenário 14.0. Conclui-se disso, que a plataforma I4.0 se fundamenta em uma infraestrutura de conectividade loT e integração vertical e horizontal de informações (Smart Factory) sob uma arquitetura orientada a serviços - IoS, conforme esquematizado na revisão bibliográfica (Fig. 33). Sobre esta plataforma se abrem várias possibilidades, o que permite que cada empresa tenha uma perspectiva particular sobre o cenário futuro, causando esta nebulosidade sobre o que vem a ser a 14.0 e sobre que tecnologias fazem parte desta plataforma. Entendese com este modelo (Fig. 60) que das tecnologias mencionadas nas várias perspectivas, muitos já estão em curso, alguns ainda são apenas visões e outras ainda desconhecidas podem surgir. O estudo mostrou que a adoção destas tecnologias pelos usuários industriais dependerá principalmente dos retornos que as mesmas proporcionam. Hoje os usuários industriais ainda não conseguem enxergar ou quantificar os retornos pragmáticos ou identificar oportunidades de novos negócios na maioria destas novas tecnologias. 


\subsubsection{Análise de Oportunidades}

Com base no estudo várias lacunas tecnológicas foram identificadas que representam oportunidades de atuação para as empresas participantes da CFSAM.

Aumento de eficiência - $O$ aumento de eficiência através das informações em tempo real, tanto dos processos internos como de processos externos é revelado pelo estudo como um dos grandes atrativos para a adesão das empresas à plataforma 14.0. Espera-se que a conectividade possa trazer maior visibilidade nos processos de negócio e com isso exercer um controle mais preciso sobre as tomadas de decisão. A informação em tempo real do mundo conectado permite elevar o nível de controle da produção para níveis preditivos, mas os analíticos avançados, baseados em técnicas estatísticas prometem elevar este nível ainda mais para o que se chama de controle prescritivo (SOUZA, 2014). Desta forma, a visibilidade dos processos de manufatura, perseguida através das técnicas organizacionais de lean manufacturing pode ser alcançada agora através das tecnologias da 14.0 num nível jamais atingido anteriormente. Isto é uma mudança disruptiva em relação às técnicas atuais de gestão da produção que pode melhorar a eficiência de forma inédita.

Flexibilidade na Manufatura - Este é um dos impactos previstos na literatura, porém o estudo mostrou que ainda está num estágio muito incipiente. $\mathrm{O}$ estudo mostrou que ainda há uma grande lacuna tecnológica para que as máquinas se tornem flexíveis e adaptáveis. Carece tanto de uma infraestrutura SOA com padrões semânticos como de máquinas e equipamentos com qualidades ciberfísicas de tal maneira que suas funcionalidades possam ser encapsuladas como serviços disponíveis na rede. Justamente por toda esta carência, representa uma oportunidade de desenvolvimento de soluções, tanto em termos de máquinas como infraestrutura. Os fabricantes de máquina precisarão repensar seus conceitos para que a nova geração de máquinas para a manufatura possa atender estas demandas de flexibilidade. Há ainda oportunidade para que desenvolvedores de sistemas, mesmo as PMEs, ofereçam pequenas soluções modularizadas para um sistema aberto, reduzindo a complexidade.

Qualificação Profissional - identificou-se no estudo que a 14.0 demandará profissionais com qualificações multidisciplinares principalmente para os atores dos grupos de tecnologia e infraestrutura. Conforme citado por uma das empresas, o 
gestor ou coordenador destes projetos de implantação da plataforma 14.0 precisa unificar os conhecimentos em TI com TO, pois a maior dificuldade está nesta região de convergência. Exemplo disto é que em duas empresas estudadas, uma da área de TO celebrou acordo de cooperação com empresa de TI e a outra fez a aquisição de uma empresa atuante no segmento MES para complementar a expertise faltante. Ambas com o propósito de ocupar esta zona de convergência. Com a padronização de uma rede de comunicação digital no chão de fábrica e componentes cíberfísicos que permitem a conectividade ampla do chão de fábrica à rede digital abre-se um campo de atuação ainda pouco explorado até então, que é a zona de convergência de TI com TO, ou seja, nos níveis 3 e 2 da ISA-95 onde atuam os sistemas MES, MOM, APS, SCADA, Supervisórios etc. Contudo, estes sistemas terão agora novas oportunidades e funções com a necessidade de integrar os sistemas de TO com os sistemas de TI. Como esta zona envolve conhecimentos na área de $\mathrm{TI}$ e na área de TO que tradicionalmente vêm sendo desenvolvido por profissionais com formações distintas, com ferramentas distintas, há naturalmente uma dificuldade de unificação entre elas.

O desafio agora envolve integrar estas duas áreas e formar profissionais ou equipes multidisciplinares com competência para atuar neste nível. Dentre as competências foram citadas pelos entrevistados: habilidades em TI, automação industrial, redes digitais, estatística e engenharia de produção.

Contudo, Gorbach (2016) da Arc Advisory Group endossa a visão de Hepplemann, CEO da PTC, que argumenta que a real oportunidade não está apenas na convergência de TI/TO, mas na convergência Físico-Digital em função das mudanças que o produto em si está sofrendo com a loT. E mudanças no produto causam também mudanças no papel e responsabilidades da indústria. Novos sistemas de sistemas e sistemas de produtos, podem juntos agregar novos valores. Tudo muda, inclusive a engenharia, produção, operações, vendas, serviços e marketing e, portanto, novas demandas de qualificação não são apenas na área de convergência entre TI e TO. Ainda há o registro de uma empresa de tecnologia de TO que uniu se à outra do segmento de cíbersegurança para complementar o conhecimento faltante e oferecer soluções mais robustas e seguras para a integração entre os ambientes de TI e TO. 
Todos estes exemplos mostram que a 14.0 requer novas expertises multidisciplinares que precisam ser apreendidas.

PMEs - O estudo revela que a 14.0, ao contrário do que muitos gestores das PMEs imaginam, representa uma grande oportunidade de inclusão nas redes colaborativas para estas empresas, principalmente no setor de Serviços. A agilidade, estruturas menores e enxutas das PMEs são vistas como características essenciais para se quebrar a inflexibilidade e a inércia dos sistemas atuais das grandes corporações. A democratização da manufatura citada por Rifkin (2012) e a Agilidade na manufatura como ponto chave para a 14.0, citada por Festo, (2015) são reforçadas pela visão das empresas estudadas que veem nas PMEs a oportunidade para modularizar externamente a manufatura através das redes colaborativas ou Cloud Manufacturing. A Empresa FT2 lembra ainda que as PMEs não necessariamente precisam ter uma estrutura Smart Manufacturing para participar das redes colaborativas da 14.0, bastaria apenas estar conectada à rede colaborativa través de uma Smart ERP.

A 14.0 representa uma grande oportunidade tanto para as empresas de tecnologia e infraestrutura que terão a oportunidade de oferecer seus serviços para implantar a plataforma 14.0. Sendo a 14.0 uma plataforma aberta, mais empresas poderão participar deste fornecimento, com vários aplicativos modularizados permitindo que os sistemas sejam mais flexíveis e mais customizados. Com a abertura, o desenvolvimento e fornecimento destes aplicativos modularizados não ficam mais restritos à uma única grande empresa, permitindo que mesmo PMEs possam participar da construção desta infraestrutura. Radziwon et al., (2014) vão além sugerindo que as soluções para a automação das PMEs devam ser desenvolvidas também por empresas PMEs e não por grandes empresas de automação. Argumentam que embora grandes fornecedores de tecnologia tenham maior capacidade há uma desproporcionalidade de valores que poderá ser percebida apenas por um fornecedor PME. Assim, haveria oportunidades também para as PMEs dos grupos de tecnologia e infraestrutura.

A maioria das empresas estudadas concordam que a 14.0 deve trazer novas oportunidades paras as PME's. Todavia o estudo aponta que, seguindo a tendência nacional, as oportunidades para as PME's participarem das redes colaborativas está mais nas camadas superiores da pirâmide: de negócios e serviços. Nas camadas 
inferiores de manufatura, embora a tecnologia de ponta já esteja disponível no Brasil, há uma percepção de que ainda deve demorar a surgir oportunidades pois mesmo as grandes empresas não estão investindo maciçamente neste nível. Embora haja uma percepção entre as empresas estudadas de que a 14.0 ao reduzir o Outsourcing de grandes empresas estrangeiras pode subtrair o volume de atividades de manufatura do Brasil, por outro lado, as atividades de negócios e prestação de serviços precisarão ser locais, ou seja, no Brasil. Na opinião de alguns entrevistados, as empresas não precisam necessariamente aderir à plataforma completa da 14.0 para participar da rede colaborativa. Por exemplo, uma empresa pode participar da rede colaborativa da 14.0 apenas no nível de negócios, sem uma estrutura de produção. No entanto, segundo Empresa FT2, mesmo neste caso, a infraestrutura mínima de interface (Smart ERP) com a rede colaborativa deve estar presente nestas PMEs.

Portanto, para que as PMEs possam aproveitar estas oportunidades é primordial que estejam preparadas tanto pela qualificação como pelo planejamento de um modelo de negócio neste ambiente conectado. Burmeister et al., (2015) alertam que a futura posição de mercado e a rentabilidade das empresas será o resultado de ter o modelo de negócio (inovador) correto no lugar correto, aproveitando as oportunidades oferecidas pela I4.0, no tempo correto.

Servitização - A oferta de produtos como serviço tem sido verificada como uma tendência crescente, principalmente pela conectividade, na qual a loS deve impulsionar o setor de serviços, tanto pela oferta de produtos como serviços, como também pela migração de trabalhadores do setor manufatureiro para o setor de serviços. A servitização segundo estudos, permite também que as empresas de manufatura reduzam gastos com CAPEX e trabalhem de maneira mais enxuta e escalável com os recursos de OPEX. Portanto, a servitização representa uma oportunidade para os usuários industriais bem como para as empresas que fornecem recursos produtivos como serviços.

Como a camada de negócios é a que está mais adianta em termos de adesão aos conceitos da 14.0, as oportunidades de servitização e oportunidades na rede colaborativa tendem a surgir na frente das oportunidades relacionadas à camada de chão de fábrica. 


\section{CONCLUSÃO}

Para responder à questão da pesquisa e compreender as reações das empresas brasileiras aos impactos da 14.0, o estudo de múltiplos casos foi de fundamental importância para confirmar, ou não, as tendências apontadas pela survey, corrigindo percepções equivocadas dos respondentes. Embora a 14.0 ainda não esteja no platô de produtividade (Fig. 44) o estudo de múltiplos casos com as empresas promotoras de tecnologia e infraestrutura permitiram compreender melhor os motivos para o baixo nível de engajamento prático na implantação da plataforma 14.0 pelas empresas de manufatura no Brasil. As limitações deste trabalho estão na escassez de casos práticos de aplicações e implantações nas empresas de manufatura e na falta de assimilação dos conceitos da 14.0 pelos trabalhadores de toda estrutura vertical nas empresas. Essa escassez de dados impede um estudo quantitativo mais robusto baseado em dados práticos que evidencie o relacionamento dos impactos com o engajamento prático na implantação da plataforma 14.0. A falta de assimilação dos conceitos da 14.0 entre os trabalhadores ao longo de toda estrutura vertical também limita o Estudo de Múltiplos Casos à opinião de apenas alguns trabalhadores integrantes do grupo de trabalho de projetos 14.0 impossibilitando uma coleta de visão mais ampla em todos os níveis hierárquicos das empresas. Como o platô de produtividade da 14.0 ainda está longe de ser atingido, trabalhos futuros poderiam incluir estes aspectos quando a maturidade das empresas brasileiras na implantação da plataforma 14.0 estiver mais avançada.

No que diz respeito ao engajamento na implantação da 14.0 identificaram-se três grupos de atores com diferentes estratégias para as tecnologias da 14.0: os fornecedores de tecnologia, os fornecedores de infraestrutura e os usuários industriais.

Os grandes fornecedores de tecnologia são na maioria empresas estrangeiras com atuação no Brasil. São empresas com raízes nos países que estão liderando as tecnologias em loT e 14.0 e, portanto, possuem e podem ofertar tecnologia de ponta, iguais aos ofertados nos países líderes em 14.0. Estas empresas estão, portanto, bastante engajados na venda e promoção de soluções para 14.0, cada qual dentro de seu espectro de tecnologia de que dispõe. É o caso da Empresa FT1, Empresa FT2 e Empresa FT3. Contudo, o engajamento não difere de outros usuários 
industriais quando se trata de equipar suas próprias unidades de manufatura no Brasil. Ou seja, o nível de conectividade e aplicação dos conceitos da 14.0 no chão de fábrica é muito baixo ou inexistente mesmo sendo eles os próprios fornecedores de tecnologia.

Os fornecedores de infraestrutura, principalmente as que possuem competências para atuar na região de convergência TI/TO, veem a 14.0 como oportunidade de ampliar seus negócios e têm atuado, intensamente, na promoção desta plataforma no sentido de despertar o interesse das empresas usuárias industriais para sistemas como o MES. Na opinião de alguns fornecedores de tecnologia, há pouquíssimas empresas no Brasil hoje, com competência para atuar nessa região de convergência TI/TO. Constatou-se ainda que da mesma forma como os fornecedores de tecnologia, os fornecedores de infraestrutura também não aplicam suas próprias soluções em suas unidades de produção. Alegam que a tecnologia não se aplica a eles por não se tratarem de empresas de manufatura, embora alguns destes integradores também sejam fabricantes de máquinas e equipamentos.

Apesar do intenso trabalho de promoção dos fornecedores de tecnologia e de infraestrutura os usuários industriais no Brasil, mesmo demonstrando interesse pelo assunto, pouco têm investido nestas tecnologias nos níveis inferiores da automação. Segundo as empresas estudadas, a tendência no Brasil não é de liderança nas tecnologias da 14.0, mas de seguidor. Mesmo empresas novas, de origem europeia que estão se instalando no Brasil, ou que estão adquirindo novas máquinas, demonstram pouca preocupação com a conectividade de chão de fábrica. Os motivos citados são a falta de recursos para investimento na conjuntura econômica atual do pais, o alto custo da tecnologia no Brasil em função da tributação e a dificuldade de justificar o retorno sobre o investimento. Embora muitas concordem que a adesão à plataforma 14.0 é fundamental para a competitividade da empresa, a maioria não consegue enxergar novos modelos de negócio ou ganhos que justifiquem a adoção dessas tecnologias. Há um consenso de que o parque de máquinas na indústria brasileira ficará novamente para trás, defasada em tecnologia, e que a adoção das plataformas 14.0 somente deverá acontecer depois que todos os outros países líderes a fizerem. Já nos níveis superiores de negócios e serviços, existem casos de aplicação dos conceitos da arquitetura SOA como em integração de negócios empresarial (DELL, 2017), transformação de processos de negócios (IBM, 2008), criação de 
serviços de negócios e integração de sistemas ERP com sistemas legados (IPROCESS, 2007) dentre outros. Como estes conceitos que pretendem revolucionar o paradigma de automação em TO surgiram inicialmente para resolver problemas no ambiente de TI, naturalmente os níveis superiores de negócio estão mais avançados na adoção destes conceitos que nos níveis inferiores de TO. Além disso, tradicionalmente, o nível de TI sempre esteve mais à frente liderado principalmente pelas atividades bancárias.

Já no nível operacional, como a plataforma 14.0 depende de uma infraestrutura de rede semântica e arquitetura orientada a serviços, como base para a loT, que precisa ser padronizada em muitos aspectos, ainda não é possível a sua implantação com o pleno aproveitamento do seu potencial revolucionário. Sem esta infraestrutura, ainda não é possível simplificar a complexidade dos sistemas integrados proporcionando características como auto-organização e adaptabilidade de sistemas simplificando processos de comunicação tais como M2M e promovendo autonomia para a loT e loS. Sem esta infraestrutura também não é possível que sistemas de $\mathrm{TI}$ monolíticos sejam modularizados através da integração de aplicativos distribuídos como serviço, em padrões abertos e de fornecedores diversos.

Atualmente, as empresas brasileiras que se dizem engajadas na implantação da plataforma 14.0 estão na realidade, testando a conectividade dos sistemas de TI com dispositivos físicos, desenvolvendo equipamentos industriais com maior modularidade e conectividade, oferecendo serviços pela internet ou em nuvem, implantando a integração horizontal na cadeia de fornecimento, etc., porém, ainda sobre a tradicional arquitetura de rede da 13.0. Portanto, apesar de estarem testando conceitos da 14.0 pontualmente, faltam-Ihes a infraestrutura básica de conectividade que caracteriza a mudança disruptiva da 13.0 para a 14.0.

O principal motivo do baixo engajamento prático é que a plataforma 14.0 ainda não está no platô de produtividade, carecendo ainda de definições e padronizações, e as empresas brasileiras não têm interesse em assumir o papel de liderança neste campo. Outros fatores citados incluem ainda o alto custo de investimento em algo que ainda não está bem definido, a falta de visibilidade de novos modelos de negócio nesta plataforma e a dificuldade de comprovar retorno sobre tais investimentos.

A viabilidade prática de se atingir benefícios como agilidade e flexibilidade na produção ainda não puderam ser percebidas pelas empresas de manufatura 
brasileiras como algo de alcance imediato, pelo menos enquanto a infraestrutura de conectividade e elementos CPS não estiverem definidos para permitir simplificações como o encapsulamento das funções das máquinas como serviços e a comunicação M2M autônoma entre máquinas. A conectividade com as máquinas com o propósito de torna-las mais flexíveis e auto-organizáveis ainda é percebida como uma realidade muito distante, principalmente quando se leva em conta a integração com parque de máquinas e equipamentos legados que não possuem funcionalidades ciberfísicas.

Este trabalho traz desta maneira, uma contribuição acadêmica no sentido de apontar as tendências para os atores da CFSAM e identificar as lacunas tecnológicas que representam as oportunidades de atuação para os participantes desta cadeia conforme já discutido no item 5.3.3. As oportunidades mais imediatas estão relacionadas com as atuações na CFSAM objetivando o aumento da eficiência produtiva, através da coleta e uso das informações por meio de sistemas amplamente conectados, proporcionando uma visibilidade maior não apenas da manufatura, mas de toda a rede colaborativa. Outra oportunidade vislumbra a inclusão e a importância cada vez maior das PMEs nas plataformas 14.0 em que características como a flexibilidade e a modularização são melhor atendidas por empresas menores e mais ágeis, principalmente no segmento de serviços (Servitização), em que há maior facilidade para que PMEs, mesmo sem estruturas de manufatura, participem das redes colaborativas da 14.0. A qualificação profissional dos atores da CFSAM também constitui uma grande oportunidade, visto que a 14.0 requer profissionais com habilidades na integração dos ambientes de TO e TI que são tratados hoje, como ambientes totalmente distintos cada qual com a sua técnica, linguagem e profissional especializado. Aliás, a integração perfeita destes dois ambientes através de sistemas autônomos que possam se descobrir e conversar entre si através de linguagem M2M é o cerne do conceito da 14.0 e também o maior desafio da implantação desta plataforma que permitirá diversas novas possibilidades tecnológicas na fábrica do futuro. 


\section{REFERÊNCIAS}

AKYILDIZ, Ian F.; MELODIA, Tommaso; CHOWDHURY, Kaushik R. A survey on wireless multimedia sensor networks. Computer networks, v. 51, n. 4, p. 921-960, 2007.

ALBERTS, C. J.; DOROFEE, A. J.; CREEL, R.; ELLISON, R. J.; WOODY, C. - A systemic approach for assessing software supply-chain risk. In: System Sciences (HICSS), 2011 44th Hawaii International Conference on. IEEE, 2011. p. 1-8.

ANDERL, Reiner. Industrie 4.0-advanced engineering of smart products and smart production. In: 19th International Seminar on High Technology, Technological Innovations in the Product Development, Piracicaba, Brazil. 2014.

ARUMUGAM, Sivabalan; KALLE, Ritesh Kumar; PRASAD, Anand R. Wireless robotics: Opportunities and challenges. Wireless personal communications, v. 70, n. 3, p. 1033-1058, 2013.

ATZORI, Luigi; IERA, Antonio; MORABITO, Giacomo. The internet of things: A survey. Computer networks, v. 54, n. 15, p. 2787-2805, 2010.

BAINES, Tim; W. LIGHTFOOT, Howard. Servitization of the manufacturing firm: Exploring the operations practices and technologies that deliver advanced services. International Journal of Operations \& Production Management, v. 34, n. 1, p. 2-35, 2013.

BELL, Michael. Service-oriented modeling (SOA): Service analysis, design, and architecture. John Wiley \& Sons, 2008

BELLIFEMINE, Fabio Luigi; CAIRE, Giovanni; GREENWOOD, Dominic. Developing multi-agent systems with JADE. John Wiley \& Sons, 2007.

BELLO, Lucia Lo. The case for ethernet in automotive communications. ACM SIGBED Review, v. 8, n. 4, p. 7-15, 2011.

BERNERS-LEE, Tim et al. The semantic web. Scientific american, v. 284, n. 5, p. 28-37, 2001.

BETTIN, Jorn. Model-Driven Software Development Teams. Building a Software Supply Chain for Distributed Global Teams, SoftMetaWare, 2004.

BLOEM, Jaap et al. The Fourth Industrial Revolution. Things Tighten, 2014.

BLOOMBERG, Jason; SCHMELZER, Ronald. Service orient or be doomed!: how service orientation will change your business. John Wiley \& Sons, 2006.

BRANDL, Dennis; OWEN, Peter. Manufacturing Operations Management. University of Cambridge, institute for Manufacturing, 2003.

BRANDL, Dennis OPC UA and ISA 95 - Interoperability for MES by implementing ISA 95 with OPC UA, ATP Edition, 2013.

BRECHER, Christian (Ed.). Advances in production technology. Springer International Publishing, 2015.

BRETTEL, M.; FRIEDERICHSEN, N.; KELLER, M.; ROSENBERG, M. - How virtualization, decentralization and network building change the manufacturing landscape: An Industry 4.0 Perspective. International Journal of Mechanical, Industrial Science and Engineering, v. 8, n. 1, p. 37-44, 2014.

BRUNER, Jon. Industrial Internet. " O'Reilly Media, Inc.", 2013. 
BURMEISTER, Christian; LÜTTGENS, Dirk; PILLER, Frank T. Business Model Innovation for Industrie 4.0: Why the Industrial Internet Mandates a New Perspective on Innovation. vol. 0, p. 1-31, 2015.

CAMARINHA-MATOS, L. M.; GOES, J.; GOMES, L.; MARTINS, J. - Contributing to the Internet of Things. In: Doctoral Conference on Computing, Electrical and Industrial Systems. Springer Berlin Heidelberg, 2013. p. 3-12.

CÂNDIDO, G.; BARATA, J.; COLOMBO, A. W.; JAMMES, F. - SOA in reconfigurable supply chains: A research roadmap. Engineering applications of artificial intelligence, v. 22, n. 6, p. 939-949, 2009.

CÂNDIDO, G.; BARATA, J.; COLOMBO, A. W.; JAMMES, F. - Service-oriented Architecture at device level to support Evolvable Production Systems. In: Industrial Electronics (ISIE), 2010 IEEE International Symposium on. IEEE, 2010. p. 2669-2674.

CÂNDIDO, G.; COLOMBO, A. W.; BARATA, J.; JAMMES, F. - Service-oriented infrastructure to support the deployment of evolvable production systems. IEEE Transactions on Industrial Informatics, v. 7, n. 4, p. 759-767, 2011.

CÂNDIDO, G., BARATA, J., COLOMBO, A. W., JAMMES, F. - SOA in reconfigurable supply chains: A research roadmap. Engineering applications of artificial intelligence, v. 22, n. 6, p. 939-949, 2009.

CAO, Chengxuan; YE, Heng-Qing; YUAN, Xue-Ming. e-Business strategies for software focused supply chain management. In: Industrial Informatics, 2006 IEEE International Conference on. IEEE, 2006. p. 765-769.

$\mathrm{CICHOCKI}$, Andrzej et al. Workflow and process automation: concepts and technology. Springer Science \& Business Media, 2012.

CHEN, Chaomei. CiteSpace II: Detecting and visualizing emerging trends and transient patterns in scientific literature. Journal of the American Society for information Science and Technology, v. 57 , n. 3, p. 359-377, 2006.

CHEN, C.; CHEN, Y.; HOROWITZ, M.; HOU, H.; LIU, Z.; PELLEGRINO, D. - Towards an explanatory and computational theory of scientific discovery. Journal of Informetrics, v. 3, n. 3, p. 191-209, 2009.

CHEN, Chaomei; IBEKWE-SANJUAN, Fidelia; HOU, Jianhua. The structure and dynamics of cocitation clusters: A multiple-perspective cocitation analysis. Journal of the American Society for Information Science and Technology, v. 61, n. 7, p. 1386-1409, 2010.

CHEN, Min; MAO, Shiwen; LIU, Yunhao. Big data: A survey. Mobile networks and applications, v. 19, n. 2, p. 171, 2014.

CHOU, M. C.; YE, H.; YUAN, X. M.; CHENG, Y. N.; CHUA, L.; GUAM, Y.; LEE, S.E.; TAY, Y. C. Analysis of a software-focused products and service supply chain. IEEE Transactions on Industrial Informatics, v. 2, n. 4, p. 295-302, 2006.

CHRISTIN, Delphine; MOGRE, Parag S.; HOLLICK, Matthias. Survey on wireless sensor network technologies for industrial automation: The security and quality of service perspectives. Future Internet, v. 2 , n. 2, p. 96-125, 2010.

COLOMBO, Armando Walter; BANGEMANN, Thomas; KARNOUSKOS, Stamatis. A system of systems view on collaborative industrial automation. In: Industrial Technology (ICIT), 2013 IEEE International Conference on. IEEE, 2013. p. 1968-1975.

COLOMBO, Armando Walter; BANGEMANN, Thomas; KARNOUSKOS, Stamatis. IMC-AESOP outcomes: Paving the way to collaborative manufacturing systems. In: Industrial Informatics (INDIN), 2014 12th IEEE International Conference on. IEEE, 2014. p. 255-260.

CRESWELL, John W. Educational research: Planning, conducting, and evaluating quantitative. Upper Saddle River, NJ: Prentice Hall, 2012. 
CUCINOTTA, T.; MANCINA, A.; ANASTASI, G. F.; LIPARI, G.; MANGERUCA, L.; CHECCOZZO, R.; RUSINÀ, F. - A real-time service-oriented architecture for industrial automation. IEEE Transactions on Industrial Informatics, v. 5, n. 3, p. 267-277, 2009.

DAVIS, J.; EDGAR, T.; PORTER J.; BERNADEN J.; SARLI, M. - Smart manufacturing, manufacturing intelligence and demand-dynamic performance. Computers \& Chemical Engineering, v. 47, p. 145156, 2012.

DELSING, J.; ROSENQVIST, F.; CARLSSON, O.; COLOMBO, A. W.; BANGEMANN, T. - Migration of industrial process control systems into service oriented architecture. In: IECON 2012-38th Annual Conference on IEEE Industrial Electronics Society. IEEE, 2012. p. 5786-5792.

DI ORIO, G.; BARATA, D.; ROCHA, A.; BARATA, J. - A cloud-based infrastructure to support manufacturing resources composition. In: Doctoral Conference on Computing, Electrical and Industrial Systems. Springer International Publishing, 2015. p. 82-89.

DRATH, Rainer; HORCH, Alexander. Industrie 4.0: Hit or hype?[industry forum]. IEEE industrial electronics magazine, v. 8, n. 2, p. 56-58, 2014.

ELLISON, R. J.; ALBERTS, C.; CREEL, R.; DOROFEE, A.; WOODY, C. - Software supply chain risk management: From products to systems of systems. CARNEGIE-MELLON UNIV PITTSBURGH PA SOFTWARE ENGINEERING INST, 2010a.

ELLISON, R. J.; GOODENOUGH, J. B.; WEINSTOCK, C. B.; WOODY, C. - Evaluating and mitigating software supply chain security risks. CARNEGIE-MELLON UNIV PITTSBURGH PA SOFTWARE ENGINEERING INST, 2010b.

ERL, Thomas. Service-oriented architecture: a field guide to integrating $\mathrm{XML}$ and web services. Prentice hall, 2004.

ERL, Thomas. Service-oriented architecture: concepts, technology, and design. Pearson Education India, 2005.

EVANS, P. C.; ANNUNZIATA, M. - Industrial internet: Pushing the boundaries. General Electric Reports (2012).

FREEMAN, Linton C. A set of measures of centrality based on betweenness. Sociometry, p. 35-41, 1977.

GARCÍA, Rodrigo García; GELLE, Esther; STROHMEIER, Alfred. A software architecture for industrial automation. In: Enterprise Distributed Object Computing Conference, 2003. Proceedings. Seventh IEEE International. IEEE, 2003. p. 315-320.

GRUNER, Sten; EPPLE, Ulrich. Paradigms for unified runtime systems in industrial automation. In: Control Conference (ECC), 2013 European. IEEE, 2013. p. 3925-3930.

GUINARD, D., TRIFA, V., KARNOUSKOS, S., SPIESS, P., \& SAVIO, D. Interacting with the soa-based internet of things: Discovery, query, selection, and on-demand provisioning of web services. IEEE transactions on Services Computing, v. 3, n. 3, p. 223-235, 2010.

GUNGOR, Vehbi C.; HANCKE, Gerhard P. Industrial wireless sensor networks: Challenges, design principles, and technical approaches. IEEE Transactions on industrial electronics, v. 56, n. 10, p. 4258-4265, 2009.

HADDARA, Moutaz; ELRAGAL, Ahmed. The Readiness of ERP Systems for the Factory of the Future. Procedia Computer Science, v. 64, p. 721-728, 2015. 
HARTMANN, Herman; TREW, Tim. Using feature diagrams with context variability to model multiple product lines for software supply chains. In: Software Product Line Conference, 2008. SPLC'08. 12th International. IEEE, 2008. p. 12-21.

HE, Jing et al. A smart web service based on the context of things. ACM Transactions on Internet Technology (TOIT), v. 11, n. 3, p. 13, 2012.

HENDERSON, John C.; VENKATRAMAN, Harihara. Strategic alignment: Leveraging information technology for transforming organizations. IBM systems journal, v. 32, n. 1, p. 472-484, 1993.

HERMANN, Mario; PENTEK, Tobias; OTTO, Boris. Design principles for industrie 4.0 scenarios. In: System Sciences (HICSS), 2016 49th Hawaii International Conference on. IEEE, 2016. p. 39283937.

HUANG, S. H., LIU, P., MOKASDAR, A., HOU, L. - Additive manufacturing and its societal impact: a literature review. The International Journal of Advanced Manufacturing Technology, p. 1-13, 2013.

IMTIAZ, Jahanzaib; JASPERNEITE, Jürgen. Scalability of OPC-UA down to the chip level enables "Internet of Things". In: Industrial Informatics (INDIN), 2013 11th IEEE International Conference on. IEEE, 2013. p. 500-505.

INDUSTRIE 4.0 WORKING GROUP - Recommendations for implementing the strategic initiative INDUSTRIE 4.0. Final report, April, 2013.

ISLAM, M. M., HASSAN, M. M., LEE, G. W., \& HUH, E. N. - A survey on virtualization of wireless sensor networks. Sensors, v. 12, n. 2, p. 2175-2207, 2012.

JAMMES, F.; SMIT, H. - Service-oriented paradigms in industrial automation. IEEE Transactions on Industrial Informatics, v. 1, n. 1, p. 62-70, 2005.

JARA, A. J.; VARAKLIOTIS, S.; SKARMETA, A. F.; KIRSTEIN, P. - Extending the Internet of Things to the Future Internet through IPv6 support. Mobile Information Systems, v. 10, n. 1, p. 3-17, 2014.

KAGERMANN, Henning et al. Recommendations for implementing the strategic initiative INDUSTRIE 4.0: Securing the future of German manufacturing industry; final report of the Industrie 4.0 Working Group. Forschungsunion, 2013.

KALOGERAS, A. P.; GIALELIS, J. V.; ALEXAKOS, C. E.; GEORGOUDAKIS, M. J.; KOUBIAS, S. A. Vertical integration of enterprise industrial systems utilizing web services. IEEE Transactions on Industrial Informatics, v. 2, n. 2, p. 120-128, 2006.

KARNOUSKOS, Stamatis. Stuxnet worm impact on industrial cyber-physical system security. In: IECON 2011-37th Annual Conference on IEEE Industrial Electronics Society. IEEE, 2011. p. 4490-4494.

KLEINBERG, Jon. Bursty and hierarchical structure in streams. In: Proceedings of the eighth ACM SIGKDD international conference on Knowledge discovery and data mining. ACM, 2002. p. 91101.

KORBER, Hans-Jrg; WATTAR, Housam; SCHOLL, Gerd. Modular wireless real-time sensor/actuator network for factory automation applications. IEEE Transactions on Industrial Informatics, v. 3, n. 2, p. 111-119, 2007.

KYUSAKOV, R., MÄKITAAVOLA, H.; DELSING, J.; ELIASSON, J. - Efficient XML interchange in factory automation systems. In: IECON 2011-37th Annual Conference on IEEE Industrial Electronics Society. IEEE, 2011. p. 4478-4483.

LA LONDE, Bernard J.; MASTERS, James M. Emerging logistics strategies: blueprints for the next century. International journal of physical distribution \& logistics management, v. 24, n. 7 , p. 3547, 1994.

LA REGINA, Veronica. EU-Japan Centre for Industrial Cooperation, 2015. 
LAMBERT, Douglas M.; STOCK, James R.; ELLRAM, Lisa M. Fundamentals of logistics management. McGraw-Hill//rwin, 1998.

LASTRA, Jose L. Martinez; DELAMER, M. Semantic web services in factory automation: fundamental insights and research roadmap. IEEE Transactions on Industrial Informatics, v. 2, n. 1, p. 1-11, 2006.

LAURINDO, F. J. B.; SHIMIZU, T.; CARVALHO, M. D.; RABECHINI Jr, R. - O papel da tecnologia da informação (TI) na estratégia das organizações. Gestão \& Produção, v. 8, n. 2, p. 160-179, 2001.

LEE, Hau L.; BILLINGTON, Corey. Designing products and processes for postponement. In: Management of Design. Springer Netherlands, 1994. p. 105-122.

LEE, Edward A. Cyber physical systems: Design challenges. In: Object oriented real-time distributed computing (isorc), 2008 11th ieee international symposium on. IEEE, 2008. p. 363-369.

LEE, Jay et al. Recent advances and trends in predictive manufacturing systems in big data environment. Manufacturing Letters, v. 1, n. 1, p. 38-41, 2013.

LEE, Jay; KAO, Hung-An; YANG, Shanhu. Service innovation and smart analytics for industry 4.0 and big data environment. Procedia Cirp, v. 16, p. 3-8, 2014.

LEE, Jay; BAGHERI, Behrad; KAO, Hung-An. A cyber-physical systems architecture for industry 4.0based manufacturing systems. Manufacturing Letters, v. 3, p. 18-23, 2015.

LEITÃO, Paulo. Agent-based distributed manufacturing control: A state-of-the-art survey. Engineering Applications of Artificial Intelligence, v. 22, n. 7, p. 979-991, 2009.

LEITÃO, Paulo; MAŘ́lK, Vladimír; VRBA, Pavel. Past, present, and future of industrial agent applications. IEEE Transactions on Industrial Informatics, v. 9, n. 4, p. 2360-2372, 2013.

LEITÃO, Paulo; COLOMBO, Armando Walter; KARNOUSKOS, Stamatis. Industrial automation based on cyber-physical systems technologies: Prototype implementations and challenges. Computers in Industry, v. 81, p. 11-25, 2016.

LEITAO, P.; KARNOUSKOS, S.; RIBEIRO, L., LEE, J.; STRASSER, T.; COLOMBO, A. W. - Smart Agents in Industrial Cyber-Physical Systems. Proceedings of the IEEE, v. 104, n. 5, p. 1086-1101, 2016.

LUFTMAN, Jerry N.. ; LEWIS, Paul R.. ; OLDACH, Scott H.. . Transforming the enterprise: The alignment of business and information technology strategies. IBM systems journal, v. 32, n. 1, p. 198221, 1993.

MA, M.; YUAN, X.-M. A performance model for software focused supply chains. In: Industrial Informatics, 2005. INDIN'05. 2005 3rd IEEE International Conference on. IEEE, 2005. p. 192-197.

MACDOUGALL, William. Industrie 4.0: Smart manufacturing for the future. Germany Trade \& Invest, 2014.

MACKENZIE, C. Matthew, Laskey, K.; McCabe, F.; Brown, P. F.; Metz, R., \& Hamilton, B. A. Reference model for service oriented architecture 1.0. OASIS standard, v. 12, p. 18, 2006.

MAHNKE, Wolfgang; LEITNER, Stefan-Helmut; DAMM, Matthias. OPC unified architecture. Springer Science \& Business Media, 2009.

MAROPOULOS, P. G.; MUELANER, J. E.; SUMMERS, M. D.; MARTIN, O. C. - A new paradigm in large-scale assembly - research priorities in measurement assisted assembly. The International Journal of Advanced Manufacturing Technology, v. 70, n. 1-4, p. 621-633, 2014. 
MONOSTORI, László. Cyber-physical production systems: Roots, expectations and R\&D challenges. Procedia CIRP, v. 17, p. 9-13, 2014.

MORA, D.; TAISCH, M.; COLOMBO, A. W; MENDES, J. M. - Service-oriented architecture approach for industrial "System of Systems": State-of-the-Art for Energy Management. In: Industrial Informatics (INDIN), 2012 10th IEEE International Conference on. IEEE, 2012. p. 1246-1251.

MORITZ, Guido et al. Devices profile for web services in wireless sensor networks: Adaptations and enhancements. In: Emerging Technologies \& Factory Automation, 2009. ETFA 2009. IEEE Conference on. IEEE, 2009. p. 1-8.

NAGORNY, Kevin; COLOMBO, Armando Walter; SCHMIDTMANN, Uwe. A service-and multi-agentoriented manufacturing automation architecture: An IEC 62264 level 2 compliant implementation. Computers in Industry, v. 63, n. 8, p. 813-823, 2012.

NEVES, P., FERREIRA, J., ONORI, M., RIBEIRO, L.; BARATA, J. - Prospection of methods to support design and configuration of self-organizing mechatronic systems. In: Systems, Man, and Cybernetics (SMC), 2013 IEEE International Conference on. IEEE, 2013. p. 3854-3861.

OKUBO, Yoshiko. Bibliometric indicators and analysis of research systems. 1997.

OLLINGER, L.; SCHLICK, J.; HODEK, S. - Leveraging the agility of manufacturing chains by combining process-oriented production planning and service-oriented manufacturing automation. IFAC Proceedings Volumes, v. 44, n. 1, p. 5231-5236, 2011.

PARASURAMAN, Raja; SHERIDAN, Thomas B.; WICKENS, Christopher D. A model for types and levels of human interaction with automation. IEEE Transactions on systems, man, and cyberneticsPart A: Systems and Humans, v. 30, n. 3, p. 286-297, 2000.

PĚCHOUČEK, Michal; MAŘíK, Vladimír. Industrial deployment of multi-agent technologies: review and selected case studies. Autonomous Agents and Multi-Agent Systems, v. 17, n. 3, p. 397-431, 2008.

PEDERSEN, M. R.; NALPANTIDIS, L., ANDERSEN, R. S.; SCHOU, C.; BØGH, S.; KRÜGER, V.; MADSEN, O. - Robot skills for manufacturing: From concept to industrial deployment. Robotics and Computer-Integrated Manufacturing, v. 37, p. 282-291, 2016.

PEREIRA, Nuno; TOVAR, Eduardo; PINHO, Luís Miguel. INDEPTH: timeliness assessment of Ethernet/IP-based systems. In: Modeling, Analysis, and Simulation of Computer and Telecommunications Systems, 2004.(MASCOTS 2004). Proceedings. The IEEE Computer Society's 12th Annual International Symposium on. IEEE, 2004. p. 192-201.

PIGGIN, R. S. H. Governance, risk and compliance: impediments and opportunities for managing operational technology risk in industrial cyber security and safety. In: System Safety and Cyber Security (2014), 9th IET International Conference on. IET, 2014. p. 1-8.

POHL, A.; KRUMM, H.; HOLLAND, F.; STEWING, F. J.; LUECK, I. - Service-orientation and flexible service binding in distributed automation and control systems. In: Advanced Information Networking and Applications-Workshops, 2008. AINAW 2008. 22nd International Conference on. IEEE, 2008. p. 1393-1398.

PUTTONEN, Juha; LOBOV, Andrei; LASTRA, José L. Martinez. Semantics-based composition of factory automation processes encapsulated by web services. IEEE Transactions on industrial informatics, v. 9, n. 4, p. 2349-2359, 2013.

PESSOA, Marcelo Schneck de Paula; SPINOLA, Mauro de Mesquita. Introdução à automação: para cursos de engenharia e gestão. Elsevier, 2014.

RADZIWON, Agnieszka et al. The smart factory: exploring adaptive and flexible manufacturing solutions. Procedia Engineering, v. 69, p. 1184-1190, 2014. 
REINHART, G.; KRUG, S.; HÜTTNER, S.; MARI, Z.; RIEDELBAUCH, F.; SCHLÖGEL, M. - Automatic configuration (plug \& produce) of industrial ethernet networks. In: Industry Applications (INDUSCON), 2010 9th IEEE/IAS International Conference on. IEEE, 2010. p. 1-6.

RIEDL, M.; ZIPPER, H.; MEIER, M.; DIEDRICH, C. - Cyber-physical systems alter automation architectures. Annual Reviews in Control, v. 38, n. 1, p. 123-133, 2014.

RIFKIN, Jeremy. The third industrial revolution: How the internet, green electricity, and 3-d printing are ushering in a sustainable era of distributed capitalism. World Financial Review, v. 1, p. 4052-4057, 2012.

ROBERT, J.; GEORGES, J. P.; RONDEAU, E.; DIVOUX, T. - Minimum cycle time analysis of Ethernetbased real-time protocols. International Journal of Computers, Communications and Control, v. 7 , n. 4, p. 743-757, 2012.

SAPONARA, S.; PETRI, E.; FANUCCI, L.; TERRENI, P. - Smart transducer interface in embedded systems for networked sensors based on the emerging IEEE 1451 standard: H2 detection case study. In: Intelligent solutions in Embedded Systems, 2009 Seventh Workshop on. IEEE, 2009. p. 49-55.

SAUTER, Thilo. The continuing evolution of integration in manufacturing automation. IEEE Industrial Electronics Magazine, v. 1, n. 1, p. 10-19, 2007.

SAUTER, Thilo. The three generations of field-level networks-Evolution and compatibility issues. IEEE Transactions on Industrial Electronics, v. 57, n. 11, p. 3585-3595, 2010.

SCHMITT, M.; MEIXNER, G.; GORECKY, D.; SEISSLER, M.; LOSKYLL, M. - Mobile interaction technologies in the factory of the future. IFAC Proceedings Volumes, v. 46, n. 15, p. 536-542, 2013.

SCHOLTEN, Bianca. Integrating ISA-88 and ISA-95. ISA EXPO, v. 2007, 2007.

SHROUF, Fadi; ORDIERES, Joaquin; MIRAGLIOTTA, Giovanni. Smart factories in Industry 4.0: A review of the concept and of energy management approached in production based on the Internet of Things paradigm. In: Industrial Engineering and Engineering Management (IEEM), 2014 IEEE International Conference on. IEEE, 2014. p. 697-701.

SCHUH, G.; POTENTE, T.; WESCH-POTENTE, C.; WEBER, A. R.; PROTE, J. P. - Collaboration Mechanisms to increase Productivity in the Context of Industrie 4.0. Procedia CIRP, v. 19, p. 51-56, 2014.

SHELBY, Zach. Embedded web services. IEEE Wireless Communications, v. 17, n. 6, 2010.

SOUZA, Gilvan C. Supply chain analytics. Business Horizons, v. 57, n. 5, p. 595-605, 2014.

STEVEN, Alter. Information systems: A management perspective. 2000.

STOKIC, D.; SCHOLZE, S.; DECKER, C.; STÖBENER, K. - Engineering methods and tools for collaborative development of industrial cyber-physical based products and services. In: Industrial Informatics (INDIN), 2014 12th IEEE International Conference on. IEEE, 2014. p. 594-599.

SUCIC, S., BONY, B., GUISE, L., JAMMES, F., MARUSIC, A. - Integrating DPWS and OPC UA devicelevel SOA features into IEC 61850 applications. In: IECON 2012-38th Annual Conference on IEEE Industrial Electronics Society. 2012.

SUNDMAEKER, Harald; GUILLEMIN, Patrick; FRIESS, Peter; WOELFFLÉ Sylvie - Vision and challenges for realising the Internet of Things. Cluster of European Research Projects on the Internet of Things, European Commision, 2010.

TAN, Puay Siew; YUAN, Xue-Ming - ICT technologies for enabling software focused supply chains. In: Industrial Informatics, 2005. INDIN'05. 2005 3rd IEEE International Conference on. IEEE, 2005. p. 187-191. 
TAPSCOTT, Don; WILLIAMS, Anthony D. Wikinomics: How mass collaboration. Changes Everything, Portfolio, 2006.

THEORIN, Alfred; OLLINGER, Lisa; JOHNSSON, Charlotta. Service-oriented process control with grafchart and the devices profile for web services. In: Service Orientation in Holonic and Multi Agent Manufacturing and Robotics. Springer Berlin Heidelberg, 2013. p. 213-228.

TIEN, James M. The next industrial revolution: Integrated services and goods. Journal of Systems Science and Systems Engineering, p. 1-40, 2012.

TIEN, James M. Big data: Unleashing information. Journal of Systems Science and Systems Engineering, v. 22, n. 2, p. 127-151, 2013.

TONTA, Yaşar; DOGANM, Güleda. Industry 4.0: Mapping the Structure and Evolution of an Emerging Field, 2016.

VAN BRUSSEL, Hendrik et al. Reference architecture for holonic manufacturing systems: PROSA. Computers in industry, v. 37, n. 3, p. 255-274, 1998.

VANDERMERWE, Sandra; RADA, Juan. Servitization of business: adding value by adding services. European management journal, v. 6, n. 4, p. 314-324, 1988.

VIERHAUSER, Michael; RABISER, Rick; GRÜNBACHER, Paul. A case study on testing, commissioning, and operation of very-large-scale software systems. In: Companion Proceedings of the 36th International Conference on Software Engineering. ACM, 2014. p. 125-134.

VRBA, P.; TICHY, P.; MAŘ́KK, V.; HALL, K. H.; STARON, R. J.; MATURANA, F. P.; KADERA, P Rockwell automation's holonic and multiagent control systems compendium. IEEE Transactions on Systems, Man, and Cybernetics, Part C (Applications and Reviews), v. 41, n. 1, p. 14-30, 2011.

VYATKIN, Valeriy. IEC 61499 as enabler of distributed and intelligent automation: State-of-the-art review. IEEE Transactions on Industrial Informatics, v. 7, n. 4, p. 768-781, 2011.

WAHLSTER, Wolfgang et al. (Ed.). Towards the internet of services: The THESEUS research program. Springer, 2014.

WANG, Chunlei; FANG, Lan; DAI, Yiqi - A simulation environment for SCADA security analysis and assessment. In: Measuring Technology and Mechatronics Automation (ICMTMA), 2010 International Conference on. IEEE, 2010. p. 342-347.

WEILL, Peter. The relationship between investment in information technology and firm performance: A study of the valve manufacturing sector. Information systems research, v. 3, n. 4, p. 307-333, 1992.

WESTHEAD, Paul; STOREY, David. Management training and small firm performance: why is the link so weak?. International Small Business Journal, v. 14, n. 4, p. 13-24, 1996.

WEYER, Stephan et al. Towards Industry 4.0-Standardization as the crucial challenge for highly modular, multi-vendor production systems. IFAC-PapersOnLine, v. 48, n. 3, p. 579-584, 2015.

WU, Dazhong; GREER, M. J.; ROSEN, D. W.; SCHAEFER, D. - Cloud manufacturing: Strategic vision and state-of-the-art. Journal of Manufacturing Systems, v. 32, n. 4, p. 564-579, 2013.

XIA, L. X. X.; LEE, W.; SING, C. L.; ZHENGPING, L. - Performance metrics design framework for software focused supply chain. In: Industrial Informatics, 2005. INDIN'05. 2005 3rd IEEE International Conference on. IEEE, 2005. p. 176-180.

$\mathrm{XU}$, Xun. From cloud computing to cloud manufacturing. Robotics and computer-integrated manufacturing, v. 28, n. 1, p. 75-86, 2012. 
YEN, Chun-Tai; LIU, Yu-Chi; LIN, Chih-Chieh; KAO, Chih-Chiang; WANG, Wen-Bin; HSU, Yu-Rong Advanced manufacturing solution to industry 4.0 trend through sensing network and Cloud Computing technologies. In: Automation Science and Engineering (CASE), 2014 IEEE International Conference on. IEEE, 2014. p. 1150-1152.

YIN, Shen; KAYNAK, Okyay. Big data for modern industry: challenges and trends [point of view]. Proceedings of the IEEE, v. 103, n. 2, p. 143-146, 2015.

YU, Chunyang; XU, Xun; LU, Yuqian. Computer-integrated manufacturing, cyber-physical systems and cloud manufacturing-concepts and relationships. Manufacturing letters, v. 6, p. 5-9, 2015.

ZUEHLKE, Detlef. SmartFactory-Towards a factory-of-things. Annual Reviews in Control, v. 34, n. 1, p. 129-138, 2010.

\section{WEB SITES}

ATOS - The convergence of IT and Operational Technology, 2012 disponível em: $<$ https://atos.net/content/dam /global/ascent-whitepapers/ascent-whitepaper-the-convergence-of-itand-operational-technology.pdf> ultimo acesso em 20/06/2017.

BELYH, A. Cleverism - Industry 4.0: Everything You Need To Know, 2015. Disponível em: <http://www.cleverism.com/industry-4-0-everything-need-know/>, último acesso em 08/01/2017.

B\&R Automation - MAPP Technology Simplifies Automation (2016), Disponível em: $<$ http://industrialtechnology.events/ wp-content/uploads/2016/08/mapp-Technology-simplifiesautomation.pdf>, último acesso em 25/01/2017.

BOSCH REXROTH LTDA. A Indústria do Futuro, 2013 disponivel em: <http://www.boschrexroth.com/ country_units/south_america/brasil/pt/downloads/Industria_4.0_rex.pdf>, último acesso em 01/07/2014

BYRES \& CUSIMANO WHITEPAPER 7 Steps to ICS and SCADA Security, 2012 disponível em: https://www.tofinosecurity.com/blog/7-steps.

CAMPI, M. - Bitmag - Indústria 4.0: pesquisa mostra falta de conhecimento entre fabricantes brasileiros, 2016 disponível em: <http://www.bitmag.com.br/2016/01/industria-4-0-pesquisa-mostra-falta-deconhecimento-entre-fabricantes-brasileiros/>, último acesso em 24/06/2016.

CHEN, Chaomei. The CiteSpace Manual. (2014-04-18)[2014-05-271]<http://cluster.ischool.drexel .edu/ cchen/citespace/ Cite Space Manual.pdf>, 2014, ultimo acesso em 20/06/2017.

CLARK, Don, Presentation ISA-95, Invensys Operations Management, 2010, disponível em: <http://www.iom. invensys.com/en/.../presentation_isa\%20s95.ppt>, último acesso em 20/06/2014.

CNI - Special Survey Industry 4.0: A new Challenge for Brazilian Industries, 2016, disponível em: $<$ http://arquivos.portaldaindustria.com.br/app/cni_estatistica_2/2016/05/16/217/Special_Survey_Indust ry4.0.pdf>, último acesso em 02/11/2016.

COELI, Phisystems - Tecnologia desenha o caminho da Industria 4.0 no Brasil, disponível em: <http://www.phisystems. com.br/tecnologia-desenha-o-caminho-da-industria-4-0-no-brasil/>, último acesso em 04/11/2015.

DANGEL, Diario Catarinense - Indústria 4.0: empresas investem em fábricas inteligentes, 2015 disponivel em: <http://dc.clicrbs.com.br/sc/noticias/noticia/2015/05/industria-4-0-empresas-investemem-fabricas-inteligentes-47 52300. html>, último acesso em 04/11/2015.

DELL - Integração de negócios empresarial, 2017 disponível em: <http://www.dell.com/pt$\mathrm{br} /$ work/learn/enterprise-business-integration?ST=service $\% 20$ oriented\%20architecture\&dgc=ST\&cid= 297537\& lid=5687884\&acd=1225519911720562\& ven1=sntY5tZbW\&ven2=b>, último acesso em $22 / 03 / 2017$. 
DELOITTE CONSULTING - Industry 4.0 Challenges and solutions for the digital transformation and the use of exponential technologies, 2015 disponivel em: <http://www2.deloitte.com/content /dam/Deloitte/ch/Documents/ manufacturing/ch-en-manufacturing-industry-4-0-24102014.pdf>, último acesso em 04/11/2015.

DITTES, U. Technical and Operational Solutions for Industry 4.0 in ERP Systems, SAP disponível em: https://assets.cdn.sap.com/sapcom/docs/2016/09/f4041f45-8a7c-0010-82c7-eda71af511fa.pdf, último acesso em 30/06/2017.

Dressler U. - Internet of Things in Japan - Quietly, Systematically Plowing Ahead, Japan Industry News 2016, disponível em: https://www.japanindustrynews.com/2016/04/internet-things-japan-quietlysystematically-plowing-ahead/, ultimo acesso em 30/06/2017.

GARTNER (a) The Connected Enterprise - Accelerating the Industrial Performance, 2015 disponível em: $\quad<$ http://www. gartner.com/technology/media-products/newsletters/rockwell-automation/12JWQ2KQ/index.htm I>, ultimo acesso em 20/06/20167

GARTNER (b) Gartner's 2015 Hype Cycle for Emerging Technologies Identifies the Computing Innovations That Organizations Should Monitor, 2015 disponível em: <http://www.gartner. com/newsroom/id/3114217>, ultimo acesso em 20/06/2017.

GARTNER IT Glossary - Operational Technology (OT) 2016, disponível em <http://www.gartner.com/itglossary/operational-technology-ot>, ultimo acesso em 20/06/2017.

GERMANY TRADE AND INVEST - Industrie 4.0, 2014, disponível em <http:/l www.gtai.de/GTAl/Content/EN /Invest/_SharedDocs/Downloads/GTAl/Brochures/Industries/industrie 4.0-smart-manufacturing-for-the-future-en.pdf>, último acesso em 03/11/2015.

GORBACH, Greg - ARC ADVISORY GROUP - Forget IT-OT Convergence, Physical-Digital Convergence is the real opportunity 2016, disponivel em: <https://industrial-iot.com/2016/06/forget-otconvergence-physical-digital-convergence-realopportunity/?_cldee=cnV5Lm5ha2F5YW1hQGtub3do

YS5jb20uYnl\%3d\&utm_source= ClickDimensions\&utm_medium =email\&utm_campaign=Industrial\%20 IoT\%20and\%20Industrie\%204.0\%20Viewpoints>, último acesso em 15/06/2016.

HAHN FILHO, José Rizzo - A Indústria 4.0 desembarca no Brasil, 2015, disponível em: <http://www.amanha. com.br/posts/view/897>, último acesso em 04/11/2015.

HAVEN, B. Marketing's New Key Metric - Engagement, 2007 disponível em: https://www.forrester .com/report/Marketings+New+Key+Metric+Engagement/-/E-RES42124

HONEYWELL Process Solutions - Achieving Production Excellence: Solutions for Success, 2010 disponível em: <https://www.honeywellprocess.com/library/marketing/whitepapers/HoneywellProduc tionIntelligence_Achie ving ProductionExcellenceSolutions WP546.pdf>, último acesso em 21/06/2014.

IBM - Transformação de processos de negócios através de SOA: Agilidade sustentável para uma empresa globalmente integrada, 2008 disponível em: <https://www.ibm.com/br/services/cio/pdf/> Transformacao_de_processos.pdf, último acesso em 22/03/2017.

IEEE CG\&A, Special Issue on Visual Computing Challenges of Manufacturing and Making for Industry 4.0, Future Factories and New Foundries, 2014 disponível em: <http://ieeexplore.ieee.org/stamp /stamp.jsp ?arnumber=6834692>, último acesso em 01/07/2014.

INDIANA UNIVERSITY, Cyberinfrastructure for Network Science Center School of Library and Information Science - Science of Science (Sci2) Tool User Manual, Version Alpha 3, 2010, disponível em <http://sci.cns.iu.edu/registration/docs/Sci2_Tutorial.pdf> , último acesso em 26/10/2015.

INDUSTRIAL INTERNET CONSORTIUM, disponível em: <http://www.iiconsortium.org/>, último acesso em 04/11/2015. 
IPROCESS - SOA, 2007 disponível em: <http://iprocess.com.br/soa/, último acesso em 22/03/2017. ISA - International Society of Automation disponível em: <https://www.isa.org/ , último acesso em 21/06/2014.

KARNOUSKOS, Stamatis disponível em: <http://www.iecon2013.org/files/lECON2013_IF102_ Karnouskos. pdf> , último acesso em 05/05/2015.

KNOWLES-HALL, Sarah; VAN DER VEER, Lyle - Preparing Engineers for IT Network and Industrial Production Convergence, Schneider Electric, 2014 disponível em: <http://www.schneiderelectric.com/ww/en/ download /document/998-2095-11-28-14AR0EN>, último acesso em 04/11/2015.

$\mathrm{KOCH}, \mathrm{V}$;; KUGE, S.; GEISSBAUER, R.; SCHRAUF, S. - Industry 4.0 Opportunity and challenges of the industrial internet, 2014 disponível em: https://www.pwc.nl/en/assets/documents/pwc-industrie-4$0 . p d f$

MESA International - Business To Manufacturing Markup Language (B2MML), disponível em: <http://www.mesa.org/en/B2MML.asp>, último acesso em 21/06/2014.

NFS (2012) NFS (2012). Cyber-Physical Systems (CPS), disponível em: <http://www.nsf.gov/funding/pgm summ.jsp?pimsid=503286>, último acesso em 10/12/2016.

OASIS (2009) - Device Profile for Web Service - disponível em <www.oasis-open.org>, último acesso em 03/11/2015.

ODVA - Open Devicenet Vendors Association, Ethernet/IP Technology Overview, 2014, Disponível em <https://www.odva.org/Home/ODVATECHNOLOGIES/EtherNetIP/EtherNetIPTechnologyOverview.as px>, último acesso em 14/10/2015.

ORACLE - Java and the Internet of Things: Automating the Industrial Economy, 2015 Disponível em: <http://www.oracle.com/us/solutions/internetofthings/java-iot-industrial-automation-2430562.pdf>, último acesso em 04/11/2015.

PATHFINDER - Pointing out research priorities leading to the next generation of simulation and forecasting technologies, 2014 disponível em: <http://www.pathfinderproject.eu/downloads /results/Pathfinder_White Paper1.pdf>, último acesso em 04/11/2015.

PLATFORM INDUSTRIE 4.0, Neue Chancen für unsere Produktion - 17 Thesen des Wissenschaftlichen Beirats der Plattform Industrie 4.0, 2014 disponível em: <http://www.plattformi40.de/neue-chancen-f\%C3\%BCr-unsere-produktion-17-thesen-des-wissenschaftlichen-beirats-derplattform-industrie>, último acesso em 19/08/2015.

PÜHRINGER, A. Japan's Take on the Industrial Internet of Things, 2016 disponível em: https://www. automationworld.com/article/industry-type/all/japans-take-industrial-internet-things, ultimo acesso em $30 / 07 / 2017$

RIFKIN, Jeremy. In New Economy, 'Social Skills Count More Than Work Skills', The World Post, 2015 disponível em: <http://www.huffingtonpost.com/2015/03/02/rifkin-new-economy-social-kills_n_67776 46.html? clear>, último acesso em: 17/08/2015.

ROCKWELL AUTOMATION - The Connected Enterprise - Execution Model, 2014, disponível em: $<$ http://literature.rockwellautomation.com/idc/groups/literature/documents/sp/cie-sp011_-en-p.pdf?eve nt-category=Whitepaper\&event-action=Download\&event-label=ConnectedEnterprise_ExecutionModel _EN>, ultimo acesso em 20/06/2017.

ROLAND BERGER CONSULTANTS, Industry 4.0 The new industrial revolution How Europe will succeed, 2014, disponível em: <https://www.rolandberger.com/media/pdf/Roland_Berger TAB_Industry_4_0_20140403.pdf> último acesso em 27/04/2015.

RUNKLER, Thomas - Cyber Physical Systems for Manufacturing and Production, 2013 disponível em: <http://download.steinbeis-europa.de/2013-10-29-30_CPS/30102013-cps-runkler.pdf>, último acesso em 04/11/2015. 
SCHNEIDER ELECTRIC - Control and automation Ethernet TCP/IP and the Web Navigate freely across a universal network, 2005 disponível em: <http://download.schneiderelectric.com/files?p_File_Id=27478488\& p_File_Name=DIA9ED1040804EN.pdf $>$ último acesso em 22/06/2014.

SIEMENS Totally Integrated Automation - Product Guide, 2013, disponível em: http://www industry.siemens.com/topics/global/en/tia/Documents/tia-product-guide-en.pdf último acesso em $21 / 06 / 2014$.

THE ECONOMIST - A third industrial revolution, 2013 Disponível em: <http://web.mit.edu/pie /news/Economist .pdf>, último acesso em 04/11/2015.

TÜV RHEINLAND - Cybersecurity Trends 2015, 2015 Disponível em: <https://www.tuv.com/media/germany /isec/flyer_2/Cybersecurity_Trends_2015-E_.pdf>, último acesso em 04/11/2015.

VERHAPPEN, lan - Prepare for Tomorrow's Digital Plant: Ubiquitous and cheap data will transform how an enterprise operates, Chemical Processing, 2010, disponível em: <http://www.chemicalprocessing .com/ articles/2010/065/> último acesso em 21/06/2014.

VDI \& ASME Industry 4.0 - A Discussion of Qualifications and Skills in the Factory of the Future: A German and American Perspective, 2015 disponível em: <http://m.vdi.eu/fileadmin/vdi_de/ redakteur/karriere_bilder/VDI-ASME_2015_White_Paper_final.pdf>, último acesso em 04/11/2015.

VDMA, 2015 Industrie 4.0 - From Vision To Reality disponível em: <http://www.smartindustry.nl/wpcontent/ uploads/2015/01/2.1-internationaal-Industry_4.0_Master_Forum_i40_SmartIndustryLaunch22 January.pdf>, último acesso em 20/04/2016.

W3C World Wide Web Consortium, disponível em: <https://www.w3.org/>, último acesso em 10/12/2016.

WAHLSTER, Wolfgang. Industry 4.0: From the Internet of Things to Smart Factories, 2012 disponível em: <https://www.google.com.br/url?sa=t\&rct=j\&q=\&esrc=s\&source=web\&cd=1\&cad=rja\&uact=8\&ved

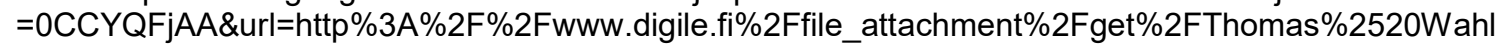
ster.pdf\%3Fattachment_id\%3D121\&ei=QqxWVfuzAsHjsAShq4DgCw\&usg=AFQjCNEHI5OEdfzRlofFD YZOTQMnPYSuHw\&sig2=I_yL6LhYrORX_SnEvmHDBg\&bvm=bv.93564037,d.cWc>, último acesso em 15/05/2015.

WEB OF SCIENCE disponível em: <https://apps.webofknowledge.com/WOS_AdvancedSearch_ input.do?produ ct=WOS\&SID=2DPmJh6YetYPQMLYE27\&search_mode=AdvancedSearch>, último acesso em 29/10/2016. 


\section{ANEXOS}

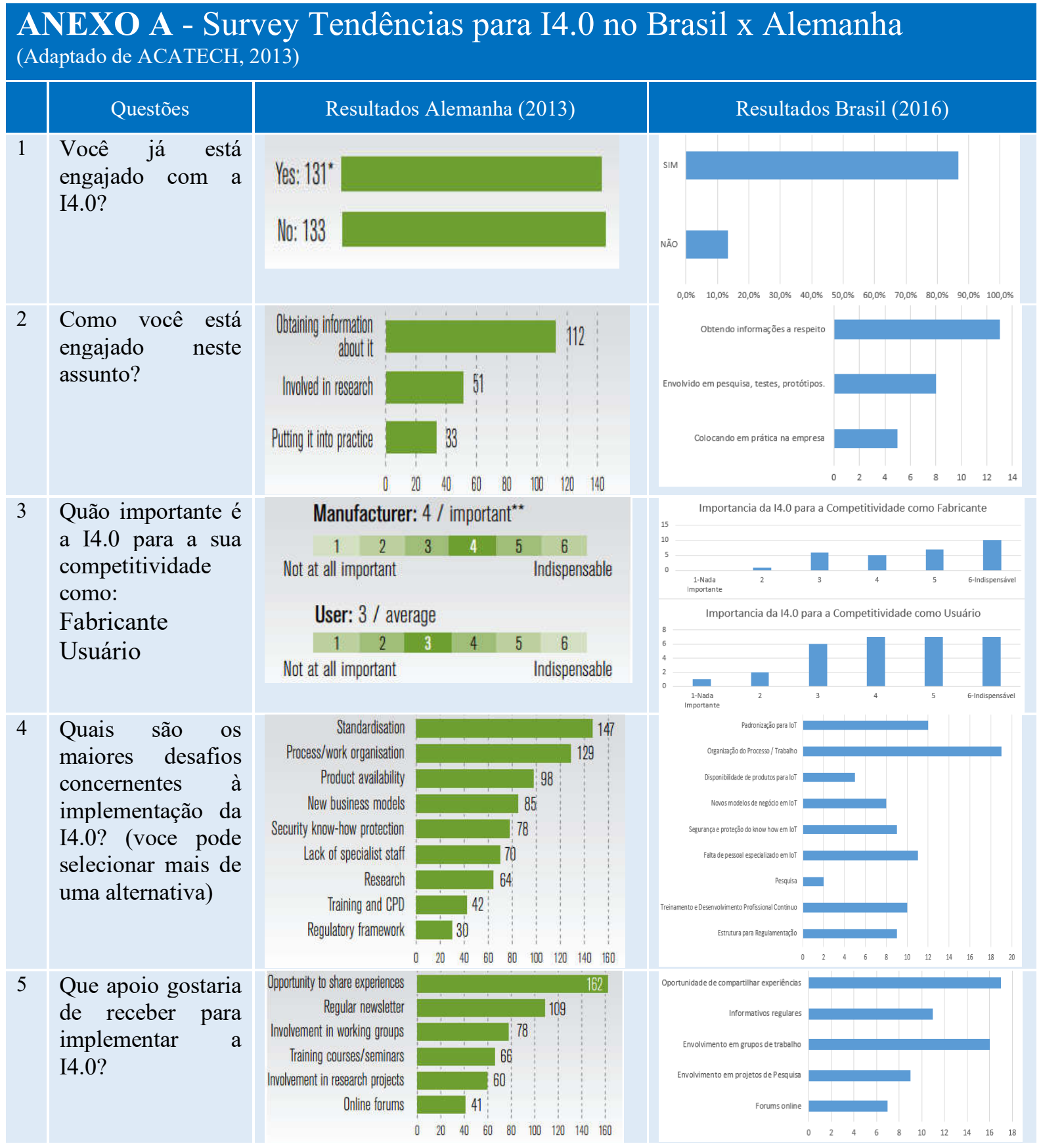




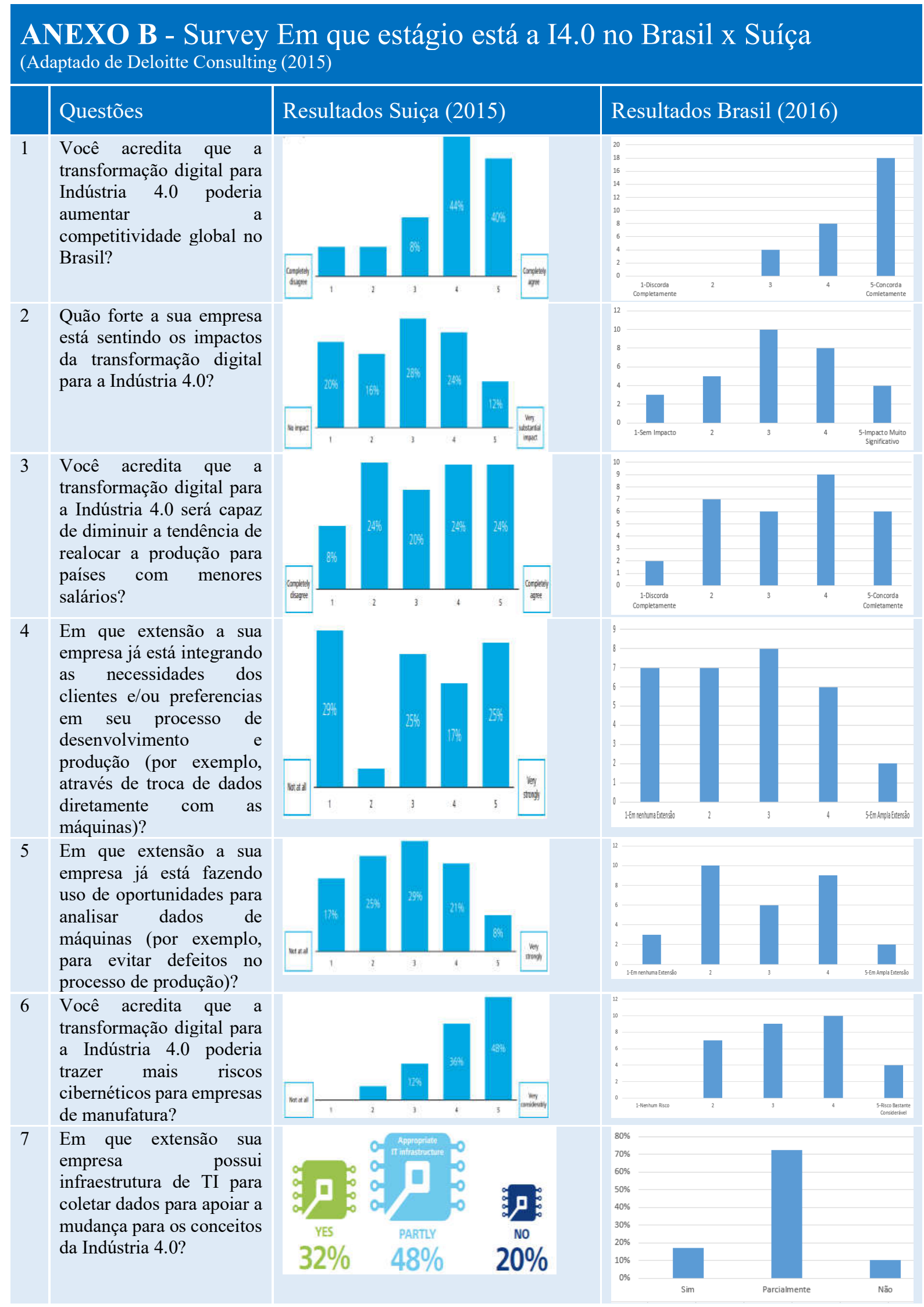


8 A transformação digital para a Indústria 4.0 trará novos desafios para os profissionais. A sua empresa possui pessoal qualificado para atender a estas demandas?

9 Que segmento de negócio em sua empresa passaram por maior e menor transformação como parte da implantação da Indústria 4.0?

10 Que segmento de negócio em sua empresa tem o maior potencial para se beneficiar da transformação digital para a Indústria 4.0?

11 Você concorda que a impressão 3D tem potencial para ser uma tecnologia fundamental, que poderá acelerar a transformação digital da Manufatura Brasileira para a Indústria 4.0?

12 Quão intensamente a sua empresa já está fazendo uso da oportunidade que a tecnologia de impressão 3D oferece para os processos de produção e desenvolvimento?

13 A sua empresa planeja começar ou continuar investindo em tecnologia de impressão $3 \mathrm{D}$ no futuro?
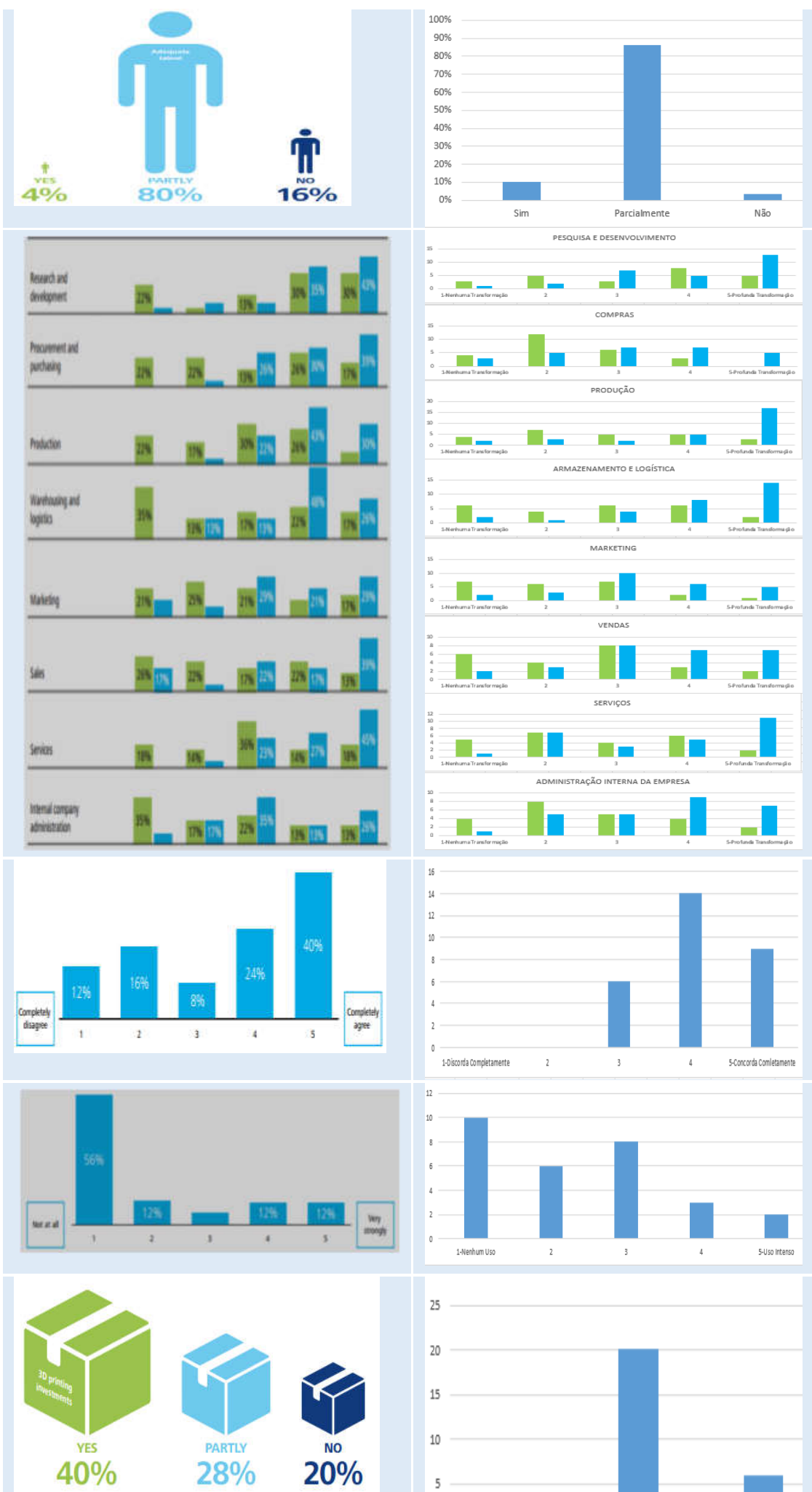

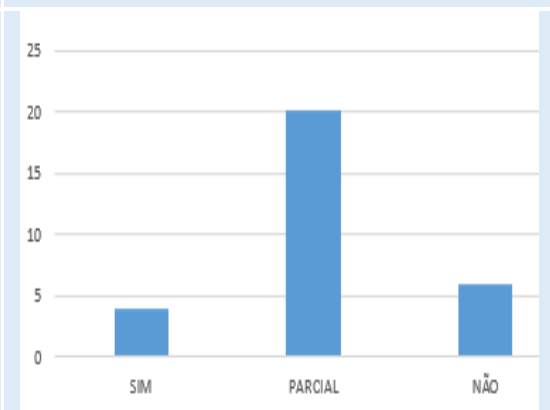




\section{ANEXO C - Questionário para Survey}

São Paulo, 28 de janeiro de 2016.

Prezado(a) Senhor(a),

A Indústria 4.0 (14.0) ou Indústria 4.0 (conhecido também por outros termos como Internet Industrial, Manufatura Inteligente, etc.) tem sido divulgada como um novo paradigma na automação industrial e visto como a Quarta Revolução Industrial. Baseada em tecnologias emergentes de informação e comunicação, mais especificamente a Internet das Coisas (IoT), software de SERP compatível com esta tecnologia (Smart ERP) e a Internet de Serviços (IoS), a $\mathbf{1 4 . 0}$ promete revolucionar de forma radical a produção industrial através de ampla conectividade, comunicação entre máquinas (M2M) e total integração entre a manufatura e negócios, incluindo a cadeia de valor (rede de empresas colaborativas).

Embora muitos países já estejam engajados neste novo paradigma, a indústria brasileira aparenta estar bastante defasada tecnologicamente neste sentido, o que pode representar grandes perdas ou oportunidades para os atores desta cadeia globalizada. Neste contexto, a sua colaboração através do compartilhamento de informações sobre a atuação corrente e planos futuros da sua empresa será de fundamental importância para compreender o estado atual e planos de reação da indústria brasileira diante deste novo paradigma.

O objetivo deste estudo é compreender, do ponto de vista de gestão, como estes avanços tecnológicos estão mudando, no Brasil, os paradigmas de controle e conectividade na automação industrial, os impactos que eles trazem na Cadeia de Fornecimento de Sistemas para Automação da Manufatura (CFSAM) e consequentemente, que atuações emergentes estão surgindo como oportunidades para os atores desta cadeia.

A sua participação nesta pesquisa é voluntária. Embora seja solicitada a sua identificação e de sua empresa na pesquisa para nosso controle e acompanhamento, o seu anonimato e a confidencialidade das informações serão asseguradas. Contudo, ao retornar esta pesquisa respondida, estará consentindo a compilação de seus dados juntamente com os dos demais respondentes. O uso destes dados será restrito à apresentação como tese de doutoramento ao Departamento de Engenharia de Produção da Universidade de São Paulo e em artigos de jornais acadêmicos e congressos. Em caso de ressalvas particulares ou dúvidas, poderá fazer as observações ao retornar a pesquisa ou através do contato abaixo.

Agradecemos imensamente pela sua participação e pedimos o retorno através de e-mail conforme endereço abaixo, preferencialmente até o dia 04 de março de 2016, com as respostas marcadas neste mesmo arquivo eletrônico com um $\mathbf{X}$ no espaço entre parênteses da resposta selecionada.

Muito obrigado pela sua valiosíssima contribuição e tempo dispensado nesta pesquisa.

Atenciosamente,

Ruy Somei Nakayama

ruy.nakayama@usp.br

Doutorando EPUSP - GTI

Universidade de São Paulo

Av. Prof. Almeida Prado, trav. 2, no.128

05.508-070 São Paulo, SP 


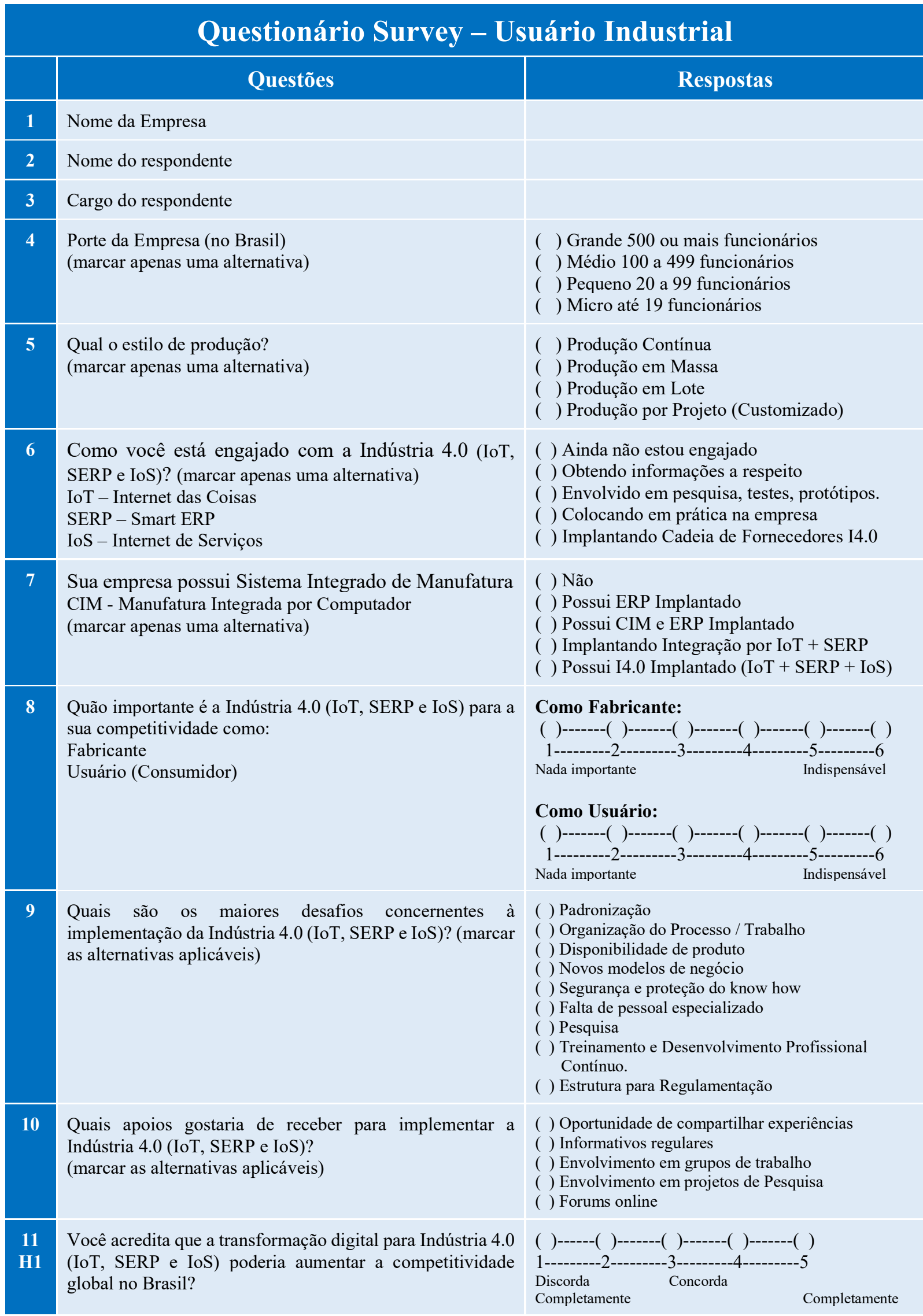


Quão forte a sua empresa está sentindo os impactos da transformação digital para a Indústria 4.0 (IoT, SERP e IoS)?

Você acredita que a transformação digital para a Indústria 4.0 (IoT, SERP e IoS) será capaz de diminuir a transferência da produção para países com menores salários (ex. China, India, etc.)?

Em que extensão a sua empresa já está integrando as necessidades dos clientes e/ou preferências em seu processo de desenvolvimento e produção através de troca de dados diretamente entre máquinas (M2M)?

Em que extensão a sua empresa já está fazendo uso de oportunidades para analisar dados de máquinas (por exemplo, para evitar defeitos no processo de produção)?

Você acredita que a transformação digital para a Indústria 4.0 (IoT, SERP e IoS) poderia trazer mais riscos cibernéticos para empresas de manufatura?

Em que extensão sua empresa possui infraestrutura de TI para coletar dados para apoiar a mudança para os conceitos da Indústria 4.0 (IoT, SERP e IoS)?

A transformação digital para a Indústria 4.0 (IoT, SERP e IoS) trará novos desafios para os profissionais. A sua empresa possui pessoal qualificado para atender a estas demandas.

Qual segmento de negócio em sua empresa passou por maior e menor transformação como parte da implantação da Indústria 4.0 (IoT, SERP e IoS)?

Atribuir escala de 1 a 5:

1= Nenhuma Transformação

5=Profunda Transformação
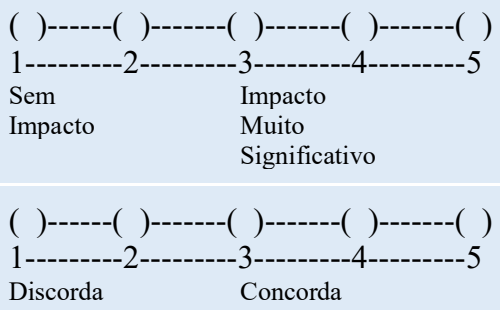

Completamente Completamente

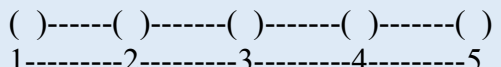

$\begin{array}{ll}\text { Em nenhuma } & \\ \text { Extensão } & \text { Extensão }\end{array}$

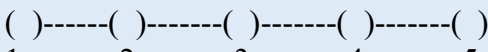

1 ----------2----------3----------4----------5

Em nenhuma Em Ampla

Extensão Extensão

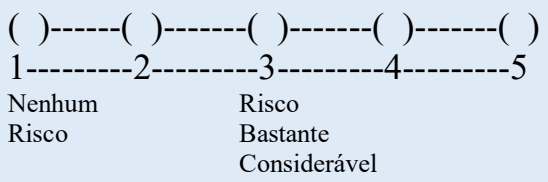

( )------( )-------( )-------( )-------( )

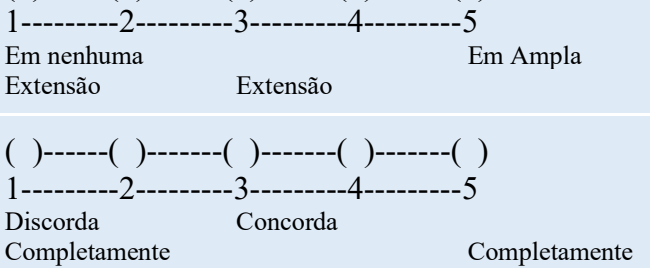

Pesquisa e Desenvolvimento

( )------( )-------( )-------( )-------( )

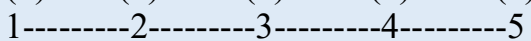

Compras

( )------( )-------( )-------( )------( )

$1---------2---------3---------4---------5$

Produção

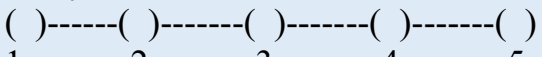

$1---------2---------3---------4---------5$

Armazenamento e Logística

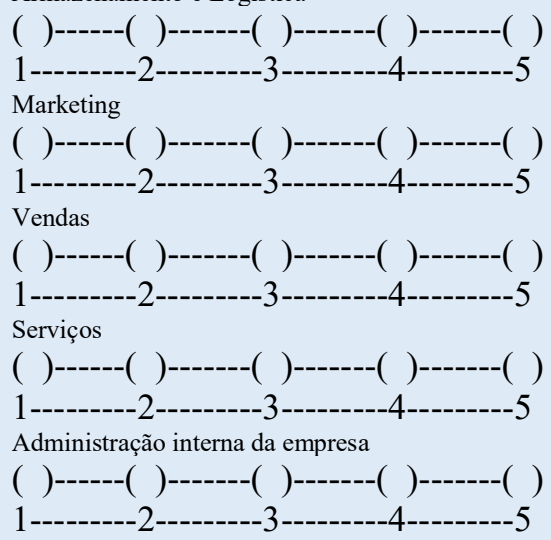


Que segmento de negócio em sua empresa tem o maior potencial para se beneficiar da transformação digital para a Indústria 4.0 (IoT, SERP e IoS)?

Atribuir escala de 1 a 5:

$1=$ Nenhum Potencial

$5=$ Potencial muito elevado
Pesquisa e Desenvolvimento

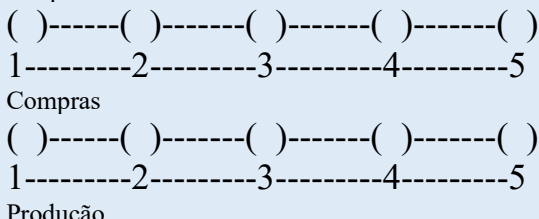

Produção
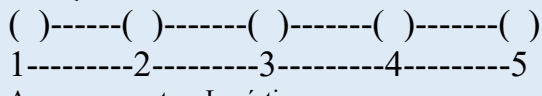

Armazenamento e Logística
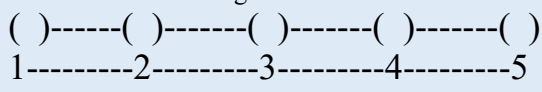

Marketing
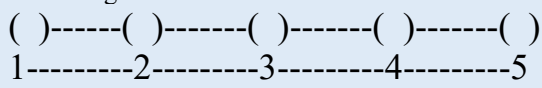

Vendas
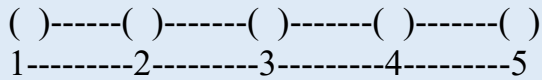

Serviços
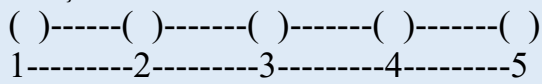

Administração interna da empresa
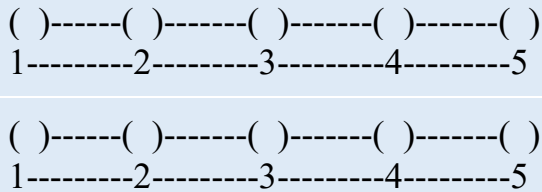

Discorda
Completamente
transformação digital da Manufatura Brasileira para Indústria 4.0 (IoT, SERP e IoS)?

Quão intensamente a sua empresa já está fazendo uso da oportunidade que a tecnologia de impressão 3D oferece para os processos de produção e desenvolvimento?

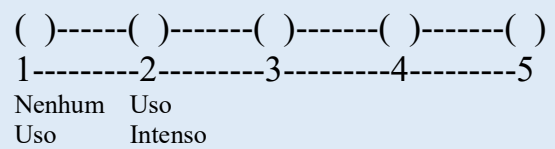

A sua empresa planeja começar ou continuar investindo em tecnologia de impressão 3D no futuro.

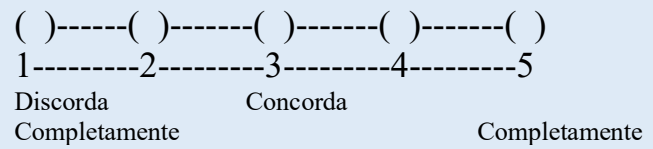

Qual a quantidade de variantes (customizações) de um mesmo produto pode fabricar em sua empresa?

(Considerar a média dos produtos)

(marcar apenas uma alternativa)
( ) $>100$
( ) de 76 a 99
( ) de 51 a 75
( ) de 26 a 50
( ) 1 a 25

Quais os planos de aumentar a quantidade de variantes (customizações) por produto em 2020?

(Considerar a média dos produtos)

(marcar apenas uma alternativa)

( ) aumentar $>200 \%$

( ) aumentar em até $200 \%$

( ) manter a quantidade atual

( ) reduzir entre quantidade atual e $50 \%$ do atual

( ) reduzir para $<50 \%$ do atual

Que variação na demanda do volume de produção a sua empresa está normalmente preparada para atender?

(marcar apenas uma alternativa)

( ) A capacidade produtiva é fixa

( ) Pode atender aumentos de 0 a $25 \%$

( ) Pode atender aumentos de 26 a $50 \%$

( ) Pode atender aumentos de 51 a $100 \%$

( ) Pode atender aumentos $>100 \%$

Quais os planos de aumentar a capacidade de atender variações na demanda do volume de produção em 2020 ?

( ) aumentar $>200 \%$

( ) aumentar em até $200 \%$

(Considerar a média dos produtos)

( ) manter a quantidade atual 
(marcar apenas uma alternativa)

28

H3

Qual o lote mínimo de produção a sua empresa pode atender para um determinado pedido?

(pela menor unidade produzida: frasco de 1litro, bisnaga de $50 \mathrm{~g}$, 1 veículo, garrafa de $750 \mathrm{ml}$, lata de $350 \mathrm{ml}$, rolo de fio de $5 \mathrm{~m}$; mangueira em múltiplos de $1 \mathrm{~m}$, etc.)

(marcar apenas uma alternativa)

29

H3

Quais os planos de o lote mínimo de produção em 2020?

(Considerar a média dos produtos)

(marcar apenas uma alternativa)

30

H1

Que benefícios os indicadores de monitoramento em tempo real e sistemas analíticos trouxeram para a sua empresa? $\mathrm{OEE}=$ Índice de Eficiência Global de Equipamentos (marcar as alternativas aplicáveis)

31

H1

Quais os planos de utilizar indicadores de monitoramento em tempo real e sistemas analíticos em 2020 ?

(Considerar a média dos produtos)

(marcar as alternativas aplicáveis)

( ) reduzir entre quantidade atual e 50\% do atual

( ) reduzir para $<50 \%$ do atual

( ) 1 un (lote unitário)

( ) 10 un

( ) 50 un

( ) 100 un

( ) $>500$ un

( ) 1 un (lote unitário)

( ) 10 un

( ) 50 un

( ) 100 un

( ) $>500$ un

( ) Não possui indicadores ou analíticos.

( ) Permitiu identificar problemas na produção

( ) Permitiu aumentar a produtividade

( ) Permitiu reduzir quantidade de defeitos

( ) Melhorou a OEE

( ) Reduziu o tempo de parada de máquinas

( ) Não usar indicadores ou analíticos.

( ) Permitir identificar problemas na produção

( ) Permitir aumentar a produtividade

( ) Permitir reduzir quantidade de defeitos

( ) Melhorar a OEE

( ) Reduzir o tempo de parada de máquinas

32

H4

Qual a quantidade de Pequenas e Médias Empresas (PMEs) ( $<500$ funcionários), participam na cadeia de valor de seus produtos atualmente? (total de empresas PMEs na cadeia de fornecimento)

(marcar apenas uma alternativa)

33

H4

Quais os planos de aumentar a participação de Pequenas e Médias Empresas (PMEs) ( $<500$ funcionários) na cadeia de valor de seus produtos em 2020? (total de empresas PMEs na cadeia de fornecimento)

(marcar apenas uma alternativa)

34

H5

Que habilidades, faltam aos funcionários em geral, na sua empresa para implantar ou operar a I4.0?

(marcar as alternativas aplicáveis)

\section{0 ?}

Quais os planos para capacitação de funcionários para

(marcar apenas uma alternativa)
Atualmente a sua empresa possui sistemas de segurança cibernética para SW de automação de automação da Manufatura?

(marcar as alternativas aplicáveis)
( ) Mais que 50 empresas (Quantos? .......)

( ) 21 a 50 empresas

( ) 11 a 20 empresas

( ) 6 a 10 empresas

( ) 1 a 5 empresas

( ) aumentar $>200 \%$

( ) aumentar em até $200 \%$

( ) manter a quantidade atual

( ) reduzir entre quantidade atual e $50 \%$ do atual

( ) reduzir para $<50 \%$ do atual

( ) Não pretende implantar I4.0

( ) Falta habilidade em TI

( ) Falta habilidade em infraestrutura de redes

( ) Falta habilidade em Engenharia de Produção

( ) Falta habilidade em estatística

( ) Falta habilidade em automação

( ) Não há planos de capacitação

( ) Melhorar habilidade em TI

( ) Melhorar habilidade em infraestrutura de redes

( ) Melhorar habilidade em Engenharia de Produção

( ) Melhorar habilidade em estatística

( ) Melhorar habilidade em automação

( ) Possui sistemas de segurança para acesso a nível corporativo 


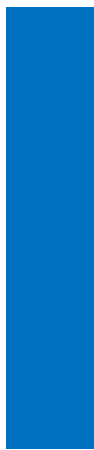

37

2020?

(Considerar a média dos produtos)

(marcar apenas uma alternativa)

( ) Possui sistemas de segurança específico para sistemas industriais tais como MES, APS, Supervisórios, SCADA etc.

( ) Possui sistemas de segurança específicos para máquinas e equipamentos, robôs, servomotores, inversores, $\mathrm{CNC}$, etc. conectados à rede.

( ) Possui sistemas de segurança específico para componentes como sensores, atuadores, válvulas de controle, etc. conectados à rede.

( ) Possui sistemas de segurança específico para computadores e aplicativos conectados na rede

( ) Implementar sistemas de segurança para acesso a nível corporativo

( ) Implementar sistemas de segurança específico para sistemas industriais tais como MES, APS, Supervisórios, SCADA etc.

( ) Implementar sistemas de segurança específicos para máquinas e equipamentos, robôs, servomotores, inversores, $\mathrm{CNC}$, etc. conectados à rede.

( ) Implementar sistemas de segurança específico para componentes como sensores, atuadores, válvulas de controle, etc. conectados à rede.

( ) Implementar sistemas de segurança específico para computadores e aplicativos conectados na rede

38

Quais os planos de utilizar mão de obra ou componentes do exterior na cadeia de valor de seus produtos em 2020 ? (Considerar a média dos produtos) (marcar apenas uma alternativa)

Que percentual de seus produtos são oferecidos como serviços?
Atualmente sua empresa utiliza-se de mão de obra ou de componentes do exterior na cadeia de valor de seus produtos? (Considerar média dos produtos) (marcar apenas uma alternativa)
( ) 0 a $20 \%$ do custo dos produtos vem de fora do país

( ) 21 a $40 \%$ do custo dos produtos vem de fora do país

( ) 41 a $60 \%$ do custos do produtos vem de fora do país

( ) 61 a $80 \%$ do custos do produtos vem de fora do país

( ) 81 a $100 \%$ do custos do produtos vem de fora do país

( ) 0 a $20 \%$ do custo dos produtos vem de fora do país

( ) 21 a $40 \%$ do custo dos produtos vem de fora do país

( ) 41 a $60 \%$ do custos do produtos vem de fora do país

( ) 61 a $80 \%$ do custos do produtos vem de fora do país

( ) 81 a $100 \%$ do custos do produtos vem de fora do país

(marcar apenas uma alternativa)
( ) 81 a $100 \%$ dos produtos são ofertados como serviços na Internet.

( ) 61 a $80 \%$ dos produtos são ofertados como serviços na Internet.

( ) 41 a 60 dos produtos são ofertados como serviços na Internet.

( ) 21 a $40 \%$ dos produtos são ofertados como serviços na Internet.

( ) 0 a $20 \%$ dos produtos são ofertados como serviços na Internet. 
41

H8
Quais os planos de oferecer produtos como serviços na Internet em 2020?

(Considerar a média dos produtos)

(marcar apenas uma alternativa)
( ) 81 a $100 \%$ dos produtos serão ofertados como serviços na Internet.

( ) 61 a $80 \%$ dos produtos serão ofertados como serviços na Internet.

( ) 41 a 60 dos produtos serão ofertados como serviços na Internet.

( ) 21 a $40 \%$ dos produtos serão ofertados como serviços na Internet.

( ) 0 a $20 \%$ dos produtos serão ofertados como serviços na Internet. 


\begin{tabular}{|c|c|c|}
\hline & Questões & Respostas \\
\hline 1 & Nome da Empresa & \\
\hline 2 & Nome do respondente & \\
\hline 3 & Cargo do respondente & \\
\hline $\begin{array}{l}4 \\
\mathrm{VC1}\end{array}$ & $\begin{array}{l}\text { Porte da Empresa (no Brasil) } \\
\text { (marcar apenas uma alternativa) }\end{array}$ & $\begin{array}{l}\text { ( ) Grande } 500 \text { ou mais funcionários } \\
\text { ( ) Médio } 100 \text { a } 499 \text { funcionários } \\
\text { ( ) Pequeno } 20 \text { a } 99 \text { funcionários } \\
\text { ( ) Micro até } 19 \text { funcionários }\end{array}$ \\
\hline $\begin{array}{l}5 \\
\text { VC2 }\end{array}$ & $\begin{array}{l}\text { Qual a atuação da empresa no Brasil } \\
\text { (marcar todas as alternativas aplicáveis) }\end{array}$ & $\begin{array}{l}\text { ( ) Venda de equipamentos para automação } \\
\text { ( ) Venda de máquinas para produção } \\
\text { ( ) Venda de serviços de integração } \\
\text { ( ) Venda de software } \\
\text { ( ) Materiais para Infraestrutura de rede } \\
\text { ( ) Materiais comunicação móvel e sem fio. }\end{array}$ \\
\hline $\begin{array}{ll}6 \\
\text { E1 }\end{array}$ & $\begin{array}{l}\text { Como você está engajado com a Indústria } 4.0 \text { (IoT, } \\
\text { SERP e IoS)? (marcar apenas uma alternativa) } \\
\text { IoT - Internet das Coisas } \\
\text { SERP - Smart ERP } \\
\text { IoS - Internet de Serviços }\end{array}$ & $\begin{array}{l}\text { ( ) Ainda não estou engajado } \\
\text { ( ) Obtendo informações a respeito } \\
\text { ( ) Envolvido em pesquisa, testes, protótipos IoT } \\
\text { ( ) Desenvolvendo produtos para IoT industrial } \\
\text { na empresa. } \\
\text { ( ) Implantando a IoT e SERP na minha } \\
\text { produção. } \\
\text { ( ) Já vende produtos compatíveis com a } \\
\text { tecnologia IoT para indústria. } \\
\text { ( ) Integrando a minha rede colaborativa através } \\
\text { da I4.0 }\end{array}$ \\
\hline $\begin{array}{l}7.1 \\
\text { M3.0 }\end{array}$ & $\begin{array}{l}\text { Sua empresa possui Sistema Integrado de Manufatura } \\
\text { CIM - Manufatura Integrada por Computador } \\
\text { (marcar apenas uma alternativa) }\end{array}$ & $\begin{array}{l}\text { ( ) Não } \\
\text { ( ) Possui ERP Implantado } \\
\text { ( ) Possui CIM e ERP Implantado } \\
\text { ( ) Implantando Integração por IoT + SERP } \\
\text { ( ) Possui I4.0 Implantado (IoT + SERP + IoS) }\end{array}$ \\
\hline 7.2 & $\begin{array}{l}\text { Quantos clientes já compraram produtos IoT de sua } \\
\text { empresa para aplicação industrial? }\end{array}$ & $\begin{array}{l}\text { ( ) } 0 \\
\text { ( ) } 1 \text { a } 10 \text { clientes industriais } \\
\text { ( ) } 11 \text { a } 20 \text { clientes industriais } \\
\text { ( ) } 21 \text { a } 30 \text { clientes industriais } \\
\text { ( ) }>30 \text { clientes }\end{array}$ \\
\hline $\begin{array}{l}8 \\
\text { E2 }\end{array}$ & $\begin{array}{l}\text { Quão importante é a Indústria } 4.0 \text { (IoT, SERP e IoS) para a } \\
\text { sua competitividade como: } \\
\text { a) Fabricante } \\
\text { b) Usuário (Consumidor) }\end{array}$ & 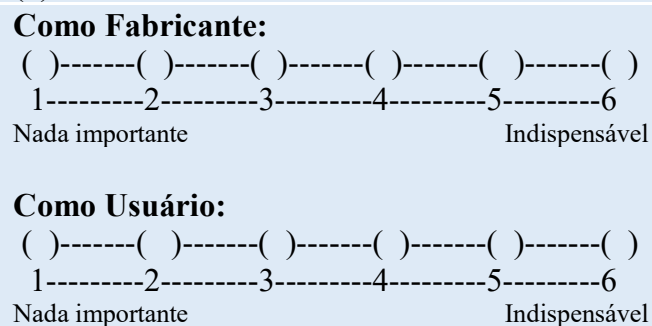 \\
\hline $\begin{array}{l}9 \\
\mathbf{E} 3\end{array}$ & $\begin{array}{l}\text { Quais são os maiores desafios concernentes à } \\
\text { implementação da Indústria } 4.0 \text { (IoT, SERP e IoS) na sua } \\
\text { empresa? (marcar as alternativas aplicáveis) }\end{array}$ & $\begin{array}{l}\text { ( ) Padronização para IoT } \\
\text { ( ) Organização do Processo / Trabalho } \\
\text { ( ) Disponibilidade de produtos para IoT } \\
\text { ( ) Novos modelos de negócio em IoT } \\
\text { ( ) Segurança e proteção do know how em IoT } \\
\text { ( ) Falta de pessoal especializado em IoT } \\
\text { ( ) Pesquisa } \\
\text { ( ) Treinamento e Desenvolvimento Profissional } \\
\text { Contínuo. } \\
\text { ( ) Estrutura para Regulamentação }\end{array}$ \\
\hline
\end{tabular}


Quais apoios gostaria de receber para implementar a Indústria 4.0 (IoT, SERP e IoS)?

(marcar as alternativas aplicáveis)

Quais são as maiores dificuldades colocadas pelos seus clientes industriais para a implantação da I4.0 (IoT, SERP e IoS)?

(marcar as alternativas aplicáveis)

HW de CPS = Hardware de sistemas cíberfísicos

$\mathrm{TI}=$ Tecnologia da Informação

Você acredita que a transformação digital para Indústria 4.0 (IoT, SERP e IoS) poderia aumentar a competitividade global no Brasil?

Quão forte a sua empresa está sentindo os impactos da transformação digital para a Indústria 4.0 (IoT, SERP e IoS)?

Você acredita que a transformação digital para a Indústria 4.0 (IoT, SERP e IoS) será capaz de diminuir a transferência da produção para países com menores salários (ex. China, India, etc.)?

Em que extensão a sua empresa já está integrando as necessidades dos clientes e/ou preferências em seu processo de desenvolvimento e produção através de troca de dados diretamente entre máquinas (M2M)?

Em que extensão a sua empresa já está fazendo uso de oportunidades para analisar dados de máquinas (por exemplo, para evitar defeitos no processo de produção)?

Você acredita que a transformação digital para a Indústria 4.0 (IoT, SERP e IoS) poderia trazer mais riscos cibernéticos para empresas de manufatura?

Em que extensão sua empresa possui infraestrutura de TI para coletar dados para apoiar a mudança para os conceitos da Indústria 4.0 (IoT, SERP e IoS)?

A transformação digital para a Indústria 4.0 (IoT, SERP e IoS) trará novos desafios para os profissionais. A sua empresa possui pessoal qualificado para atender a estas demandas.

Qual segmento de negócio em sua empresa passou por maior e menor transformação como parte da implantação da Indústria 4.0 (IoT, SERP e IoS)?

Atribuir escala de 1 a 5:

$1=$ Nenhuma Transformação

5=Profunda Transformação
( ) Oportunidade de compartilhar experiências

( ) Informativos regulares

( ) Envolvimento em grupos de trabalho

( ) Envolvimento em projetos de Pesquisa

( ) Forums online

( ) Falta de padronização em infraestrutura de comunicação, dificultando a interoperabilidade.

( ) Falta de sistemas capazes de integrar HW de CPS com TI para operacionalizar a IoT (Software, sistema operacional, ERP, etc.)

( ) Falta de infraestrutura de TIC adequada para operacionalizar Big Data e analíticos.

( ) Qualificação requerida para os trabalhadores na plataforma I4.0.

( ) Alto nível de investimento requerido em infraestrutura para IoT

( ) Dificuldade com novos modelos de negócio e integração horizontal com parceiros de negócio clientes.

( ) Segurança e proteção de dados em ambiente IoT.

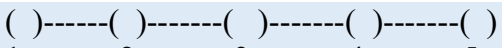

1---------2---------3---------4---------5

Discorda Concorda

Completamente Completamente

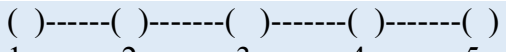

1---------2---------3----------4---------5

Sem Impacto

Impacto Muito Significativo

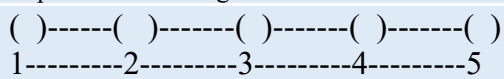

Discorda Concorda

Completamente Completamente
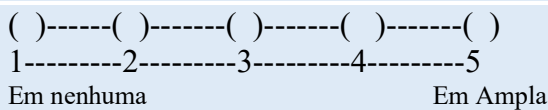

Extensão Extensão

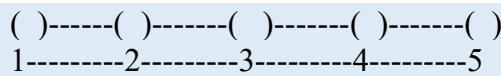

Em nenhuma $\quad$ Em Ampla

Extensão Extensão
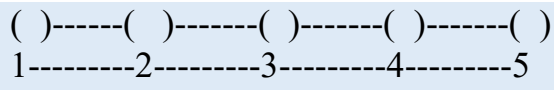

Nenhum Risco

Risco Bastante Considerável
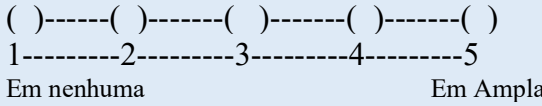

Extensão Extensão

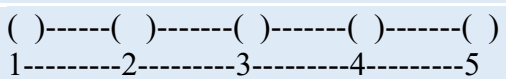

Discorda Concorda

Completamente Completamente

Pesquisa e Desenvolvimento
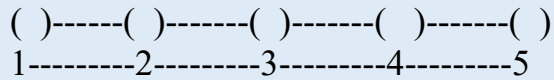

Compras

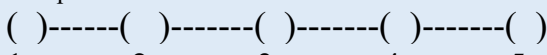

1----------2----------3----------4---------5

Produção

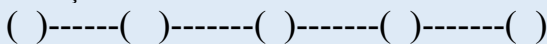




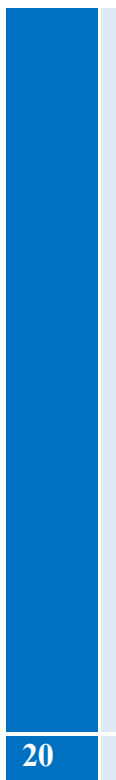

Que segmento de negócio em sua empresa tem o maior potencial para se beneficiar da transformação digital para a Indústria 4.0 (IoT, SERP e IoS)?

Atribuir escala de 1 a 5:

$1=$ Nenhum Potencial

$5=$ Potencial muito elevado
Você concorda que a impressão 3D tem potencial para ser uma tecnologia fundamental, que poderá acelerar a transformação digital da Manufatura Brasileira para a Indústria 4.0 (IoT, SERP e IoS)?

Quão intensamente a sua empresa já está fazendo uso da oportunidade que a tecnologia de impressão 3D oferece para os processos de produção e desenvolvimento?

A sua empresa planeja começar ou continuar investindo em tecnologia de impressão 3D no futuro.

Qual a quantidade de variantes (customizações) de um mesmo produto pode fabricar em sua empresa?

(Considerar a média dos produtos)

(marcar apenas uma alternativa)

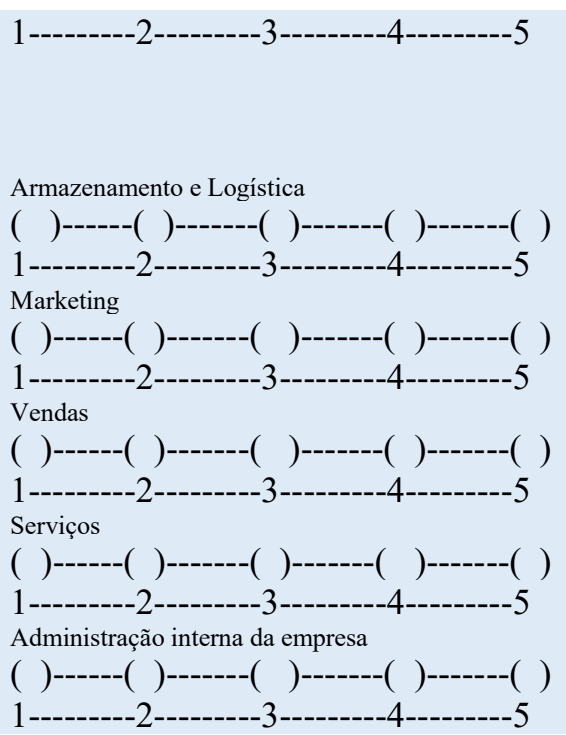

Pesquisa e Desenvolvimento

( )------( )-------( )-------( )-------( )

1---------2----------3----------4---------5

Compras

( )-----( )-------( )-------( )------( )

1---------2----------3----------4----------5

Produção

( )------( )-------( )-------( )-------( )

1---------2----------3----------4---------5

Armazenamento e Logística

( )------( )-------( )-------( )-------( )

1---------2----------3----------4---------5

Marketing

( )------( )--------( )--------( )-------( )

1---------2----------3----------4---------5

Vendas

( )------( )-------( )-------( )-------( )

1----------2----------3----------4----------5

Serviços

( )------( )--------( )-------( )-------( )

1----------2----------3----------4----------5

Administração interna da empresa

( )------( )-------( )-------( )-------( )

1----------2-----------3----------4----------5

( )------( )-------( )-------( )-------( )

1----------2----------3----------4----------5

Discorda Concorda

Completamente Completamente

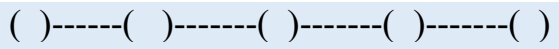

1---------2----------3----------4---------5

Nenhum Uso

Uso Intenso

( )------( )-------( )-------( )-------( )

1---------2----------3---------4---------5

Discorda Concorda

Completamente

Completamente

( ) $>100$

( ) de 76 a 99

( ) de 51 a 75

( ) de 26 a 50

( ) 1 a 25 
25

H1

\section{(n)}

Quais os planos de aumentar a quantidade de variantes (customizações) por produto em 2020?

(Considerar a média dos produtos)

(marcar apenas uma alternativa)
Que variação na demanda do volume de produção a sua empresa está normalmente preparada para atender?

(marcar apenas uma alternativa)

Quais os planos de aumentar a capacidade de atender variações na demanda do volume de produção em 2020? (Considerar a média dos produtos) (marcar apenas uma alternativa)

Qual o lote mínimo de produção a sua empresa pode atender para um determinado pedido?

(pela menor unidade produzida: frasco de 1litro, bisnaga de $50 \mathrm{~g}, 1$ veículo, garrafa de $750 \mathrm{ml}$, lata de $350 \mathrm{ml}$, rolo de fio de $5 \mathrm{~m}$; mangueira em múltiplos de $1 \mathrm{~m}$, etc.) (marcar apenas uma alternativa)

Quais os planos para o lote mínimo de produção em 2020 ? (Considerar a média dos produtos)

(marcar apenas uma alternativa)

Que benefícios os indicadores de monitoramento em tempo real e sistemas analíticos trouxeram para a sua empresa? $\mathrm{OEE}=$ Índice de Eficiência Global de Equipamentos (marcar as alternativas aplicáveis)

Quais os planos de utilizar indicadores de monitoramento em tempo real e sistemas analíticos em 2020?

(Considerar a média dos produtos)

(marcar as alternativas aplicáveis)

Qual a quantidade de Pequenas e Médias Empresas (PMEs) ( $<500$ funcionários), participam na cadeia de valor de seus produtos atualmente? (total de empresas PMEs na cadeia de fornecimento)

(marcar apenas uma alternativa)
( ) aumentar $>200 \%$

( ) aumentar em até $200 \%$

( ) manter a quantidade atual

( ) reduzir entre quantidade atual e $50 \%$ do atual

( ) reduzir para $<50 \%$ do atual

( ) A capacidade produtiva é fixa

( ) Pode atender aumentos de 0 a $25 \%$

( ) Pode atender aumentos de 26 a $50 \%$

( ) Pode atender aumentos de 51 a $100 \%$

( ) Pode atender aumentos $>100 \%$

( ) aumentar $>200 \%$

( ) aumentar em até $200 \%$

( ) manter a quantidade atual

( ) reduzir entre quantidade atual e $50 \%$ do atual

( ) reduzir para $<50 \%$ do atual

( ) 1 un (lote unitário)

( ) 10 un

( ) 50 un

( ) 100 un

( ) $>500$ un

( ) 1 un (lote unitário)

( ) 10 un

( ) 50 un

( ) 100 un

( ) $>500$ un

( ) Não possui indicadores ou analíticos.

( ) Permitiu identificar problemas na produção

( ) Permitiu aumentar a produtividade

( ) Permitiu reduzir quantidade de defeitos

( ) Melhorou a OEE

( ) Reduziu o tempo de parada de máquinas

( ) Não usar indicadores ou analíticos.

( ) Permitir identificar problemas na produção

( ) Permitir aumentar a produtividade

( ) Permitir reduzir quantidade de defeitos

( ) Melhorar a OEE

( ) Reduzir o tempo de parada de máquinas

( ) Mais que 50 empresas (Quantos? .......)

( ) 21 a 50 empresas

( ) 11 a 20 empresas

( ) 6 a 10 empresas

( ) 1 a 5 empresas 
Quais os planos de aumentar a participação de Pequenas e Médias Empresas (PMEs) ( $<500$ funcionários) na cadeia de valor de seus produtos em 2020? (total de empresas PMEs na cadeia de fornecimento)

(marcar apenas uma alternativa)

Que habilidades, faltam aos funcionários em geral, na sua empresa para implantar ou operar a I4.0?

(marcar as alternativas aplicáveis)

Quais os planos para capacitação de funcionários para

2020 ?

(marcar as alternativas aplicáveis)

Atualmente a sua empresa possui sistemas de segurança cibernética para SW de automação de automação da Manufatura?

(marcar as alternativas aplicáveis)
( ) aumentar $>200 \%$

( ) aumentar em até $200 \%$

( ) manter a quantidade atual

( ) reduzir entre quantidade atual e $50 \%$ do atual

( ) reduzir para $<50 \%$ do atual

( ) Não pretende implantar I4.0

( ) Falta habilidade em TI

( ) Falta habilidade em infraestrutura de redes

( ) Falta habilidade em Engenharia de Produção

( ) Falta habilidade em estatística

( ) Falta habilidade em automação

( ) Não há planos de capacitação

( ) Melhorar habilidade em TI

( ) Melhorar habilidade em infraestrutura de redes

( ) Melhorar habilidade em Engenharia de Produção

( ) Melhorar habilidade em estatística

( ) Melhorar habilidade em automação

( ) Possui sistemas de segurança para acesso a nível corporativo

( ) Possui sistemas de segurança específico para sistemas industriais tais como MES, APS, Supervisórios, SCADA etc.

( ) Possui sistemas de segurança específicos para máquinas e equipamentos, robôs, servomotores, inversores, $\mathrm{CNC}$, etc. conectados à rede.

( ) Possui sistemas de segurança específico para componentes como sensores, atuadores, válvulas de controle, etc. conectados à rede. ( ) Possui sistemas de segurança específico para computadores e aplicativos conectados na rede

( ) Implementar sistemas de segurança para acesso a nível corporativo

( ) Implementar sistemas de segurança específico para sistemas industriais tais como MES, APS, Supervisórios, SCADA etc.

( ) Implementar sistemas de segurança específicos para máquinas e equipamentos, robôs, servomotores, inversores, $\mathrm{CNC}$, etc. conectados à rede.

( ) Implementar sistemas de segurança específico para componentes como sensores, atuadores, válvulas de controle, etc. conectados à rede.

( ) Implementar sistemas de segurança específico para computadores e aplicativos conectados na rede 
Atualmente sua empresa utiliza-se de mão de obra ou de componentes do exterior na cadeia de valor de seus produtos? (Considerar média dos produtos)

(marcar apenas uma alternativa)

Quais os planos de utilizar mão de obra ou componentes do exterior na cadeia de valor de seus produtos em 2020 ? (Considerar a média dos produtos) (marcar apenas uma alternativa)

Que percentual de seus produtos são oferecidos como serviços?

(marcar apenas uma alternativa)

Quais os planos de oferecer produtos como serviços na Internet em 2020?

(Considerar a média dos produtos)

(marcar apenas uma alternativa)
( ) 0 a $20 \%$ do custo dos produtos vem de fora do país

( ) 21 a $40 \%$ do custo dos produtos vem de fora do país

( ) 41 a $60 \%$ do custos do produtos vem de fora do país

( ) 61 a $80 \%$ do custos do produtos vem de fora do país

( ) 81 a $100 \%$ do custos do produtos vem de fora do país

( ) 0 a $20 \%$ do custo dos produtos vem de fora do país

( ) 21 a $40 \%$ do custo dos produtos vem de fora do país

( ) 41 a $60 \%$ do custos do produtos vem de fora do país

( ) 61 a $80 \%$ do custos do produtos vem de fora do país

( ) 81 a $100 \%$ do custos do produtos vem de fora do país

( ) 81 a $100 \%$ dos produtos são ofertados como serviços na Internet.

( ) 61 a $80 \%$ dos produtos são ofertados como serviços na Internet.

( ) 41 a 60 dos produtos são ofertados como serviços na Internet.

( ) 21 a $40 \%$ dos produtos são ofertados como serviços na Internet.

( ) 0 a $20 \%$ dos produtos são ofertados como serviços na Internet.

( ) 81 a $100 \%$ dos produtos serão ofertados como serviços na Internet.

( ) 61 a $80 \%$ dos produtos serão ofertados como serviços na Internet.

( ) 41 a 60 dos produtos serão ofertados como serviços na Internet.

( ) 21 a $40 \%$ dos produtos serão ofertados como serviços na Internet.

( ) 0 a $20 \%$ dos produtos serão ofertados como serviços na Internet. 